PNL-2720

\title{
Preconceptual Design and Assessment of a Tokamak Hybrid Reactor
}

September 1980

Prepared for the U.S. Department of Energy under Contract DE-ACn6-76RLO 1830

Pacific Northwest Laboratory

Operated for the U.S. Department of Energy

by Battelle Memorial Institute 


\title{
NOTICE
}

This report was prepared as an account of work sponsored by the United States Government. Neither the United States nor the Department of Energy, nor any of their employees, nor any of their contractors, subcontractors, or their employees, makes any warranty, express or implied, or assumes any legal liability or responsibility for the accuracy, completeness or usefulness of any information, apparatus, product or process disclosed, or represents that its use would not infringe privately owned rights

The views, opinions and conclusions contained in this report are those of the contractor and do not necessarily represent those of the United States Government or the United States Department of Energy.

\author{
PACIFIC NORTHWEST LABORATORY \\ operated by \\ BATTELLE \\ for the \\ UNITED STATES DEPARTMENT OF ENERGY \\ Under Contract EY-76-C-06-1830
}

\author{
Printed in the United States of America \\ Available from \\ National Technical Information Service \\ United States Department of Commerce \\ 5285 Port Royal Road \\ Springfield, Virginia 22151
}

Price: Printed Copy $\$$

$\because$ Microfiche $\$ 3.00$

$\begin{array}{lr}\text { •Pages } & \begin{array}{c}\text { NTIS } \\ \text { Selling Price }\end{array} \\ 001-025 & \$ 4.00 \\ 026-050 & \$ 4.50 \\ 051-075 & \$ 5.25 \\ 076-100 & \$ 6.00 \\ 101-125 & \$ 6.50 \\ 126-150 & \$ 7.25 \\ 151-175 & \$ 8.00 \\ 176-200 & \$ 9.00 \\ 201-225 & \$ 9.25 \\ 226-250 & \$ 9.50 \\ 251-275 & \$ 10.75 \\ 276-300 & \$ 11.00\end{array}$




\section{6}

\section{PRECONCEPTUAL DESIGN AND ASSESSMENT} OF A TOKAMAK HYBRID REACTOR
V. L. Teofilo
J. E. Morrison
B. R. Leonard, Jr.
R. T. Perry
D. T. Aase
S. C. Schulte
W. E. Bickford
C. E. Willingham
N. J. McCormick
T. L. Willke
R. T. McGrath
A. D. Rockwood

September 1980

Prepared for the U.S. Department of Energy under Contract DE-ACO6-76RLO 1830

Pacific Northwest Laboratory

Richland, Washington 99352 



\section{PREFACE}

This report serves as a basis for comparing the tokamak fusion-fission energy system with other advanced technology breeding concepts considered in the Nonproliferation Alternative Systems Assessment Program (NASAP). As a result of the limited time and resources that could be devoted to the preparation of the preliminary conceptual design contained herein, this information must not be considered as the best potentially available for the described concept. However, because of the significant theoretical and experimental data base available for tokamaks, as well as their potential for minimizing the recirculating power fraction of the fusion driver system when operated in the ignition mode, the tokamak hybrid deserves commensurate consideration with other hybrid and advanced breeding concepts that have received considerably more conceptual design system study to date. 



\section{SUMMARY}

The preconceptual design of a commercial Tokamak Hybrid Reactor (THR) power plant has been performed. The tokamak fusion driver for this hybrid is operated in the ignition mode. The D-T fusion plasma, which produces $1140 \mathrm{MW}$ of power, has a major radius of $5.4 \mathrm{~m}$ and a minor radius of $1.0 \mathrm{~m}$ with an elongation of 2.0. Double null poloidal divertors are assumed for impurity control. The confining toroidal field is maintained by $D$-shaped $\mathrm{Nb}_{3} \mathrm{Sn}$ superconducting magnets with a maximum field of $12 T$ at the coil.

Three blankets with four associated fuel cycle alternatives have been combined with the ignited tokamak fusion driver. A summary of the representative parameters for these system combinations is listed in Table 1. The plutonium recycle blanket is fueled with UC fuel. If the plutonium is not recycled and the system is operated for electric power production (oncethrough) the busbar cost of the electricity produced more than doubles. The refresh cycle utilizes either fresh or spent $\mathrm{UO}_{2}$ fuel.

Although no reprocessing is required after the fertile fuel is enriched or refreshed in the hybrid, a refabrication step is assumed due to fuel assembly material degradation and geometric incompatibilities. The Pu-Catalyzed $\mathrm{Th}-233 \mathrm{U}$ blanket consisted of a mixed-oxide $\left(\mathrm{PuO}_{2}-\mathrm{UO}_{2}\right)$ fueled neutron multiplying converter region in addition to a ThC fueled ${ }^{233} \mathrm{U}$ breeding region. Tritium is bred in all blankets considered, both behind the fertile

\section{TABLE 1. Tokamak Hybrid Reactor Parameters}

\begin{tabular}{|c|c|c|c|}
\hline & \multicolumn{3}{|c|}{ Fuel Cycle } \\
\hline & $\begin{array}{c}\text { Pu Recycle } \\
\text { (Once Through) }\end{array}$ & Refresh & Pu-Catalyst \\
\hline Thermal Power (MWt) & 4150 & 3715 & 6600 \\
\hline Net Electric Power (MWe) & 1000 & 853 & 1835 \\
\hline $\begin{array}{l}\text { Fissile Fuel Production } \\
(\mathrm{kg} / \mathrm{yr})\end{array}$ & $1950(\mathrm{Pu})$ & $1390(\mathrm{Pu})$ & $3810\left({ }^{233} U\right)$ \\
\hline Capital Cost $(\$ / k W t)$ & 501 & 536 & 396 \\
\hline Busbar Power Cost (mills/kWh) & $18(47)$ & 19 & 16 \\
\hline
\end{tabular}


fueled region of the outer blanket as well as in the inner shield. If some other impurity control scheme other than poloidal divertors were implemented (e.g., bundle divertors or gas puffing), the additional blanket volume available is estimated to augment the performance of the THR in electric and fissile fuel production by approximately $40 \%$.

The engineering, material, and balance of plant design requirements for the THR are briefly described. Estimates of the capital, operating and maintenance, and fuel cycle costs have been made for the various driver/blanket combinations and an assessment of the market penetrability of hybrid systems is presented.

An analysis has been made of the nonproliferation aspects of the hybrid and its associated fuel cycles relative to fission reactors. It is evident that any fission fuel cycle option recommended for reduced proliferation can be adopted with hybrids in the system. Moreover, new fuel cycles that start with natural or depleted material and discard the spent-fuel elements can be envisioned. In addition, the hybrid may have unique potential for implementing the denaturing cycles for both uranium and plutonium.

The current and required level of technology for both the fusion and fission components of the hybrid system has been reviewed. Following the current generation of experiments (after 1982-85), the necessary fusion performance requirements should be attainable as a next step. Similarly, the fission requirements are perceived as having been demonstrated or could be demonstrated with a modest investment of research and development funds.

Licensing hybrid systems is also considered. With the significant absence of criticality as a key concern, the hybrid introduces no issues that have not been identified in the fission and fusion programs. Because it is the earliest proposed commercial application of fusion energy, the hybrid may be the first energy system to introduce the unique fusion issues (e.g., tritium management, vacuum rupture, magnet accidents) to the licensing community. This is not seen as time-constraining on the date for introducing the first commercial systems, provided the identified issues are resolved without delay. 


\section{CONTENTS}

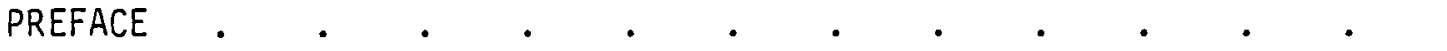

SUMMARY

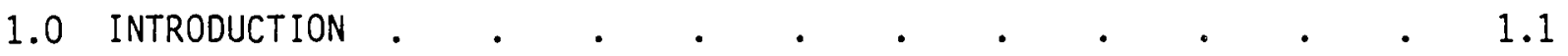

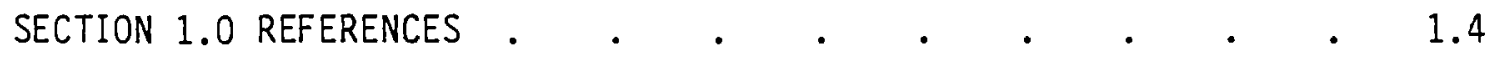

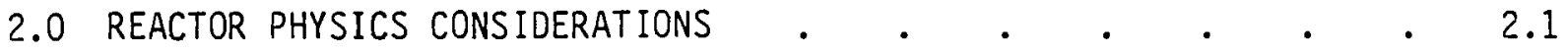

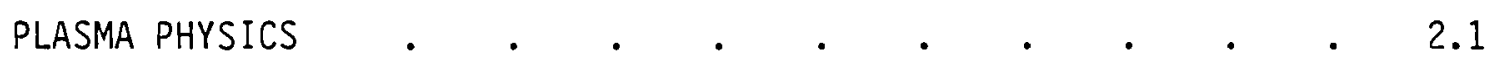

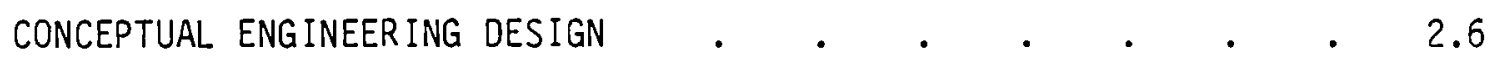

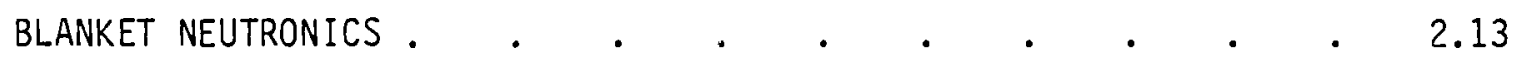

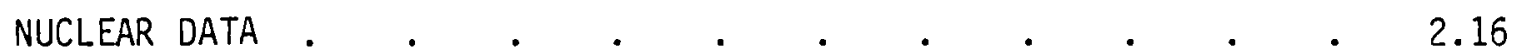

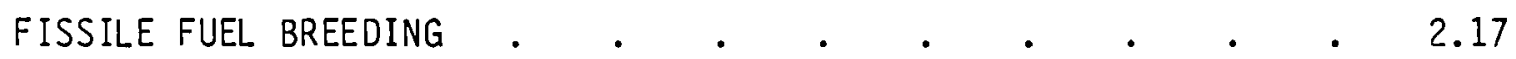

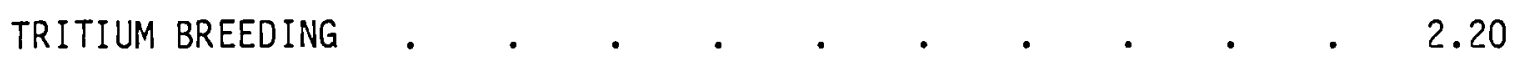

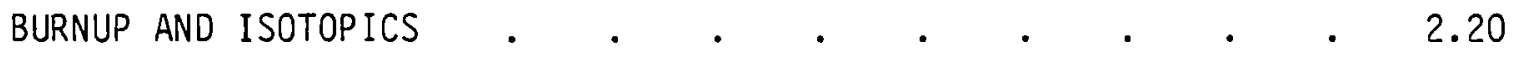

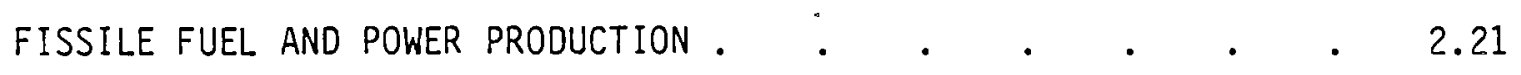

SECTION 2.0 REFERENCES . . . . . . . . . . . . . 2.27

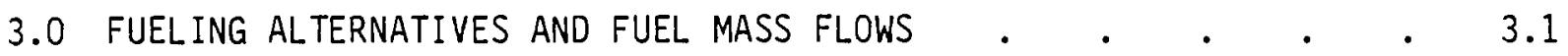

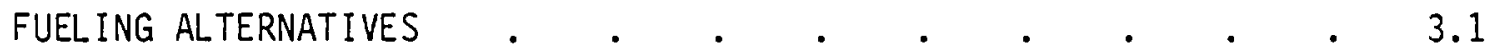

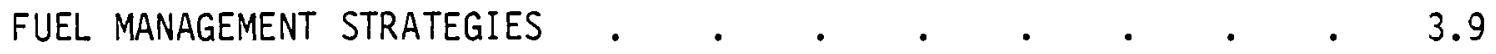

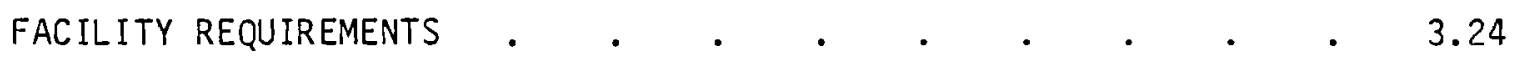

SECTION 3.0 REFERENCES . . . . . . . . . . . . . . 3.48

4.0 MECHANICAL AND THERMAL HYDRAULIC CONSIDERATIONS . $\quad . \quad$. $\quad$ • 4.1 REMOTE DISASSEMBLY AND MAINTENANCE $\quad$ • $\quad$. $\quad . \quad$. $\quad . \quad$. 4.4

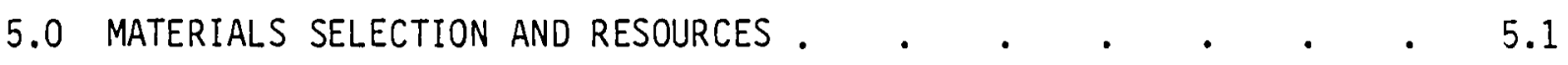

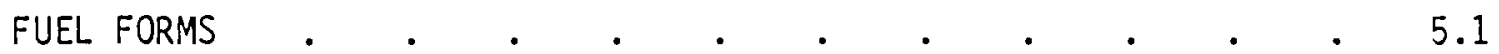

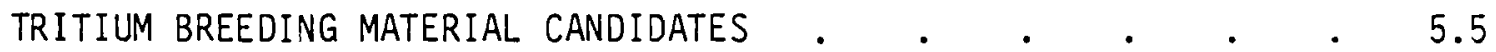




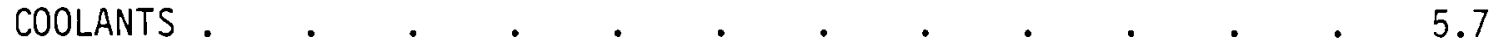

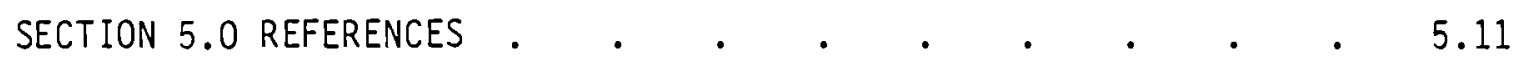

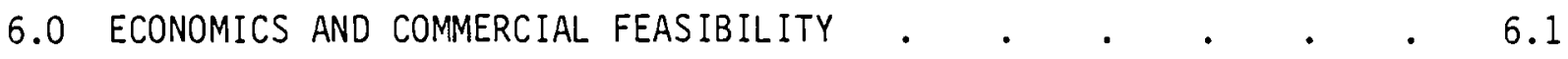

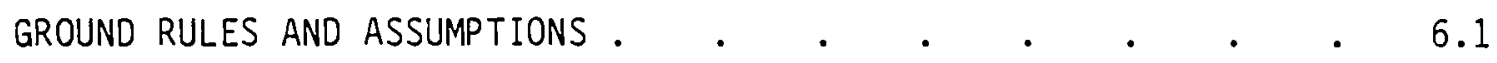

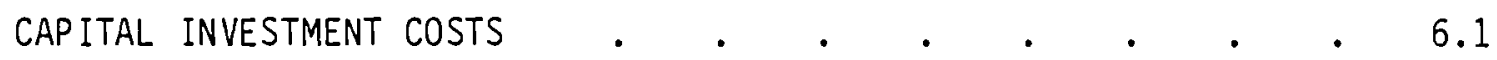

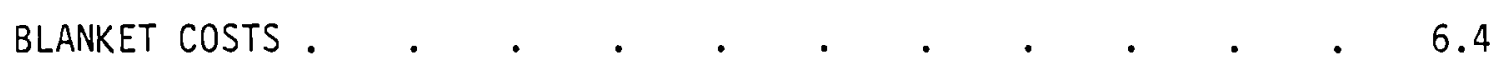

ANNUAL OPERATING AND MAINTENANCE COSTS . $. \quad . \quad . \quad . \quad . \quad 6.4$

FUEL CYCLE COSTS (HYBRID/FISSION REACTOR SYSTEM) • • • • • $\quad 6.5$

LEVELIZED ENERGY COSTS

FISSILE FUEL VALUE

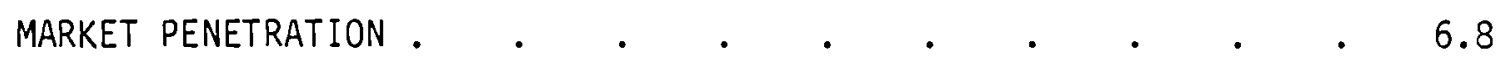

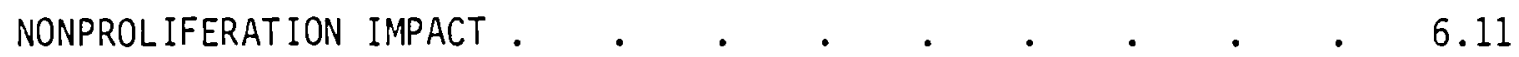

SECTION 6.0 REFERENCES $. \quad . \quad . \quad . \quad . \quad . \quad . \quad . \quad . \quad . \quad . \quad 6.13$

7.0 CONCEPTUAL PLANT DESIGN •

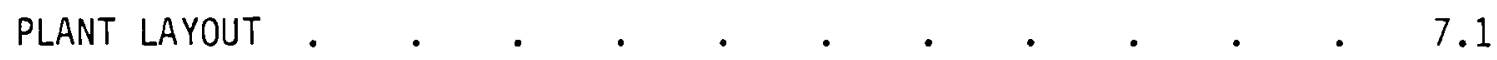

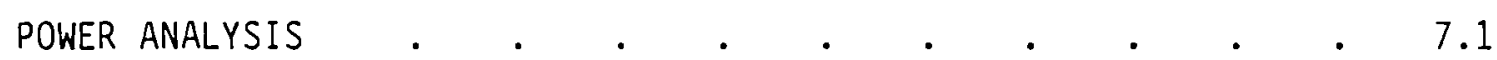

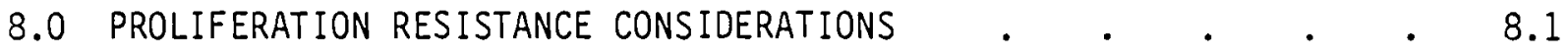

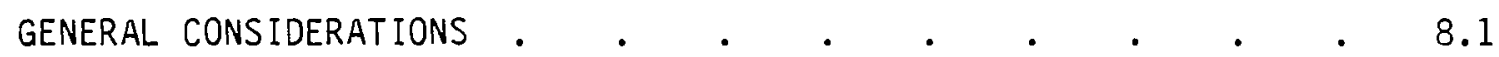

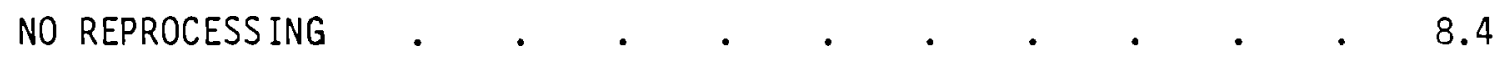

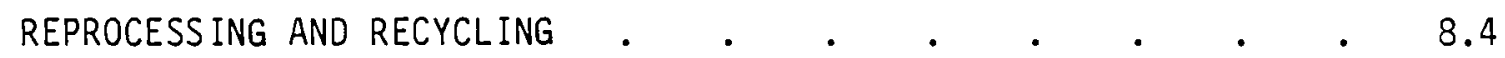

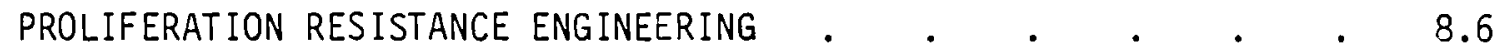

SECTION 8.0 REFERENCES .

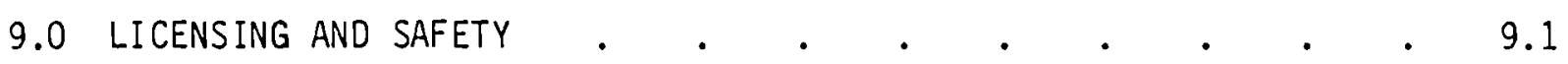
GENERIC DISCUSSIONS OF THE HYBRID CONCEPT $\quad . \quad$ • $\quad . \quad$ • $\quad 9.1$

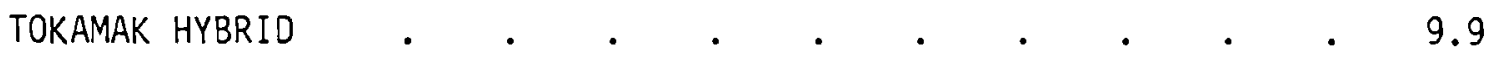




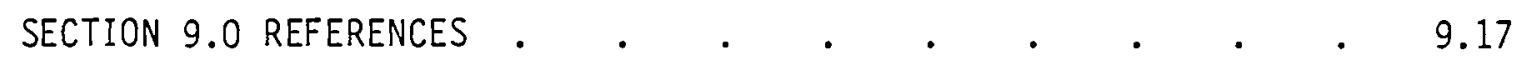

10.0 ENVIRONMENTAL CONSIDERATIONS .

FUSION FUEL CYCLE

FISSION FUEL CYCLE .

MAGNETIC FIELDS $\quad$ •

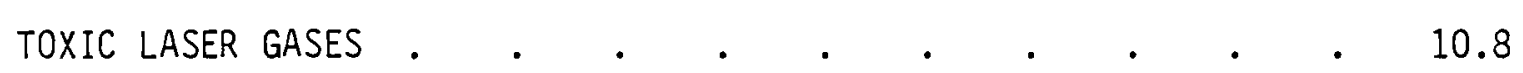

UNIQUE RESOURCE REQUIREMENTS •

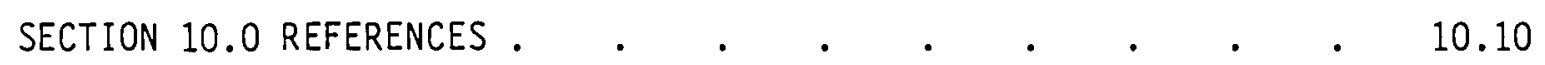

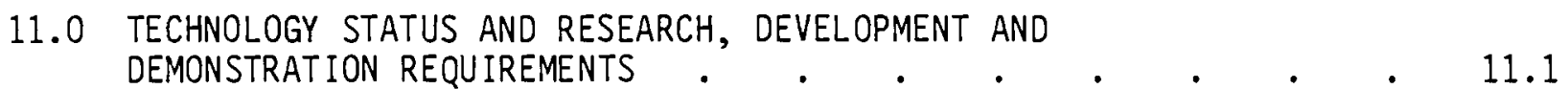

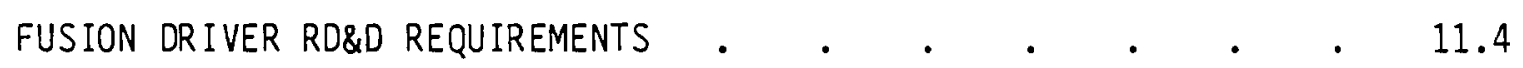

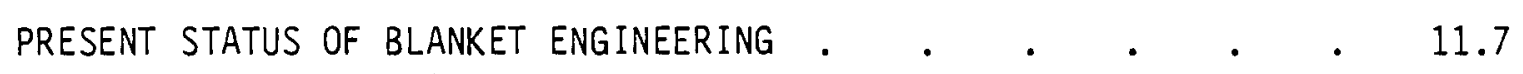

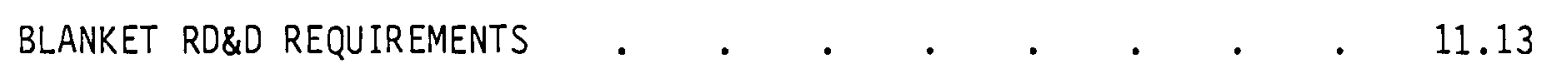

POSSIBLE HYBRID RD\&D PROGRAM • • • • • • • • • • • 11.15

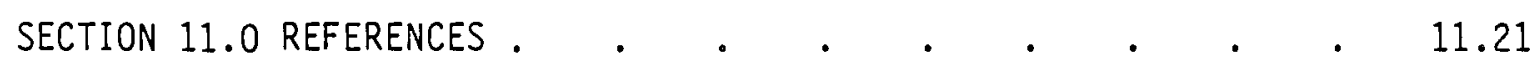

APPENDIX A: CAPITAL INVESTMENT COST ESTIMATES $\quad . \quad \cdots \quad . \quad$ • $\quad$ A.1

APPENDIX B: LEVELIZED ENERGY COST ESTIMATES $\quad . \quad \cdots \quad \cdot \quad \cdot \quad$ • $\quad$ • 



\section{FIGURES}

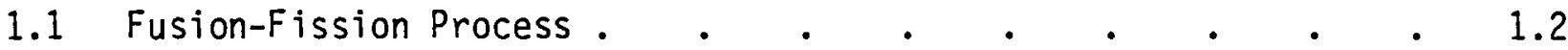

2.1 D-T Fusion Reaction Rate as a Function of Temperature . $\quad 2.2$

2.2 Cross Section of the Tokamak Hybrid Reactor . . . . 2.4

2.3 "D"-Shaped Constant Tension Toroidal Field Magnet Design . . 2.8

2.4 Maximum Neutralization Efficiency Calculated by Berkner . . 2.11

25 Schematic Diagram of the Neutral Beam System Using $\begin{aligned} & \text { Positive Ion Sources } \\ & \text { P. . }\end{aligned}$

2.6 Reactor Calculational Schematic . . . . . . . 2.14

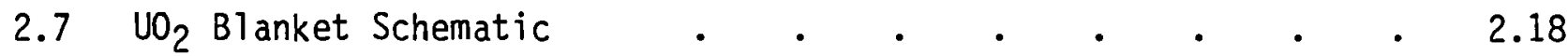

2.8 UC Blanket Schematic . . . . . . . . . . . 2.18

$2.9 \mathrm{PuO}_{2}-\mathrm{UO}_{2}-\mathrm{ThC}_{2} \mathrm{Bl}$ anket Schematic.$\quad \cdot \quad \cdot \quad \cdot \quad \cdot \quad \cdot 2.19$

2.10 Heating Rates as a Function of Radius for Three
Blanket Types . . . . . . . . . 2.24

2.11 A Fast and Thermal Group Flux as a Function
of Radius . . . . . . . . . . . 2.25

2.12 A Fast and Thermal Group Flux as a Function
of Reactor Radius. . . . . . . . . 2.26

3.1 Uranium Nuclear Fuel Cycle . . . . . . . . . 3.4

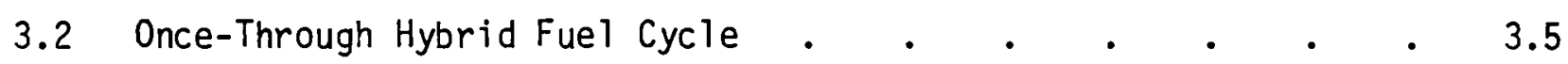

3.3 Refresh Hybrid Fuel Cycle . . . . . . . . . . 3.6

3.4 Thorium LWR Fuel Cycle . . . . . . . . . 3.8

3.5 Thorium Hybrid Fuel Cycle . . . . . . . . $\quad 3.10$

3.6 Plutonium Recycle . . . . . . . . . . . . 3.11

3.7 Tokamak Hybrid Reactor Fuel Flow - Once-Through
Fuel Cycle . . . . . . 3.18

3.8 Tokamak Hybrid Reactor Fuel Flow - Pu Recycle . . . . $\quad 3.19$ 
3.9 Tokamak Hybrid Reactor Fuel Flow - Pu-Catalyst

3.10 Tokamak Hybrid Reactor Fuel Flow - Refresh

Fuel Cycle . . . . . . . . . . . . 3.21

3.11 Fabrication Facility Layout . . . . . . . . 3.28

$3.12 \mathrm{UO}_{2} / \mathrm{PuO}_{2}$ Fabrication Facility for Pu-Catalyst

Fuel Cycle . . . . . . . . . . . . 3.31

4.1 Tokamak Hybrid Blanket Segment . . . . . . . . 4.3

4.2 Helium Coolant Flow in the Tokamak Hybrid Reactor . . 4.5

4.3 Tokamak Hybrid Module Detail . . . . . . . . 4.6

4.4 Tokamak Hybrid Reactor Cross Section . . . . . . 4.8

5.1 Thermal Efficiency of Typical Thermo-Dynamic Cycles as a Function of Peak Cycle Temperature . $\quad . \quad$. $\quad . \quad 5.9$

6.1 Annual Cost of Electricity and Levelized Energy Cost . . . $\quad 6.7$

7.1 Tokamak Hybrid Reactor Hall • • . . . . . 7.2

7.2 Power Conversion System for Tokamak Hybrid Reactor . . . 7.3

7.3 Tokamak Hybrid Plant Schematic . . . . . . . 7.4

11.1 Technical Progress and Outlook in Magnetic Fusion
Source: Magnetic Fusion Program Sumary Document . . . $\quad 11.3$

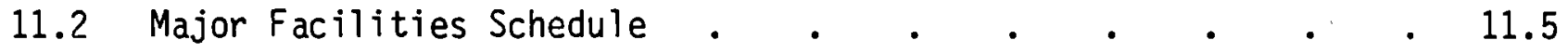

11.3 Engineering Facilities Schedule . • • • • • . . 11.8

11.4 Hybrid Development Facilities Schedule . . . . . 11.18 


\section{TABLES}

1. Tokamak Hybrid Reactor Parameters . . . . . . . . V v

2.1 Plasma Parameters for Tokamak Hybrid Reactor . . . . . 2.3

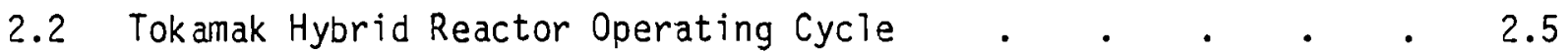

2.3 Power Requirements for a Tokamak Hybrid Reactor . . . . $\quad 2.12$

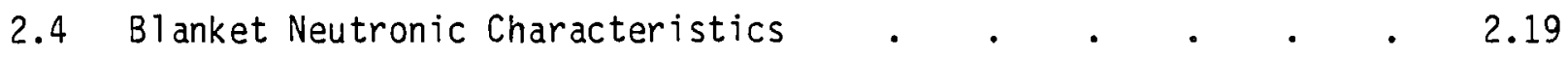

2.5 Isotopic Concentrations After One Year Operation $\quad$ • $\quad$ • $\quad$ - 2.22

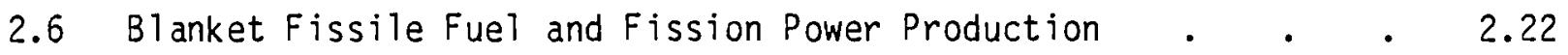

3.1 Tokamak Hybrid Fue 1 Management Data . . . . . . . 3.12

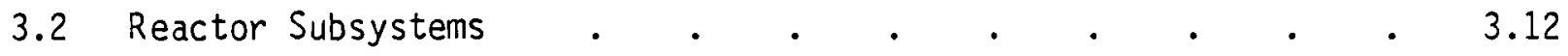

3.3 Tokamak Hybrid Reactor Initial Material Requirements . . 3.14

3.4 Once-Through and Pu-Recycle Fuel Charge Data . . . . . 3.15

3.5 Once-Through and Pu-Recycle Fuel Discharge Data . . . . 3.16

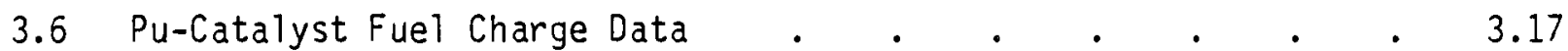

3.7 Once-Through and Pu-Recycle to Thermal Reactors
Fuel Fabrication Facility

3.8 Material Stream Characteristics . . . . . . . . . 3.29

3.13 Pu-Catalyst Fuel Fabrication Facility Characteristics • • 3.34

3.10 Material Stream Characteristics . . . . . . . . . . 3.35

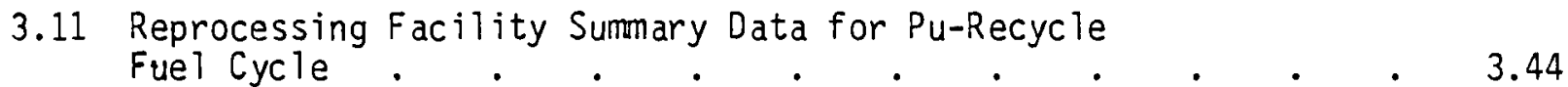

3.12 Material Stream Characteristics . . . . . . . . . 3.45

3.13 Reprocessing Facility Sumary Data for Pu-Catalyst . 3.46

3.14 Material Stream Characteristics . . . . . . . . . . . 3.47

4.1 Typical Reactor Power Densities . $\quad$. $\quad$. $\quad$. 4.1

\begin{tabular}{l} 
4.2 Tokamak Hybrid Mechanical and Thermal Hydraulic \\
Information .. .5 \\
\hline
\end{tabular} 


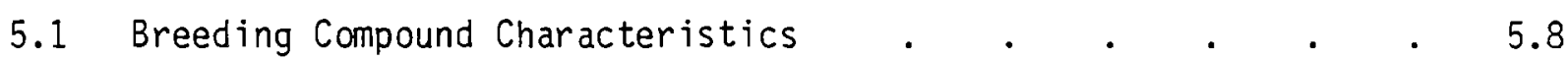

6.1 Economic Parameters/Unit Costs . . . . . . . . . . . . 6.2

6.2 Capital Investment Cost Summary . . . . . . . . . . . 6.3

6.3 Capitol Investment Cost Summary . . . . . . . . . . . 6.3

6.4 Annual Operating and Maintenance Cost Summary . . . . . . 6.5

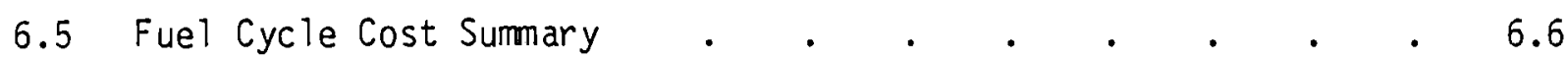

6.6 Levelized Energy Cost Sumary . . . . . . . . . . . 6.6

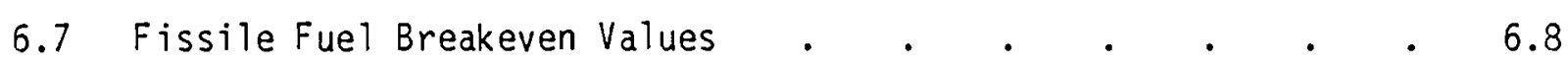

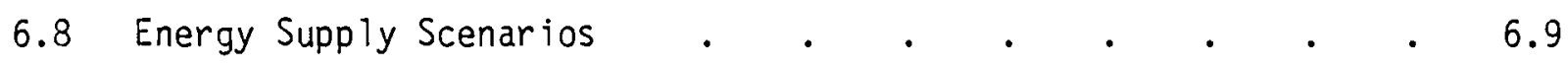

6.9 Market Penetration Assessment - Economic
and Performance Parameters . . . . . . . . . . 6.10

6.10 Market Penetration Assessment/Scenario 1 . $\quad$. $\quad$. 6.10

6.11 Market Penetration Assessment/Scenario 2 . $2 . \quad$. $\quad$. 6.11

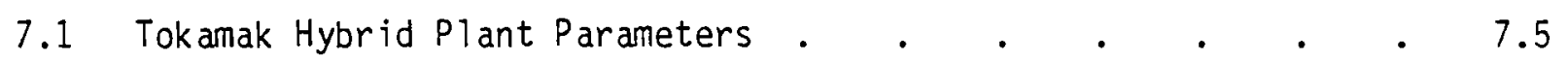

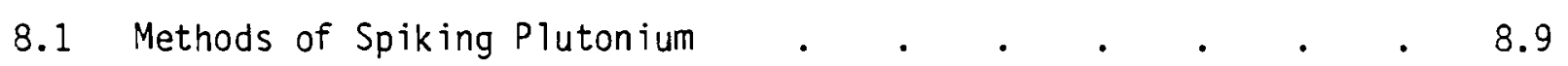

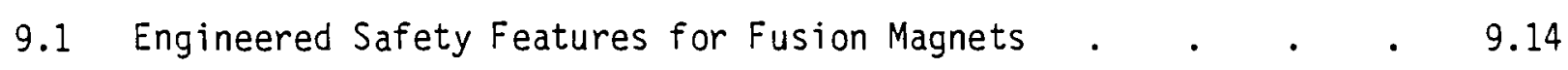

10.1 Total Domestic Demand for Important Fusion Materials . • . 10.9

10.2 Depletion of 1974 U.S. Reserves of Important Fusion Power Plant Materials . $\quad . \quad$. $\quad . \quad$. 10.10

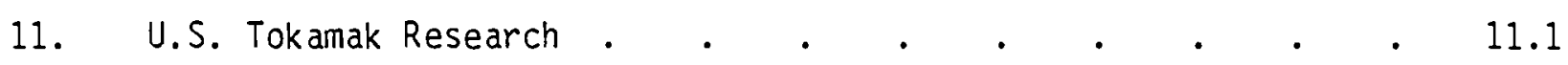

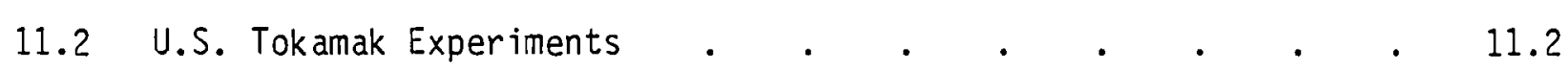

11.3 Objectives of Major Fusion Reactor Facilities . . . . . 11.6

\begin{tabular}{l}
11.4 Features of the Tokamak Fusion Driver Related \\
to Large Tokamak Experience \\
\hline
\end{tabular}

11.5 Objectives of Major Fusion Engineering Facilities . . . 11.9

11.6 Hybrid Reactor Technological Advance Requirements . . • 11.17

11.8 Hybrid Facility Cost Estimates . . . . . . . . . . 11.20 


\subsection{INTRODUCTION}

A concept that has potential for future application in the electric power sector of the U.S. energy economy is a combination of fusion and fission technology (Leonard 1973). The fusion-fission energy system, called a hybrid, is distinguished from its pure fusion counterpart by incorporation of fertile materials (uranium or thorium) in the blanket region of a fusion reactor.

The neutrons produced by the fusion process can be used to produce fue 1 for fission power reactors through capture events in the fertile material. For the current hybrid design concepts being studied, 5-10 LWRs can be expected to be supported from the hybrid's annual fissile production. Although fuel production is envisioned as the chief benefit of a fission-fusion system, the thermal energy generated through fission events in the blanket could be used to generate electricity. The performance requirements of the fusion component of hybrids are perceived as being less stringent than those for pure fusion electrical power plants. The performance requirements of the fission component of hybrids are perceived as having been demonstrated or could be demonstrated with a modest incremental investment of research and development funds. In addition, the fission blanket is inherently subcritical, which precludes criticality accidents and mitigates the afterheat problems suffered in potential loss of coolant accidents.

This concept is currently being evaluated as one of the alternative advanced concepts in the U.S. Nonproliferation Alternative Systems Assessment Program (NASAP). Conceptual studies indicate that fusion component performance requirements are substantially lower for the hybrid than for pure fusion electric plants. The major fission technology requirements for the hybrid are expected to be developed in the course of research and development of fission power reactors and their fuel cycles. Thus, a hybrid could conceivably be developed and deployed near the turn of the century.

In the hybrid reactor, a blanket region of fertile material is placed around the fusion plasma. The fusion-fission process is depicted in Figure 1.1 . 


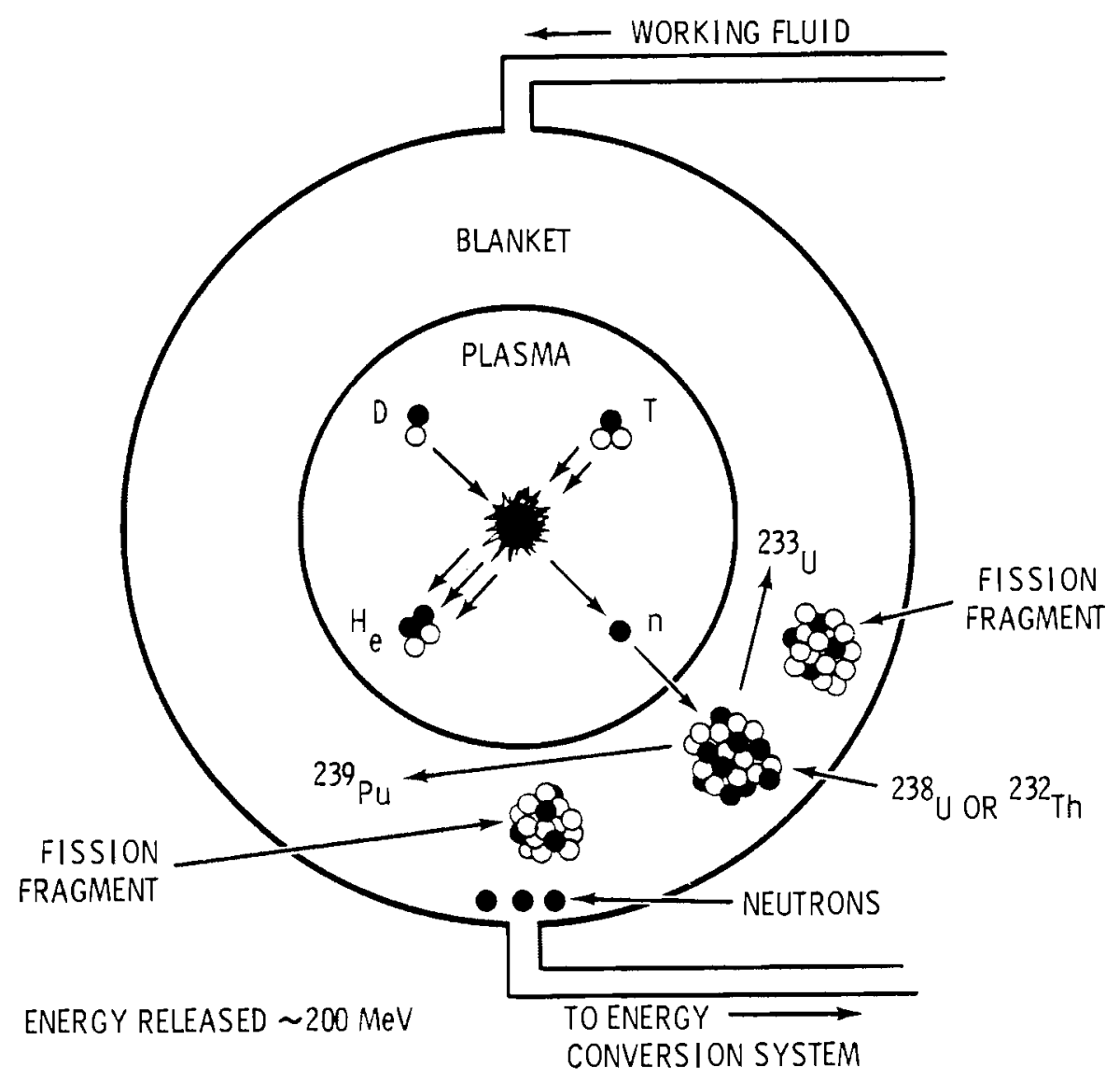

FIGURE 1.1. Fusion-Fission Process

The $14 \mathrm{MeV}$ neutron produced in the fusioning plasma travels to the blanket where it deposits its energy and is absorbed by the fertile material. Subsequent reactions, neutron re-emission, fission or capture, can take place depending on the energy of the absorbed neutron. The blanket reactions in the fusion-fission system are the neutron interactions with ${ }^{6}{ }_{L i}$ and ${ }^{7}{ }_{L}$

$$
\begin{aligned}
& \frac{7}{3} \mathrm{Li}+\frac{1}{0_{0}}+2.5 \mathrm{MeV} \rightarrow{ }_{1}^{3} \mathrm{~T}+{ }_{2}^{4} \mathrm{He}+\frac{1}{0^{n}} \\
& \frac{6}{3} \mathrm{Li}+{ }_{0} \mathrm{n} \rightarrow{ }_{1}^{3} \mathrm{~T}+{ }_{2}^{4} \mathrm{He}+4.8 \mathrm{MeV}
\end{aligned}
$$


and the fission reactions involving either uranium or thorium

$$
\begin{aligned}
{ }_{92}^{238} U+{ }_{0}^{1} n & +{ }_{92}^{237} U+2{ }_{0}^{1} n \\
& +{ }_{92}^{236} U+3{ }_{0}^{1} n \\
& \\
92 & + \text { multiple neutrons }
\end{aligned}
$$

If the incident neutron energy is greater than $\sim 2 \mathrm{MeV}$, then the multiplying reactions of Equation (2) and the fission reaction of Equation (3) are dominant. The multiplying and fission reactions given in Equations (2) and (3) can also occur if thorium is used as the fertile blanket material. About $180 \mathrm{MeV}$ of energy plus secondary neutrons are released in the fission reactions. If the neutron energy is degraded below $\sim 2 \mathrm{MeV}$ then the principal absorption reaction is capture $(n, y)$. The capture reactions and the end product as the result of $B$ decay are

$$
\begin{aligned}
& \frac{238}{92} U+{ }_{0}^{1} n \rightarrow{ }_{92}^{239} U+\gamma \\
& \underset{92}{239} U \stackrel{\beta}{\rightarrow} \underset{93}{239} n_{p} \stackrel{\beta}{\rightarrow} \underset{94}{239} \mathrm{Pu} \\
& 232 \mathrm{Th}+{ }_{0}^{1} n \rightarrow{ }_{90}^{233} \mathrm{Th}+\gamma \\
& 233 \mathrm{Th} \stackrel{\beta}{\rightarrow} 233 \mathrm{~Pa} \stackrel{\beta}{\rightarrow} 233 \mathrm{~g} \mathrm{~J} \\
& 90
\end{aligned}
$$


The final products of the reactions are ${ }^{233} \mathrm{U}$ and ${ }^{239} \mathrm{Pu}$. These isotopes are both fissile materials and thereby candidate fuels for fission power plants.

Comparison of the fusion and hybrid processes shows that more energy is released in the hybrid when fission occurs. The fusion process yields $\sim 18 \mathrm{MeV}$ of energy, whereas fission in the hybrid blanket yields $2180 \mathrm{MeV}$, roughly ten times more energy release. In the high energy absorption and fission processes, additional neutrons are also released. Thus, in the hybrid both energy and neutron multiplication take place, which are considered desirable features for power reactor applications.

Projections of the electric generation mix in the U.S. Overview 1977 to the year 2000 (1978-1982), lead to a prediction of a potential shortfall of fissile material shortly after the year 2000. Interest in hybrids stems from the possibility that fuel-breeding hybrids might be developed in time to ease or eliminate this potential shortfall and stabilize fissile fuel costs.

Because of the uncertainty in the future supply of $235_{\mathrm{U}}$, electrical utilities that rely on nuclear power are interested in the hybrid concept to produce fissile fuel for existing power plants. With an additional supply of fissile material for the future, nuclear increment of the electric generation mix might grow substantially.

The hybrid concept is also viewed as a step along the pathway to pure fusion power. The many uncertainties in plasma physics, plasma engineering, and blanket engineering performance of pure fusion systems may conceivably be resolved through the development of hybrids. Thus, hybrids would be a step on the road to achieving the benefits of pure fusion technology. In the following chapters, this concept will be developed more fully for a tokamak fusion plasma.

\section{SECTION 1.0. REFERENCES}

B. R. Leonard, Jr., "A Review of Fusion-Fission (Hybrid) Concepts." 1973. Nucl. Tech. 20:161.

Research and Development Program for 1978-1982 Overview. 1977. Electric Power Research Institute, Palo ATto, CA. 


\subsection{REACTOR PHYSICS CONSIDERATIONS}

PLASMA PHYSICS

The fusion core of a Tokamak Hybrid Reactor (THR) should have the highest possible fusion power density to maximize the neutron fluence supplied to the surrounding fusion blanket. The plasma conditions for optimizing the fusion power in a beam driven tokamak reactor are discussed by Jassby (1975). In such a Two-Energy Component Tokamak (Dawson, Furth and Tenney 1971), the temperature of the tritium bulk plasma is maintained against transport and radiation losses by injected energetic deuterons that undergo fusion reaction with the relatively cold tritons. At plasma temperatures $<10 \mathrm{keV}$, the maximum fusion power obtainable in this mode of operation is considerably larger than that obtainable for an ignited plasma composed of a 50/50 D-T mixture. However, operation in the TCT mode requires that the neutral beam injectors remain at full power during the entire burn. This places strict performance requirements on the neutral beam system and, more importantly, demands that a sizable recirculating power fraction be maintained to meet the large power requirements for continuous operation of the beam injector system. Based on these factors, the decision was made that the desired fusion power level for the THR is obtained by using a $>10 \mathrm{keV}$ ignited 50/50 D-T plasma. This relaxes the performance demands on the neutral beam system and establishes an efficient operating cycle by minimizing the recirculating power requirements. Under ignition conditions the plasma temperature is maintained by the confinement of fusion alpha particles, which is sufficient to balance the transport and radiation losses. Finally, the tokamak driver design is based on nearterm projected technological developments.

High toroidal field, high beta and elongated plasma cross sections are found to be essential for obtaining ignited tokamak plasma. For a tokamak plasma of arbitrary $q, A=R / a, B p<A$, and axial magnetic field $B_{t}(k G)$, the fusion power is given by

$$
P_{f}=1.1 \times 10^{-18}\left(\frac{B t S}{q A}\right)^{4} \quad p^{2} \frac{\overline{\sigma V}}{T c^{2}}
$$




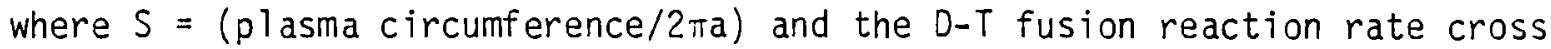
section is given in Figure 2.1. The plasma minor radius a (in meters) is the plasma half-width at the mid-plane. Equation (1) clearly indicates that the fusion power increases rapidly with toroidal field strength and leads to the use of high field superconducting coils. This design utilizes $\mathrm{Nb}_{3} \mathrm{Sn}$ coils to produce an on-axis field of $66.6 \mathrm{kG}$. The poloidal beta value--the ratio of particle pressure to magnetic pressure--is fixed at $p=0.7 \mathrm{~A}=3.8$. This value is somewhat lower than the maximum value that insures MHD stability. In the design study the aspect ratio, safety factor, shape factor, and plasma elongation were fixed at the values listed in Table 2.1. The plasma temperature and minor radius were varied to find a suitable operating point with a sufficiently high fusion power output. A plasma with a minor radius of $1 \mathrm{~m}$ and a major radius of $5.4 \mathrm{~m}$, operating at a temperature of $11.3 \mathrm{keV}$ was chosen. This plasma provides 1160 MW of fusion power.

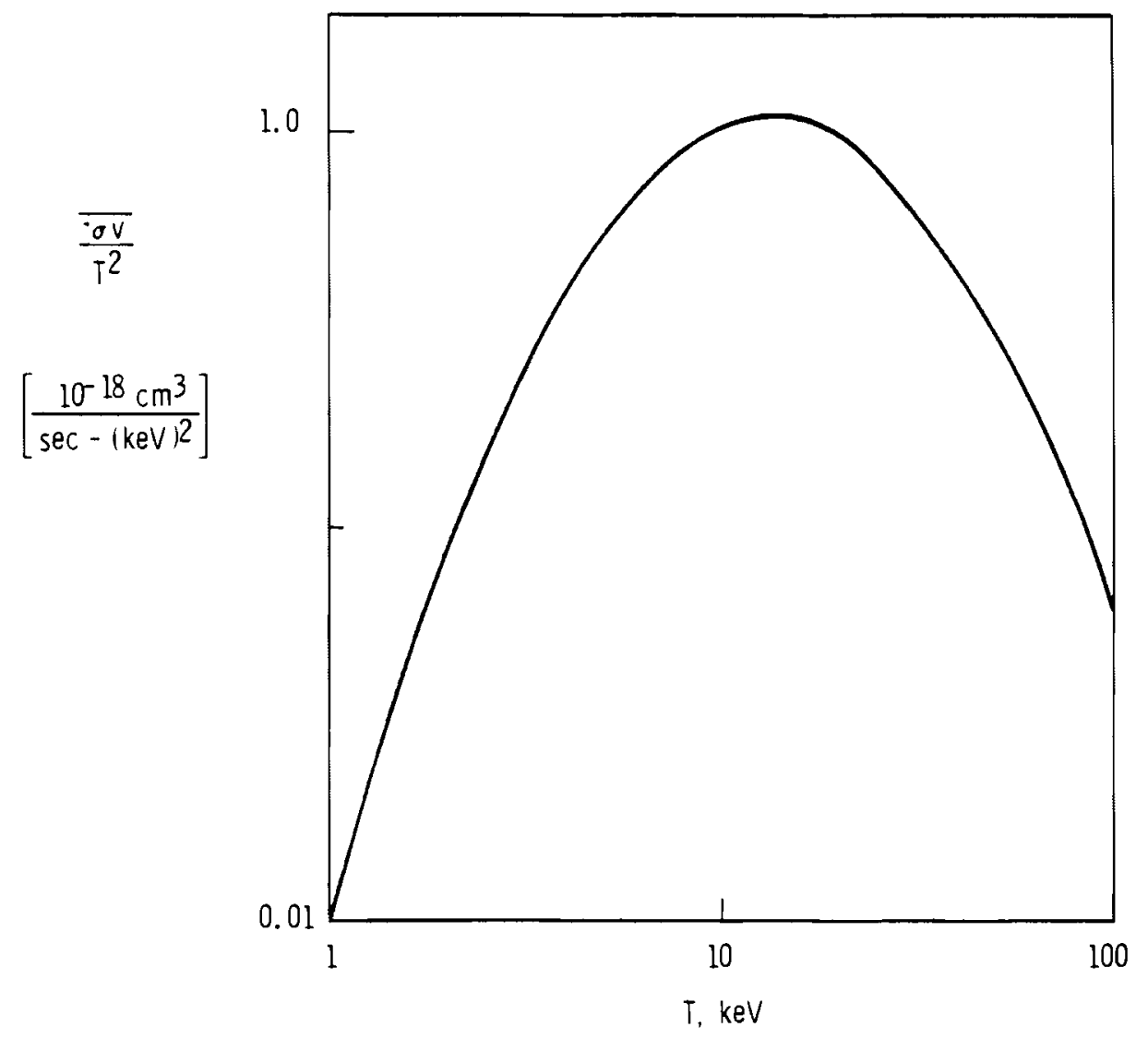

FIGURE 2.1. D-T Fusion Reaction Rate As A Function of Temperature 
TABLE 2.1. P1asma Parameters for Tokamak Hybrid Reactor

$\begin{array}{ll}R_{0} & 5.4 \mathrm{~m} \\ a & 1.0 \mathrm{~m} \\ A & 5.4 \\ \text { Elongation, } K & 2.0 \\ \text { Shape Factor, } S & 1.53 \text { (flattened "D" shape) } \\ \text { Horizontal Wa11 Radius } & 1.3 \mathrm{~m} \\ \text { Wa11 Area } & 425 \mathrm{~m}^{2} \\ \text { Plasma Volume } & 175 \mathrm{~m}^{3} \\ \text { Axial B } & 6.66 \mathrm{~T} \\ \mathrm{I}_{\mathrm{p}} & 5.6 \mathrm{MA} \\ \mathrm{q} & 2.4 \\ \overline{\mathrm{n}}_{\mathrm{e}} & 2.54 \times 10^{14} \mathrm{~cm}^{-3} \\ \overline{\mathrm{T}}_{\mathrm{e}}=\overline{\mathrm{T}}_{\mathrm{i}} & 11.5 \mathrm{keV} \\ \overline{\mathrm{n}}_{\mathrm{e}} \tau_{E} & 4.2 \times 10^{14} \mathrm{~cm}^{-3} \mathrm{~s} \\ \text { Bp } & 3.8 \\ \text { Fusion Power } & 1160 \mathrm{MW} \\ \text { Neutron Power } & 928 \mathrm{MW} \\ \text { Neutron Wa11 Loading } & 2.2 \mathrm{MW} / \mathrm{m}^{2} \\ \text { Power Density } & 6.6 \mathrm{MW} / \mathrm{m}^{3} \\ \end{array}$

Table 2.1 also lists the plasma parameters characterizing the tokamak fusion driver. At an electron temperature of $11.5 \mathrm{keV}$, the electron density is found to be $2.54 \times 10^{14} / \mathrm{cm}^{3}$. With Alcator-type scaling the resulting $\bar{n}_{e}$ is $4.2 \times 10^{14} \mathrm{sec} / \mathrm{cm}^{3}$, well above the value required for ignition conditions. While tokamak plasmas to date have operated in quasi-steady-state 
only at $\beta_{p} \approx 1<R / a$, experiments have been performed (Mirnov 1970; Hosea 1975) in which $\beta_{p}$ was increased well above unity by an abrupt decrease in the plasma current with apparently no adverse effect on the plasma equilibrium.

A cross-sectional view of the Tokamak Hybrid Reactor is shown in Figure 2.2. The plasma cross section is in the shape of a flattened "D" $(S=1.53)$. This cross section lends itself well to the implementation of a double-null poloidal divertor, which is used for the removal of $D$ and $T$ ions, impurities, and alphas emerging from the discharge (Emmert, Mense and Donhowe 1974; Meade et a1. 1974). The elongated plasma cross section, however, has a

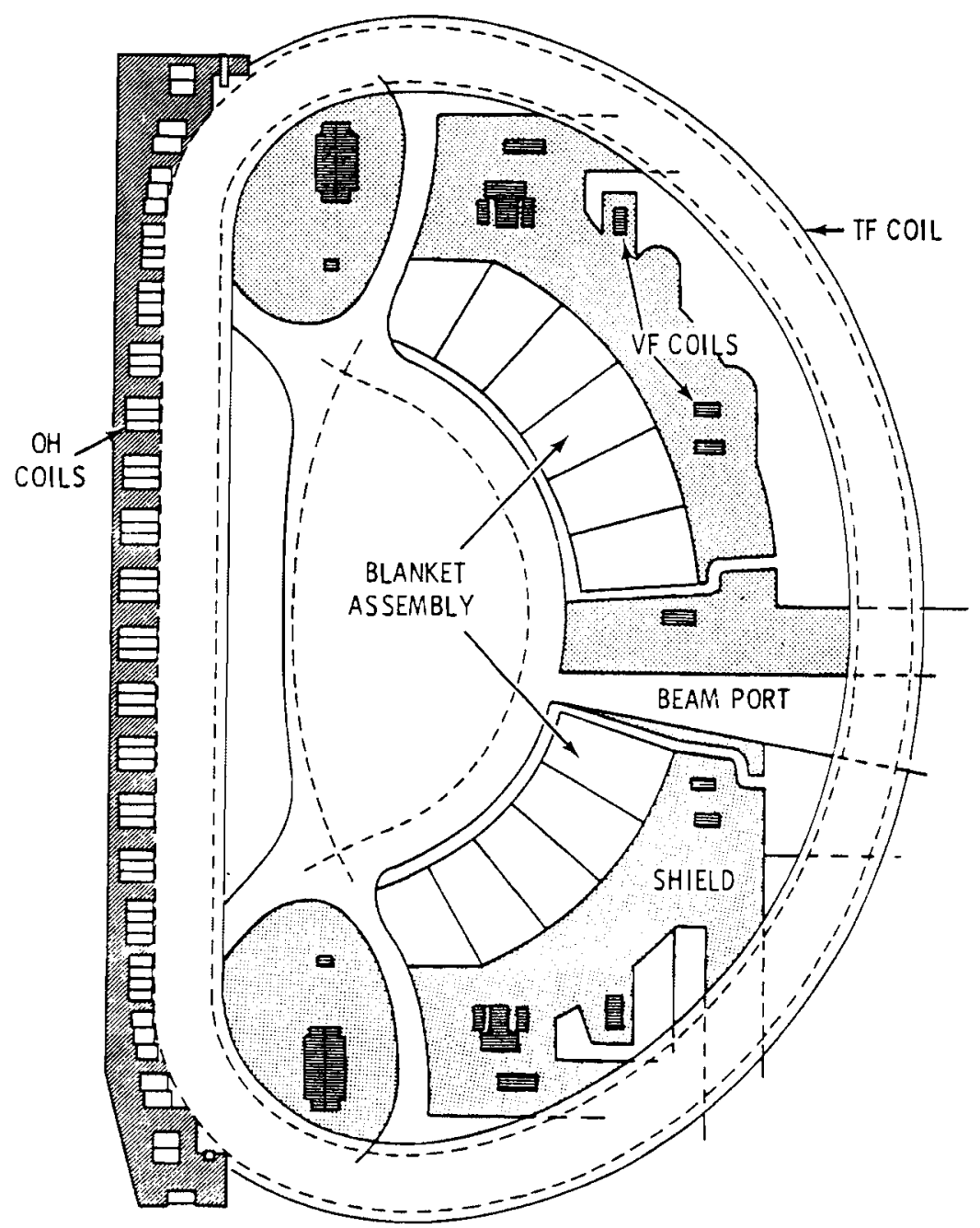

FIGURE 2.2. Cross Section of the Tokamak Hybrid Reactor 
negative decay index; hence, feedback stabilization of the plasma vertical position is required (Moses and Young 1975). The plasma position is stable in the horizontal direction, but variation in the plasma current or pressure may cause it to sit off-center horizontally. Consequently, a feedback loop is included to keep the plasma centered horizontally as well. The peak power required during a transient to return the plasma to its equilibrium positon is $90 \mathrm{MN}$.

The operating cycle of the Tokamak Hybrid Reactor consists of 1) gas filling, 2) discharge current rise and startup of beam injectors, 3) injector shutdown and full power operation, 4) current reduction, and 5) vacuum system purge. The duty factor is the ratio of full power operation to the total cycle time and is determined by the maximum duration of the ohmic discharge, impurity buildup in the plasma, and refueling techniques. From Table 2.2, which outlines the selected operation cycle, the duty factor is seen to be 0.87 .

All the variables involved in the fusion power for this tokamak driver have not been optimized. Nevertheless, the present design indicates that a fusion hybrid system with a tokamak driver may be economically attractive in the near future.

TABLE 2.2. Tokamak Hybrid Reactor Operating Cycle

Time (seconds)

$0-1$

$1-4$

$4-106$

$106-107.5$

$107.5-116.5$
Phase Description

Startup: Plasma and divertor currents rise to full maximum; transformer currents begin to drop, plasma ohmically heats to $T_{e}=2.1 \mathrm{keV}$.

Injection Heating: Neutral beams heat the plasma to operating temperature, $\mathrm{T}_{\mathrm{e}}=11.5 \mathrm{keV}$, transformer currents continue to drop.

Burn: Neutral beams shut down after ignition is achieved, transformer currents drop to maximum negative values.

Shutdown: Current in transformer reversed plasma and divertor currents drop to zero.

Recharge: Plasma cooldown, residual gas pumped out; chamber refilled with fresh fuel, transformer currents reset to initial values. 


\section{CONCEPTUAL ENGINEERING DESIGN}

Vacuum System

The THR has a major radius of $5.4 \mathrm{~m}$, a minor radius of $2 \mathrm{~m}$ and a plasma elongation factor of 2.0. The plasma volume for the device is $175 \mathrm{~m}^{3}$. The total area of the first wa11, allowing for the vacuum gap separating the plasma and the first wall, is calculated to be $425 \mathrm{~m}^{2}$. The coverage of the fission blanket is up nearly $33 \%$ of this area (approximately $140 \mathrm{~m}^{2}$ ) and less than $1 \%$ of this area is taken up by the neutral beam ports.

The first wall consists of a $0.5 \mathrm{~cm}$ carbon liner inside a double-walled stainless steel shel1 $5 \mathrm{~cm}$ thick, having channels for helium coolant at 700 psi. On the inner zone of the torus, where a large fraction of the tritium is bred, the stainless steel backing is $1.5 \mathrm{~cm}$ thick. This carbonstainless steel first wall will be subjected to a neutron flux of $2.2 \mathrm{MW} / \mathrm{m}^{2}$. The poloidal divertors will minimize physical and chemical interactions with the first wall, considerably reducing first wall sputtering. The magnetic flux density in the vessel region varies from $70 \mathrm{kG}$ to over $100 \mathrm{kG}$ in portions of the divertor channel in proximity to the TF coils. The divertors are also expected to keep the impurity concentration in the plasma at a low level. The bulk of these impurities are expected to be found in the outer region of the plasma. The resulting radiation to the first wall is $\sim 25 \mathrm{MW}$, resulting in a heating rate of $5.9 \mathrm{~W} / \mathrm{cm}^{2}$. This, together with the neutron flux, will result in a heating rate $\sim 60 \mathrm{~W} / \mathrm{cm}^{2}$ in the first wall region. The coolant flow rate through the first wall coolant channels of $190 \mathrm{~kg} / \mathrm{s}$ at $70 \mathrm{~m} / \mathrm{s}$ velocity provides a heat transfer coefficient of $0.35 \mathrm{~W} / \mathrm{cm}^{20} \mathrm{C}$, which is sufficient to keep the first wall at $35^{\circ} \mathrm{C}$.

The function of the primary vacuum system on the fusion driver is to pump out the unburned fuel and the reaction products during the burn cycle, and to clean and condition the chamber surfaces during the downtime between cycles. Since the fractional burnup in a magnetically confined reactor of the tokamak type is very low, several percent, most of the fuel leaves the plasma in the form of charge particles and eventually has to be pumped out as a gas. Moreover, each D-T reaction produces an alpha particle that also leaves the plasma and is pumped out as helium. 
The gas throughput in such a reactor is extremely high and requires a very large capacity pumping system in a rather limited space. Furthermore, since the effluent is recycled for fuel recovery, it must be uncontaminated with hydrocarbons or any other contaminants, which severely limits the type of pumps that can be used. The THR is envisioned to have 110 rotatable cryosorption pump pairs, 55 in each divertor zone, similar to those designed for the Tokamak Engineering Test Reactor. One-half of these pumps are to be on-line at any given time. As soon as the cryo-sorption surfaces of the on-line pump are saturated, the pump pair is rotated $180^{\circ}$, which places the freshly regenerated pump in place to begin pumping.

Cryo-sorption pumps have been the leading candidates for use in fusion reactors. They successfully fill the requirements of high capacity and lack of contamination, are generally trouble-free, and require almost no maintenance. Few maintenance problems is an extremely important criterion since any maintenance in such close proximity to the reactor will have to be done by remote control.

\section{Magnet System}

The toroidal field magnet system consists of 20 cryogenically stable superconducting coils with $\mathrm{Nb}_{3} \mathrm{Sn}$ filaments in OFHC copper stabilizer. The TF coils are constant tension "D"-shaped, obtained from the analytical formulation by Moses and Young (1975) that produces a magnetic field of $66.6 \mathrm{kG}$ on the plasma axis. The formulation corrects the magnetic forces for variations in the field due to the discreteness of the finite number of coils and the shape of the cross section and results in field ripple at the plasma surface of only $1 \%$. Conductors embedded in structural discs are employed to hold the conductor rigidly within the supporting structure. Figure 2.3 shows the toroidal field magnet design (Tokamak Engineering Test Reactor 1977).

The shell structure between toroidal field magnets is designed along with the magnet dewar to sustain the lateral loads that result from pulsing fields from the VF coils and plasma current and the much larger loads produced if one adjacent magnet should lose current. These shells also provide for magneto electric stability of the toroidal field coils. 


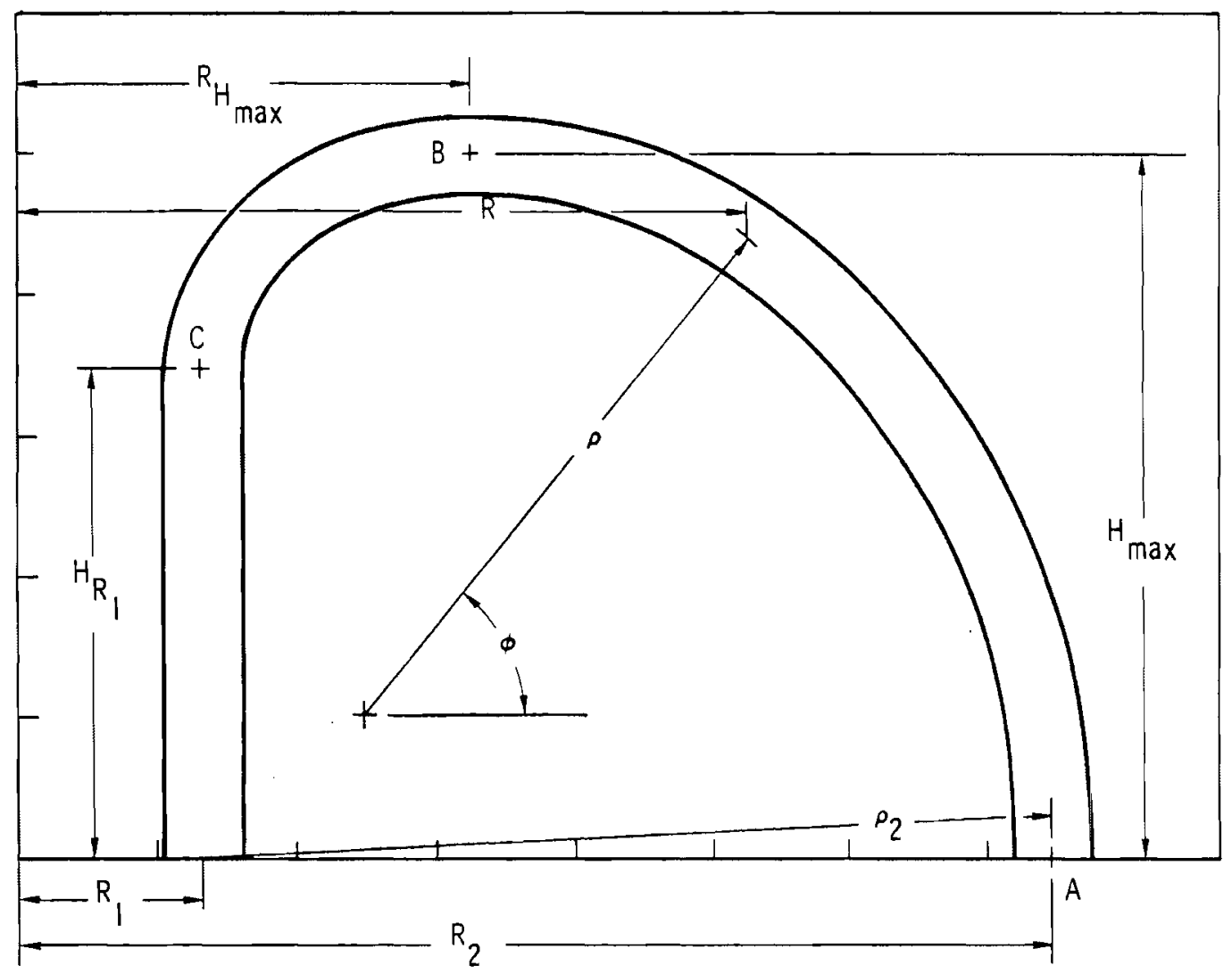

FIGURE 2.3. "D"-Shaped Constant Tension Toroidal Field Magnet Design

The vertical field (VF) coils are conventional water-cooled copper conductors operated at $64^{\circ} \mathrm{C}$. The technology for such coils is well established, needs no extrapolation, and can be used to design rapidly pulsed coils without adverse effects. A major advantage is that copper conductors can be joined and repaired by conventional brazing techniques. The VF system is not space1 imited and does not require high-strength superinsulation because the VF coils are not near cryogenic structures.

The VF coils not only provide the poloidal field needed for plasma confinement and stability, but also provide the flux lines along which charged particles leaving the plasma are diverted to the particle collector plates. The multipurpose nature of the VF coil system substantially complicated the VF system requiring additional coils with more ampere turns than is usually 
required. The $\mathrm{OH}$ coils are high purity aluminum crogenic coils operated at $4.2 \mathrm{~K}$ because the coils are located in the central support structure, which is cooled to that temperature.

To avoid the technological complexity of pulsing superconducting coils during the short one- to two-second rise time of the plasma current, the VF and $\mathrm{OH}$ coils are wound with normal metal conductors. Figure 2.2 shows the locations of the toroidal, vertical and ohmic heating coil systems.

\section{Poloidal Divertor}

The role of the poloidal divertor is to reduce the interaction between the hot plasma of a reactor and the cool ions that exist next to a material wal1. In this way the edge temperature of the plasma is elevated and ionized impurities from the walls flow into the divertor without penetrating the not plasma. This operation hinges upon the relative ease with which plasma can flow along rather than across magnetic field lines. An ion diffusion into the layer is expected to travel a long distance, with the field lines directing them toward a collecting surface, while diffusing only a short distance across the field. In this way, wall bombardment by ions will be reduced and ion collection on the collector plates enhanced. Furthermore, neutral particles from the wall ionized in the scrapeoff plasma will flow to the collector plates before diffusing across the field into the plasma core region.

Charged particles that leave the plasma are guided along the magnetic field lines into the divertor zone where they give up their energy by striking a sacrificial plate and are then pumped out in molecular form. The divertor entrance width is set at $30 \mathrm{~cm}$ to keep the plasma capture efficiency close to unity. Backflow of neutrals into the torus must be prevented to minimize charge-exchange loss of fast ions, as well as charge-exchange accommodated inside the large TF coils. The plasma flow in the scrapeoff region proceeds nearly at the speed of sound (Meade et al. 1974); the density here is relatively low $\left(\sim 2 \times 10^{13} \mathrm{~cm}^{-3}\right)$, and the plasma temperature is high ( $\left.2 \mathrm{keV}\right)$.

For an average particle containment time of $100 \mathrm{~ms}$ with a mean density of $210^{14} \mathrm{CM}^{-3}$, the first wall would sputter about $1 \mathrm{~mm}$ per year (assuming an average sputtering coefficient of 0.01) for kilovolt range ions on a carbon liner. This sputtering would present a serious problem in designing the first 
wall and would create a high-average charge $\left(z_{\text {eff }}\right)$ plasma that could not maintain sufficient ion temperatures to ignite and burn. A scrapeoff thickness of $\sim 20 \mathrm{~cm}$ is required for adequate divertor performance. Divertor technology as developed in PDX and other devices is assumed to be effective (for periods up to 100 seconds) in maintaining $z_{\text {eff }} \leqslant 1.5$ in the case of a carbon first wall.

\section{Neutral Beam Injector System}

Neutral beam injectors will be used to heat the THR plasma during startup. Positive and negative ion source systems were considered for the neutral beam injectors. The choice of ion source type is dictated by the injection energy. Figure 2.4 shows the maximum neutralization efficiency versus beam energy calculated by Berkner, Pyle and Stearns (1976) for positive and negative beams. The neutralization efficiency for $D^{+}$drops rapidly above $40 \mathrm{keV}$, while that for $D^{-}$remains large even at very high energy. For the THR beams at $150 \mathrm{keV}$, tolerable net electrical efficiency can be obtained easily with positive ions, provided direct conversion is employed to recover most of the power in the unneutralized beam fraction.

The injector system for THR neutral beam heating is the result of a $1980 \mathrm{~s}$ technology positive ion system. Twelve beam lines, each containing seven positive ion sources arranged in a vertical array, will be used to deliver $150 \mathrm{MW}$ to the plasma. At the first wall each beam line fills a window $96 \mathrm{~cm}$ (horizontal) by $25 \mathrm{~cm}$ (vertical). The beam ports take up less than $1 \%$ of the first wall area.

The Berkeley type ion sources generate positive deuterium ion beams at $150 \mathrm{keV}$ containing $25 \%$ molecular species and $75 \%$ atomic species. If allowed to enter the neutralizer cell, the molecular species would break up and produce neutral atoms at one-third and one-half the peak energy. These less energetic neutrals would not efficiently penetrate the plasma. This poor penetration could enhance the particle flux to the first wall and cause excessive sputtering. Consequently, the molecular species is removed from the beam by magnetic deflection before the beam enters the neutralizing cell.

The one-third and one-half energy components are deflected to a direct convertor where their energy is recovered. At $150 \mathrm{keV}$ the neutralization 


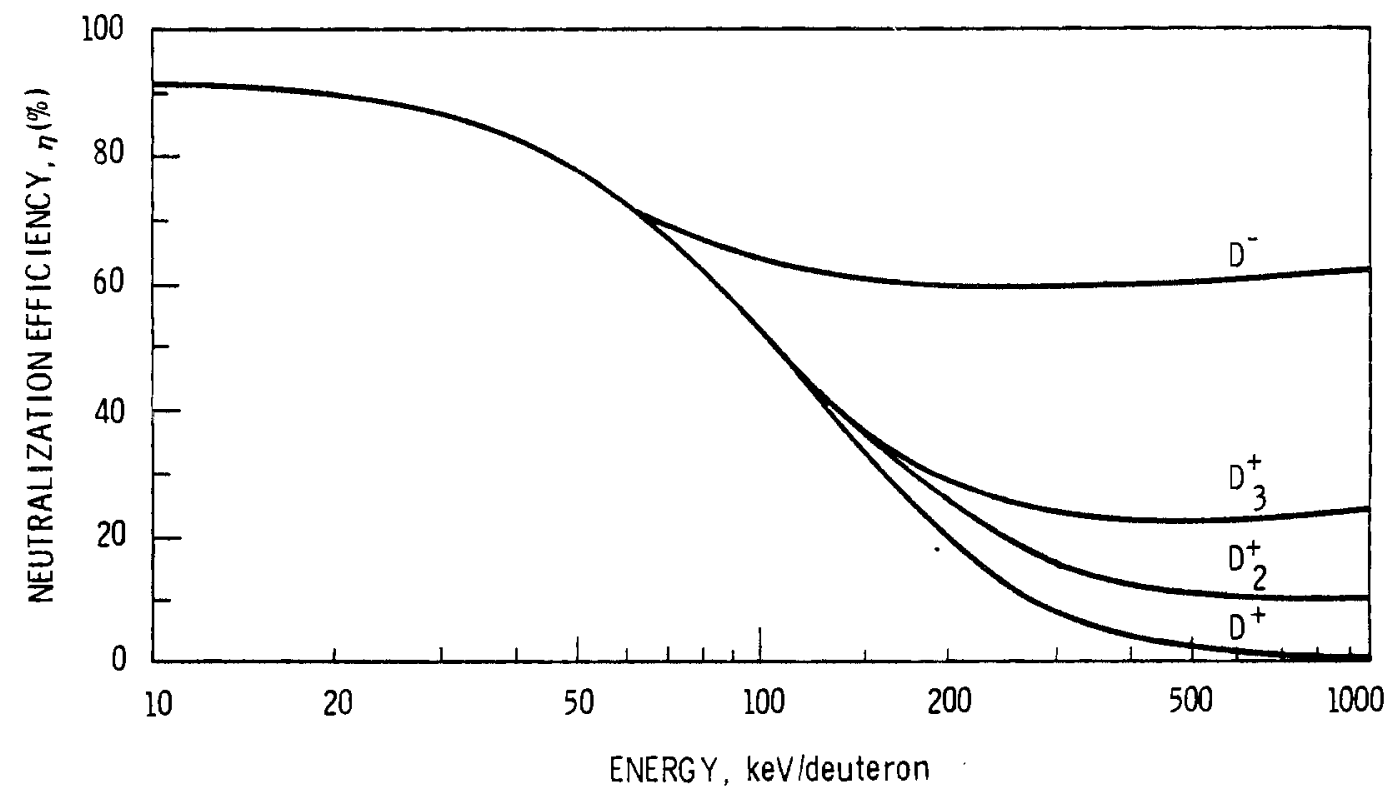

FIGURE 2.4. Maximum Neutralization Efficiency Calculated by Berkner, Pyle and Stearns (1976) for Positive and Negative Ion Beams (Moses and Young 1975)

efficiency is $33 \%$. The unneutralized fraction of the beam is also deflected to a direct convertor. Figure 2.5 shows a schematic of the positive ion source neutral beam system. To provide $150 \mathrm{MW}$ of power to the plasma at $150 \mathrm{keV}$, an injection current of $1000 \mathrm{~A}$ equivalent is required.

An alternate system based on negative ion sources could operate with a greater inherent efficiency at energies above $150 \mathrm{keV}$. Supplementary radiofrequency (RF) heating techniques to complement neutral beam heating could al so be considered. The two major categories of the heating techniques are RF clamping and supplementary electron heating. Possibilities of RF clamping of neutral beam-generated ions include lower hybrid wave heating at the fundamental or first harmonic of the ion cyclotron beam frequency. However, much more theoretical and experimental work is required before these methods can be seriously considered. Both the low frequency compressional Alfven wave and electron cyclotron resonance heating could be considered for supplementary electron heating. 


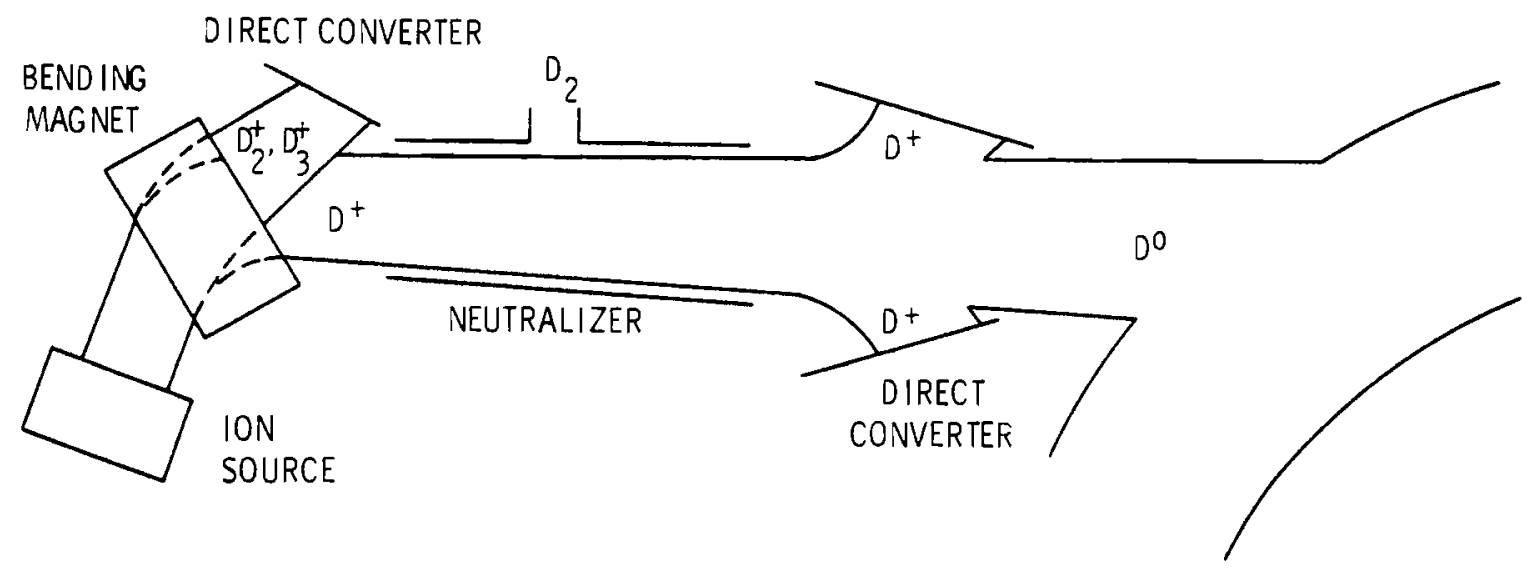

FIGURE 2.5. Schematic Diagram of the Neutral Beam System Using Positive Ion Sources (Moses and Young 1975)

\section{Power Requirements}

Table 2.3, which lists the power requirements for the THR, indicates a need for a recirculating power of $550 \mathrm{MW}$. This corresponds to a plant efficiency of about $70 \%$.

The total energy stored in the toroidal field coils, obtained by integrating the energy density, $B^{2} / 2 \mu 0$, over the volume of the toroid, is $5.06 \times 10^{10}$ joules. The time-average resistive loss in the vertical field

\section{TABLE 2.3. Power Requirements for a Tokamak Hybrid Reactor}

\begin{tabular}{lc} 
& $M W$ \\
\cline { 2 - 2 } Helium Circulating Pumps & 175 \\
Cryo-generation Systems & 70 \\
Resistive Loss of VF Coils & 100 \\
Resistive Loss of OH Coils & 140 \\
Divertor Requirements & 6 \\
Feedback Stabilization System & 30 \\
Cooling Towers & 10 \\
Neutral Beam Requirements & 5.15 \\
Additional System Support & 13.85 \\
\multicolumn{2}{c}{ Total }
\end{tabular}


coils is $100 \mathrm{MW}$, while that in the ohmic heating coils is only $100 \mathrm{~kW}$. The largest portion of the recirculating power in the THR will be drawn by the helium coolant pumps and will require $175 \mathrm{MW}$. The total power required by the cryo-generator for both the magnet and vacuum systems is $70 \mathrm{MW}$. The feedback stabilization system will draw 90 MW maximum and require an estimated 30 times averaged power.

\section{BLANKET NEUTRONICS}

The neutronics calculations were performed for all selected blankets adapted to the Tokamak Hybrid Reactor. The calculational model for the Tokamak Hybrid Reactor is shown in Figure 2.6. To represent the various blanket types, the materials of Zones 15, 16 and 17 were changed in each of the calculations. The remainder of the reactor stayed the same.

The neutron flux calculations were made with the computer code ANISN (Honek 1966), which numerically solved the one-dimensional Boltzman equation. The geometrical model was in vertical cylindrical geometry and is identical to the model described in Figure 2.6. Reflective left-hand and vacuum right-hand boundary conditions were employed. A neutron source that varied both in space and energy was used in the calculation. $\mathrm{A} \mathrm{S}_{8}-\mathrm{P}_{3}$ numerical solution was used.

The cross sections for the transport calculations were generated from ENDF/B-IV files (Bell 1973) into a thirty energy group structure. The methodology is discussed under Nuclear Data.

The burnup calculations were made with the code ORIGEN (Kiesner et al. 1969), a point code that uses one group average cross section to determine the isotopic contents of the fissile and fertile nucleus as a function of operating time. The ORIGEN library did not include cross sections to $14 \mathrm{MeV}$, so the cross sections must be generated for input into this code. This is accomplished in the following manner.

Four cross sections, $\sigma^{f}, \sigma^{c}, \sigma^{n-2 n}, \sigma^{n-3 n}$, are required for each isotope. An ANISN calculation is made for a particular fuel, for a particular time in the life of the blanket segment and the calculations begin with the 

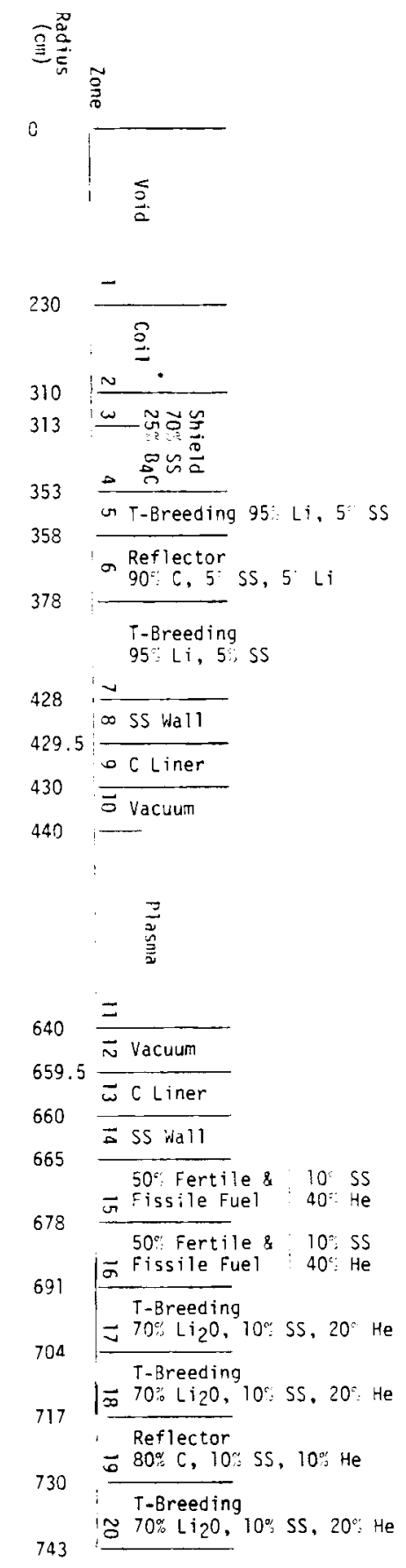

FIGURE 2.6. Reactor Calculational Schematic 
blanket segment at the beginning of life. Those isotopes that are not present at this time, such as the higher isotopes of $\mathrm{Pu}$, are placed in the calculation at a low concentration. This does not affect the numerical calculation of the flux, but does allow for the calculation of a reaction rate from which a particular cross section is obtained.

The reaction rate for a particular isotope, reaction and zone is found from the following relationship using calculated fluxes.

$$
R_{k}^{n}=\sum_{j i n \ell} \sum_{i} \Phi_{i j} V_{j} \sigma_{i k}^{n} \rho_{k \ell}
$$

where

$$
\begin{aligned}
& R_{k}^{n}=\text { the reaction rate for reaction } n \text { for isotope } k \text { in zone } l, \\
& \Phi_{i j}=\text { the group energy flux in energy group } i \text { and interval } j, \\
& V_{j}=\text { the volume of interval } j, \\
& \sigma_{i k}^{n}=\text { the cross section for reaction } n \text { for element } k \text { and energy group } i, \\
& \text { and } \\
& \rho_{k \ell}=\text { the number of density of element } k \text { in zone } \ell .
\end{aligned}
$$

The average cross section, $\bar{\sigma}$, for input into ORIGEN is then calculated from the relationship:

$$
\bar{\sigma}_{k}^{n}=R_{k \ell}^{n} /\left[\sum_{j} \sum_{i n \ell} \sum_{i} \Phi_{i j} v_{j}\right] \rho_{k \ell}
$$

and the average flux $\bar{\Phi}$ is determined by

$$
\bar{\Phi}=\left[\sum_{j \text { inl }} \quad \sum_{i} \Phi_{i j} v_{j}\right] / \sum_{j i n \ell} v_{j}
$$


In the calculations here, the average cross sections for $\sigma^{c}, \sigma^{f}$, on-2n and $n-3 n$ were generated for the following isotopes:

$$
\begin{aligned}
& { }^{230} \mathrm{Th},{ }^{232} \mathrm{Th},{ }^{231} \mathrm{~Pa},{ }^{233} \mathrm{~Pa},{ }^{232} \mathrm{U},{ }^{233} \mathrm{U},{ }^{234} \mathrm{U},{ }^{235} \mathrm{U},{ }^{236} \mathrm{U},{ }^{238} \mathrm{U}, \\
& { }^{239} \mathrm{U},{ }^{237} \mathrm{~Np},{ }^{236} \mathrm{Pu},{ }^{238} \mathrm{Pu},{ }^{239} \mathrm{Pu},{ }^{240} \mathrm{Pu},{ }^{241} \mathrm{Pu},{ }^{242} \mathrm{Pu} \text {, and }{ }^{244} \mathrm{Cm} .
\end{aligned}
$$

Since the flux and fission density changes rapidly in the blanket in a fusion reactor, ORIGEN calculations are made for different zones in the fertile and fissile blanket. This involves the calculation of the average cross sections and flux for each zone.

Based on a one year burnup calculation, isotopic generation and depletion are determined for each zone. These isotopic concentrations are then input into ANISN for new flux calculations and the process is repeated and may be repeated again for as many years as desired. The accuracy may be improved by decreasing the zone width, in effect creating more zones for which calculations are made, and decreasing the time period for the burnup calculation, as the flux is assumed constant during this period of time.

\section{NUCLEAR DATA}

The cross sections for the transport calculation were generated from ENDF/B-IV into thirty energy groups and cover the energy range from $18 \mathrm{MeV}$ to thermal. ETOG (Kusner et al. 1969) generates the epi-thermal and fast data, and FLANGE (Honek and Finch 1971) is used to process the thermal data. These group cross sections are processed with scattering matrices expanded in Legendre polynomials. A11 the cross sections generated in this manner are infinite dilute, and thus the important isotopes, such as $U^{235}, U^{238}$ and $T h^{232}$ must be resonance self-shielded.

The shielded cross sections are generated with the cell code EGGNIT (Richey 1967). In this code a typical unit cell in the fissionable lattice is mocked up. A unit cell calculation is made using a fine energy group structure to determine the flux shape in the unit cell. The Nordheim Integral 
Treatment is used for resonance self-shielding. The resultant cross sections are then flux weighted and resonance self-shielded.

Unfortunately, the cross sections in the EGGNIT library extend only to $10 \mathrm{MeV}$ and contain only a $P_{1}$ expansion of the scattering matrix. Thus it is necessary to substitute the EGGNIT-generated microscopic absorption and fission cross section into the ETOG-generated set and renormalize the total cross section. Three isotopes, ${ }^{232} \mathrm{Th},{ }^{235} \mathrm{U}$, and ${ }^{238} \mathrm{U}$, are treated in this manner.

For isotopes in which the thermal cross sections play an important role, such as ${ }^{6} \mathrm{Li},{ }^{235} \mathrm{U}$ and ${ }^{238} \mathrm{Pu}$, the thermal cell code GRANIT (Bennett 1976) is used to generate the thermal cross section and these cross sections replace the FLANGE-generated thermal cross section.

\section{FISSILE FUEL BREEDING}

Three separate blanket types were considered:

Case $1-\mathrm{UO}_{2}$

Case 2 - UC

Case 3 - $\mathrm{PuO}_{2}-\mathrm{UO}_{2}$ CONVERTER followed by ThC 2 Zone

In Figures $2.7,2.8$, and 2.9 the outside blanket is represented for each of the three types. The different zones correspond to Zones 15 to 20 in Figure 2.6.

In the first case, the fuel is natural uranium in the form of $\mathrm{UO}_{2}$ in a $26 \mathrm{~cm}$ thick zone. In the second case, the fuel is natural uranium in the form of $U C$ in a $26 \mathrm{~cm}$ thick zone. In the third case, natural uranium in the form of $\mathrm{UO}_{2}$ is mixed with ${ }^{239} \mathrm{PuO}_{2}$ in an equilibrium mixture in a $13 \mathrm{~cm}$ thick zone. This is followed by a $\mathrm{ThC}_{2}$ zone, $26 \mathrm{~cm}$ thick. The volume fraction of all fuels is $50 \%$ with $10 \%$ stainless steel as the structural material. Helium is the coolant and occupies $40 \%$ of the volume.

ANISN calculations were made to determine the neutron flux from which the fission rate and ${ }^{239} \mathrm{Pu}$ and $233 \mathrm{U}$ production rates were calculated. The results for the three blankets at the initial start up are given in Table 2.4. 


\begin{tabular}{|c|c|c|c|c|c|c|}
\hline & $\begin{array}{r}\text { FERTILE } \\
\text { FUE! }\end{array}$ & $\begin{array}{l}\text { D FISSILE } \\
\text { ONES }\end{array}$ & $\begin{array}{r}\text { TRITIUN } \\
\mathrm{ZO}\end{array}$ & $\begin{array}{l}\text { BREEDING } \\
\text { NES }\end{array}$ & RE & $\begin{array}{l}\text { TRITIUM } \\
\text { BREEDING }\end{array}$ \\
\hline & $50 \%$ UC & $50 \%$ UC & $70 \% \mathrm{Li}_{2} \mathrm{O}$ & $70 \% \mathrm{Li}_{2} \mathrm{O}$ & & $70 \% \mathrm{Li}_{2}$ \\
\hline & $10 \%$ SS & $10 \%$ SS & $10 \%$ SS & $10 \%$ SS & & $10 \%$ SS \\
\hline & $40 \% \mathrm{He}$ & $40 \% \mathrm{He}$ & $20 \% \mathrm{He}$ & $20 \% \mathrm{He}$ & & $20 \% \mathrm{He}$ \\
\hline & $\begin{array}{l}\text { NAT. U- } \\
0.7 \% 235 \mathrm{U}\end{array}$ & $\begin{array}{l}\text { NAT. U- } \\
0.7 \%{ }^{235} \mathrm{U}\end{array}$ & $\begin{array}{l}\text { ENRICHED } \\
90 \%{ }^{\circ} \mathrm{Li}\end{array}$ & $\begin{array}{l}\text { ENRICHED } \\
90 \%{ }^{6} \mathrm{Li}\end{array}$ & & $\begin{array}{l}\text { ENRICHED } \\
90 \%{ }^{6} \mathrm{Li}\end{array}$ \\
\hline RADIUS $(\mathrm{cm}) 665$ & & & 1 & 94 & 717 & 0 \\
\hline ZONE & & & 6 & 17 & 18 & 9 \\
\hline
\end{tabular}

FIGURE 2.7. $\mathrm{UO}_{2}$ Blanket Schematic

\begin{tabular}{|c|c|c|c|c|c|}
\hline \multicolumn{2}{|c|}{$\begin{array}{l}\text { FERTILE AND FISSILE } \\
\text { FUEL ZONES }\end{array}$} & \multicolumn{2}{|c|}{$\begin{array}{l}\text { TRI TIUM BREEDING } \\
\text { ZONES }\end{array}$} & REFLEC TOR & $\begin{array}{l}\text { TRITIUM } \\
\text { BREEDING }\end{array}$ \\
\hline $50 \% \cup_{2}$ & $50 \% \mathrm{UO}_{2}$ & $70 \% \mathrm{Li}_{2} \mathrm{O}$ & $70 \% \mathrm{Li}_{2} \mathrm{O}$ & $80 \% \mathrm{C}$ & $70 \% \mathrm{Li}_{2} \mathrm{O}$ \\
\hline $10 \%$ SS & $10 \%$ SS & $10 \%$ SS & $10 \%$ SS & $10 \%$ SS & $10 \% \mathrm{SS}$ \\
\hline $40 \% \mathrm{He}$ & $40 \% \mathrm{He}$ & $20 \% \mathrm{He}$ & $20 \% \mathrm{He}$ & $10 \% \mathrm{He}$ & $20 \% \mathrm{He}$ \\
\hline $\begin{array}{l}\text { NAT. U- } \\
0.7 \% 235 \mathrm{U}\end{array}$ & $\begin{array}{l}\text { NAT. U- } \\
0.7 \% 235 \mathrm{U}\end{array}$ & $\begin{array}{l}\text { ENRICHED } \\
90 \% 6 \mathrm{Li}\end{array}$ & $\begin{array}{l}\text { ENRICHED } \\
90 \% 6 \mathrm{Li}\end{array}$ & & $\begin{array}{l}\text { ENRICHED } \\
90 \% 6 \mathrm{Li}\end{array}$ \\
\hline & 8 & 691 & 104 & 717 & 30 \\
\hline & & 16 & 17 & 18 & 19 \\
\hline
\end{tabular}

FIGURE 2.8. UC Blanket Schematic

When the $\mathrm{UO}_{2}$ blanket is compared with the UC blanket, UC is obviously the best blanket, from the standpoint of the number of fissions per fusion and the $\mathrm{Pu}$ production. This arises from the fact that although both blankets have the same volume percent of fuel, the UC blanket has more $U / \mathrm{cm}^{3}$ than the $\mathrm{UO}_{2}$ 


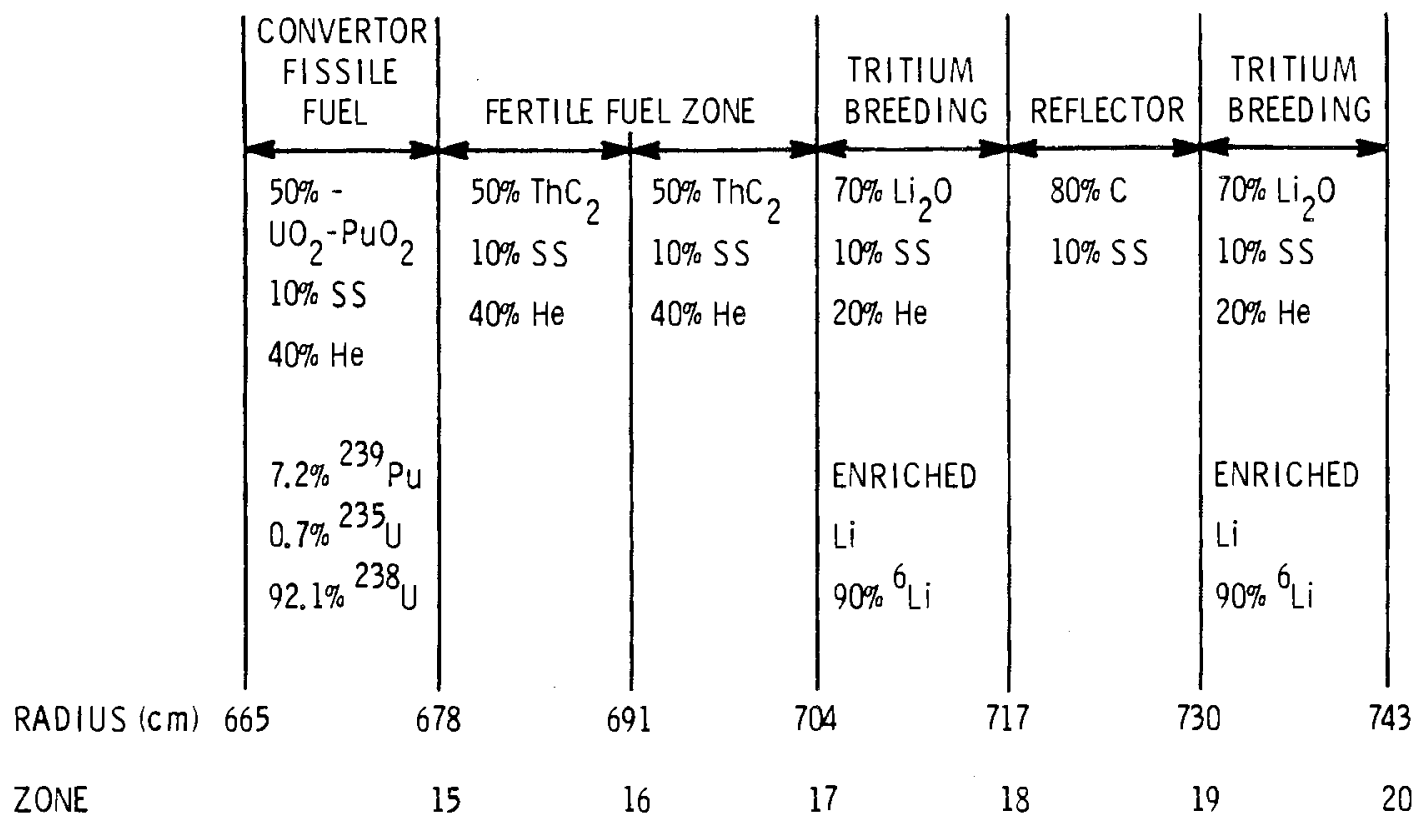

FIGURE 2.9. $\mathrm{PuO}_{2}-\mathrm{UO}_{2}-\mathrm{ThC}_{2} \mathrm{Bl}$ anket Schematic

TABLE 2.4. Blanket Neutronic Characteristics

\begin{tabular}{|c|c|c|c|c|}
\hline Blanket & $\begin{array}{l}\text { Net Fissions } \\
\text { Per Source } \\
\text { Neutron } \\
\end{array}$ & $\begin{array}{l}\text { Net Pu } \\
\text { Production Per } \\
\text { Source Neutron } \\
\end{array}$ & $\begin{array}{l}\quad \text { Net } 233 \mathrm{U} \\
\text { Production Per } \\
\text { Source Neutron } \\
\end{array}$ & $\begin{array}{l}\text { Tritium } \\
\text { Breeding } \\
\text { Ratio } \\
\end{array}$ \\
\hline $\mathrm{UO}_{2}$ & 0.186 & 0.440 & -- & 1.17 \\
\hline$U C$ & 0.220 & 0.618 & -- & 1.19 \\
\hline $\begin{array}{c}\mathrm{PuO}^{-\mathrm{UO}_{2}} \\
\mathrm{ThC}_{2}\end{array}$ & 0.424 & 0.047 & 1.24 & 1.18 \\
\hline
\end{tabular}

blanket. Thus, more $U$ is exposed to the $14 \mathrm{MeV}$ flux than for the $\mathrm{UO}_{2} \mathrm{blanket}$ and thus, more $U$ is exposed to the $14 \mathrm{MeV}$ flux than for the $\mathrm{UO}_{1}$ blanket, which results in a greater number of fast fissions and more secondary neutrons. The greater the number of secondary neutrons, the greater the number of neutrons being absorbed in $\mathrm{Pu}$ and tritium breeding reactions.

The third case in which a converter of $\mathrm{UO}_{2}$ in ${ }^{239} \mathrm{PuO}_{2}$ is followed by a $\mathrm{ThC}_{2}$ blanket combines the best features of both fuel cycles. The high $238 \mathrm{U}$ fission cross section for $14 \mathrm{MeV}$ neutrons and resulting 25 neutrons per 
fission coupled with the high thermal absorption in Th for ${ }^{233} \mathrm{U}$ production results in the best blanket from the standpoint of fissile fuel production. An equilibrium mixture of $\mathrm{PuO}_{2}$ results in a larger power output, due to thermal fission, compared to the $\mathrm{UO}_{2}$ or UC blankets that had only $0.7 \%$ $235 \mathrm{U}$.

\section{TRITIUM BREEDING}

In each case the tritium breeding regions follow the fertile and fissile zones. These regions contain stainless steel clad pins of $L i_{2} O$ enriched to $90 \%$ in ${ }^{6} \mathrm{Li}$ to capitalize on the thermal flux. Few fast neutrons remain this far from the fast neutron source and little tritium is bred by the ${ }^{7} \mathrm{~L}(\mathrm{n}$, $\left.n^{\prime} \alpha\right) T$ reaction. Because of the tritium is bred by the $\sigma_{L i}(n, \alpha) T$ reaction, a helium-cooled Tokamak must employ enrichments in ${ }^{6}{ }_{L i}$ in the tritium breeding compound. The use of natural Li coolant may obviate this need in Tokamaks and other confinement geometries. In fact, natural $\mathrm{Li}$ compounds could be used in this Tokamak geometry with helium coolant to obtain tritium breeding ratios $>1$, but only at the expense of fissile fuel production.

In the inside blanket, natural liquid lithium is used. Here, fast flux may be used for the breeding of tritium without the loss of a neutron in the ${ }^{L} \mathrm{Li}\left(n, n^{\prime} \alpha\right) T$ reaction. However, the bulk of the tritium is bred through the ${ }^{6} \mathrm{Li}(n, \alpha) T$ reaction here also.

The results for the three blankets at the initial start up are given in Table 2.4. In each case the tritium breeding ratio is greater than one with sufficient excess that each could be self-sustaining for tritium requirements. If tritium had not been bred, the neutrons could be used for fissile fuel production with the increase in production rates of fissile fuel being greater per source neutron than the number of tritium atoms produced per source neutron.

\section{BURNUP AND ISOTOPICS}

The burnup calculations that determine the isotopic buildup and depletion are sensitive to the average flux used in the calculation because ${ }^{239} \mathrm{Pu}$ and 
other fissile isotopes that build up greatly affect the average power determined by ORIGEN. For example, an average flux of $1.21 \times 10^{15} \mathrm{n} / \mathrm{cm}^{2}-\mathrm{sec}$ for a five year period of time produces an average power of $15.51 \mathrm{MW} / \mathrm{metric}$ ton of $U$. An average flux of $2.91 \times 10^{15} \mathrm{n} / \mathrm{cm}^{2}-\mathrm{sec}$ over a five year period produces an average power of $45.15 \mathrm{MW} / \mathrm{metric}$ ton of $U$. Both cases had the same initial conditions of natural $\mathrm{UO}_{2}$ as fuel.

The average flux is determined by the fusion power level and the isotopic concentration used in the ANISN calculation. One year burnup was chosen as the time period for which the flux should remain almost constant. The isotopic concentration of major isotopes following a one year burn is shown in Table 2.5 for Zone 15 and 16 of Figure 2.6. This is a $\mathrm{UO}_{2}$ blanket containing natural uranium as initial conditions. The table lists only the isotopes that would be used in the next ANISN calculation.

Note that the isotopic concentration buildup and the $14 \mathrm{MeV}$ flux and fast flux in Zone 15 much larger than that in Zone 16. The fast flux is responsible for many of the reactions; therefore, the average cross in Zone 16 is smaller than Zone 15. The average flux in Zone 16 is smaller than in Zone 15. As expected, much of the Pu build will occur in the first few centimeters until it reaches an equilibrium concentration of about $8 \%$.

\section{FISSILE FUEL AND POWER PRODUCTION}

The fissile fuel and fission power production in the hybrid blanket combined with the Tokamak Fusion driver have been calculated from the blanket neutronic characteristics as computed by the ANISN and ORIGEN codes as displayed in Tables 2.4 and 2.5. The annual fissile fuel production, as well as the thermal power averaged over the four-year fuel-management cycle, are tabulated in Table 2.6. The plant availability (0.75), the driver duty factor, and the effective blanket coverage for the penetration of the beam ports, divertor channels, and poloidal field coils have all been taken into account in computing these averages. It should also be noted that in addition to the blanket fission power, the thermal power includes the fusion neutron power distributed in the blanket and shield as well as the fusion alpha power and any radiation generated in the fusion plasma incident on the first wall. 
TABLE 2.5. Isotopic Concentrations After One Year Operation Gram-Atom per Metric Tonne of Uranium

\section{Zone $15 \& 16$}

Initial

$\frac{\text { Isotope }}{230_{T h}} \quad \frac{\text { Concentration }}{0}$

${ }^{232} \mathrm{Th}$

$231_{\mathrm{Pa}}$

$233 \mathrm{~Pa}$

$232 \mathrm{U}$

$233 \mathrm{U}$

$234_{\mathrm{U}}$

$235 \mathrm{U}$

$236 \mathrm{U}$

$238_{\mathrm{U}}$

$239_{\mathrm{U}}$

$237 \mathrm{~Np}$

$236 \mathrm{Pu}$

$238 \mathrm{Pu}$

$239 \mathrm{Pu}$

$240 \mathrm{Pu}$

$241_{\mathrm{Pu}}$

${ }^{242} \mathrm{Pu}$

${ }^{244} \mathrm{Cm}$

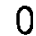

0

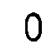

0

0

0

0

30.2

0

4170

\section{0}

0

0

0

0

0

0

0 \begin{tabular}{l}
$\begin{array}{l}\text { Zone } 15 \\
\text { One Year }\end{array}$ \\
\hline $2.75 \times 10^{-8}$
\end{tabular}

$5.8 \times 10^{-8}$

$2.7 \times 10^{-8}$

$2.6 \times 10^{-7}$

$1.5 \times 10^{-4}$

$1.4 \times 10^{-3}$

$1.9 \times 10^{-2}$

26.7

3.99

4100

$2.5 \times 10^{-3}$

7.51

$1.77 \times 10^{-3}$

$1.07 \times 10^{-2}$

37.5

0.584

$8.9 \times 10^{-3}$

$5.2 \times 10^{-5}$

$8.9 \times 10^{-10}$
Zone 16

One Year

$8.1 \times 10^{-9}$

$1.8 \times 10^{-8}$

$2.8 \times 10^{-8}$

$3.5 \times 10^{-12}$

$1.3 \times 10^{-5}$

$3.7 \times 10^{-4}$

$5.8 \times 10^{-3}$

28.4

1.22

4140

$1.41 \times 10^{-3}$

2.26

$1.53 \times 10^{-4}$

$1.49 \times 10^{-3}$

21.1

0.16

$1.08 \times 10^{-3}$

$3.24 \times 10^{-6}$

$1.32 \times 10^{-11}$

TABLE 2.6. Blanket Fissile Fuel and Fission Power Production

\begin{tabular}{|c|c|c|}
\hline Blanket & $\begin{array}{l}\text { Production } \\
\mathrm{kg} / \mathrm{yr}\end{array}$ & $\begin{array}{l}\text { Power } \\
\text { MWt }\end{array}$ \\
\hline $\mathrm{UO}_{2}$ & $1388, \mathrm{Pu}$ & 2439 \\
\hline$U C^{2}$ & $1950, \mathrm{Pu}$ & 2867 \\
\hline $\begin{array}{l}\mathrm{PuO}_{2}-\mathrm{UO}_{2} \\
\mathrm{ThC}_{2}\end{array}$ & $3810,{ }^{233} U$ & 5327 \\
\hline
\end{tabular}


The heating rates calculated for the reactor at startup for the three blankets combined with the Tokamak driver are shown in Figure 2.10. The power production for the $U C$ and the $\mathrm{UO}_{2}$ blanket is due almost entirely to the fast fissions. The power profile in these two blankets almost parallels the fast flux in the blankets shown in Figure 2.11. Both the power and fast flux are down by two orders of magnitude after transversing the $26 \mathrm{~cm}$ fuel region of the blanket. In these blankets little may be gained in the way of power by increasing the thickness of the fission blanket.

The UC blanket produces a greater amount of power than the $\mathrm{UO}_{2}$ blanket. In the UC blanket, uranium occupies a greater percent of the volume of the zone than in the $\mathrm{UO}_{2}$ blanket, even though the volume percent of the fuel ( $\mathrm{UO}_{2}$ or UC) is the same in both cases, i.e., 50\%. This increased density of uranium results in a greater percent of the uranium being exposed to the fast flux, resulting in a greater number of fissions. Because of the righer density the fast flux decreases faster in the UC blanket than in the $\mathrm{UO}_{2} \mathrm{blanket}_{\text {, }}$ as noted in Figure 5.11. Thus, increased power production may be obtained by increasing the ratio of fission/ absorption in the blanket. For example, U-Mo could be expected to be a better fuel than UC in terms of power production.

The most dramatic changes in power production may be obtained by enriching the fuel. Figure 2.10 compares the heating rates of $\mathrm{UO}_{2}-\mathrm{PuO}_{2}$ blanket with the $U C$ and $\mathrm{UO}_{2}$ blanket. The $\mathrm{UO}_{2}$ and the $U C$ blanket contains natural uranium, while the $\mathrm{PuO}_{2}-\mathrm{UO}_{2}$ blanket contains $7.2 \%{ }^{239} \mathrm{PuO}$. The power profile is not as steep in the mixed-oxide blanket, indicating a considerable amount of power is being generated by the fission of ${ }^{239} \mathrm{Pu}$, rather than by fast fission of $U$. This is also evident from Figure 2.12, which shows the perturbation in the thermal flux in the converter region.

The fast flux in all three cases has been degraded by several orders of magnitude by the time it reaches the tritium breeding zones, as shown in Figures 2.11 and 2.12. Thus, little tritium from the ${ }^{7} L i(n, n \alpha) T$ reaction will be produced. These zones have been enriched in ${ }^{6} \mathrm{Li}$ to increase the macroscopic cross secton for the ${ }^{6}{ }_{L}(n, \alpha) T$ reaction and therefore reduce the parasitic absorptions that do not result in a tritium atom. 


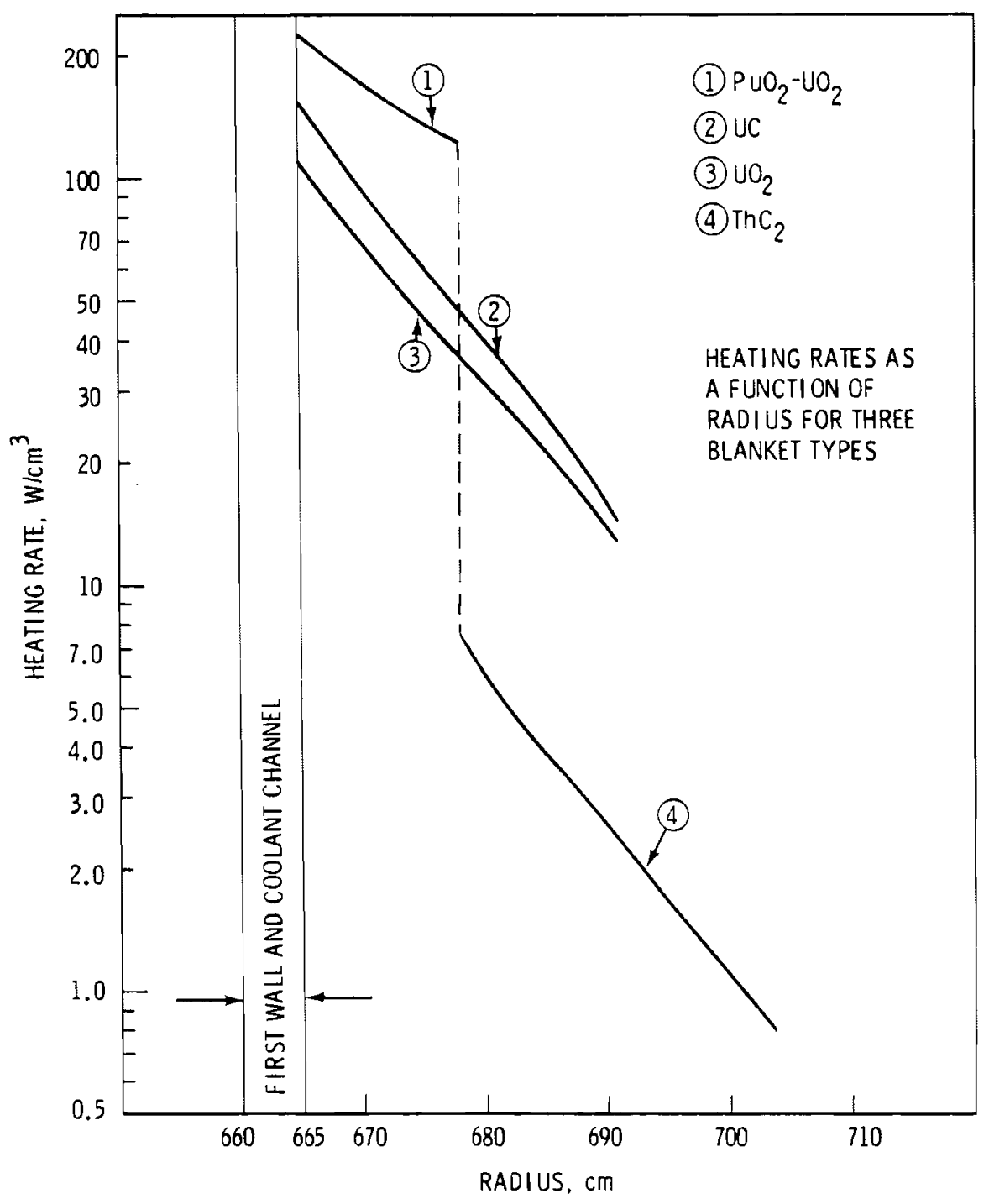

FIGURE 2.10. Heating Rates as a Function of Radius for Three Blanket Types

Fast fission will occur in thorium. However, the cross section is small compared to the fast fission cross section for uranium. Thus, for any reasonable power production a uranium converter is needed. At $680 \mathrm{~cm}$ in Figure 2.10, the fast flux is about the same for the $\mathrm{UO}_{2}, U C$ and $\mathrm{ThC}_{2}$ blanket, yet the power production in the $\mathrm{ThC}_{2}$ is about $7 \mathrm{~W} / \mathrm{cm}^{3}$, while the $\mathrm{UO}_{2}$ and $\mathrm{UC}$ blankets are about $35 \mathrm{~W} / \mathrm{cm}^{3}$. 


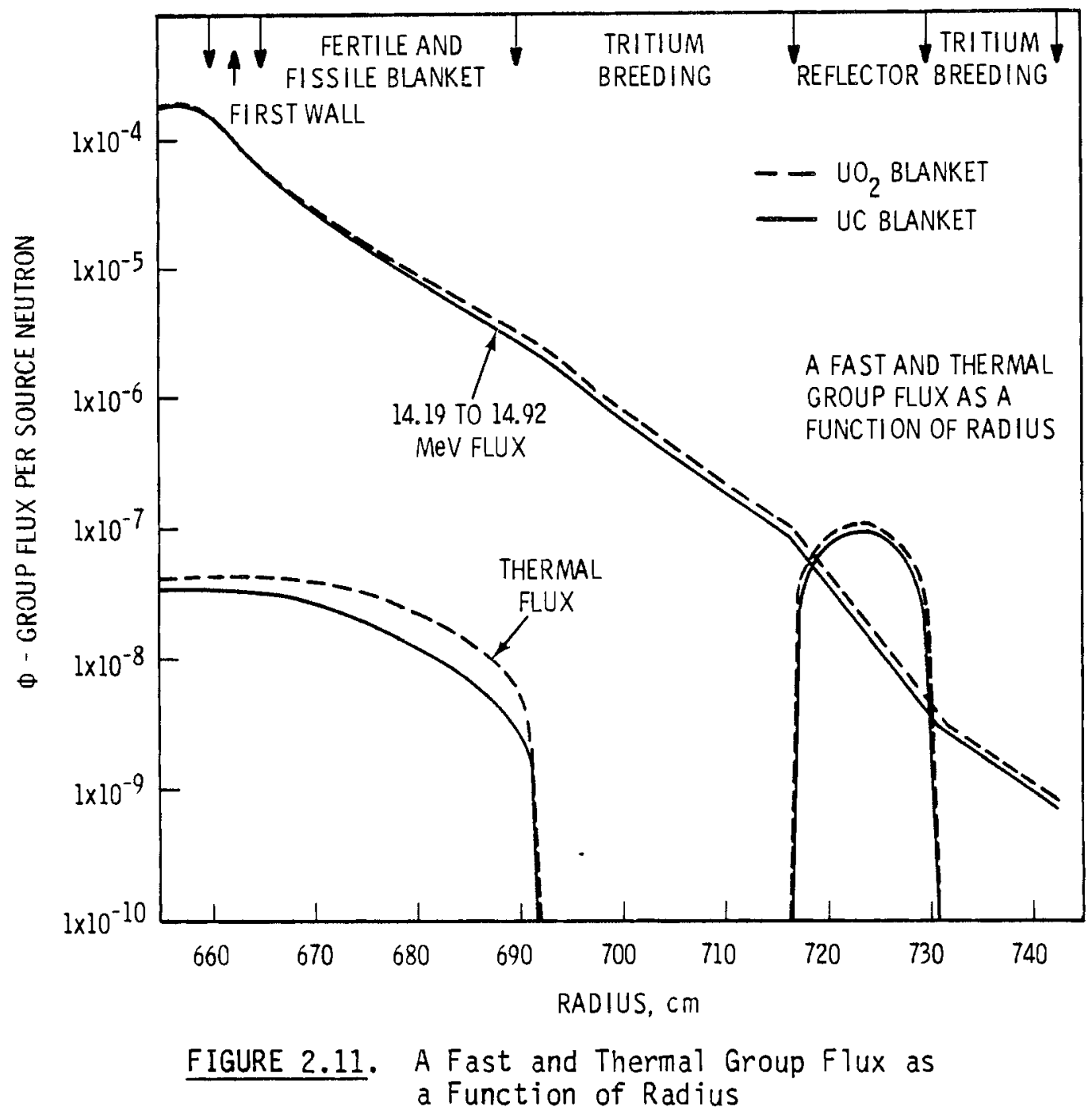

No fissionable material exists in the inside blanket (Zone 7 ) because the area was thought to be inaccessible. Only liquid lithium was placed there because it could be pumped. Had the reactor been large enough for a uranium converter to be placed in this zone, a significant increase in both fuel and power production could be obtained. In the current configuration a large percent of the fusion neutrons do not enter a uranium containing zone, and therefore do not have the opportunity to cause a fast fission. 


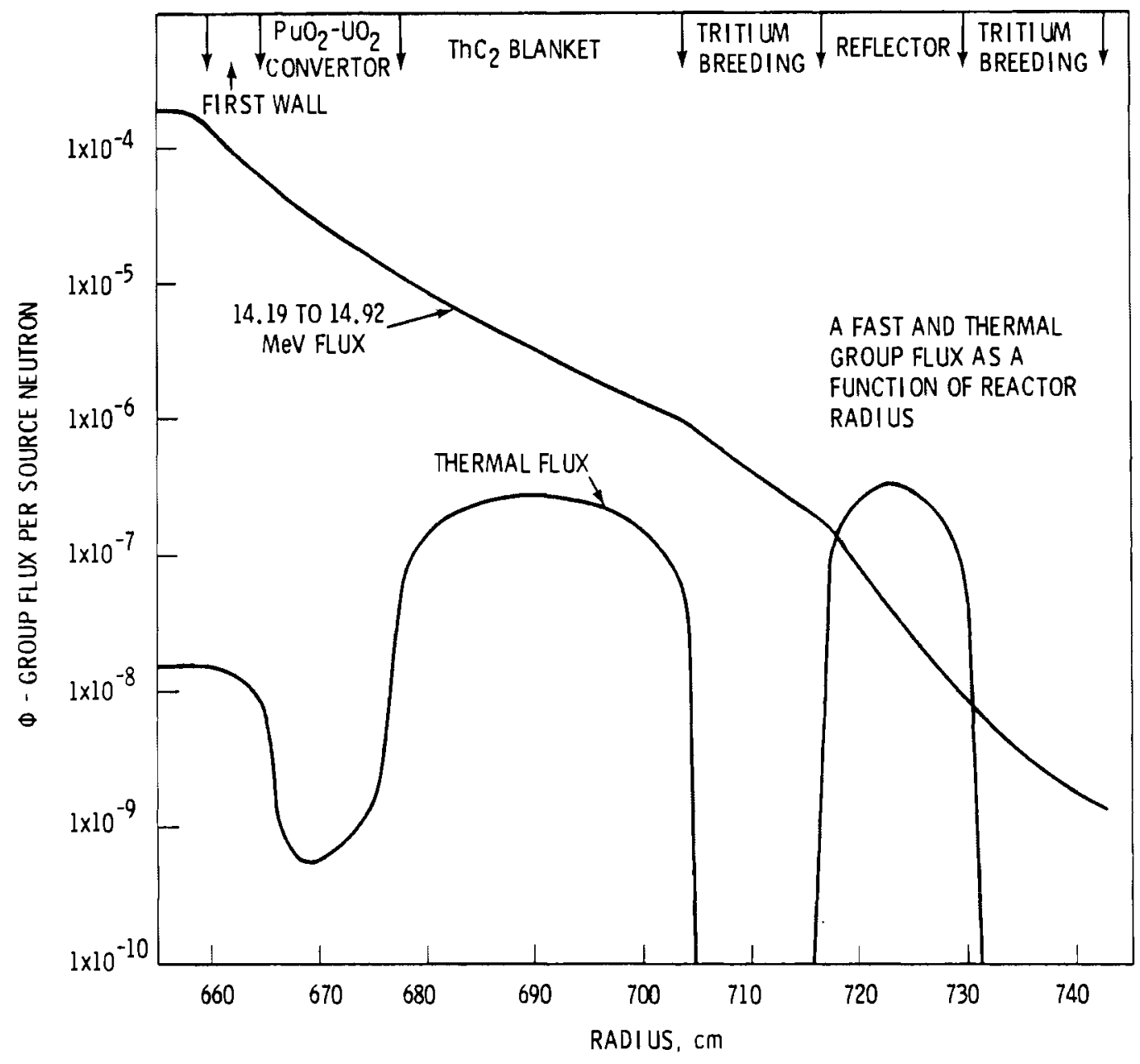

FIGURE 2.12. A Fast and Thermal Group Flux as a Function of Reactor Radius

In conclusion, increased performance in blankets may be obtained by increasing the fusion neutron power and the ratio of the macroscopic fast fission cross section to the macroscopic absorption. The most dramatic increase in power is obtained by increasing the enrichment in the blanket. Although $\mathrm{ThC}_{2}$ gives impressive fissile fuel production, it requires a uranium converter to stop a serious decrease in performance from occurring. 
SECTION 2.0 REFERENCES

Be11, M. J. 1973. ORIGEN - The ORNL Isotope Generation and Depletion Code. Oak Ridge National Laboratory, Oak Ridge, TN.

Bennett, C. L. 1971. GRANIT: A Code for Calculating Position Dependent Thermal Neutron Spectra in Doubly Heterogeneous Systems by the Integral Transport Method. BNWL-1634, Pacific Northwest Laboratory, Richland, WA.

Dawson, J. M., H. P. Furth and F. H. Tenney. 1971. Phys. Rev. Lett., 26,1156. Also see H. P. FUrth and D. L. Jassby. 1974. Phys. Rev. Lett., 32: 1176 .

Emmert, G. A., A. T. Mense and J. M. Donhowe. 1974. "A Poloidal Divertor for the UWMAK-I Tokamak Reactor," Proced. 1st Top. Meet. on the Technology of Cont. Nucl. Fusion, USAEC Conf. 740402-P1 p. 417.

Engle, W. W., Jr. 1967. A Users Manual for ANISN. K-1693, Oak Ridge National Laboratory, Oak Ridge, TN.

Honeck, H. C. 1966. ENDF/B, Specifications for an Evaluated Nuclear Data File for Reactor Applications. BNWL-50066, Brookhaven National Laboratory, Upton, NY.

Honeck, H. C. and D. R. Finch. 1971. FLANGE II, A Code to Process Thermal Neutron Data from an ENDF/B Tape. DP-1278, Savannah River Laboratory, Aiken, SC.

Hosea, J. C. 1975. Princeton Plasma Physics Laboratory Report. MATT-1128.

Jassby, D. L. 1975. "Beam Driver Tokamak Fusion-Fission Hybrid Reactor," Princeton Plasma Physics Laboratory Report MATT-1115.

Kusner, D. E. et al. 1969. ETOG-I, A Fortran IV Program to Process Data from the ENDF/B File to the MUFT, GAM, and ANISN Formats. WCAP-3845-1, ENDF-114, Westinghouse Electric Corporation.

Meade, D. M. et a1. 1974. "The Effects of Impurities and Magnetic Divertors on High Temperature Tokamaks," Proced. 5th International Conf. on Plasma Physics and Cont. Nucl. Fusion Research, IAEA, Tokyo, Vol. 1, p. 605.

Mirnov, S. V. 1970. JETP Lett., 12:64.

Moses, R. W., Jr. and W. C. Young. 1975. "Analytic Expressions for Magnetic Force on Sectored Toroidal Coils," Proced. 6th Symposium on Engr. Problems of Fusion Research, p. 917.

Richey, C. R. 1967. EGGNIT: A Multigroup Cross Section Code. BNWL-1230, Pacific Northwest Laboratory, Richland, Wa. 
Tokamak Engineering Test Reactor. 1977. UWF DM-191 University of Wisconsin, Dept. of Nuc T. Engr. 


\subsection{FUELING ALTERNATIVES AND FUEL MASS FLOWS}

The fuel cycle options for the Tokamak Hybrid Reactor (THR) will be characterized so that a nonproliferation assessment of these systems can be made. Two scenarios will be discussed: 1) no-reprocessing, and 2) reprocessing to recover fissile material for recycle purposes. The relationship between the THR and LWR reactor will be developed for the reprocessing scenarios.

Fue 1 management strategies will also be discussed. Blanket management information such as module 1 ifetime, maximum exposure, blanket replacement time, and the number of modules replaced each year will be identified. The initial quantities of fertile fuel, stainless steel structure, $\mathrm{Li}_{2} \mathrm{O}$ tritium breeding material, and graphite reflector will be determined. In addition, the 30-year blanket fuel charge and discharge amounts for some of the fuel cycles will be determined.

Facility requirements, the blanket fuel rod fabrication and module reprocessing facilities will be described. This description will facilitate the identification of potential diversion points and possible proliferation paths.

\section{FUELING ALTERNATIVES}

To develop facility descriptions, a characterization of each fuel cycle is needed. Four fuel cycle scenarios are being investigated for the hybrid reactor:

1. Once-Through - natural uranium fueled hybrid in throwaway mode (power production only)

2. Pu-Recycle to Thermal Reactors - hybrid with dual role of fissile fuel production and power production

3. Refresh Fuel cycle - hybrid reactor re-enriching PWR fuel and returning re-enriched fuel to PWR. Another Refresh type fuel cycle being investigated is a denatured U-235 (20\%) in U-238.

The spent PWR fuel from the cycle, about $9 \% \mathrm{U}-235 / \mathrm{U}$ will be re-enriched in the hybrid with the buildup of the fissile isotope U-233. 
4. Pu-Th (Pu Catalyst) - hybrid reactor breeds U-233 in a plutoniumthorium target; $U-233$ is then recycled in LWRs while the plutonium is recycled in the hybrid.

The proliferation resistance, which may be attributed to a reactor and its associated fuel cycles, may only be estimated by assessing the facility and speed with which weapons usable material can be extracted or diverted from the systems involved. These systems may be "hardened" to resist extraction or diversion by technical and institutional measures. In principle, any such measures or "fixes" that may be available to fission reactor fuel cycles can also be employed in the hybrid reactor system. Moreover, hybrid systems may have some unique nonproliferation advantages over fission breeder reactors since the spectrum of their copious source of fusion neutrons may be tailored in appropriate blanket designs that are more readily adaptable to such technical fixes.

To place the hybrid concept in some nonproliferation perspective the candidate THR fuel cycles may be related to the fuel cycle scenarios and technical fixes being considered for fission reactors. This perspective may give some indication as to whether or not these fuel cycles possess desirable nonproliferation qualities that may permit the appropriate criteria for proliferation resistance to be achieved (Laney and Huebotter 1978). Two scenarios may be considered: 1) no reprocessing of spent-fuel, and 2) reprocessing of spent-fuel to recover and recycle fissile materials in fission reactors. In the reprocessing scenario recovery and recycle of denatured $233 \mathrm{U}$ in fission reactors, and plutonium in fission reactors are examined.

\section{No-Reprocessing}

The Light Water Reactor (LWR) is the main type of commercial reactor in operation in the U.S. The High Temperature Gas Cooled Reactor (HTGR) has seen limited commercial deployment. The LWR fuel cycle in the case of no-reprocessing in which spent fuel assemblies are stored is outlined below and the hybrid fuel cycle options related to these. 
The current once-through LWR fuel cycle is shown in Figure 3.1. The spent LWR fuel is shown going to storage where it stays until a decision is made on its ultimate disposition.

In the no-reprocessing scenario, the hybrid role is limited to producing power for sale. The hybrid fuel cycle analogous to the once-through LWR cycle is shown in Figure 3.2. Natural uranium in the form of uranium carbide is used as blanket material for the hybrid. The blanket is irradiated, and the uranium fissions and power are generated. The spent blanket is discharged and temporarily stored in a decay heat removal area similar to LWR spent fuel pools awaiting ultimate disposition.

Another hybrid fuel cycle that operated in the no-reprocessing mode is the "refresh cycle" and is shown in Figure 3.3. Natural uranium is mined and refined in order to produce uranium dioxide for fabricating blanket modules. The blanket is irradiated in the hybrid where neutrons are captured in U-238 to produce Pu-239 and the bred Pu blanket material is then inserted in a fission reactor to produce power. After the fuel is depleted in the fission reactor, it is sent back to the hybrid to be "refreshed" in Pu-239. Upon refresining, the fuel is again used in the fission reactor for power production. Fuel might be shuffled between fission reactor and hybrid two to three times, depending on the obtainable fuel life. After this cycle the spent fuel is stored for ultimate disposition. The fuel could possibly require refabrication between irradiations to remove the bulk of the fission products and extend fuel life.

In addition to the "refresh" cycle discussed above, the hybrid reactor might be used to "refresh" or "re-enrich" normal spent fuel (i.e., as in Figure 3.1 where the fresh fue 1 is enriched to $\sim 3 \% 235 \mathrm{U}$ in $U$ at the start of life and is depleted to $21.0 \%{ }^{235} U$ in $U$ at the end of its life.) In this concept fission reactor spent-fuel would be shipped from the reactor discharge basin to a refabrication center. The spent fuel would be mechanically refabricated into fresh hybrid blanket module assemblies. This fuel would then be re-enriched in the hybrid and, after an appropriate decay period, returned to the fission reactor. 

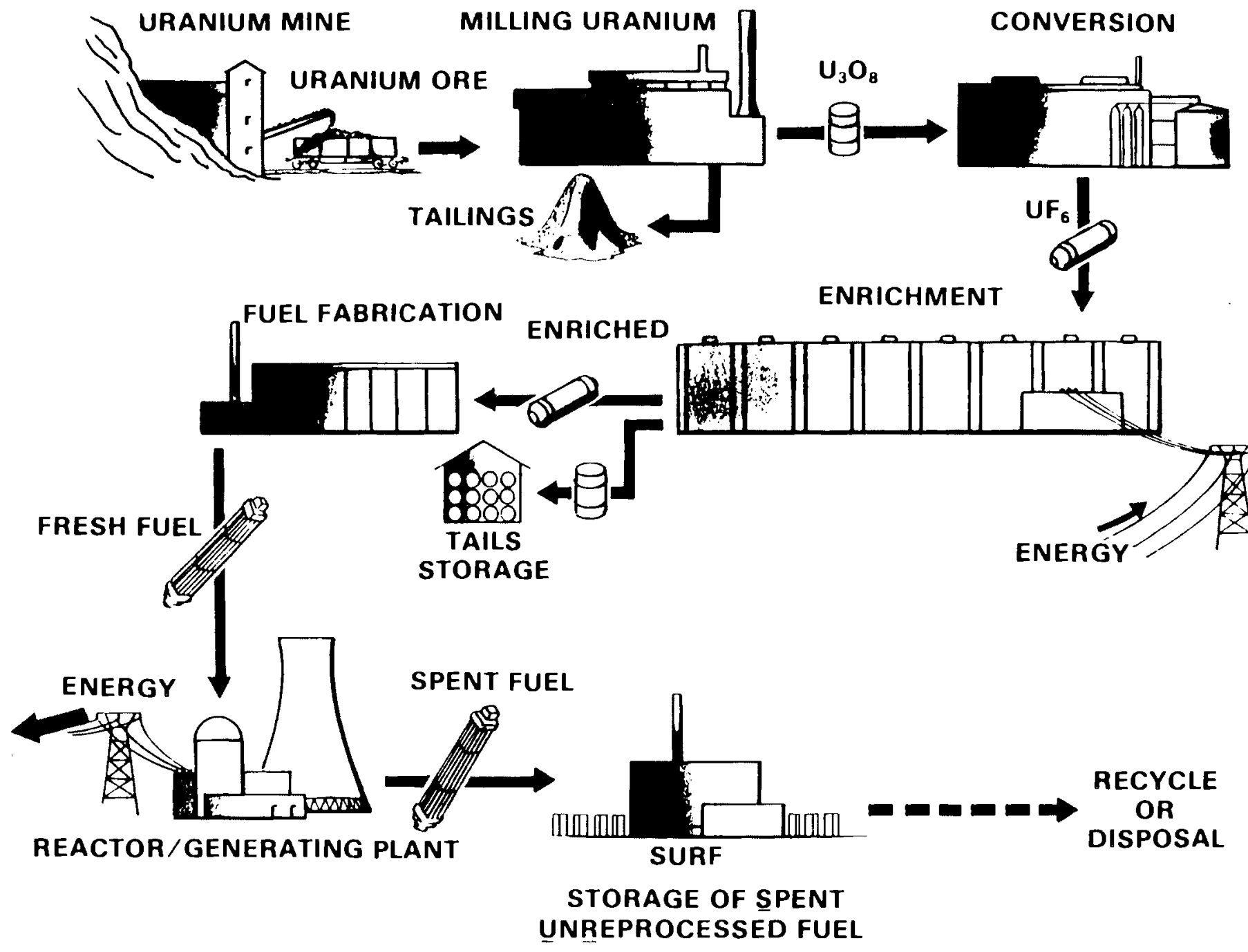

FIGURE 3.1. Uranium Nuclear Fuel Cycle 


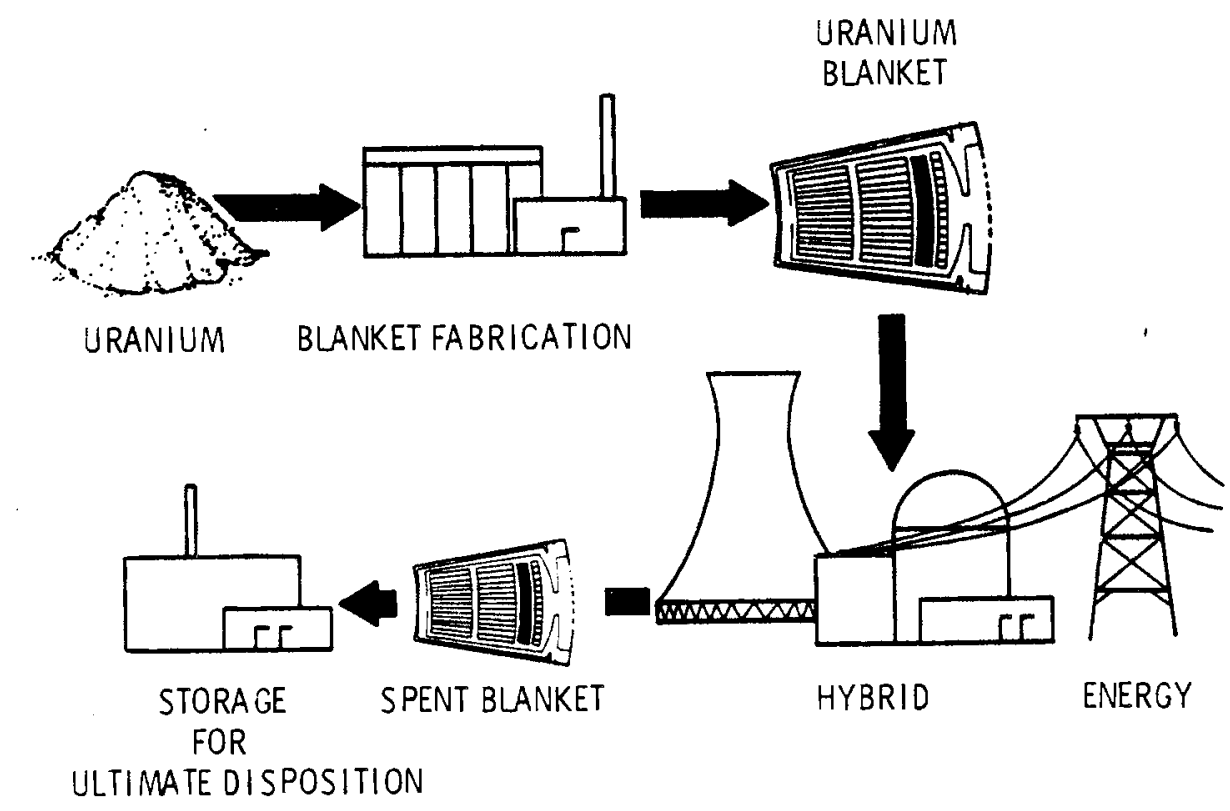

FIGURE 3.2. Once-Through Hybrid Fuel Cycle

\section{Reprocessing and Recycle of Fissile Materials}

Denaturing a fissile isotope means diluting it with another isotope of the same element to the extent that a nuclear weapon cannot be made from the material. In the case of the fissile uranium isotopes $\left({ }^{235} U\right.$ and $\left.233_{U}\right) 238 U$ serves as the diluent. Until recently, it was generally felt that plutonium could not be denatured to render it unusable for weapons purposes. Recently, Allied-General Nuclear Services proposed that ${ }^{238} \mathrm{Pu}$ in sufficient quantity in the plutonium can make the plutonium unusable for weapons because of its high heat generation rate (Energy Daily 1978). Other technical and institutional fixes to make the fuel cycle proliferation resistant include:

- keeping the fissile and fertile materials together at all times (e.g., coprocessed U-Pu) to dilute the fissile content to below weapons-grade

- making the fuel highly radioactive (e.g., having highly radioactive materials in the fuel) to preclude handling

- combining the above two in the CIVEX Process (Starr, Culler, Levenson, Flowers et al. 1978) 


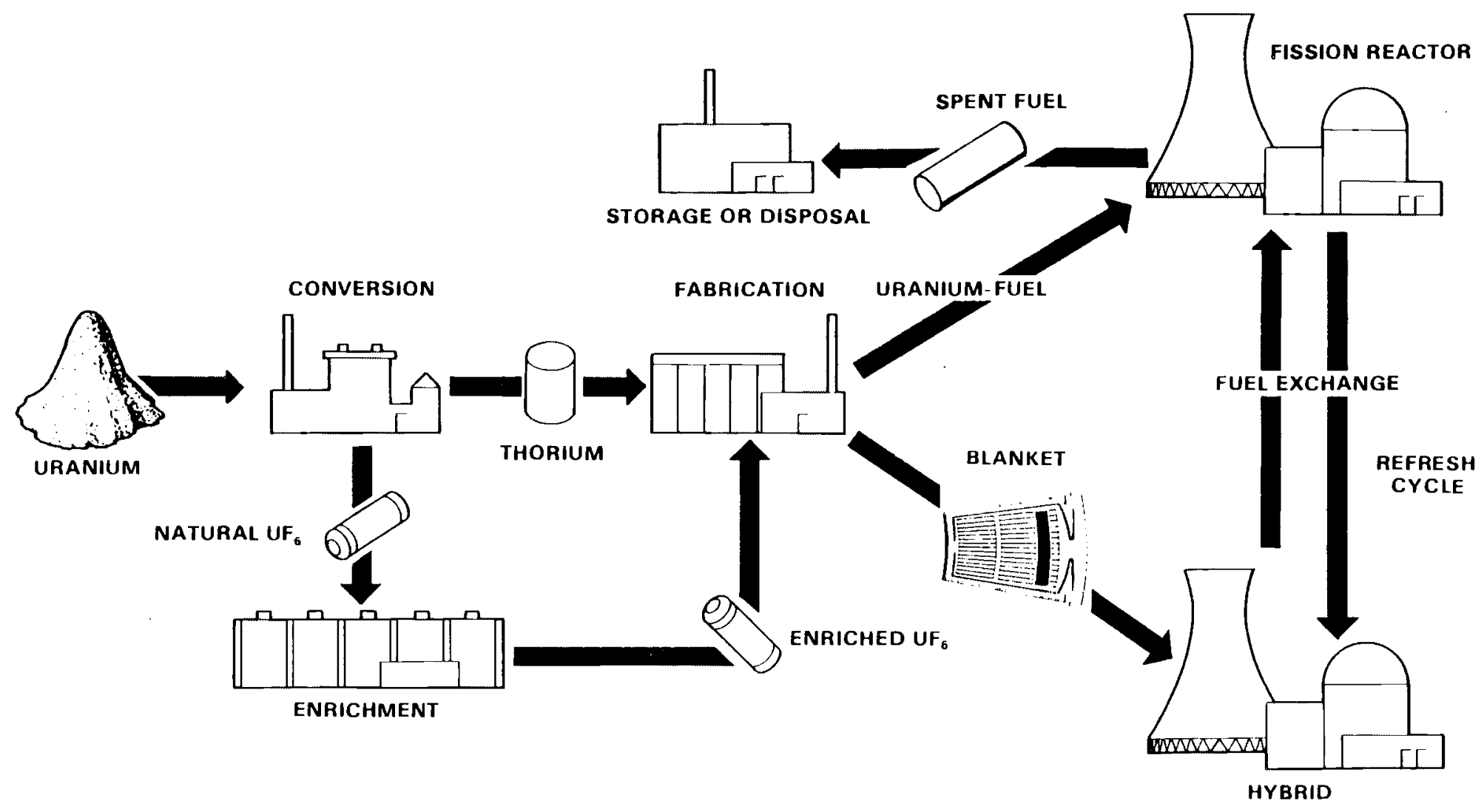

FIGURE 3.3. Refresh Hybrid Fuel Cycle 
- restricting use to fuel cycle centers.

These $233 \mathrm{U}$ and plutonium cycle concepts are briefly described below.

Denatured ${ }^{233} \cup$ Cycle

This scenario assumes that uranium and therefore its fissile component $235 \mathrm{U}$, are in short supply. The limitation of $235 \mathrm{U}$ supply can be alleviated through utilization of thorium to generate ${ }^{233} \mathrm{U}$ (which is denatured) and thereby extend the supply of fissile material for fission reactors. The LWR thorium cycle is shown in Figure 3.4. Raw materials bearing thorium are refined to produce $\mathrm{ThO}_{2}$, which is mixed with enriched $\mathrm{UO}_{2}$ to fabricate $\mathrm{ThO}_{2}-\mathrm{UO}_{2}$ fuel for an LWR. The spent fuel is reprocessed to recover denatured $233 \mathrm{U}$, which is refabricated into new fuel. Since this is not a breeder cycle, an external source of $233 U$ is needed to sustain the system and allow it to grow. The hybrid could be the external source.

The hybrid concept based on this scenario is shown in Figure 3.5. Mined thorium is refined and a thorium blanket for the hybrid is fabricated. Irradiating this blanket in the hybrids, builds in $233 \mathrm{U}$, which is reprocessed and denatured $\left({ }^{238} U\right.$ added during reprocessing). The denatured uranium is mixed with thorium during fabrication to produce LWR fuel. Once the spent fuel is discharged from the LWR, the steps shown in Figure 3.5 would be followed.

The isotope $232 U$ builds up in these cycles to the point that the radiation levels are sufficient to require massive shielding during handling and processing (Leonard and Jenquin 1976). The requirements for shielding are perceived as adding proliferation resistance to the fuel cycle.

\section{Plutonium Recovery and Recycle}

As mentioned above, sufficient addition of $238 \mathrm{pu}$ in the plutonium has been suggested to render it unusable for weapons purposes. The level of ${ }^{238} \mathrm{Pu}$ can be increased by recovering uranium and ${ }^{237} \mathrm{~Np}$ from the spent fuel. The isotope ${ }^{236} \mathrm{U}$ builds up during irradiation of the fresh $\mathrm{UO}_{2}$ fuel in the LWR. Subsequent irradiation of the ${ }^{236} \mathrm{U}$ and ${ }^{237} \mathrm{~Np}$ produces ${ }^{238} \mathrm{Pu}$ in the 


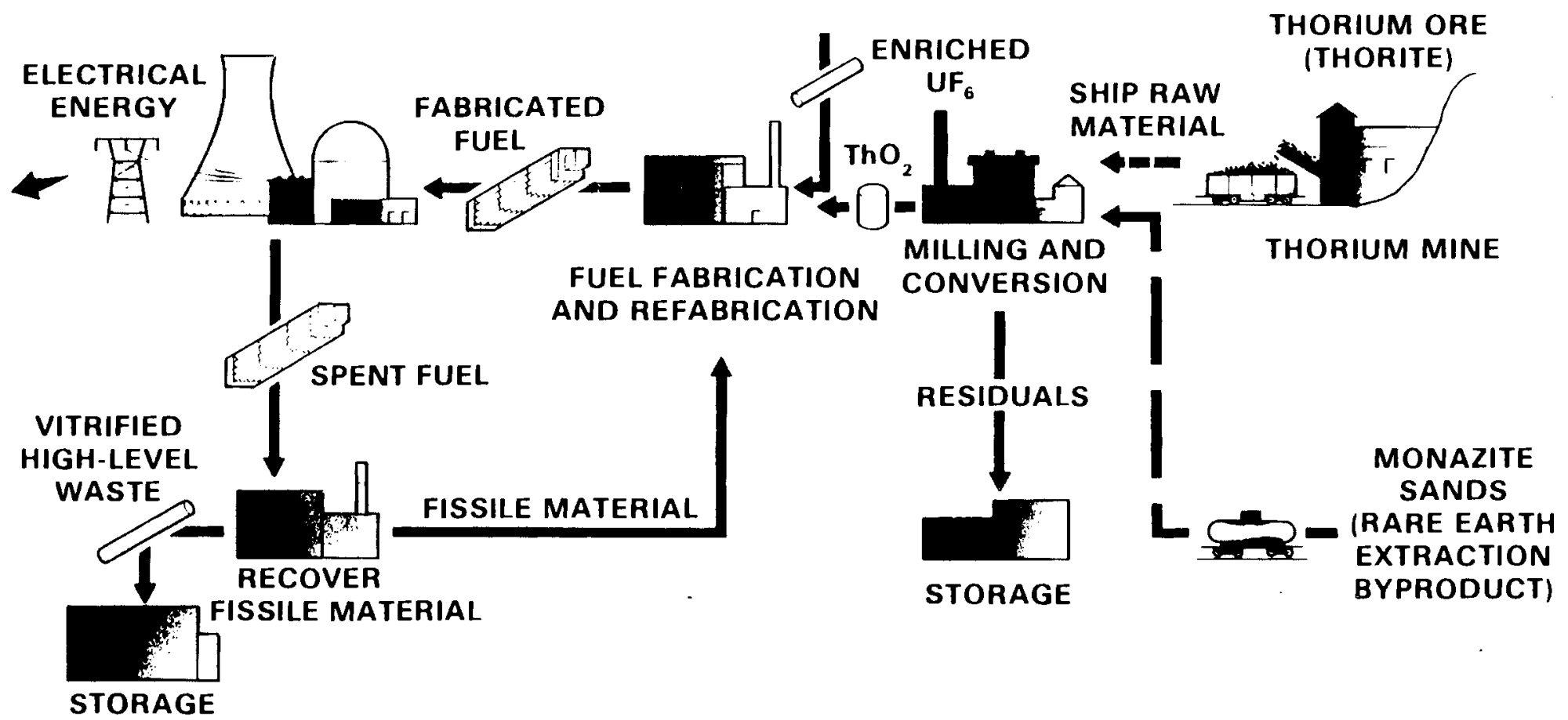

FIGURE 3.4. Thorium LWR Fuel Cycle 
plutonium. The plutonium produced in a hybrid has been shown to contain significant fractions of ${ }^{236} \mathrm{Pu}$ and ${ }^{238} \mathrm{Pu}$ (Leonard and Jenquin 1976).

Since LWRs do not convert a sufficient amount of plutonium to fuel themselves, an external source of plutonium is needed to sustain the system and allow it to grow. As shown in Figure 3.6 the hybrid could be the external source of proliferation-resistant plutonium. The sources of uranium include: mixed natural, depleted uranium from the enrichment plants and/or the uranium recovered in reprocessing spent $\mathrm{UO}_{2} \mathrm{LWR}$ fuel.

The hybrid fuel cycle in this scenario is similar to the fission breeder cycles because fission reactor fuel supply requirements are extended by converting ${ }^{238} \mathrm{U}$ to fissile plutonium. The plutonium produced in hybrid blankets could be subject to the same restrictions as that produced in reactor fuels; namely, it would be rendered proliferation resistant at the same stage as fission reactor fuel.

\section{FUEL MANAGEMENT STRATEGIES}

The blanket module management scheme is to place fertile fuel into the hybrid reactor and expose the fuel to a specified burnup. After the maximum burnup level is achieved the spent module is removed and placed into a hot cell operations area. Here the fuel is unloaded and prepared for shipment to a reprocessing plant where fissile fuel created in the hybrid is separated from the spent fuel. The thermal output of the blanket is increased as it resides in the hybrid due to energy multiplication resulting from the fissioning of fissile material created in the hybrid blanket. THR should be operated such that the blanket management tends to minimize the power variations within the blanket modules.

The Tokamak Hybrid Reactor blanket modules are divided into 4 fuel management regions. The tokamak blanket consists of 60 slices with each slice made up of 11 modules (660 total modules). The blanket life is assumed to be 4 years so that each year 165 modules or $1 / 4$ of the blanket fuel is removed and replaced with fresh fuel. Table 3.1 gives some pertinent fuel management information. 


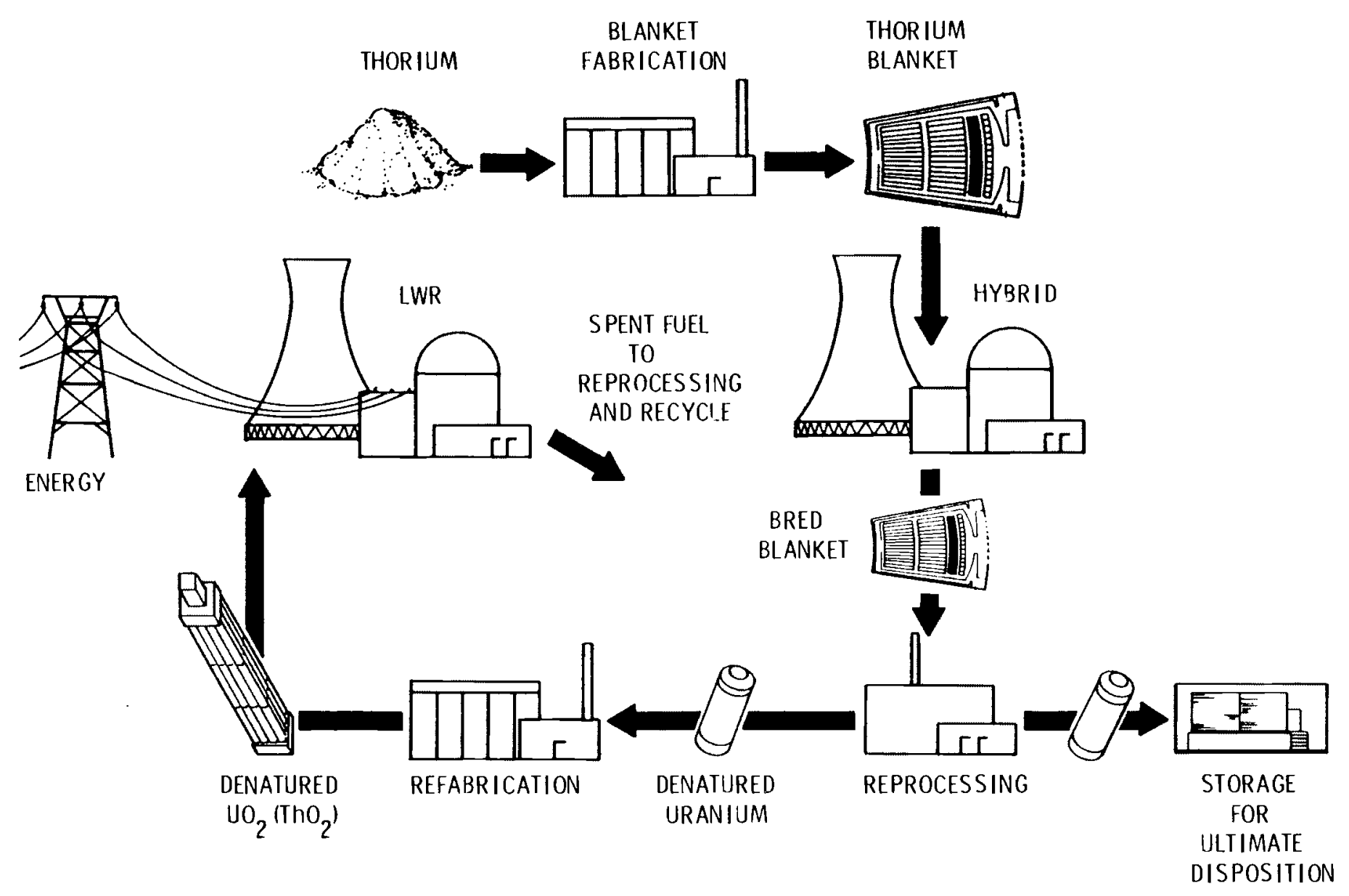

FIGURE 3.5. Thorium Hybrid Fuel cycle 


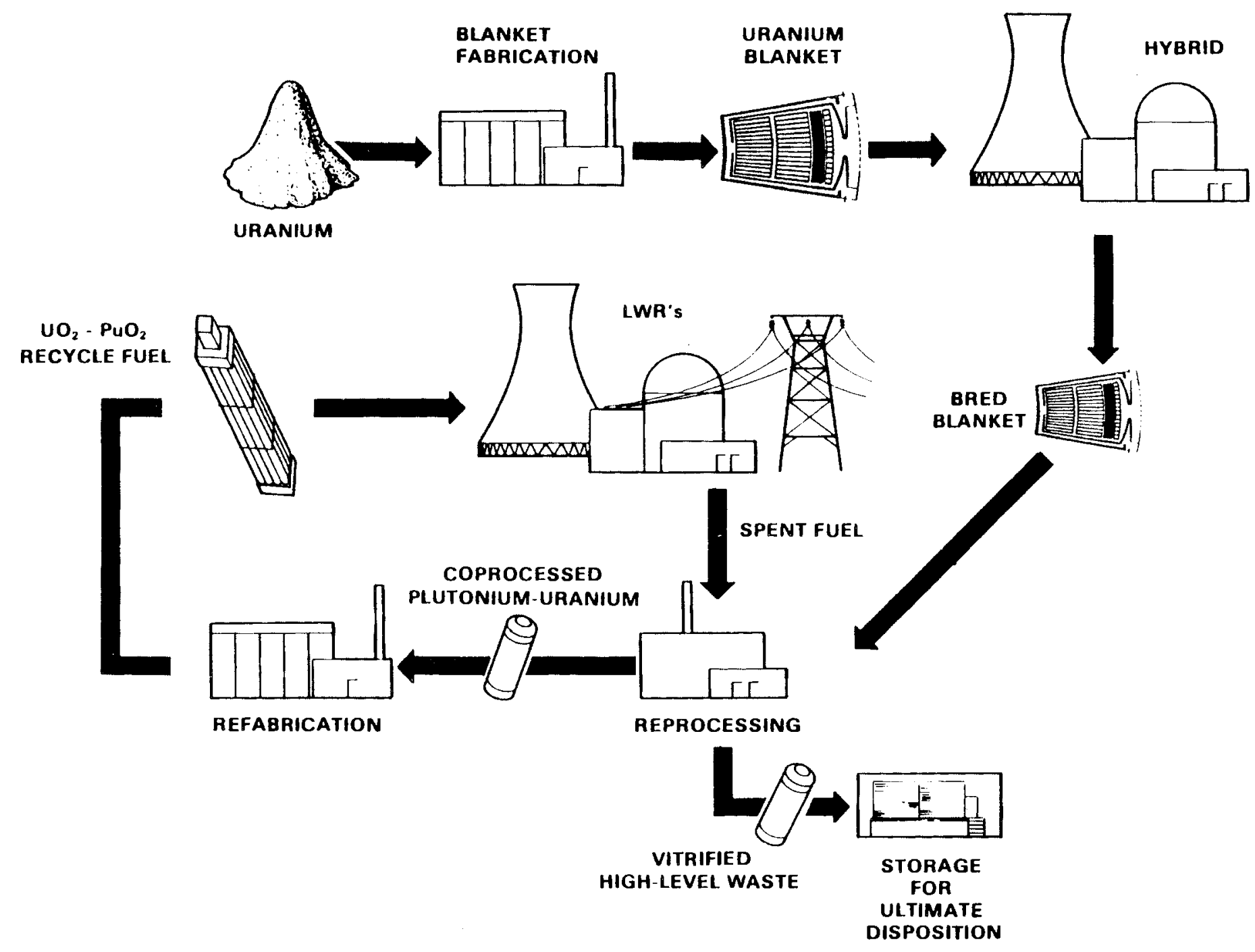

FIGURE 3.6. Plutonium Recycle 
TABLE 3.1. Tokamak Hybrid Fuel Management Data

$\begin{array}{ll}\text { Number of Fuel Management Regions } & 4 \\ \text { Blanket Lifetime } & 4 \text { years } \\ \text { Plant Capacity Factor } & 0.75 \\ \text { Maximum Exposure } & 9.6 \mathrm{MWy} / \mathrm{m}^{2} \\ \text { Blanket Replacement Time } & 35 \text { days } \\ \text { Fuel Management Interval } & 1.3 \text { years }\end{array}$

The capacity factor for the Tokamak Hybrid Reactor is influenced by several factors. Some of the many subsystems that require maintenance are listed in Table 3.2.

\section{TABLE 3.2. Reactor Subsystems}

1. Coolant Loops

2. Cryopump, $\mathrm{N}_{2}$, He supplies

3. Divertor plates

4. Neutral Beam injectors

5. Inspection of toroidal field coils, poloidal field coils, fluid lines and manifolds

6. Tritium cleanup systems, coolant purification, and sieve getter beds

7. Shielding

For the purposes of this study, maintenance of these systems is assumed to be accomplished during blanket module replacement. Unscheduled maintenance results from first wall burn-through, coolant leaks, isolation of failed modules or any abnormal operating conditions. The unscheduled maintenance is taken to be $\sim 50$ to 60 days/year. A portion of this time is for some scheduled maintenance not performed during blanket change operations. The blanket replacement outage will last $\sim 35$ days $(1.5$ days/slice plus 5 days for shutdown, decay heat removal, and tritium outgassing).

Shown in Table 3.3 are the initial fertile fuel, structure, tritium breeder, and reflector material requirements. 
The blanket configuration for the Once-Through and Pu-Recycle fuel cycles both use uranium carbide as the fertile material, while the Pu-Catalyst fuel cycle has a converter region of uranium dioxide and plutonium dioxide and a fertile region of thorium carbide. The refres' fuel cycle makes use of uranium dioxide. The isotopic feed for each of these fuel cycles is natural uranium $\left(0.72 \%{ }^{235} U\right)$. In the Pu-Catalyst fuel cycle the converter region uses a mixed-oxide $\left(\mathrm{UO}_{2} / \mathrm{PuO}_{2}\right)$ fuel matrix with an equilibrium concentration of $28 \% \mathrm{PuO}_{2}$. The tritium breeding material, $\mathrm{Li}_{2} \mathrm{O}$, is enriched to $90 \%{ }^{5} \mathrm{Li}$. Both the fertile fuel and tritium breeder are contained in stainless steel rods. A graphite reflector region is also incorporated into the blanket module.

Using the fuel management information presented in Table 3.3, the annual charge and discharge fuel quantities can be determined. The 30-year requirements are given in Tables 3.4 through 3.6. This isotopic information was obtained through the use of the ORIGEN computer code (Be11 1973). ORIGEN is a point depletion code that solves equations of radioactive growth and decay. The ORIGEN Program considers $(n, \gamma),(n, 2 n),(n, p)$ and $(n, \alpha)$ reactions for light elements and structural material. The actinides have $(n, \gamma),(n, f i s-$ sion), $(n, 2 n)$ and $(n, 3 n)$ reactions included. The total fuel mass flows for each of the four cycles are shown in Figures 3.7 through 3.10. Some of the assumptions used in developing these fuel flows are listed below.

a. Once-Through Assumptions

a) Li content in crude ore is $5 \%$ Li/ore.

b) D-T requirements represent quantity burned. Hybrid wil1 become self-sufficient after a certain time (B.R. = 1.19) - external tritium supply is unnecessary.

c) Uranium assay is $0.2 \% \mathrm{U} / \mathrm{crude}$ ore $\left(\mathrm{U}_{3} \mathrm{O}_{8}\right)$.

d) A plant factor of $75 \%$ is used.

e) The fuel cycle is 4 years with $1 / 4$ modules replaced each year.

f) D-T processing losses are not considered in unburned fuel quantity. 
TABLE 3.3. Tokamak Hybrid Reactor Initial Material Requirements

\begin{tabular}{|c|c|c|c|c|c|}
\hline \multirow{2}{*}{\multicolumn{2}{|c|}{$\frac{\text { Reactor/Fuel cycle }}{\text { Tokamak/Once-Through }}$}} & Fuel & Structure & $\begin{array}{c}\text { Tritium } \\
\text { Breeding Material }\end{array}$ & Other \\
\hline & & 317.8 MTUC & $170.9 \operatorname{MTSS}(a)$ & $123.62 M T L_{i}{ }^{0}(b)$ & $55.97 \operatorname{MTC}(\mathrm{c})$ \\
\hline & $\begin{array}{l}\text { Tok amak/Pu Recycle } \\
\text { to Thermal Reactors }\end{array}$ & 317.8 MTUC & 170.9 MTSS & $123.62 \mathrm{MT} \mathrm{Li}{ }_{2} 0$ & $55.97 \mathrm{MTC}$ \\
\hline & Tokamak/Refresh & $234.0 \mathrm{MT} \mathrm{UO} 2$ & 170.9 MTSS & $123.62 \mathrm{MT} \mathrm{Li}{ }_{2} \mathrm{O}$ & $55.97 \mathrm{MTC}$ \\
\hline \multirow{4}{*}{$\stackrel{\omega}{\dot{\omega}}$} & Tokamak/Pu-Catalyst & $113 \mathrm{MT} \mathrm{U} \mathrm{O}_{2}$ & & & \\
\hline & & 223 MT ThC & 170.9 MTSS & $85.8 \mathrm{MT} \mathrm{Li}{ }_{2} \mathrm{O}$ & $55.97 \mathrm{MTC}$ \\
\hline & & 9 MT $\mathrm{PuO}_{2}$ & & & \\
\hline & $\begin{array}{l}\text { (a) Stainless steel } \\
\text { (b) Tritium breeding } \\
\text { (c) Graphite is for }\end{array}$ & $\begin{array}{l}t \text { includes } c \\
\text { rial, } \mathrm{Li}_{2} 0, \\
\text { ctor region }\end{array}$ & $\begin{array}{l}\mathrm{ng} \text { and module } \\
\text { hed to } 90 \% 6 \mathrm{~L} \\
\text { dule. }\end{array}$ & & \\
\hline
\end{tabular}


TABLE 3.4. Once-Through and Pu-Recycle Fuel Charge Data

GUEL MANAGEMENT CHARACTERISTICS

Reactor Type Tokamak Hybrid

Fuel Type Natural Uranium Carbide

Reactor Fuel Charge Data

\begin{tabular}{|c|c|c|c|c|c|c|c|c|c|c|c|c|}
\hline \multirow{2}{*}{ Year } & \multirow{2}{*}{$\begin{array}{c}\text { Annual } \\
\text { Capacity Factor, } \%\end{array}$} & \multirow{2}{*}{$\begin{array}{c}\text { Heavy Metal, } \\
\mathrm{kg}\end{array}$} & \multirow{2}{*}{$\begin{array}{c}\text { Thorium, } \\
\mathrm{kg} \\
\end{array}$} & \multicolumn{5}{|c|}{ Uranium, $\mathrm{kg}$} & \multicolumn{4}{|c|}{ Plutonium, $\mathrm{kg}$} \\
\hline & & & & $\underline{233}$ & 234 & 235 & $\underline{236}$ & 238 & $\underline{239}$ & $\underline{240}$ & $\underline{241}$ & 242 \\
\hline 1 & 75 & 302,540 & 0 & 0 & 0 & 2178 & 0 & 300,345 & 0 & 0 & 0 & 0 \\
\hline 2 & 75 & 75,635 & . & . & . & 544 & . & 75,086 & - & • & • & \\
\hline 3 & 75 & 75,635 & . & . & . & 544 & . & 75,086 & . & - & . & \\
\hline 4 & 75 & 75,635 & . & - & . & 544 & - & 75,086 & . & . & - & \\
\hline 5 & . & . & . & - & • & . & . & . & . & • & - & \\
\hline 6 & - & - & . & . & . & • & - & . & - & - & . & \\
\hline 7 & . & - & . & . & . & • & . & . & . & . & . & \\
\hline 8 & & & & & & & & & & & & \\
\hline
\end{tabular}


TABLE 3.5. Once-Through and Pu-Recycle Fuel Discharge Data

fuel MANAGEMENT CHARACTERISTICS

React or Type Tok anak Hybrid

Fuel Type Natural Uranium Carbide

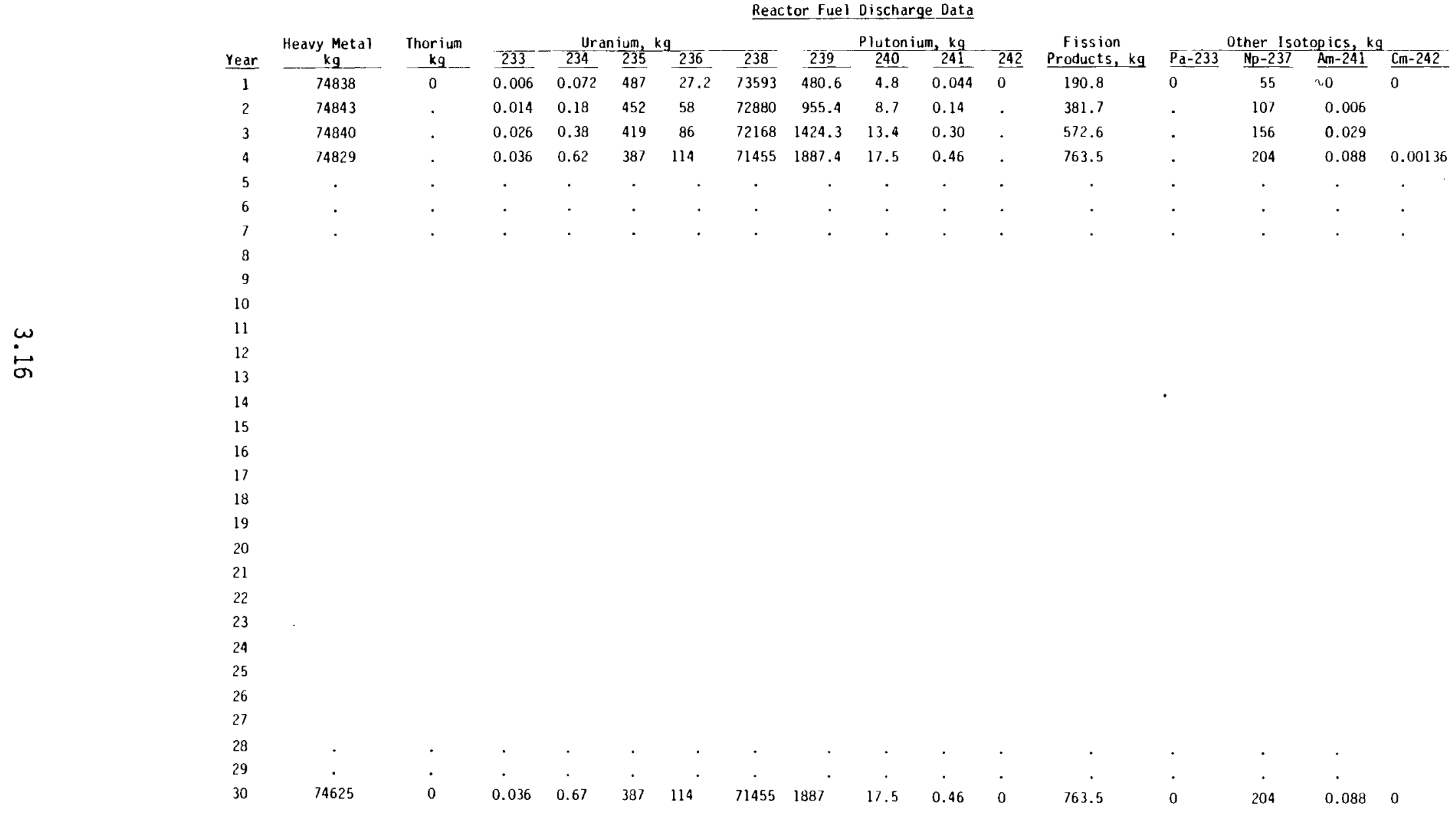




\section{TABLE 3.6. Pu-Catalyst Fuel Charge Data}

\section{FUEL MANAGEMENT CHARACTERISTICS}

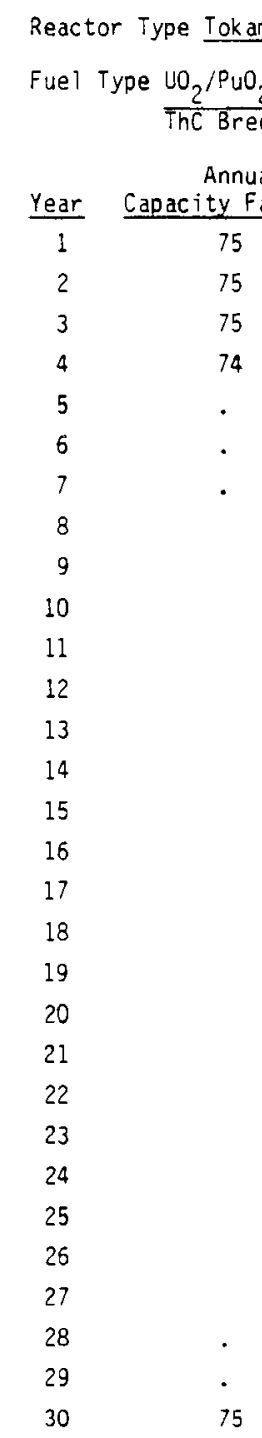

\begin{tabular}{|c|c|c|c|c|c|c|c|c|c|}
\hline \multirow{2}{*}{$\begin{array}{c}\text { Thorium, } \\
\mathrm{kg}\end{array}$} & \multicolumn{9}{|c|}{ Reactor Fuel Charge Data } \\
\hline & 233 & 234 & 235 & $2 \overline{36}$ & 238 & 239 & 240 & 241 & 242 \\
\hline 212,033 & 0 & 0 & 717.2 & 0 & 98,889 & 7968 & 3498 & 1870 & 699 \\
\hline 53,008 & . & . & 179.3 & . & 24,722 & 1992 & 874 & 467 & 174 \\
\hline 53,008 & . & . & 179.3 & . & 24,722 & 1992 & 874 & 467 & 174 \\
\hline 53,008 & - & - & 179.3 & . & 24,722 & 1992 & 874 & 467 & 174 \\
\hline - & - & - & - & . & - & $=$ & . & . & . \\
\hline$\cdot$ & $\cdot$ & $\cdot$ & - & $\cdot$ & 。 & . & - & - & . \\
\hline · & . & - & . & . & . & . & · & - & . \\
\hline
\end{tabular}

(a) LWR Discharge Plutonium. 


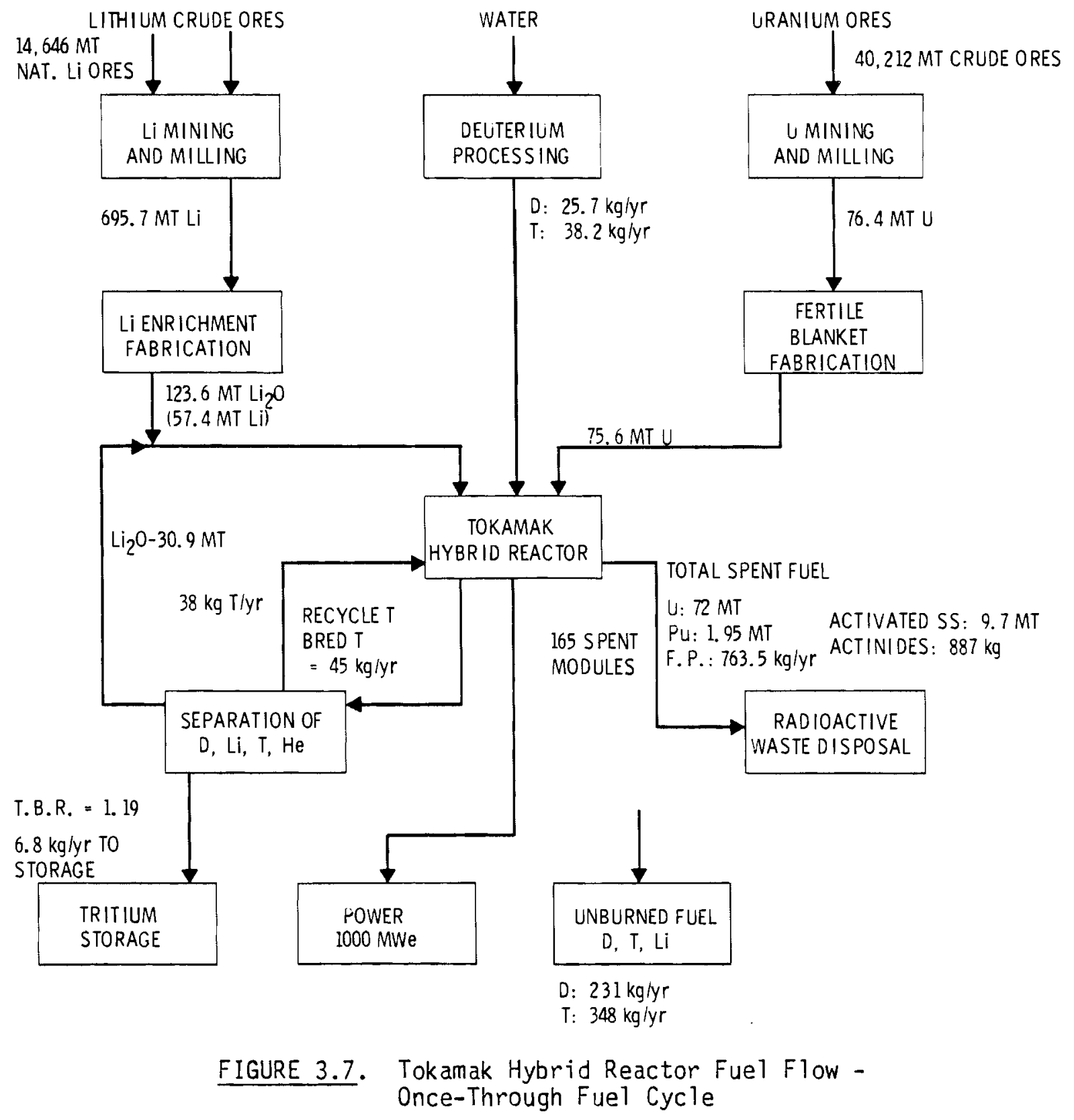




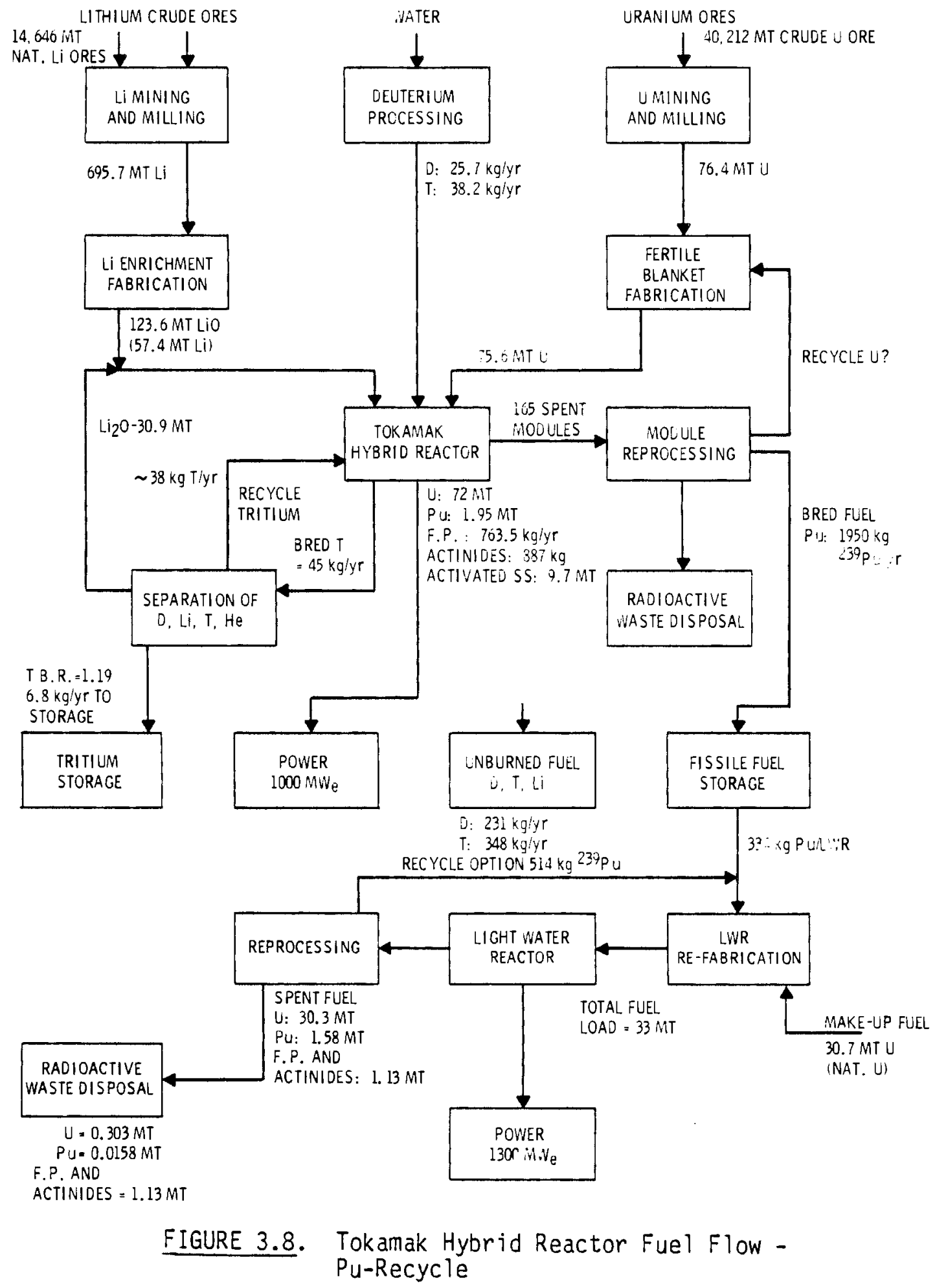




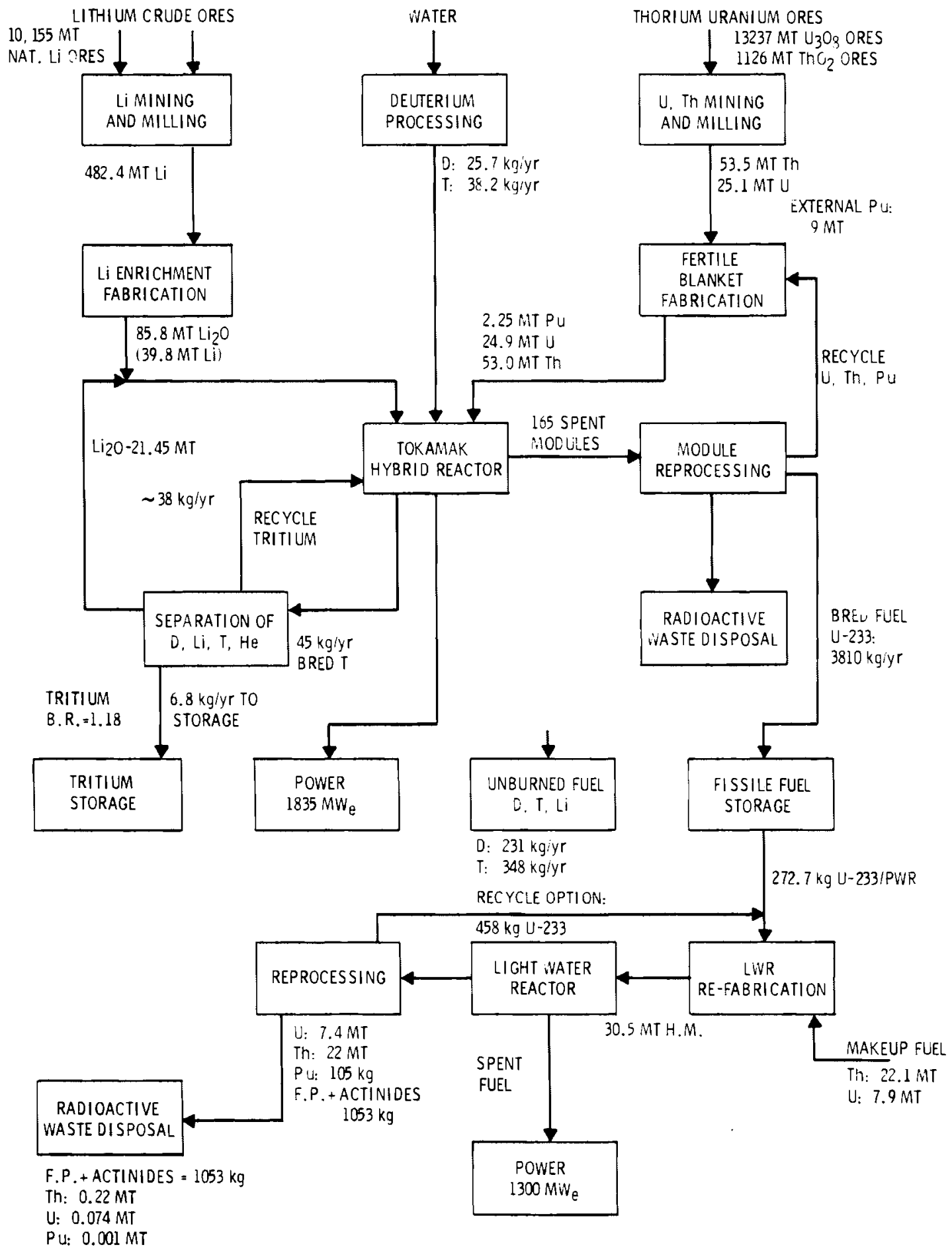

FIGURE 3.9. Tokamak Hybrid Reactor Fuel Flow Pu-Catalyst Fuel Cycle 


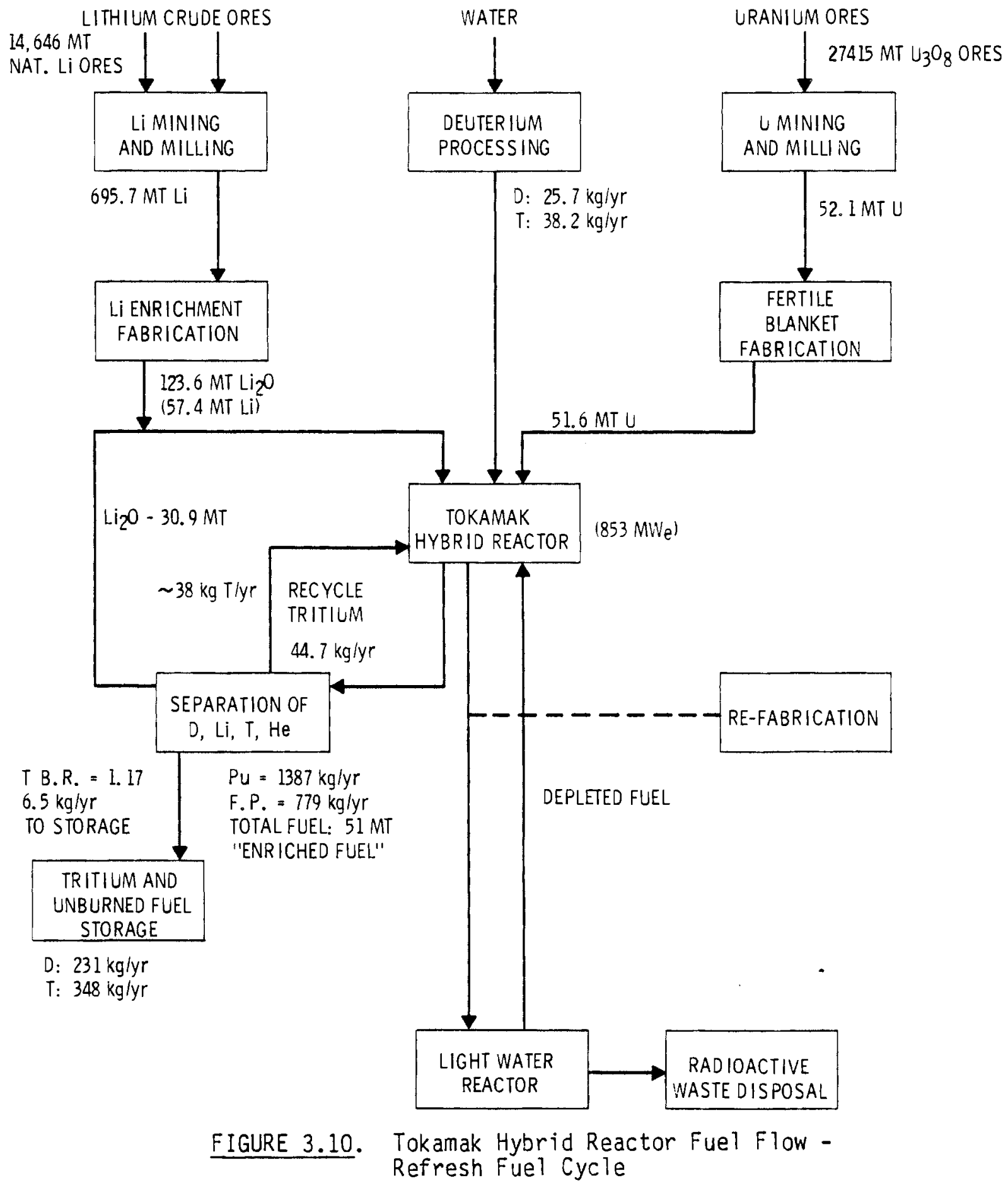


g) Lithium is $90 \%{ }^{6} \mathrm{Li}$ enriched. The amount of natural $\mathrm{Li}$ required to obtain this enrichment is $12 \times$ amount desired.

h) $\quad \mathrm{Li}_{2} \mathrm{O}$ breeding pins are reused. A continuous supply is unnecessary since the quantity of ${ }^{6} \mathrm{Li}$ consumed, $76 \mathrm{~kg} /$ year, is small compared to the initial inventory (124 MT $\left.\mathrm{Li}_{2} 0,57 \mathrm{MT} L i\right)$. The ${ }^{6} \mathrm{LI}$ consumption is based on one atom consumed per fusion neutron.

i) The module stainless steel structure is reused. The only components replaced are the fertile fuel pins and occasionally a tritium breeding rod may be replaced. The graphite reflector region is also recycled each year.

j) The tritium extraction is a batch method in which the pins are heated and the outgassed tritium is collected. This process will occur in a separate vacuum containment and hot cell module maintenance area.

k) The fabrication process losses are taken to be $1 \%$ of the feed inventory. The milling process is assumed to recover $95 \%$ of the available $U$ or $L i$ in the ores.

\section{Pu-Recycle to Thermal Reactor}

This fuel cycle is based on the same assumptions that made up the oncethrough fuel cycle plus the following assumptions:

a) The reprocessing losses are taken to be $1 \%$ of initial feed material (spent fuel).

b) ATthough separate reprocessing facilities for the LWR and Hybrid are shown in the diagram, these processes would probabiy be carried out at a common reprocessing facility. The Tokamak Hybrid fuel rods are similar to the LWR fuel rods. The fabrication of $\mathrm{Li}_{2} \mathrm{O}$ and UC fuel rods could also be achieved at the same facility. 
c) In the fuel cycle the uranium separated from the bred plutonium is recycled back to be used as fuel material in fresh fertile module elements.

d) The LWR data (Pu requirements, power, etc.) are based upon the Combustion Engineering PWR Pu/U fuel cycle. Averaged over 30 years the charge to the reactor is $854 \mathrm{~kg}$ and discharge is $519 \mathrm{~kg}$ (Helm et al. 1977). This leaves $\sim 334 \mathrm{~kg}$, makeup which is supplied by the hybrid reactor.

\section{Pu Catalyst Fuel Cycle}

a) An initial amount of $\mathrm{PuO}_{2}$ is required for startup (8\% by weight in the converter region).

b) $U$ and Th are recycled back to the hybrid modules.

c) LWR fuel cycle used is the PWR cycle: denatured (20\%) U-235/Th fuel with $U-233$ self-generated recycle and $U-233$ makeup from the hybrid reactor. This is a Combustion Engineering PWR fuel cycle ( $\mathrm{Helm}$ et al. 1977).

d) The thorium ore essay is 5\% Tho/monazite sands.

\section{Refresh Fuel Cycle}

a) A direct exchange of fuel occurs between Hybrid and PWR.

b) The replacement schedule is based upon the number of years required to obtain $\mathrm{Pu} / \mathrm{U}$ enrichment of $\sim 2.7 \%$.

c) Refabrication is a mechanical separation of fuels and cladding/assemblies, etc.

d) PWR is based on Combustion Engineering Pu/U reactor fuel cycle. The hybrid produced mixed-oxide fuel has Pu-239 quality of $200-98 \%$ as compared to normal Pu-239 feed quality of $\sim 55 \%$.

The Pu-recycle fuel cycle utilizes the Tokamak Hybrid both as a power producer and fissile fuel producer. The fissile output, $1950 \mathrm{~kg} \mathrm{Pu-239/year,} \mathrm{is} \mathrm{used}$ in a Pu/U fueled PWR. The reference PWR used in this study is a Combustion 
Engineering design producing 1300 MWe. The 30-year average annual Pu makeup requirement is $334 \mathrm{~kg} /$ year, assuming that recycle $\mathrm{Pu}$ from PWR spent fuel reprocessing is used. The Tokamak Hybrid could theoretically support the annual fissile makeup requirements for 5- 6 PWRs.

The Pu-catalyst fuel cycle, al so operating in the reprocessing mode, consists of the Tokamak Hybrid Reactor coupled with a PWR operating on a denatured $\mathrm{U}-233$ fuel cycle. This reactor is also a Combustion Engineering fuel cycle design producing 1300 MWe. Based on the annual U-233 makeup requirements and assuming that the PWR has self-generated $U-233$ recycle, the hybrid breeder could support 13-14 PWRs.

The refresh fuel cycle uses the annual discharge fuel from the Tokamak Hybrid to fuel a PWR. In this scenario the hybrid spent fuel is mechanically separated and refabricated into PWR fuel elements and assemblies. No chemical separation or reprocessing is required. An initial feed of natural uranium exposed to a four-year burn cycle would result in a fissile Pu/U enrichment of 2 to $3 \%$. It is possible that the annual discharge of fuel from the Tokamak Hybrid could support two PWRs in this manner.

\section{FACILITY REQUIREMENTS}

The major facilities of the hybrid fuel cycles are analogous and in some instances identical to the LWR fuel cycle facilities now in use. Blanket module fabrication, operational wastes, spent fuel storage, and reprocessing facilities will be characterized for each hybrid fuel cycle type. The current status of LWR fuel cycle technology relevant to the hybrid fuel cycle will be discussed.

\section{Fuel Fabrication - Mainline Process Description}

The reference fuel and blanket module fabrication facility performs chemical and mechanical operations in the manufacturing of hybrid blanket modules. The facility receives natural uranium $\left(\mathrm{U}_{3} \mathrm{O}_{8}\right)$ concentrates and enriched $\mathrm{Li}_{2} \mathrm{O}$ $\left(90 \%{ }^{6}{ }_{L i}\right)$. The natural uranium is to be the on ly radioactive material present in the reference facility. Four basic operations are performed in the facility: chemically converting the $\mathrm{U}_{3} \mathrm{O}_{8}$ to $\mathrm{UO}_{2}$ powder and then to a carbide (UC); 
mechanical processing including preparation of UC pellets by cold pressing and sintering, fabrication of stainless steel clad UC fuel rods (the tubes are loaded with finished pellets, fitted with end plugs, and welded), and manufacture of $\mathrm{Li}_{2} \mathrm{O}$ tritium breeding pins; manufacturing of first wall and module structures and placing finished fuel and tritium breeding rods into the module; and recovering of uranium and $\mathrm{Li}_{2} \mathrm{O}$ from off-specification and scrap material. The finished blanket modules are to be shipped to appropriate hybrid commercial reactors.

- Chemical Conversion of $\mathrm{U}_{3} 0_{8}$ to UC

$\mathrm{U}_{3} \mathrm{O}_{8}$ concentrates are received from the mill facility and are reacted with hydrogen to produce $\mathrm{UO}_{2} \cdot \mathrm{UC}$ is then produced by an oxide-carbon solution preparation. This fuel conversion is identical to the process used in the light water reactor industry.

- Blending and Packaging

The UC from the conversion processes is pulverized and then collected into leaches for blending. Acceptable UC is packaged in canisters for transfer to the pellet manufacturing area, while rejected $U C$ is recycled back into the conversion step. $\mathrm{Li}_{2} \mathrm{O}$ is purified and collected into canisters for shipment to the pellet operations area.

- Pelletizing

UC from the conversion or scrap recovery area is received in the pellet area where it is prepared for low pressure pressing. After UC is densified in the slug processing operation, the slugs are granulated and screened to obtain the proper size. At the pelleting station the granulated densified UC is pressed into pellets. These pellets are passed through a sintering furnace and then placed in a drying oven.

- Rod Loading and Finishing

Dried UC pellets are unloaded and the pellets manually loaded into stainless steel rods. The top and bottom of the rods are 
welded and sealed. $L i_{2} 0$ powder will be loaded directly into the tritium breeding pins. The $\mathrm{Li}_{2} \mathrm{O}$ powder is compacted within the rods and then sealed with end plugs.

- Module Assembly

The finished $U C$ and $\mathrm{Li}_{2} \mathrm{O}$ rods are unloaded from their storage racks and containers and are inserted into the module body. The fabrication steps of the stainless steel module structure are dependent upon the hybrid reactor type. Some of the modules will be wedge-shaped and some will be cylindrical. Once the modules are assembled and completed, they are shipped to a hybrid reactor site.

\section{- Scrap Recovery}

Scrap in various forms is sent to the recovery process operation where it is handled on a batch basis. Scrap recovery in this reference plant is relatively clean uranium-containing scrap that is amenable to recovery of uranium of acceptable quality by a modest amount of processing (i.e., without solvent extraction). Dirty scrap that requires more processing is either packaged and stored for later processing or shipped as waste.

Initial steps in scrap recovery involve concentration and conversion of the scrap into forms that can be readily processed into $\mathrm{U}_{3} \mathrm{O}_{8}$ powder. The basic sequence of the scrap recovery process involves: dissolving the solid forms in nitric acid, converting to slurry, dewatering the slurry form by wet mechanical separation, calcining the resulting sludge in regular or controlled atmosphere furnaces, and packaging and storing the resulting product. Some scrap does not require processing through the entire sequence. Acceptable product is recycled by returning it to the powder preparation step in the pellet area. Unacceptable product is transferred to the $\mathrm{pH}$ adjustment station or the calcination station in the conversion area. Solid waste is collected for disposal. 
Liquid effluents held in the quarantine tanks are transferred to a waste treatment building when they do not exceed the specified release levels. A typical fabrication facility outlay is shown schematically in Figure 3.11.

Tables 3.7 and 3.8 give a surmary of the isotopic, physical, and chemical characteristics of the material present in the fabrication facility. The average quantity of feed material that enters the facility is also given. The tritium breeding pins will not require continuous replacement but instead can be recycled into the fresh module. The graphite reflector region can also be reused in the hybrid module. The only nonfuel material required for module fabrication is stainless steel used as the cladding.

\section{UO $/ \mathrm{PuO}_{2}$ Fuel Fabrication}

In the Pu-Catalyst fuel cycle $233 \mathrm{U}$ is bred in a ThC breeding region of the blanket module. To enhance this process and improve neutron multiplication, $\mathrm{PuO}_{2}$ is added to the converter region. In this region the amount of $\mathrm{PuO}_{2}$ is relatively constant, at $8 \%$, because the rate of $\mathrm{Pu}$ production is approximately equal to the Pu burnup rate. Of course, the $\mathrm{UO}_{2} / \mathrm{PuO}_{2}$ pins will need to be reclad due to neutron bombardment and radiation effects. It is unrealistic to assume that the fuel pins (converter region) would retain their cladding integrity for a large number of cycles. In the following discussion the mixed oxide fabrication facility is characterized.

$\underline{U O}_{2} \underline{P u O}_{2}$ Fuel Fabrication Mainl ine Process Description

Summary Description of Overall Process

The reference $\mathrm{UO}_{2} / \mathrm{PuO}_{2}$ fuel fabrication facility receives $\mathrm{UO}_{2}$ (natural $\mathrm{U}$ ) and $\mathrm{PuO}_{2}$ powder. The $\mathrm{UO}_{2}$ and $\mathrm{PuO}_{2}$ are blended with recycled $\mathrm{UO}_{2} / \mathrm{PuO}_{2}$ powders from other process steps in the facility. The blended mixture is cold pressed and sintered to yield $\mathrm{UO}_{2} / \mathrm{PuO}_{2}$ pellets, which are loaded into tubes to produce convertor region hybrid type, stainless steel $\mathrm{clad}, \mathrm{UO}_{2} / \mathrm{PuO}_{2}$ fuel rods. The welded and inspected fuel rods are shipped to the hybrid fuel fabrication facility for incorporation into appropriate blanket modules. 


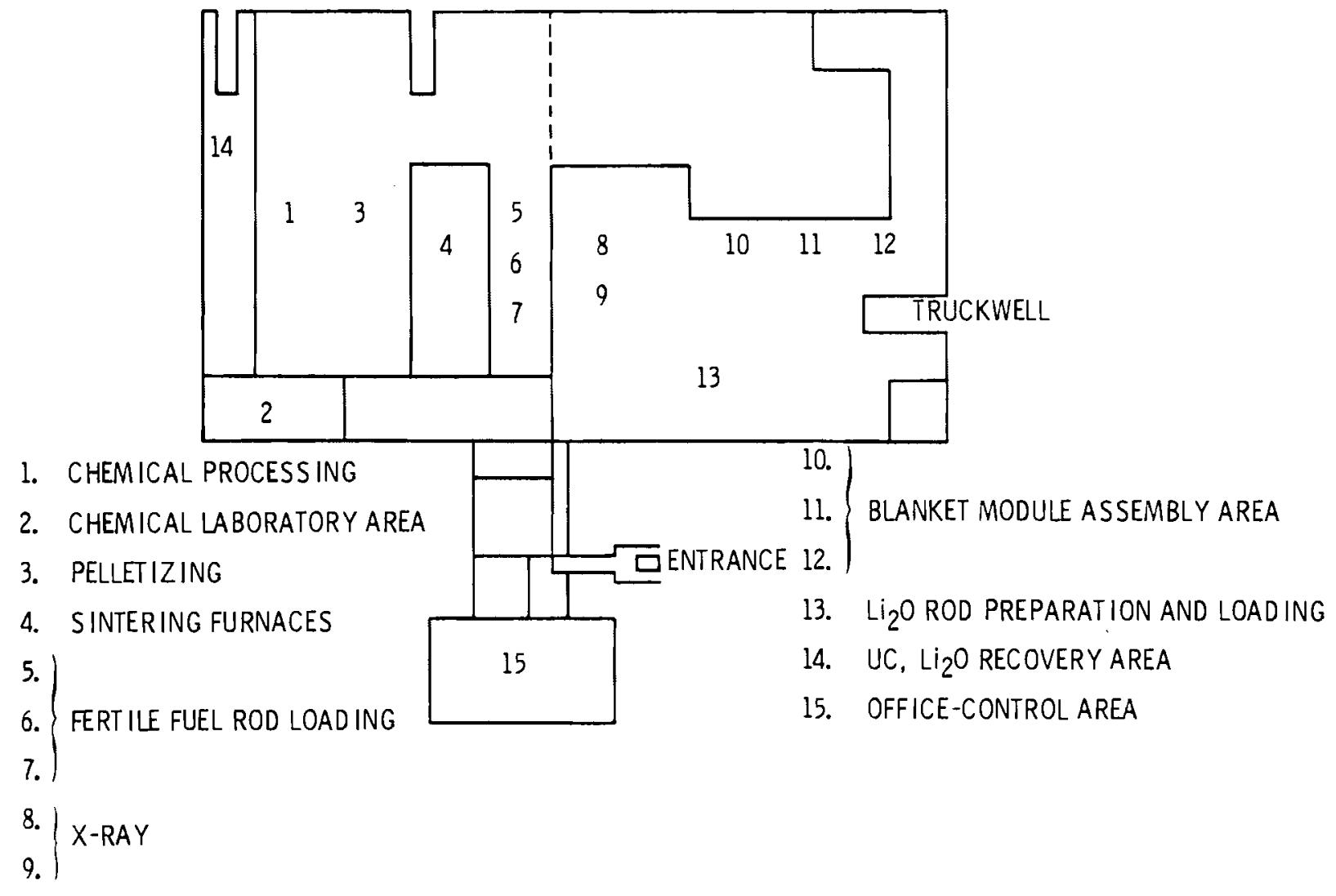

$$
\begin{aligned}
& 1 \text { - Chemical Processing } \\
& 2 \text { - Chemical Laboratory Area } \\
& 3 \text { - Pelletizing } \\
& 4 \text { - Sintering Furnaces }
\end{aligned}
$$$$
5,6,7 \text { - Fertile Fuel Rod Loading }
$$$$
8,9-X \text {-Ray }
$$

10, 11, 12 - Blanket Module Assembly Area

13 - Li 20 Rod Preparation and Loading

14 - UC, Li, 0 Recovery Area

15 - Office-Control Area

FIGURE 3.11. Fabrication Facility Layout 
TABLE 3.7. Once-Through and Pu-Recycle to Thermal Reactors Fuel Fabrication Facility

Fuel Type

- Uranium carbide fertile fuel rods clad with stainless steel. Lithium oxide $\left(90 \% 6_{L}\right.$ i) clad with stainless steel is tritium breeding material.

Type of Material

- Contact-remote fabrication unnecessary with natural uranium as fuel feed.

Technology Status

- Fertile fuel pin fabrication utilizes LWR technology. Some modification of existing fabrication facilities will be needed for $\mathrm{Li}_{2} \mathrm{O}\left(90 \% \sigma_{L} \mathrm{i}\right)$ pin fabrication.

Throughput (Range expected for commercial operation):

Tokamak Hybrid

- 70 to $80 \mathrm{MT} / \mathrm{yr}$-reactor (a)

TABLE 3.8. Material Stream Characteristics

\begin{tabular}{lllll}
\multirow{2}{*}{ Feed } & \multicolumn{1}{c}{ Physical Form } & Chemical Form & $\begin{array}{l}\text { Fissile Isotopic } \\
\text { Composition }\end{array}$ \\
\cline { 2 - 3 } Pellowcake Concen- & $\mathrm{U}_{3} \mathrm{O}_{8}$ & $0.72 \% 235 \mathrm{U}$ \\
trates & $\mathrm{UC}$ & $0.72 \% 235 \mathrm{U}$ \\
Waste & $\begin{array}{l}\text { Fertile Fuel Pins } \\
\text { with Stainless Steel } \\
\text { Cladding }\end{array}$ & $\begin{array}{l}\text { Airborne Particles, } \\
\text { Solid and Liquid } \\
\text { Operational Wastes }\end{array}$ & $\begin{array}{l}\text { U-Contaminated } \\
\text { Material }\end{array}$ & $0.72 \% 235 \mathrm{U}$ \\
& & &
\end{tabular}

Plant Modification Feasibility/Proliferation Criteria:

Material Flow Change: low feasibility

Process Change: low feasibility

Proliferation Criteria: fabrication of natural fuel entails limited proliferation risks.

(a) Annual throughput of natural uranium for fertile fuel pin fabrication. 
The reference $\mathrm{UO}_{2} / \mathrm{PuO}_{2}$ fuel fabrication facility contains equipment in "canyon" type areas where mixed oxide pellets are fabricated on a remote, batch-type basis. The fabrication plants for the Pu-Catalyst hybrid fuel cycle will use batch-type operations and semi-remote (glove box) methods for all the steps through the final welding on the fuel rod. Mixed-oxide fuel is currently prepared commercially by dry (mechanical blending) or wet (coprecipitation) processes. The hybrid fuel fabrication facility will use the dry technique in the pelletization process (Figure 3.12 ).

\section{Description of Process Steps}

Each of the major processes involved in manufacturing the $\mathrm{UO}_{2} / \mathrm{PuO}_{2}$ rods will be discussed below. This description will apply only to the $\mathrm{UO}_{2} / \mathrm{PuO}_{2}$ portion of fuel fabrication for the Pu-Catalyst fuel cycle.

- $\underline{\text { PuO }}_{2}$ Receiving/Unloading

The $\mathrm{PuO}_{2}$ arrives in special shipping containers from a reprocessing facility. The containers are opened inside a ventilated enclosure, the inner cans opened, and the $\mathrm{PuO}_{2}$ transferred to a restricted storage vessel.

\section{- Powder Blending}

Natural $\mathrm{UO}_{2}, \mathrm{PuO}_{2}$, and recycled $\mathrm{UO}_{2} / \mathrm{PuO}_{2}$ powder are blended in batch increments. The $\mathrm{UO}_{2}$ powder is shipped from a fuel fabrication facility to the $\mathrm{UO}_{2} / \mathrm{PuO}_{2}$ facility in 55-gal drums. The $\mathrm{UO}_{2} / \mathrm{PuO}_{2}$ mixture is $92 \%$ (weight) $\mathrm{UO}_{2}$ and $8 \% \mathrm{PuO}_{2}$ (weight). Rejected $\mathrm{UO}_{2}$ and $\mathrm{PuO}_{2}$ ( $71 \%$ moisture) goes to scrap recovery and drying. The batch of $\mathrm{UO}_{2} / \mathrm{PuO}_{2}$ is transferred from the blender to a storage area.

- Compaction, Granulation, Pelletization and Pellet Storage

$\mathrm{UO}_{2} / \mathrm{PuO}_{2}$ powder is transferred by the air conveyor from a silo to the siug press where the powder is compacted into slugs, which are then granulated and classified. Acceptable granules are sent to the pelletizing press, oversized granules (indicates broken classifier 


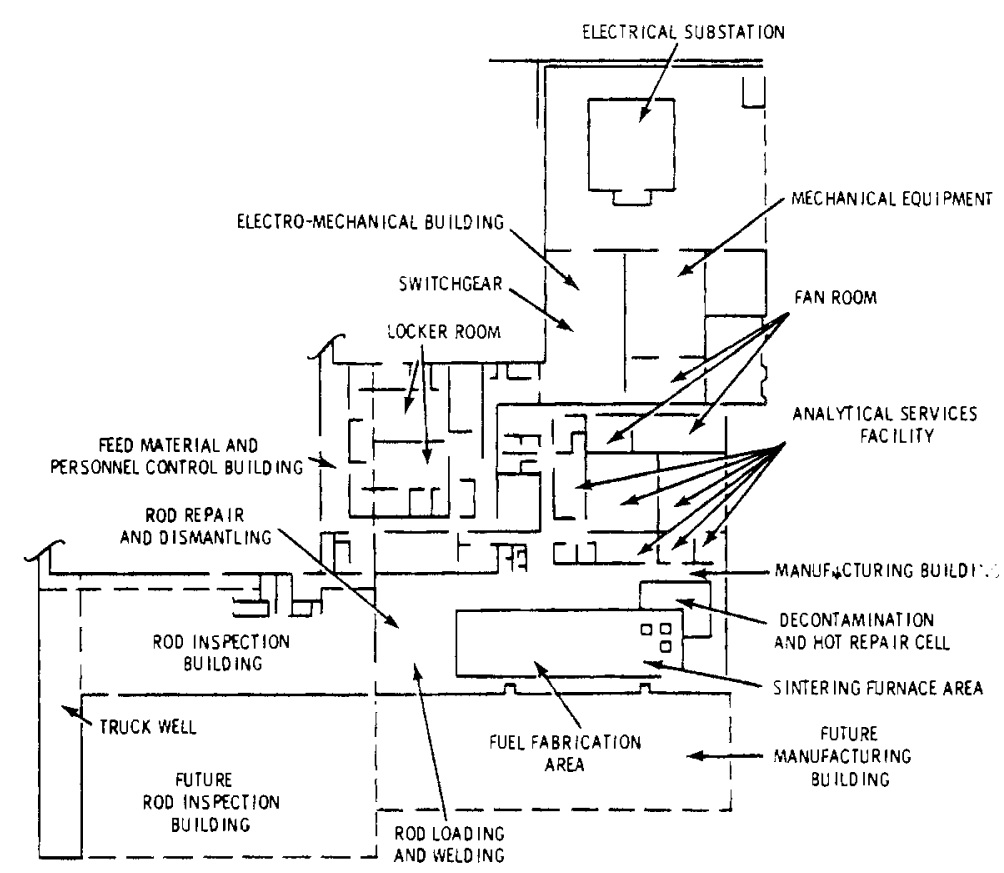

first LEVEL

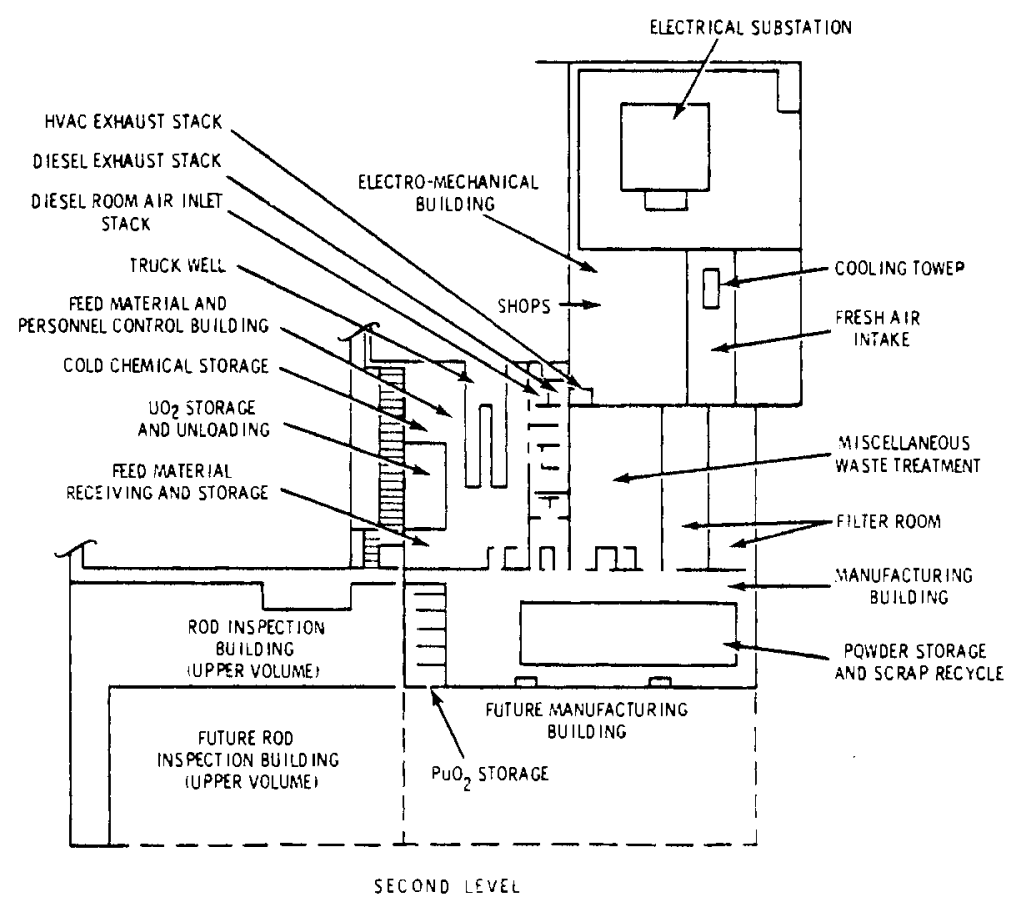

FIGURE 3.12. $\mathrm{UO}_{2} / \mathrm{PuO}_{2}$ Fabrication Facility for Pu-CataTyst Fuel Cycle 
screen) are considered dirty scrap, and undersized granules are directly recycled back to the slug press. Acceptable green (i.e., unsintered) pellets from the pelletizing press are moved by mechanical conveyor to boats (i.e., trays) which are, in turn, placed in green pellet storage; rejected green pellets are collected as clean scrap.

- Sintering, Boat Conveyance and Pellet Storage

Boats of green pellets are moved by shuttle car to the sintering furnaces. The fabrication facility will apparently have several furnaces. The pellets pass through the furnaces to an inspection station for sintered pellets. The acceptable pellets are sent to sintered pellet boat storage; underfired pellets are recycled back through the furnace, and overfired pellets are sent to scrap recovery.

\section{- Pellet Grinding, Inspection and Storage}

Boats of sintered pellets from the furnace storage area are transferred by motor-driven conveyor. The pellets are mechanically unloaded and conveyed single file through a centerless grinder for surface grinding (water coolant used). The water coolant used in pellet grinding is pumped to a sludge separator. A high-velocity air stream (from nozzles) passes over the ground pellets and dries them.

The ground pellets are inspected for diameter. Acceptable pellets go to the nick inspection station, undersize pellets are transferred to scrap recovery, and oversize pellets are sent back for regrinding. From the nick inspection station, acceptable pellets are mechanically conveyed single-file to a tray loader. The loaded trays of pellets are mechanically conveyed single-file to a tray loader. The loaded trays of pellets are mechanically conveyed through a heated-air drier. Trays of dried, inspected pellets are mechanically conveyed to the pellet storage unit. Before pellets are released from the storage units for insertion into tubes at the 
loading station, selected trays of pellets are conveyed to the inspection and sampling station. Trays of acceptable pellets are moved from the storage units to the loading station.

- Fuel Rod Loading

The fuel rod loading station is in a glove box and has a mechanical device to load pellets into stainless steel tubes. After the rods are loaded, they are removed to a decontamination station. From here, the finished rods are sent to an inspection station where the welds and dimensions of the rod are checked. Acceptable rods are moved to a storage area before being shipped to the fuel fabrication plant where the breeding pins, ThC, are manufactured. Here the $\mathrm{UO}_{2} / \mathrm{PuO}_{2}$ rods are inserted into the completed blanket modules.

Tables 3.9 and 3.10 list the fuel fabrication facility characteristics for the Pu-Catalyst fuel cycle.

Refresh Fuel Cycle Fabrication.

The Refresh fuel cycle employs a direct exchange of fuel between the hybrid and light water reactor. The initial fabrication will be identical to the $\mathrm{UO}_{2}$ fuel pin fabrication for LWRs. Before the hybrid spent fuel can be loaded into a LWR, the fuel is mechanically pressed out of the stainless steel cladding. The fuel separated from the old cladding is transferred to another area of the fabrication facility where it is baked to remove fission product gases and then compressed and machined into pellets before it can be clad in "Zircaloy" tubing. A11 of these operations must be performed on a remote basis.

ThC Fuel Fabrication

The Pu-Catalyst blanket module fabrication facility performs the chemical and mechanical operations in the manufacture of hybrid fuel rods. The facility receives natural uranium, thorium, and $\mathrm{PuO}_{2}$. The $\mathrm{UO}_{2} / \mathrm{PuO}_{2}$ or convertor fuel rod fabrication process was described previously. This section will characterize the manufacturing of the breeder region fuel rods, ThC. 
TABLE 3.9. Pu-Catalyst Fuel Fabrication Facility Characteristics

Fuel Type

- Mixed-oxide $\left(\mathrm{UO}_{2} / \mathrm{PuO}_{2}\right)$ convertor fuel pins clad with stainless steel. ThC and $\mathrm{Li}_{2} \mathrm{O}\left(90 \% \sigma_{\mathrm{L}} \mathrm{i}\right)$ breeding material clad with staintess steel.

Type of Material

- Remote fabrication processes carried out in a hot cell operations area. Initial $\mathrm{PuO}_{2}$ loading is LWR grade plutonium.

Technology Status

- Mixed-oxide convertor pin fabrication based on technology developed for the LMFBR.

Throughput (Range expected for commercial operation):

Tokamak Hybrid

- 20 to $30 \mathrm{MT} / \mathrm{yr}$-reactor U

50 to $60 \mathrm{MT} / \mathrm{yr}$-reactor Th

3 to $4 \mathrm{MT} / \mathrm{yr}$-reactor $\mathrm{Pu}$

Mirror Hybrid

- 20 to $30 \mathrm{MT} / \mathrm{yr}$-reactor U

45 to $55 \mathrm{MT} / \mathrm{yr}$-reactor Th

3 to $4 \mathrm{MT} / \mathrm{yr}$-reactor $\mathrm{Pu}$

Laser Hybrid

- 35 to $45 \mathrm{MT} / \mathrm{yr}$-reactor U

75 to $85 \mathrm{MT} / \mathrm{yr}$-reactor Th

Theta-Pinch Hybrid $\bullet 180$ to $185 \mathrm{MT} / \mathrm{yr}$-reactor U 500 to $600 \mathrm{MT} / \mathrm{yr}$-reactor Th

20 to $30 \mathrm{MT} / \mathrm{yr}$-reactor $\mathrm{Pu}$ 
TABLE 3.10 Material Stream Characteristics

Feed

Physical Form

Yellowcake Concen-

concentrates, Thor-

ium Ores, and

Plutonium from LWR

Reprocessing

Product Convertor Fuel Pins

and Fissile Fuel

Breeding Pins

Waste
Airborne Particles,
U-Contaminated
Solid and Liquid
Material, Pu
Operational Wastes

Fissile Isotopic

Chemical Form
$\mathrm{U}_{3} \mathrm{O}_{8}, \mathrm{ThO}_{2}$
and $\mathrm{PuO}_{2}$

Composition

$0.72 \%{ }^{235} U(U)$ $70 \%{ }^{239} \mathrm{Pu}$ and

${ }^{241} \mathrm{Pu}$ (Pu)

Plant Modification Feasibility/Proliferation Criteria:

Material Flow Change: low feasibility

Process Change: low-medium feasibility

Proliferation Criteria: fabrication of mixed-oxide entails proliferation risks. Diversion proof measures are required at this facility. 


\section{Chemical Conversion/Packaging}

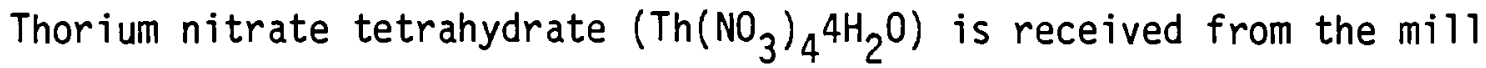
facility. The thorium nitrate solution must first be converted into a finely divided powder, $\mathrm{ThO}_{2}$. The nitrate solution is transferred to a vessel where superheated steam is used to drive off nitric acid and leaves a $\mathrm{ThO}_{2}$ powder. The oxide solution is then transferred to another area where the oxide is formed into an oxide-carbon solution by heating it with channelblack carbon added to the vessel. The ThC material is then collected and purified before being transferred to the pellet process area.

\section{Pelletizing}

ThC is received in the pellet area from the conversion or scrap recovery area. After the ThC is densified in the slug processing operation, the slugs are granulated and screened to obtain the proper size. At the pelleting station the granulated, densified ThC is pressed into pellets. These pellets are passed through a sintering furnace and then placed in a drying oven.

The remainder of the fabrication process (rod loading and finishing, module assembly, scrap recovery) are identical to the processes for the other fuel manufacturing facilities.

\section{Hybrid Fuel Storage}

Most LWR reactors have spent fuel storage pools that are capable of handling $1-1 / 3$ to 2 core loadings. The blanket module management plans for the hybrid reactors are based on replacing one-fourth of the blanket each year. The spent fuel storage for the hybrids should have a capacity of 1-1/4 of the total blanket loading. The spent fuel basin will utilize water as a coolant and shield. Special storage canisters will be needed to store the spent fuel rods since the module structure itself is reused in the blanket. Additional storage may be required at the reactor for Once-Through fuel cycles. Operational Waste Facilities

In addition to the radioactive wastes generated by blanket replacement operations, wastes that are not present in a fission reactor station result from the operation of the hybrid and are associated with the operation of a 
fusion reactor. Tritium contamination of the primary coolant system occurs. Tritium wastes are also associated with the vacuum system and cryopump systems. Recovery bed wastes (contaminated sieve beds) will be generated by the bred tritium removal system, which is used to remove tritium bred in the $\mathrm{Li}_{2} \mathrm{O}$ pins of the blanket module. These wastes introduce safety and waste disposal problems. However, from a proliferation or diversion perspective these types of wastes pose no risk. The quantities of tritium involved are small, and no fissile materials are present.

Reprocessing Spent Hybrid Fuel

Two fuel cycles or blankets require reprocessing: Pu Recycle to Thermal Reactors and Pu-Catalyst. The Once-Through cycle employs a throwaway blanket concept optimized for power production only. The Refresh fuel cycles will use a mechanical type separation process.

Several options that render the product less vulnerable to proliferation are available in the hybrid spent fuel reprocessing. The Purex process can be adjusted to produce a coprocessed product, $\mathrm{Pu}$ and $\mathrm{U}$. Or the normal Purex process can be adjusted to yield coprocessed $U$, Pu with fission product spike (partial decontamination). Although the Thorex process will be used to reprocess $\mathrm{Pu}$ catalyst spent fuel, the $\mathrm{UO}_{2} / \mathrm{PuO}_{2}$ portion will usually remain inside the module and will not be replaced with fresh fuel. The cladding will need to be replaced periodically.

\section{Pu Recycle to Thermal Reactor Reprocessing: Mainline Process Descriptions}

The mainline processes employed at the hybrid reprocessing facility can be divided into three main categories: 1) the process used to recover uranium and plutonium in highly purified nitrate solutions, 2) the process used to convert purified uranium from nitrate solution to uranium carbide, and 3 ) the process used to convert purified plutonium from nitrate solution to plutonium dioxide.

The uranium nitrate solution is converted to a carbide form and recycled back into the hybrid reactor. The $\mathrm{Pu}_{2}$ is transferred to a mixed-oxide fabrication system where it can be used in light water reactors. An available option in the reprocessing step is to leave the $U$ and $\mathrm{PU}$ in solution 
(co-process) and use this fuel as light-water feed material. The first process description will apply to partitioned U/Pu streams. The significant processes present in coprocessing will be emphasized following the partitioned processing discussion.

\section{Description of Process Steps}

\section{Recovery of Uranium and Plutonium}

The hybrid reprocessing facility uses the Purex recovery process, which has been in large-scale use for over 20 years and is currently employed, with minor variations, by most of the reprocessing plants now operating throughout the world.

- Spent Module Receiving

The irradiated hybrid fuel rods arrive at the facility in shielded casks that are monitored for outside radioactive contamination to determine if any leakage has occurred and then are washed. The hybrid spent fuel elements are stored on reactor site in a decay heat pool for approximately one year.

- Hybrid Fuel Rod Shearing and Dissolution

The fuel rods are remotely transferred from the storage pool to the feed mechanism of the mechanical bundle type shear after a full processing lot has been accumulated. Here the fuel elements are chopped into segments $\approx 5$ to $12 \mathrm{~cm}$ long to expose the fuel to the dissolvent. The fuel segments are put into the dissolver containing hot 3 to $8 \mathrm{M}$ nitric acid (and gadolinium nitrate, which serves as a neutron poison), which dissolves virtually all the uranium, plutonium, and fission products. The undissolved cladding materials and accompanying hardware of stainless steel remain in the dissolver basket. The dissolver solution is centrifuged to remove fine solids, which are sent to the high level to tanks to be sampled for accountability and to adjust the acid concentration to 2 to $3 \mathrm{M}$ nitric acid before being fed to the solvent extraction process. The cladding hulls are rinsed, monitored for residual fissile material, packaged, and transferred to the interim underground waste storage area. 
- Solvent Extraction, Partitioning, and Stripping of Plutonium and Uranium

After acid adjustment, the feed solution is sent to the first solvent extraction cycle where it is contacted countercurrently in a centrifugal contractor with an organic solution of tributyl phosphate. The lighter organic solution preferentially extracts the tetravalent plutonium and hexavalent uranium, leaving about $98 \%$ of the fission products in the aqueous solution. The organic solution from the centrifugal contractor passes through a pulsed scrub column where a nitric acid solution removes about $98 \%$ of the remaining fission products and is recycled back to the centrifugal contactor. The final aqueous solution leaving the centrifugal contactor contains about $99.9 \%$ (or more) of the fission products, essentially all of the transplutonium elements and about $0.5 \%$ of the uranium and plutonium; it is then sent to a high-level waste concentrator. The organic solution from the pulsed scrub column then is joined by organic raffinates from the plutonium purification sections and passes through a partitioning column where tetravalent plutonium is electrochemically reduced to the less extractable trivalent state. This process enables the plutonium to be stripped into an aqueous nitric acid solution containing hydrazine as a holding chemical reductant, all within the same electrochemical device. The organic solution passes through the final first-cycle pulsed column where the uranium is stripped into acidified water.

- Second Uranium Solvent Extraction and Concentration

The aqueous strip solution containing the uranium is concentrated, adjusted with nitric acid and sent to the second uranium solvent extraction cycle where it is again preferentially extracted by another organic solution in a pulsed column. Before leaving the column, the organic solution is scrubbed with nitric acid solution, which removes additional fission products. Hydroxylamine nitrate and hydrazine are also added to the scrub solution to remove residual plutonium by chemical reduction to the less extractable trivalent 
state. Uranium is stripped from the organic solution in another pulsed column, using acidified water. This solution is concentrated further by evaporation. Finally, if necessary, the concentrated uranium solution from the second cycle is passed through silica gel beds to remove residual traces.

- Second Plutonium Solvent Extraction

Plutonium in the aqueous stream leaving the partitioning column in the first cycle is reoxidized to the extractable tetravalent state with nitrogen dioxide or sodium nitrite and is sent to the second plutonium solvent extraction cycle. Here, it is preferentially extracted into an organic solution in another pulsed extraction column. In the top portion of the same column, the organic stream is scrubbed with nitric acid solution to remove residual extracted fission products and passes through a strip column where tetravalent plutonium is transferred to an aqueous stream of dilute nitric acid.

\section{- Third Plutonium Solvent Extraction and Concentration}

The extraction-scrubbing sequence is repeated in a third plutonium cycle for further decontamination from fission products. To effect a higher plutonium product concentration, the plutonium is reduced in the third strip column by hydroxylamine nitrate to the more readily strippable trivalent state. An organic scrub solution is added to remove residual uranium from the plutonium aqueous stream as it leaves the third strip column. The plutonium product solution is analyzed and stored in geometrically favorable tanks until it is transferred to a facility for conversion to $\mathrm{PuO}_{2}$.

An overall analysis of the uranium and plutonium recovery process shows that the uranium and plutonium product streams contain about one part in ten million of the fission products originally present in the spent fuel. This purity translates to a radioactivity level in uranium of about twice that of natural uranium. The radioactivity levels in the various processing areas range from very 
high levels that require artificial cooling to remove the heat from radioactive decay to levels low enough to permit direct personal contact.

\section{Conversion of Uranium Nitrate to Uranium Carbide}

The fuel reprocessing facility also converts uranium nitrate solutions to uranium carbide.

- Uranyl Nitrate Receiving and Storage

The conversion area receives uranyl nitrate solution recovered from spent fuel in the adjoining separations area. The solution is received in an accountability tank where it is measured, sampled, and then transferred to the storage tanks.

- Uranyl Nitrate Concentration

From storage, uranyl nitrate solution is pumped to a steamheated thermo-syphon reboiler where water is removed to form uranyl nitrate hexahydrate (UNH), containing $78.5 \mathrm{wt} \%$ uranyl nitrate. The excess removed water is condensed and returned to the separations facility for recycle.

- Uranyl Nitrate Hexahydrate Calcination

Next, the UNH is calcined to uranium trioxide $\left(\mathrm{UO}_{3}\right)$ in a bed of $\mathrm{UO}_{3}$ fluidized by superheated steam at $315^{\circ} \mathrm{C}$. A controlled discharge of $\mathrm{UO}_{3}$ is withdrawn from the bed and fed to the next process step. By denitrating in steam, the nitrate values are converted to nitric acid $\left(\mathrm{HNO}_{3}\right)$, which is condensed and returned to the separations facility for recycle.

- Uranium Trioxide Reduction

Calcined $\mathrm{UO}_{3}$ is put through a feed preparation step, where it is sized to a uniform particle size, activated by the addition of $\mathrm{H}_{2} \mathrm{SO}_{4}$ and converted to uranium dioxide $\left(\mathrm{UO}_{2}\right)$ in a fluidized bed by reduction with hydrogen that was obtained by dissociation of ammonia. 
The uranium dioxide produced by the reduction step is next reacted with carbon in a furnace. After purification and further processing uranium carbide is produced. This fertile fuel is stored and eventually recycled back to the hybrid reactor.

\section{Conversion of Plutonium Nitrate to the Dioxide}

The hybrid reprocessing facility's plutonium production facility converts plutonium nitrate solutions to plutonium dioxide powder.

The conversion process consists of continuous precipitation of plutonium oxalate, followed by calcination to plutonium dioxide $\left(\mathrm{PuO}_{2}\right)$. This process has been used for over 20 years in various nuclear installations. Two parallel conversion lines (i.e., precipitation through product packaging) are typically used, each furnishing half the total capacity of the facility.

- Plutonium Nitrate Conversion

Plutonium nitrate solution is transferred in batches from plutonium nitrate storage to feed preparation tanks where the nitric acid concentration is adjusted. The adjusted feed and oxalic acid streams flow continuously to a precipitator vessel to be mixed and to commence precipitation. From the precipitator vessel the slurry overflows to successive digestion vessels to allow crystal growth and is filtered on a rotary vacuum drum filter. The precipitate is then dried and calcined in a rotary screw calciner at temperatures up to $750^{\circ} \mathrm{C}$. The plutonium oxide powder is screened and blended to achieve product uniformity. The oxide is then sampled, packaged and storaged before shipment to a mixed-oxide LWR fuel fabrication facility.

\section{Thorex Process for U/Th Reprocessing in the Pu-Catalyst Fuel cycle}

The Thorex process decontaminates uranium/thorium nitrate solutions and separates it from the fission products. The fission products are thus separated from the uranium and thorium when the mixture of nitrate solutions is contacted with an organic solvent. The mixture is contacted in a second extraction step to partition the uranium and thorium and the separate streams are recycled through solvent extraction steps to remove the remainder of the 
fission products. Purified uranium and thorium nitrate solutions are sent to a recycle or refabrication facility.

\section{Reprocessing Options}

Listed below are the reprocessing facility options that exist for the Pu-Recycle and Pu-Catalyst fuel cycles:

\section{Process}

$$
\begin{gathered}
\text { Purex } 1 \text { Reference Purex process } \\
2 \text { Coprocessed U, Pu } \\
3 \text { Coprocessed U, Pu with fission-product spike, } \\
\begin{array}{c}
\text { i.e., only partially decontaminated } \\
4 \\
\text { Coprocessed U, Pu, pre-irradiated before } \\
\text { shipment }
\end{array}
\end{gathered}
$$

\section{Thorex 1 Reference Thorex process}

2 Corprocessed U, Th with fission-product spike

3 Partitioned products ( $U$, Th, Pu)

4 Partitioned U, Th; Pu to waste with fission products

5 Regufle 233U; denature in process; Pu, $235 \mathrm{U}$ to waste with fission products

6 Recycle 233u; denature in situ; Pu, 235u to waste with fission products

7 Recycle 233u, 235u; denature in situ; Pu to waste with fission products

A sumary of the reprocessing facility data for the Pu-Recycle fuel cycle is given in Tables 3.11 and 3.12. The summary data for the Pu-Catalyst fueling option is tabulated in Tables 3.13 and 3.14. 
TABLE 3.11. Reprocessing Facility Summary Data for Pu-Recycle Fuel Cycle

Fuel Type (feed): Irradiated fuel rods (UC) containing actinides, fission products and bred fuel (Pu). Reprocessing facility will receive fuel rods in special shipping containers.

Reprocessing Method: Purex and modified Purex for proliferation resistance measures.

Technology Status: Reference Purex methods well developed and in use in several countries. Modified Purex methods have little commercial basis.

Maintenance: $\quad$ Remote, hot cell operations.

Throughput (Spent Fuel Reprocessed in a Commercial Facility)

$$
\begin{array}{lll}
\text { Tokamak Hybrid } & -70-80 \mathrm{MT} / \text { year-reactor } \\
\text { Mirror Hybrid } & -70-75 \mathrm{MT} / \text { year-reactor } \\
\text { Laser Hybrid } & -110-115 \mathrm{MT} / \text { year-reactor } \\
\text { Theta-Pinch Hybrid } & -500-600 \mathrm{MT} / \text { year-reactor }
\end{array}
$$

Throughput (Range Expected for Normal Commercial Operation)

Tokamak Hybrid - Pu: $1900-2000 \mathrm{~kg} /$ year-reactor 763 . $\mathrm{kg} /$ year-reactor F.P.

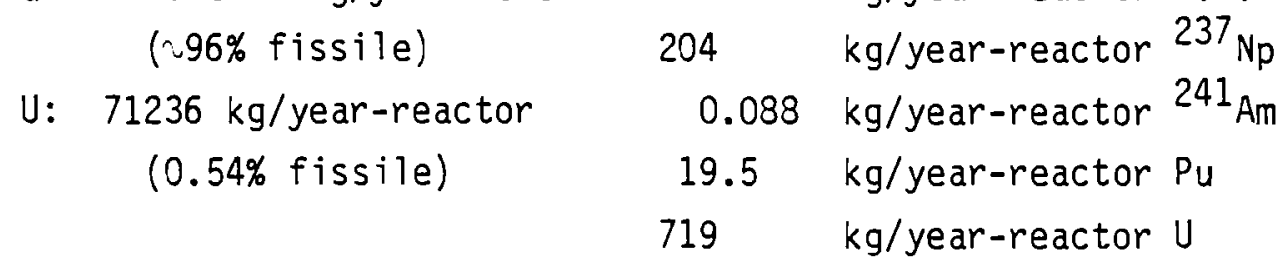


TABLE 3.12. Material Stream Characteristics

\begin{tabular}{|c|c|c|}
\hline Feed & $\begin{array}{l}\text { Spent UC fue } 1 \text { rods containing } \\
\text { actinides, fission products, } \\
\text { activated structure (S.S.) }\end{array}$ & $\begin{array}{l}238 U-99.3 \% \\
235 U=0.54 \% \\
236 u=0.16 \%\end{array}$ \\
\hline Product & $\begin{array}{l}\text { Partitioned stream of pluton- } \\
\text { ium nitrate }\left(\mathrm{Pu}\left(\mathrm{NO}_{3}\right)_{4}\right) \text { convert- } \\
\text { to } \mathrm{PuO}_{2} \text { and } \mathrm{UC}\left(\mathrm{NO}_{3}\right)_{2}\end{array}$ & Isotopics same as above \\
\hline Wastes & $\begin{array}{l}\text { SS cladding hulls, acidic high } \\
\text { level waste from the extrac- } \\
\text { tion and concentrator steps. } \\
\text { High level solid wastes from } \\
\text { initial centrifugation process. }\end{array}$ & $\begin{array}{l}\text { All fission products and actinides } \\
\text { other than } U \text { or Pu are disposed } \\
\text { of as wastes. Fission products } \\
\text { are } 1-2 \% \text { of initial spent fuel } \\
\text { feed while actinides other than } U \\
\text { and Pu are } \sim 0.6 \% \text { of initial spent } \\
\text { fue } 1 \text {. Some of the more important } \\
\text { actinides are: } \\
237 \mathrm{~Np}-0.56 \% \text { of spent fuel } \\
241 \mathrm{Am}-1.8 \times 10-3 \% \text { of spent fuel } \\
242 \mathrm{Cm}-1.6 \times 10^{-5 \%} \text { of spent fuel }\end{array}$ \\
\hline \multicolumn{3}{|c|}{ Plant Modification Feasibility/Proliferation Criteria } \\
\hline \multicolumn{3}{|c|}{ Material Flow Change: medium-high feasibility } \\
\hline \multicolumn{3}{|c|}{ Process Change: low feasibility } \\
\hline \multicolumn{3}{|c|}{$\begin{array}{ll}\text { Proliferation Criteria: } & \text { reprocessing facility located in a secure nuclear } \\
& \text { center would present limited proliferation risks. } \\
& \text { Technical fixes such as coprocessing and fission } \\
& \text { product spiking could also be employed as diversion } \\
& \text { resistant measures. }\end{array}$} \\
\hline
\end{tabular}


TABLE 3.13. Reprocessing Facility Summary Data for Pu-Catalyst Fuel Cycle

Fuel Type (feed): $\quad$ Irradiated converter fuel rods $\left(\mathrm{UO}_{2} / \mathrm{PuO}_{2}\right)$ and breeder rods (ThC) and bred fissile fuel (233 $\mathrm{U}$ ) $\mathrm{UO}_{2} / \mathrm{PuO}_{2}$ rods will be re-clad and not chemicaliy treated.

Reprocessing Method: Thorex and modified Thorex for proliferation resistant product.

Technology Status Reference Thorex process has seen limited commercial use.

Maintenance: $\quad$ Remote handling devices required heavy shielding - hot cell operations necessary.

Throughput (Spent Fuel Reprocessed in a Commercial Facility Breeding Region Only

Tokamak Hybrid - 50 - 60 MT/year-reactor

Throughput (Range Expected for Normal Commercial Operation)

Product

Tokamak Hybrid - 233U: $\quad 3800-4000 \mathrm{~kg} /$ year-reactor Th: $\quad 50,000-55,000 \mathrm{~kg} /$ year-reactor
Waste

$1648 \mathrm{~kg} /$ year-reactor F.P.

$38 \mathrm{~kg} /$ year-reactor $233 \mathrm{U}$ $500 \mathrm{~kg} /$ year-reactor Th 
TABLE 3.14 Material Stream Characteristics

\begin{tabular}{|c|c|c|}
\hline \multirow[b]{2}{*}{ Feed } & Chemical/Physical Form & Isotopics \\
\hline & $\begin{array}{l}\text { Spent } \mathrm{UO}_{2} / \mathrm{PuO}_{2} \text { converter rods } \\
\text { and ThC breeding pins contain- } \\
\text { ing actinides, fission products, } \\
\text { activated structure (S.S.) }\end{array}$ & $\left.\begin{array}{l}232 U-0.72 \% \\
233 U-98.2 \% \\
234 U-0.89 \%\end{array}\right\}$ \\
\hline Product & $\begin{array}{l}\text { Partitioned stream of } U \text { and } \mathrm{Th} \text { : } \\
\text { converter region of } \mathrm{UO}_{2} / \mathrm{PuO}_{2} \text { is } \\
\text { returned to fuel fabrication } \\
\text { facility. }\end{array}$ & $\begin{array}{l}\text { Isotopics same as } \\
\text { above }\end{array}$ \\
\hline Wastes & $\begin{array}{l}\text { SS cladding hulls acidic high } \\
\text { level waste from the extrac- } \\
\text { tion and concentrator steps. } \\
\text { High level solid wastes from } \\
\text { initial centrifugation process. }\end{array}$ & $\begin{array}{l}\text { All fission products } \\
\text { and actinides other } \\
\text { than } U \text { are disposed } \\
\text { of as wastes. Fission } \\
\text { products are } 1-2 \% \text { of } \\
\text { initial spent fuel } \\
\text { feed. }\end{array}$ \\
\hline \multicolumn{3}{|c|}{ Plant Modification Feasibility/Proliferation Criteria } \\
\hline \multicolumn{3}{|c|}{ Material Flow Change: medium-high feasibility } \\
\hline \multicolumn{3}{|c|}{ Process Change: low feasibility } \\
\hline \multicolumn{3}{|c|}{ 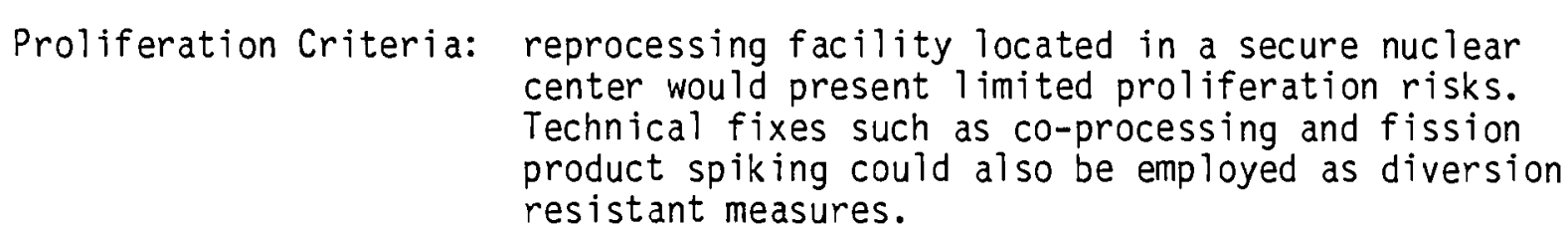 } \\
\hline
\end{tabular}




\section{SECTION 3.0: REFERENCES}

Bell, M. J. 1973. ORIGEN - The ORNL Isotope Generation and Depletion Code. ORNL-4628, Oak Ridge National Laboratory, Oak Ridge, TN.

Culler, F. L., Jr. April 1978. "Precedents for Diversion-Resistant Nuclear Fuel Cycles." Proceedings of the Fifth Energy Technology Conference, p. 111. Government Institutes, Inc., Washington, D.C.

Energy Daily. 6(142):1, July 25, 1978.

Flowers, R. H., K. D. B. Johnson, J. H. Miles and R. K. Webster. April 1978. "Possible Long Term Options for the Fast Reactor Plutonium Fuel cycle." Proceedings of the Fifth Energy Technology Conference, p. 256. Government Institutes, Inc., Washington, D.C.

Helm, T. M., ET AL. 1977. Reactor Design Characteristics and Fuel Inventory Data, Vol. 1. Hanford Engineering Development Laboratories, Richland, WA.

Laney, R. V. and P. R. Huebotter (ANL). 1978. "Nonproliferation Criteria for Nuclear Fuel Cycles." TANSA 28:320.

Leonard, B. R., Jr. and U. P. Jenquin. 1976. "The Quality of Fissile Fuel Bred in a Fusion Reactor Blanket." Second Topical Meeting on the Technology of Controlled Nuclear Fusion, Richland, WA, September 21-23, 1976. ERDA Report CONF--760935, pp. 2, 711.

Levenson, M. April 1978. "A Fast Breeder System Concept." Proceedings of the Fifth Energy Technology Conference, p. 230. Government Institutes, Inc., Washington, D.C.

Starr, C. April 1978. "Proliferation-Resistant Nuclear Technology." Proceedings of the Fifth Energy Technology Conference, p. 103. Government Institutes, Inc., Washington, D.C. 


\subsection{MECHANICAL AND THERMAL HYDRAULIC CONSIDERATIONS}

Many thermal hydraulic and mechanical design problems exist in a hybrid reactor. Generally, however, the ones that concern evaluation of the technical feasibility of a concept are in the first wail/blanket region.

The four hybrid blankets, in general, do not pose serious heat transferfluid flow design problems compared to fission reactor technology. A good measure of this is the relative power density in hybrid blankets compared to various fission reactor cores, as shown in Table 4.1. Because the fuel-coolant lattices being selected by designers are typical of gas-cooled fast reactor (GCFR) and liquid metal fast breeder reactor (LMFBR) technology some freedom appears to exist in increasing the amount of fuel in the blanket.

\section{TABLE 4.1. Typical Reactor Power Densities}

$\begin{array}{lccccc}\begin{array}{l}\text { Average Core Power } \\ \text { Density }\left(\mathrm{MW} / \mathrm{m}^{3}\right)\end{array} & 100 & \frac{\text { GCFR }}{240} & \frac{\text { LMFBR }}{360} & \frac{\text { HTGR }}{8} & \frac{\text { Hybrid }}{20} \\ \begin{array}{l}\text { Maximum Core Power } \\ \text { Density }\left(\mathrm{MW} / \mathrm{m}^{3}\right)\end{array} & 285 & 360 & 540 & 13 & 100\end{array}$

The calculational methods for heat transfer and fluid flow, developed by the fission reactor programs, are adequate for conceptual hybrid reactor blanket designs. However, detailed design and safety analyses of start-up and pulsed operation are going to require much closer coupling of thermal and mechanical analysis methods than now exist for both fuel and structures.

In assessing the status of structural design of Tokamak hybrid blankets, three areas must be addressed:

- materials properties

- structurar layout

- design anatysis.

The following comments pertain to hybrid blanket structure. The magnet shield region also has important structural implications, but hybrid designers are currently relying on the pure fusion reactor blanket and shield program to 
develop the shield requirements because of the much lower neutron flux and energy entering the shield region for the hybrid.

\section{- Materials Properties}

All components of a fusion-fission hybrid blanket are subjected to 1 arge fluences of high energy neutrons ( $>1 \mathrm{MeV}$ ). Irradiated materials properties are important when projecting reactor performance and selecting materials. The most complete irradiated properties data currently come from the LMFBR Program, which has concentrated on the 300 series stainless steels and ranges from extensive theoretical studies of damage mechanisms to the establishment of the bulk properties necessary for the designer. Irradiated stress rupture and cyclic fatigue data exist and data and correlations exist or are being developed for swelling and helium embrittlement caused by irradiation. Stainless steel is serviceable up to $600^{\circ} \mathrm{C}$ with sodium or helium coolant, while with lithium or molten salts is serviceable at $500^{\circ} \mathrm{C}$. If conceptual designers changed to alternate cladding and structural material to achieve higher operating temperatures, design adequacy and structure lifetime could not be predicted with certainty.

Designers are concerned about the adequacy of the LMFBR data in predicting performance in a high $14 \mathrm{MeV}$ neutron flux. The current Office of Fusion Energy (OFE) materials program, however, is running some preliminary experiments to see if irradiation damage (swelling and helium embrittlement) is different for $14 \mathrm{MeV}$ neutrons than LMFBR correlations predict. These experiments along with LMFBR data will form the only firm design bases available until high-energy neutron test facilities are in operation. Extensive materials properties data will not be available on alternate materials before the time frame of interest for initial hybrid operation (1990-2000).

\section{- Structural Layout}

Structural layout of current fusion-fission hybrid designs depends a great deal on the geometry of the fusion driver. 
Figure 4.1 is a modular arrangement developed in this study by PNL for the Tokamak Hybrid.

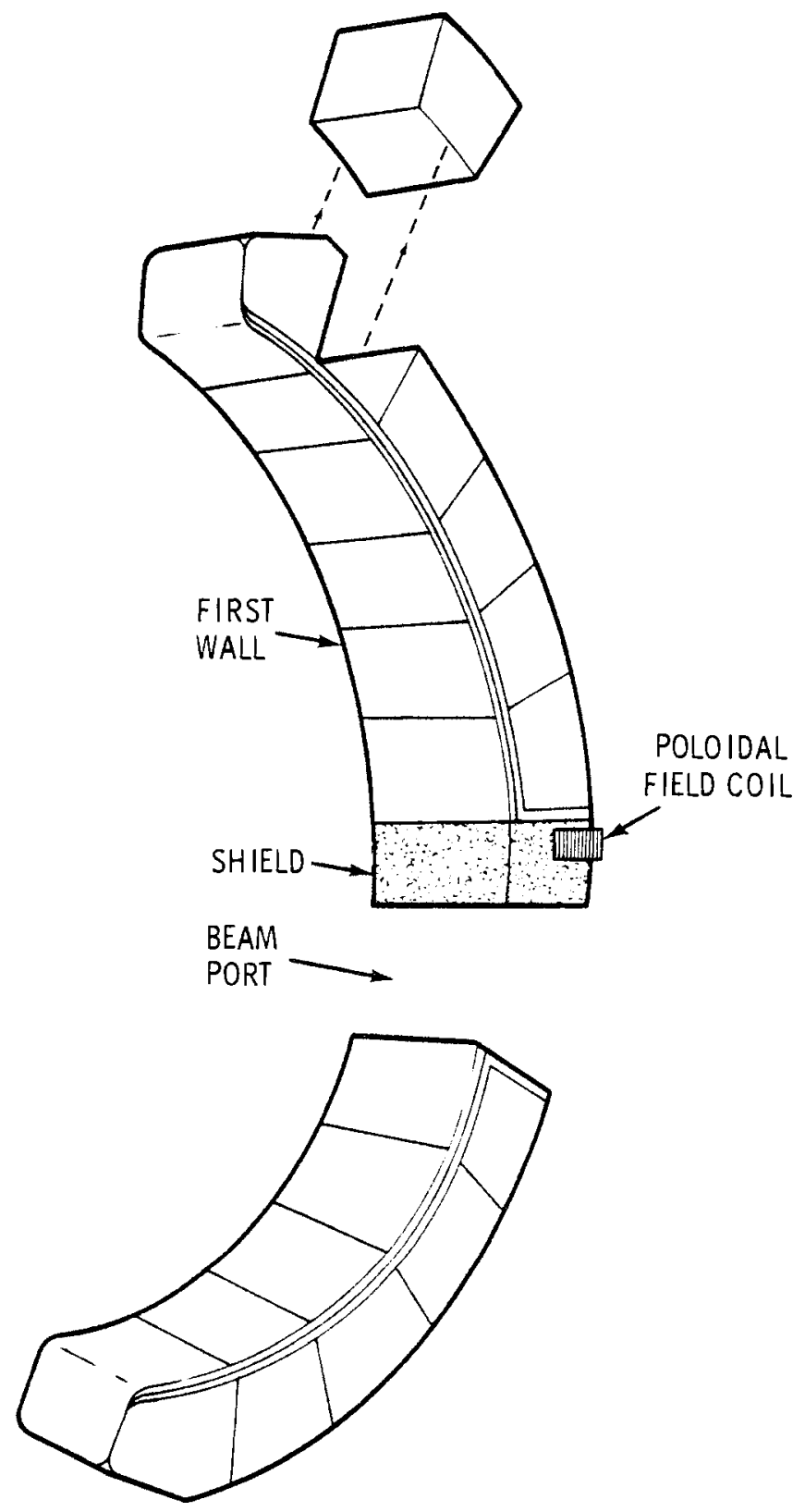

FIGURE 4.1. Tokamak Hybrid Blanket Segment 
In the Tokamak modular concept, the fuel pins are oriented radially. The helium coolant enters from the supply header, flows along the outer module wall, turns $180^{\circ}$ and flows back through the fuel region to the coolant exit header (see Figure 4.2). In some vacuum system concepts, the vacuum seal is formed where the modules connect to the header. In others, such as the one here, a separate vacuum barrier (first wall) is used to simplify module design since the high heat loads from plasma losses are taken by a separate structure. Eleven modules are located around the torus segment (see Figure 2.2). The neutral beam injection port occupies 10 to $15 \%$ of the first wall space and will extend completely around the torus, which will be divided into 60 segments, each having 11 blanket modules to make a total of 660 modules. A closeup view of a Tokamak Hybrid module is shown in Figure 4.3. The thermal or mechanical stresses in the stainless steel module wall due to the 700 psia helium coolant pressure will be wel1 below the maximum allowable $50 \mathrm{ksi}$, provided that the walls are externally supported and/or have a double-wa11 construction.

The corresponding mechanical and thermal hydraulic information for 6 blankets with the blanket-fuel cycle options are tabulated in Table 4.2. In all cases the coolant flow rates and velocities are adjusted to obtain the corresponding outlet/inlet temperatures. Helium inlet pressure of 700 psia, corresponds to velocities in the range of 10 to $100 \mathrm{~m} / \mathrm{s}$ with an approximate heat transfer coefficient of 1 to $2 \mathrm{~W} / \mathrm{cm}^{2} \mathrm{C}$.

\section{REMOTE DISASSEMBLY AND MAINTENANCE}

The blanket lifetime for the four hybrid fuel cycles is four years. The radioactivity and decay heat levels resulting from the hybrid blanket operation necessitates a blanket designed for remote maintenance and ease of access and disassembly.

A cross section view of the tokamak is shown in Figure 4.4. To gain access to the blanket modules, the following operations have to be performed: 


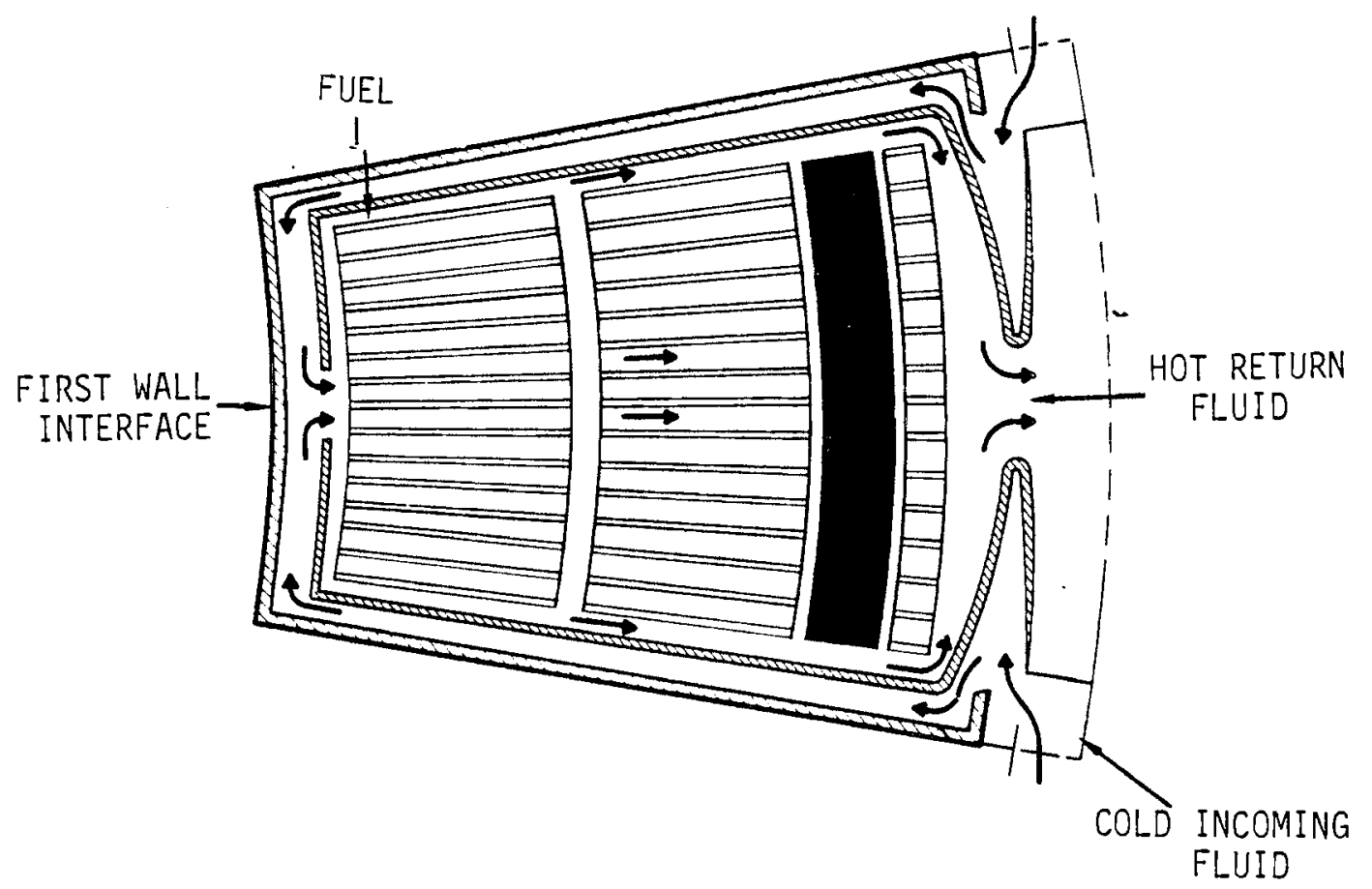

FIGURE 4.2. Helium Coolant Flow in the Tokamak Hybrid Reactor

1. Raise the upper and lower blanket shield and VF coil.

2. Swing open and secure the hinged shield.

3. Disconnect helium supply and return lines from the module manifolds.

4. Cut or machine off the welds and seals adjoining the adjacent segments.

5. Finally, lift the blanket segment out of the reactor by an overhead crane or transfer it with a remotely operated carriage.

The blanket segments are transferred to a hot cell operations area. Here the segment would be remotely dismantled and the fuel rods removed from each individual module, placed into special canisters and retired to a decay heat spent fuel storage basin. The $\mathrm{Li}_{2} \mathrm{O}$ pins and reflector region would be placed back into the module along with fresh fuel pins. Then the segment would be reassembled and placed into the reactor. 


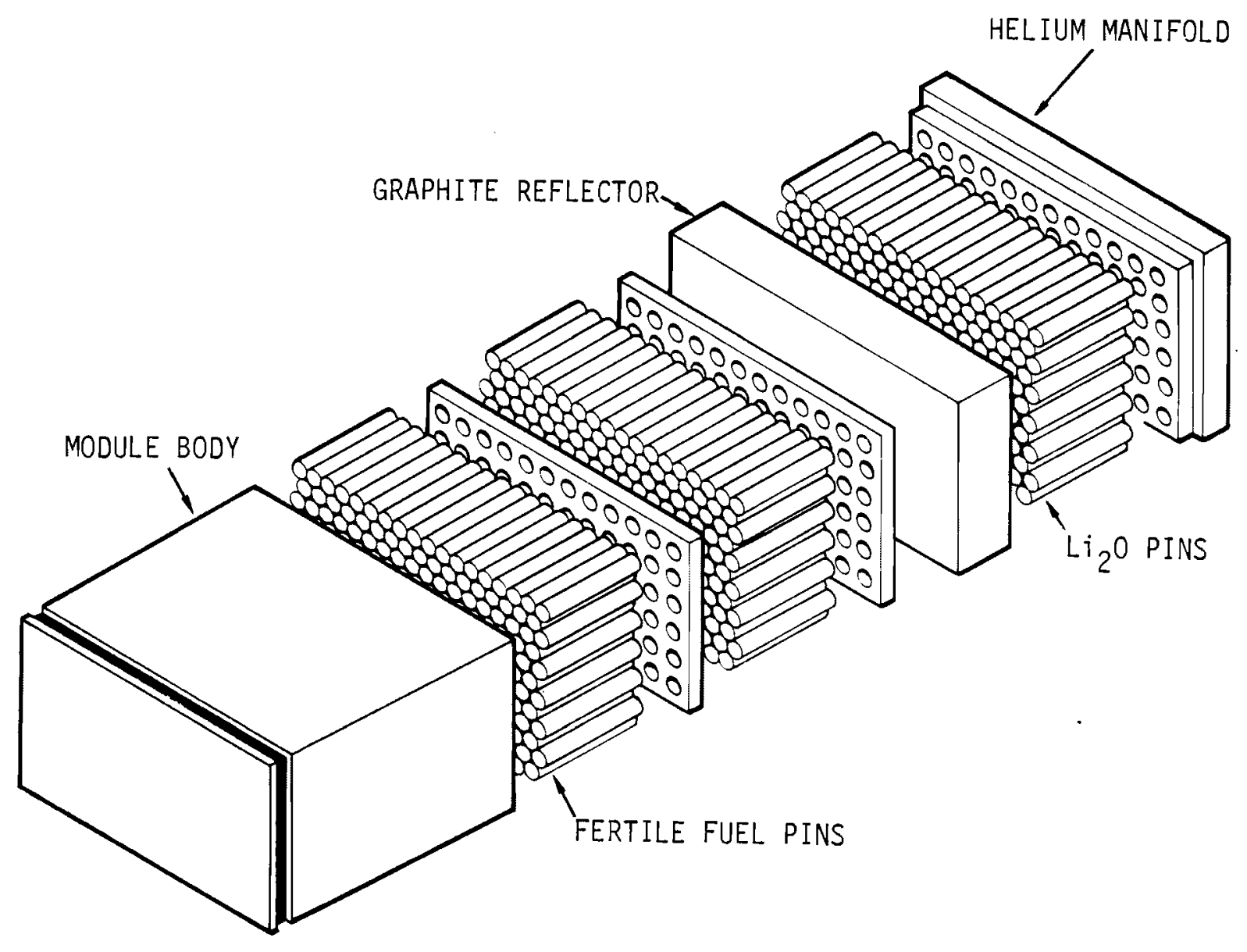

FIGURE 4.3. Tokamak Hybrid Module Detail 
TABLE 4.2. Tokamak Hybrid Mechanical and Thermal Hydraulic Information

\begin{tabular}{|c|c|c|c|}
\hline Reactor Parameter & Recycle & Catalyst & Refresh \\
\hline Reactor Thermal Power (MW ${ }_{\text {th }}$ ) & 4,144 & 6,603 & 3,715 \\
\hline Fusion Power $\left(\mathrm{MW}_{t h}\right)$ & 1,160 & 1,160 & 1,160 \\
\hline Electrical Output $\left(\mathrm{MW}_{\mathrm{e}}\right)_{\mathrm{Net}}$ & 1,000 & 1,835 & 853 \\
\hline \multicolumn{4}{|l|}{ Core Design: } \\
\hline \multicolumn{4}{|l|}{ Blanket Heat Output: } \\
\hline Fission $\left(M W_{t h}\right)$ & 2,615 & 5,136 & 2,210 \\
\hline Li Reactions $\left(\mathrm{MW}_{t h}\right)$ & 252 & 191 & 229 \\
\hline Specific Power $\left(M_{t h} / M T\right)(a)$ & 8.6 & 16.5 & 10.7 \\
\hline Power Density $\left(\mathrm{W} / \mathrm{cm}^{3}\right)^{(b)}$ & 54 & 68 & 45 \\
\hline \multicolumn{4}{|l|}{ Geometric Information: } \\
\hline Fast Fission Zone Height $(\mathrm{cm})$ & 26 & 39 & 26 \\
\hline Number of Blanket Modules & 660 & 660 & 660 \\
\hline Fuel Pins (Rods)/Module & 2,500 & 2,500 & 2,500 \\
\hline $\mathrm{Li}_{2} \mathrm{O}$ Pins/Module & $600-800$ & $600-800$ & $600-800$ \\
\hline Overall Module Dimensions $(\mathrm{L} \times \mathrm{W} \times \mathrm{H}) \mathrm{cm}$ & $84 \times 40 \times 78$ & $84 \times 40 \times 78$ & $84 \times 40 \times 78$ \\
\hline Module Material & S.S. & S.S. & S.S. \\
\hline \multicolumn{4}{|l|}{ Cladding Parameters: } \\
\hline \multicolumn{4}{|l|}{ Fue $1 / \mathrm{i}_{2} 0$ Rod: } \\
\hline Outside Diameter $(\mathrm{cm})$ & $1.0 / 2.0$ & $1.0 / 2.0$ & $1.0 / 2.0$ \\
\hline Wall Thickness (mils) & 15 & 15 & 15 \\
\hline Cladding Material & S.S. & S.S. & S.S. \\
\hline Fue 1 Type & UC & $\mathrm{UO}_{2} / \mathrm{PuO}_{2} \mathrm{ThC}$ & $\mathrm{UO}_{2}$ \\
\hline Blanket Coolant - & Helium & Helium & Helium \\
\hline Outlet/Inlet Temperature $\left({ }^{\circ} \mathrm{F}\right)$ & $1200 / 600$ & $1200 / 600$ & $1200 / 600$ \\
\hline
\end{tabular}

(a) Based on blanket fission power and total fuel loading.

(b) Power density determined from blanket fission power and fuel region volume. 


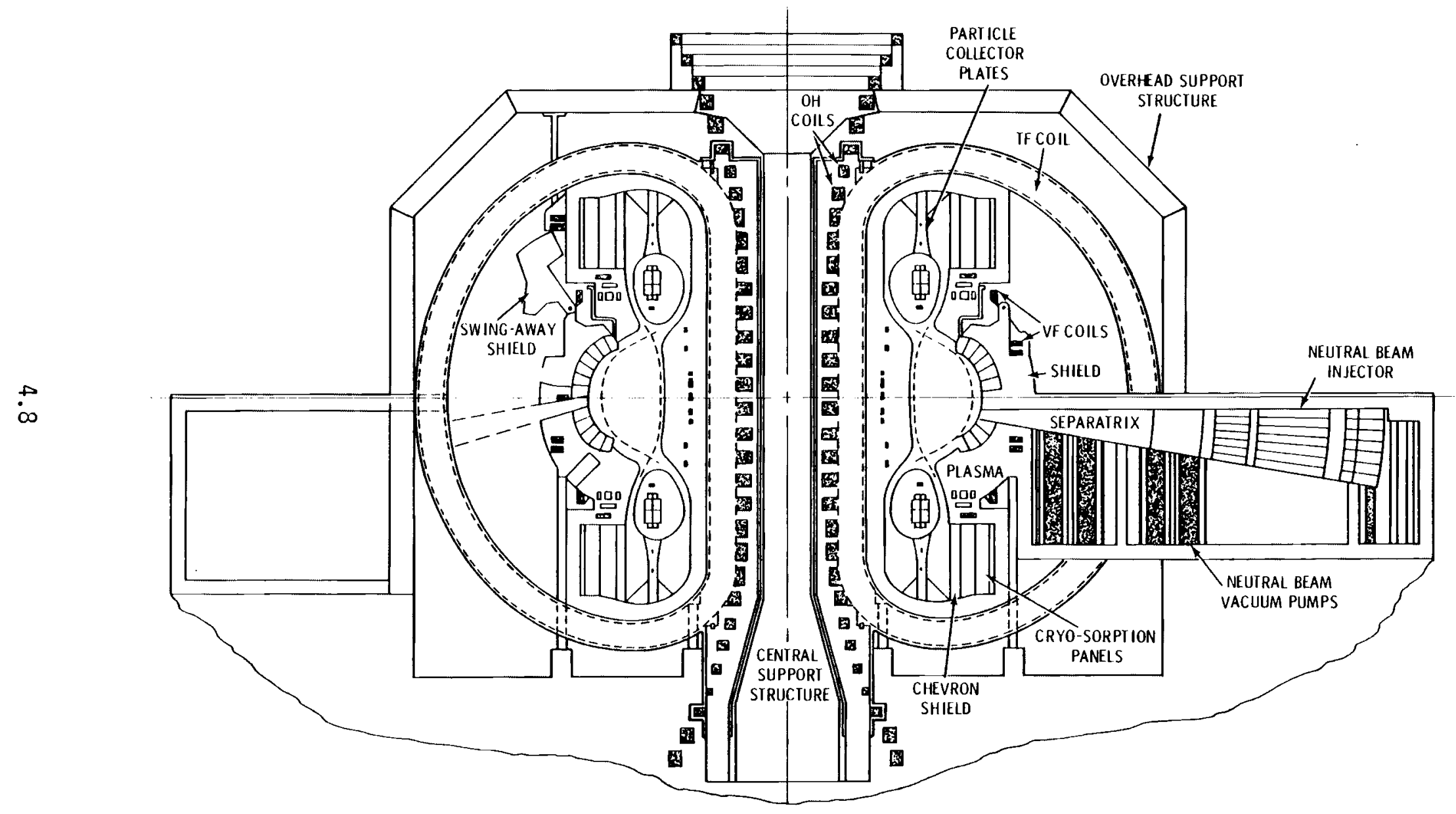

FIGURE 4.4. Tokamak Hybrid Reactor Cross Section 


\subsection{MATERIALS SELECTIONS AND RESOURCES}

\section{FUEL FORMS}

Satisfactory performance of the fusion-fission hybrid system depends a great deal on the technological basis supporting the selection of the fission fuel form. Not only is fuel performance important under operating and accident conditions but fabrication, reprocessing and ultimate waste disposal technologies must be available or developed. Generally, the technology base for a fuel form (oxide, carbide, etc.) is dependent on a specific cladding material, geometrical form (pins, microspheres, etc.), and coolant. The technological basis for $\mathrm{UO}_{2}$ fuel is limited to fuel clad in Zircaloy or stainless steel, fabricated in pins and cooled by water. In assessing the status of technology for the fuel forms of interest for the Tokamak Hybrid Reactor (THR), the following considerations must be addressed:

- Oxide Fuel - The most highly developed fuel form of interest for hybrids is $\mathrm{UO}_{2}$ clad in stainless steel. All commercial experience has been with pins assembled into bundles. Irradiation performance of water-cooled S.S.-clad $\mathrm{UO}_{2}$ fuel is fairly extensive and the LMFBR Program is rapidly developing Na-cooled data. The GCFR Program proposes to utilize LMFBR technology and has identified differences that must be resolved. The predictable performance of $\mathrm{ThO}_{2}$ should also be enhanced with this technological base. Oxide fuels achieve burnups of 40,000 to 100,000 megawatt days per metric tonne of heavy metal (MWD/MTHM). The transient performance of oxide fuels is the subject of considerable R\&D in both the Light water Reactor (LWR) Safety Program and the LMFBR Program. Extensive development of analytical methods for design is an integral part of both these programs and will be of use to hybrid blanket designers for determining the response of oxide fuels to the pulsed power operation of most fusion drivers. Current transient experiments indicate that oxide fuels containing fission products can withstand only a few rapid transients before mechanical fatigue causes failure. 
All solid fuel forms are anticipated to have this problem due to retained fission products.

- Metallic Fuel - The irradiation performance of many metallic fuels is well understood. Of the many alloys and geometric forms that have been used in production reactors, test reactors, and others, the most applicable to fusion-fission hybrid reactors may be the U-Fissium pins used as EBR II driver fuel. U-Fissium is primarily a U-Mo alloy and the pins are made up of cast U-Mo sodium bonded to 304 S.S. cladding. Burnups of 10,000 MWd/MTHM are current practice. Maximum fuel-clad temperatures of $650^{\circ} \mathrm{C}$ limit the application of this alloy-clad combination with helium coolant. The design constraints for this fuel are well understood so the steady-state performance can be reliably predicted. No transient experiments have been performed, however, so response to pulsed power operation is unknown.

- Carbide Fuel - Design information exists for carbide fuel in two forms. Stainless steel clad pins have been studied extensively as advanced fuel for LMFBR's. Although irradiation performance must yet be verified, experimental programs have been identified and await operation of the Fast Flux Test Facility (FFTF) for obtaining extensive irradiation data. Burnups of 100,000 MWd/per metric tonne of heavy metal are anticipated for fast reactor carbide fuels. The higher allowable linear heat rating ( $35 \mathrm{~kW} / \mathrm{ft}$ compared to $18 \mathrm{~kW} / \mathrm{ft}$ for oxide) will not be fully utilized in a hybrid blanket, so the incentive for carbide fuel in this form is primarily neutronic (higher atom density of $U$ or Th). The transient response of this type of fuel is unknown. However, the analytical methods developed from current oxide fuel tests are expected to form a good basis for predicting carbide fuel pin performance.

The other geometrical form of carbide fuel is the coated particle technology developed as part of the High Temperature Gas Cooled Reactor (HTGR) Program in this country and the gas cooled 
reactor program in Germany. The coated particles are TRISO or BISO coated beads 200 to $500 \mu \mathrm{m}$ in diameter. The beads are imbedded in either a spherical graphite matrix (Germany) or mixed with graphite in pellet form and put in channels in a graphite block (HTGR). Extensive experience in helium cooled systems is available for estimating irradiation performance. Burnups greater than 100,000 MWd/MTHM are achieved at a relatively low power density $(10 \mathrm{~kW} / \mathrm{l})$. Because the transient response of this fuel form has been studied extensively as part of the HTGR Safety Program, adequate methods exist for the preliminary determination of response to pulse power cycles.

- Silicide Fuel - Uranium silicide $\left(U_{3} S i\right)$, a metallic type fue 1 form, was developed as part of the CANDU Program at AECL and has been proposed in some hybrid blankets. Irradiation experiments with fuel exposure to 25,000 MWd/MTHM conducted by AECL show 1ittle swe1ling. The fuel has shown an ability to handle large step increases in power, which is important to pulsed power operation. Its linear heat rating is $20 \%$ better than $\mathrm{UO}_{2}$ at $500^{\circ} \mathrm{C}$ surface temperature. Maximum fue 1 temperature must be maintained below $900^{\circ} \mathrm{C}$, which may limit the fuel's application in helium-cooled systems. Compatibility of $\mathrm{U}_{3} \mathrm{Si}$ with liquid metal coolants and high-temperature clad materials is unknown.

- Molten Salts - Molten salts have been proposed for hybrid blanket application, primarily to alleviate fuel movement problems in the complex geometries and because tritium separation would be relatively easy. Although the molten salt reactor experiment (MSRE) demonstrated the feasibility of the concept; however, many technological areas that require development remain. Molten salt is compatible with stainless stee 1 up to $500^{\circ} \mathrm{C}$ and with graphite to $600^{\circ} \mathrm{C}$. Above that temperature Hastelloy-N must be used. The nickel in Hastelloy may produce sufficient He in a $14 \mathrm{MeV}$ neutron field to make embrittlement a problem. Although a development 
program has been defined for molten salt fission reactors, it has not been implemented, so the bases for blanket design and salt processing system are very uncertain.

If the various fuel forms are ranked in order of available technology, the list would be:

1. oxide fuel in stainless steel clad pins

2. coated particle carbide fuel

3. U-Mo alloy fuel in stainless steel clad pins

4. carbide fuel in stainless steel clad pins

5. molten salt fuel

6. silicide fuel in pins.

The degree to which technology base should influence the selection of fuel form, cladding and coolant is a topic for discussion. However, designs proposed for near-term application would be expected to weight available technology heavier than designs proposed for ultimate commercial application. On the basis of the near term application of hybrids, available or newly developed blanket fuels were selected.

The Once-Through and Pu-Recycle blanket designs have the following fuel form, cladding and coolant combination.

Fue $1 \quad-$ UC in rods

Cladding - 316 SS

Coolant - Helium

There is no basis for accurately predicting the performance of this combination. The overall performance expected from this blanket is superior enough to outweight the technological uncertainty. The Refresh blanket design has the fuel form, cladding and coolant combination of:

$$
\begin{aligned}
& \text { Fuel }-\mathrm{UO}_{2} \\
& \text { Cladding }-316 \mathrm{SS} \\
& \text { Coolant - Helium }
\end{aligned}
$$

The fuel and cladding combination for this blanket is very familiar and have had extensive use in the LWR industry. The fourth fuel cycle, Pu-Catalyst, has the following blanket composition: 


$$
\begin{array}{lll}
\text { Fuel } & -\mathrm{PuO}_{2} / \mathrm{UO}_{2} & \text { (Convertor Region) } \\
& -\mathrm{ThC} & \text { (Breeding Region) } \\
\text { Cladding } & -316 \mathrm{SS} \\
\text { Coolant } & - \text { Helium }
\end{array}
$$

This particulr fuel cycle will draw heavily on technology developed in the LMFBR program.

\section{TRITIUM BREEDING MATERIAL CANDIDATES}

The lithium compound selected as the tritium breeding material must satisfy several requirements. The tritium breeding compound must possess good neutronic and irradiation characteristics as well as exhibit good chemical stability at blanket operating temperatures. The selected lithium compound must release tritium at a rate that will not allow an excessive tritium inventory in the blanket modules. Lithium compounds fall into three classes: metallic, salts and ceramics.

- Liquid Lithium - Liquid lithium contained in stainless steel rods could be a potential tritium breeding candidate. The tritium removal would be complicated, however, by the high solubility of tritium in lithium. The blanket module tritium inventory would be very high.

- Metallic Compounds - Metallic compounds of lithium with $\mathrm{Al}, \mathrm{Bi}, \mathrm{Pb}$, Si and $S n$ may be useful for hybrid blankets. The metallic compounds show the appearance of liquid phases at low temperatures as the lithium atoms are transmuted by nuclear reactions in the blanket. The radiation stability of these compounds has not been established.

- Nonmetallic Compounds - The oxide-bearing ceramics have the highest melting points, except for the carbide. The compound $\mathrm{Li}_{2} \mathrm{O}$ has a high melting point and a high lithium atom density, although its vapor pessure prohibits its use above $21400^{\circ} \mathrm{C}$. It also has a strong affinity for water and carbon dioxide. The reaction,

$$
\mathrm{Li}_{2} \mathrm{O}+\mathrm{H}_{2} \mathrm{O}=2 \mathrm{LiOH}
$$


has calculated free energy change at $298^{\circ} \mathrm{K}$ of $-22.7 \mathrm{kcal}$ so that the equilibrium vapor pressure of $\mathrm{H}_{2} \mathrm{O}$ at $298^{\circ} \mathrm{K}$ is $210^{-14}$ torr. Consequently, the dry powder would be difficult to fabricate without producing some $\mathrm{LiOH}$, which must be dehydrated at an elevated temperature after assembiy.

Because lithium oxide compounds with $\mathrm{Al}_{2} \mathrm{O}_{3}$ and $\mathrm{SiO}_{2}$ have much lower affinity for carbon dioxide and water, these compounds could be fabricated in dry boxes. The melting point of its lithium rich compound, $\mathrm{LiAlO}_{2}$, has been reported between $1610^{\circ}$ and $1700^{\circ} \mathrm{C}$. Such determinations were difficult because of the vaporization of $\mathrm{Li}_{2} \mathrm{O}$, which began $\sim 1400^{\circ} \mathrm{C}$ and caused a change in the composition of the sample. A eutectic liquid reported at $\sim 1670^{\circ} \mathrm{C}$ between the compounds $\mathrm{Li}_{2} \mathrm{AlO}_{2}$ and $\mathrm{LiAl}_{5} \mathrm{O}_{8}$ would form as the lithium in the compound $\mathrm{LiAlO}_{2}$ is transformed by the neutron irradiation. The appearance of this liquid and the vaporization of lithia limits the usefulness of the compound to $<1400^{\circ} \mathrm{C}$. The desire to avoid excessive sintering of the ceramic compound, $\mathrm{LiAlO}_{2}$, limits its usefulness above $1300^{\circ} \mathrm{C}$.

Lithium ortho-silicate, $\mathrm{Li}_{4} \mathrm{SiO}_{4}$, and meta-silicate, $\mathrm{Li}_{2} \mathrm{SiO}_{3}$, are stable compounds that may be useful. The ortho-silicate has a high lithium atom density. The ortho-silicate melts, however, by a reaction with $\mathrm{Li}_{2} \mathrm{O}, 1255^{\circ} \mathrm{C}$, and the rapid vaporization of lithia at this temperature has been reported. Also, as the lithium in the ortho-silicate transforms as a result of neutron irradiation, a eutectic liquid forms at $1024^{\circ} \mathrm{C}$ between the ortho and metasilicates; consequently, the useful temperature limit of the ortho-silicate is $<1000^{\circ} \mathrm{C}$.

In addition to the oxide ceramics, the carbide of a metal is often a stable compound. Lithium forms a single carbide, $L i_{2} C_{2}$, which reacts readily with water to yield acetylene. Although the detailed crystal structure of this compound has not been reported yet, it probably exists as a salt in which the carbon atoms form a dimer similar to $\mathrm{CaC}_{2}$, so that it is not a stable high temperature compound. 
The lithium halide salt, LiF, has a high lithium atom density, but its relatively low melting and boiling points probably limit its usefulness. Also, the tritium that is generated in a fluoride salt would be released as molecular TF which may cause potentially serious corrosion problems if released into the helium coolant. Consequently, a low temperature fused salt mixture would have to be circulated to external equipment for removal of the TF, as has been proposed previously.

Lithium hybrid or deuteride have many desirable neutronic characteristics as a potential tritium breeding material or neutron moderators. Their low melting point and high hydrogen pressure pose serious limitations on their usefulness, however.

Some of the thermai and physical characteristics of potential tritium breeding compounds are shown in Table 5.1 .

\section{COOLANTS}

In assessing the technological bases for coolant selection and performance, several areas need to be considered:

1. status of power conversion system components

2. availability of design analysis methods and supportive data bases

3. compatibility with fuel form, cladding and structural materials

4. compatibility with tritium processing requirements

5. knowlege of magnetic field effects

6. ability to predict safety performance.

In selecting a blanket coolant, the plant power conversion system must be considered. The plant efficiency versus peak cycle temperature for both the conventional steam and gas turbine cycles are shown in Figure 5.1. These curves point out that to maintain blanket structural material temperatures within currently available technology, the conventional steam turbine generator will be employed. Therefore, whatever coolant is selected, the heat transport system must be made compatible with ultimate transfer of heat to a modern steam system. 
TABLE 5.1. Breeding Compound Characteristics(a)

\begin{tabular}{|c|c|c|c|c|c|c|}
\hline Liquid lithium & $\begin{array}{c}\text { Lithium } \\
\text { Density } \\
\text { (atoms/barn } \mathrm{cm} \text { ) } \\
0.042\end{array}$ & $\begin{array}{l}\text { Melting } \\
\text { Point } \\
\left(C^{0}\right) \\
180\end{array}$ & $\begin{array}{l}\text { Tritium } \\
\text { Retention } \\
\text { High }\end{array}$ & $\begin{array}{l}\text { Multiplier } \\
\text { Needed } \\
\text { Yes }\end{array}$ & $\begin{array}{l}\text { Chemically } \\
\text { Stable } \\
\text { Yes }\end{array}$ & $\begin{array}{l}\text { Reacts } \\
\text { with Air } \\
\text { Violently }\end{array}$ \\
\hline $\begin{array}{l}\text { Flibe } \\
\qquad\left(\begin{array}{lllll}47 & \mathrm{LiF} & 53 & \mathrm{BeF}_{2}\end{array}\right)\end{array}$ & 0.014 & 360 & Low & No & Yes & No \\
\hline \multicolumn{7}{|l|}{ Solid compounds: } \\
\hline LiAl & 0.027 & 718 & Very low & Yes & Yes & Slowly \\
\hline $\mathrm{LiAlH}_{4}$ & 0.041 & 1625 & $?$ & Yes & (Dehydride) & $?$ \\
\hline $\mathrm{LiAl0}$ & 0.023 & 1700 & Very low & Yes & Yes & No \\
\hline $\mathrm{Li}_{4} \mathrm{Si}$ & 0.013 & 635 & $?$ & No & $?$ & $?$ \\
\hline $\mathrm{Li}_{2} \mathrm{SiO}_{3}$ & 0.034 & 1204 & Very low & yes & Yes & No \\
\hline $\mathrm{Li}_{4} \mathrm{SiO}_{4}$ & 0.050 & 1256 & Very low & Yes & Yes & No \\
\hline $\mathrm{Li}_{7} \mathrm{~Pb}_{2}$ & 0.083 & 726 & Very low & No & Yes & Slowly \\
\hline $\mathrm{Li}_{3} \mathrm{~N}$ & 0.041 & 800 & $?$ & No & $?$ & Slowly (?) \\
\hline $\mathrm{Li}_{3} \mathrm{Bi}$ & 0.040 & 1145 & $?$ & No & Yes & Slowly (?) \\
\hline $\mathrm{Li}_{2} \mathrm{Be}_{2} \mathrm{O}_{2}$ & 0.038 & 1150 & $?$ & No & Yes & No \\
\hline $\mathrm{Li}_{2} \mathrm{O}$ & 0.082 & 1700 & Very low & No & No (?) & No \\
\hline $\mathrm{LiOH}$ & 0.037 & 471 & $?$ & Yes & Yes & No \\
\hline $\mathrm{LiH}$ & 0.059 & 686 & $?$ & Yes & ? (Dehydride) & NO \\
\hline
\end{tabular}

(a) Conceptual Design Study of a Non-Circular Tokamak Demonstration Fusion Power Reactor, 1976. 


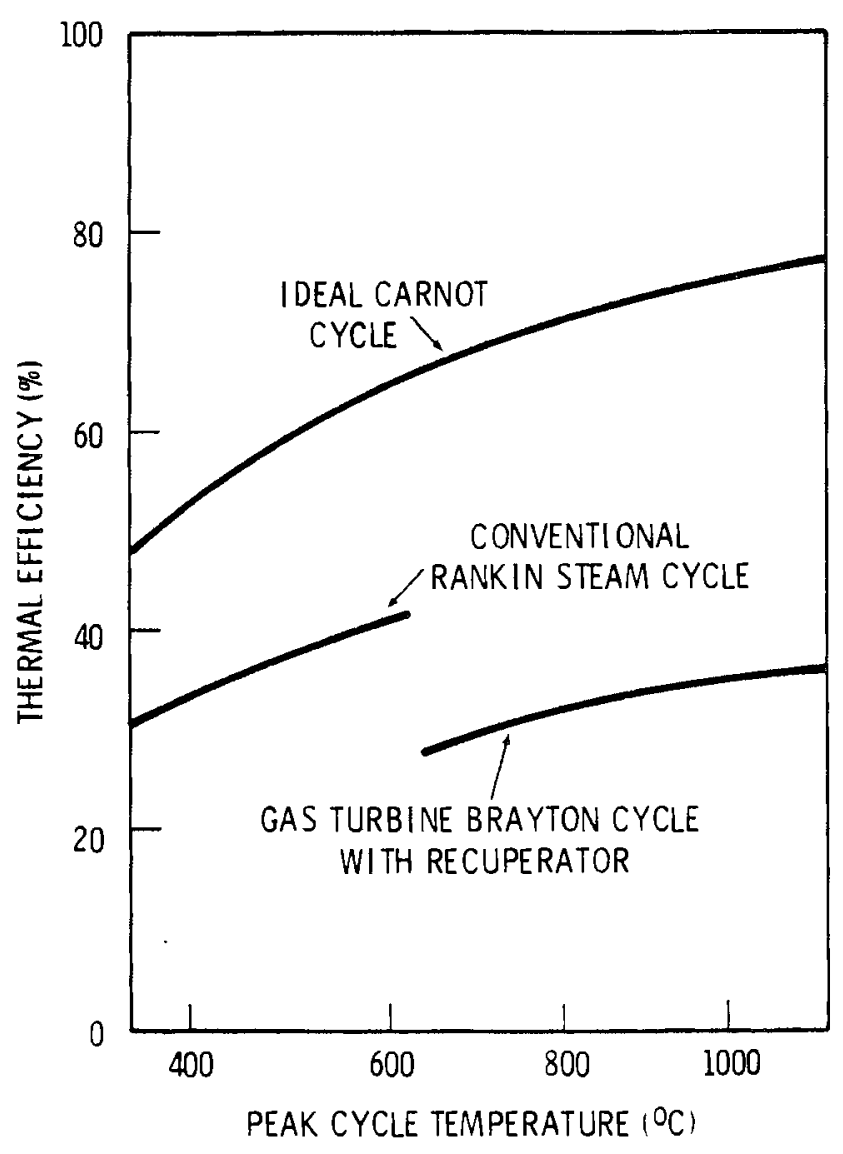

FIGURE 5.1. Thermal Efficiency of Typical ThermoDynamic Cycles as a Function of Peak Cycle Temperature

Coolant compatibility with the fission fuel form and cladding is really the only difference in selection of blanket coolant for a hybrid as opposed to a pure fission reactor.

- Water Coolant - In all the areas of technology previously mentioned, the most is known about water as a coolant. Extensive R\&D in the LWR Program has developed an adequate data base and design methods to predict water-cooled blanket performance. However, water has not been considered as a blanket coolant to date because it is nearly impossible to remove tritium from water. In LWRs, tritium releases outside the plant are controlled simply by limiting the generation 
of tritium. Impurities ( $L i$ ) in the core are reduced to levels that limit the tritium production to amounts that can be released from the plant.

- Helium Coolant - the HTGR and German Cooled Gas Reactor programs have developed and demonstrated helium-cooled power conversion system technology. Helium is compatible with all structural mater-ials with the exception of refractory metals and alloys. The impurity levels attainable in real systems result in corrosion prob- lems for the refractories.

To get adequate heat transfer and transport properties, helium systems have to be operated at relatively high pressures (50 to 70 atms). In the complex geometries of hybrid blankets, this results in a requirement for structural material fractions that increases parasitic absorption of the neutrons. Where cladding and structural materials are stainless steel, helium-cooled systems yield 30\% power conversion efficiency. If higher temperature alloys (TZM, Inconel, etc.) are used, efficiencies approaching $40 \%$ are projected. Helium has good neutronic properties with no anticipated MHD or corrosion enhancement effects in magnetic fields.

- Liquid Metal Coolants - The LMFBR program is developing data and system components for $\mathrm{Na}$ cooled systems. The major uncertainities in $\mathrm{Na}$ cooled systems are the MHD effects in rapidly changing highmagnetic fields and the effects of magnetic fields on corrosion and mass transport rates. Due to enhanced heat transfer, higher sodium temperatures can be achieved with stainless steel structural materials and thus power conversion efficiencies near $40 \%$ can be achieved without the use of high temperature alloys. The LMFBR Program is also developing for $\mathrm{Na}$ coolant an extensive data base that will be directly applicable to assessing hybrid performance.

The use of liquid $L i$ as a coolant has not been investigated for a hybrid blanket. Although it is attractive neutronically for producing tritium, the technology base for $L i$ is uncertain. Because $L i$ appears to be more corrosive 
than $\mathrm{Na}$, operating temperatures must be lower $\left(50^{\circ} \mathrm{C}\right)$ to be compatible with stainless steel, resulting in lower power conversion efficiency. The increased corrosion and mass transport rates result in uncertainty in the applicability of current $\mathrm{Na}$ power conversion system components.

Because liquid metals can be used at low pressures, they result in low structural material requirements. Where magnetic field effects are not important (vertical confinement applications) designers have proposed using both $\mathrm{Na}$ and $\mathrm{Li}$ as coolants, thus maximizing the use of R\&D benefits from the LMFBR Program.

If candidate coolants are ranked by the available technology base, they would fall in the following order:

1. water coolant

2. helium coolant

3. sodium coolant

4. lithium coolant.

The blanket coolant selected for this study is helium because it is unaffected by magnetic fields and is compatible with tritium breeding and recovery concepts.

\section{SECTION 5.0 REFERENCES}

Conceptual Design Study of a Non-Circular Tokamak Demonstration Fusion Power Reactor. 1976. GA-A13992, General Atomic Co., San Diego, CA. 


\subsection{ECONOMICS AND COMMERCIAL FEASIBILITY}

A cost assessment of constructing and operating the fusior-fission (hybrid) power reactor and fuel cycle concepts introduced in the technical sections of this report is contained in this chapter. Estimates of the Tokamak Hybrid Reactor (THR) system capital investment costs, operating and maintenance costs, and fuel cycle costs are developed along with projections of the resulting levelized energy costs or unit electricity costs. Also developed are estimates of the break-even fissile values (i.e., the projected selling value of the fissile fuel material produced in a commercial fusionfission reactor system). Projections of the extent to which the systems will be commercially deployable are given along with estimates of the economic benefits that would accrue due to this deployment. An appraisal of the specific economic penalties of utilizing proliferation resistant devices and fuel cycles is also made.

\section{GROUND RULES AND ASSUMPTIONS}

The ground rules and assumptions utilized in estimating fusion-fission reactor system costs are given in Table 6.1. These parameters were specified to ensure consistency in all phases of the evaluations.

\section{CAP ITAL INVESTMENT COSTS}

Capital investment cost or plant cost is the total cost of constructing the hybrid reactor and placing the reactor into operation (Schulte, Willke and Young 1973). Estimated THR capital investment costs for each of the blanket combinations identified in this study are given in Tables 6.2 and 6.3. Detailed cost estimates are given in Appendix A.

Estimates of reactor capital investment costs were generated on the assumption that the reactor is a commercial generating unit of optimal economic size (Guide 1969; Index 1979). The systems were costed assuming a mature industry (i.e., fifth facility of a like technology constructed), thereby excluding development and "first of a kind" costs from estimates. The following cost items or activities are excluded from estimates: 
TABLE 6.1. Economic Parameters/Unit Costs

General Economic Conditions

Rate of General Inflation

Escalation Rate for Capital Investment Costs

Escalation Rate for Operating \& Maintenance Costs

Escalation Rate for Fuel cycle Costs

Base Year for Constant Dollar Analysis

System Description Data

Assumed First Year of System Construction

System Operating Lifetime4

System Construction Period
Assumed Value

0
0
0
0
1978

1978
30 years
8 years

0.02

0.0025

0.40

0.50

0.40

0.10

0.03

0.07

0.03

Fission Fuel Cycle Unit Costs

Cost of Fertile Material (UC)

Cost of Fertile Material $\left(\mathrm{UO}_{2}\right)$

Cost of Fertile Material (Depleted Uranium)

Cost of Fertile Material (ThC)

Cost of Fertile Material $\left(\mathrm{ThO}_{2}\right)$

Cost of Blanket Fabrication

Cost of Reprocessing Spent Fertile Fuel

Cost of Shipping Spent Fertile Fuel

Plutonium Value (i.e., Pu Credit) \& $\$ 75 / \mathrm{kg}$

Separative Work

Cost of Spent Fertile Fuel Disposal

Cost of Waste Disposal (w/o Fissile Material)
$\$ 120 / \mathrm{kg}$ Heavy Metal

$\$ 100 / \mathrm{kg}$ Heavy Metal

$\$ 7 / \mathrm{kg}$

$\$ 55 / \mathrm{kg}$ Heavy Metal

$\$ 35 / \mathrm{kg}$ Heavy Meta 1

To be calculated

for each driver/

fuel cycle combination

$\$ 160 / \mathrm{kg}$ Heavy Meta 1

$\$ 25 / \mathrm{kg}$ Heavy Metal

$\$ 33 /$ gram Fissile

$\$ 95 / \mathrm{kg}$ Heavy Metal

$\$ 20 / \mathrm{kg}$ Heavy Metal

\section{Fusion Fuel Cycle Unit Costs}

Cost of Deuterium

Cost of Tritium

Cost of Lithium
$\$ 60 / \mathrm{kg}$

$\$ 1,200,000 / \mathrm{kg}$

$\$ 200 / \mathrm{kg}$ 
Fusion Fuel Cycle Unit Costs (Continued)

Cost of Blanket Fabrication

Cost of Reprocessing Lithium

Cost of Shipping Lithium

Accompanying Fission Reactors (LWR Complex)

Cost of Fission Reactor

Cost of Fabricating Mixed-0xide Fuel

Cost of Reprocessing Spent Fertile Fuel

Cost of Shipping Spent Fertile Fuel

Operating and Maintenance Costs/Yr/MWe
To be calculated

for each driver/

fuel cycle combination.

$\$ 100 / \mathrm{kg}$

$\$ 25 / \mathrm{kg}$

$\$ 650 / \mathrm{kWe}$

$\$ 245 / \mathrm{kg}$ Heavy Metal

$\$ 160 / \mathrm{kg}$

$\$ 25 / \mathrm{kg}$

$\$ 5000$

TABLE 6.2. Capital Investment Cost Summary(a)(b)(c)

\begin{tabular}{lc} 
Fuel Cycle & Cost $\left(\$ 10^{6}\right)$ \\
\hline Pu Producing & 2074 \\
U-Pu Catalyst & 2610 \\
Refresh & 1990
\end{tabular}

(a) June 1978 price.

(b) Interest and escalation costs during construction not included.

(c) Hybrid reactor costs only.

TABLE 6.3. Capitol Investment Cost Summary(a)(b)(c)

\footnotetext{
(a) June 1978 price levels.

(b) Interest and escalation costs during construction not included.

(c) Hybrid reactor costs only.
} 
1. switchyard and transmission facility

2. escalation during construction (computed in levelized energy cost calculations.

3. escalation prior to construction

4. decommissioning

5. research and development

6. working capital

7. interest during construction (computed in levelized energy cost calculations).

Blanket costs are also excluded from the capital investment cost estimates (included in the fuel cycle cost estimates). June 1978 price levels are assumed in all estimates.

\section{BLANKET COSTS}

Blanket costs consist of 1 ) purchasing the structural material and cladding components used in the blanket assemblies, and 2) fabricating the assemblies. The costs of blanket fuel materials are not included as blanket costs. Structural material and cladding costs (i.e., material costs) consist of material purchase costs and the costs of material losses during fabrication in this study assumed to be $5 \%$ of the material requirements. Fabrication costs include labor, assembly expense, and the overhead costs on the plant and equipment used in the manufacture of the blankets. All blanket costs are tabulated for as fuel cycle expenses.

Material requirements for blanket assemblies are based on driver geometries and blanket configurations. The middle regions of the blankets containing fuel material, stainless steel, and lithium dioxide were used as the basis for the blanket cost calculations.

\section{ANNUAL OPERATING AND MAINTENANCE COSTS}

Annual operating and maintenance costs are the routine day-to-day expenses required to operate the reactor system and include the costs of

\section{4}


operating staff salaries, supplies, maintenance materials, process chemicals, routine maintenance, and replacement of major reactor components such as blanket assembly modules. Estimated THR annual operating and maintenance costs for each of the blanket combinations identified in this study are given in Table 6.4.

TABLE 6.4. Annual Operating and Maintenance Cost Summary $(a)(b)$

$\begin{array}{lc}\text { Fuel Cycle } & \text { Cost }\left(\$ 10^{6}\right) \\ \begin{array}{l}\text { Pu Recycle/ } \\ \text { Once Through }\end{array} & 41 \\ \text { U-Pu Catalyst } & 52 \\ \text { Refresh } & 40\end{array}$

(a) June 1978 price levels.

(b) Hybrid reactor costs on $1 y$.

FUEL CYCLE COSTS (HYBRID/FISSION REACTOR SYSTEM)

Fuel cycle costs are the costs of operating the fuel material supply/ discharge cycle that services the fusion-fission reactor system. For some systems, fuel cycles are relatively simple, involving only fuel preparation activities before fusion-fission reactor charging and spent fuel disposal activities after fusion-fission reactor discharging. For other systems, fuel cycles are more complex, some involving the coupling of fusion-fission reactors into systems with conventional fission reactors - the fusion-fission reactor producing the fissile fuel, the conventional fission reactors consuming the fissile fuel. Regardless of the complexity of the fuel cycle, all system costs incurred for fuel material purchase, preparation, processing, storage, transportation, and disposal are considered fuel cycle costs.

Estimated fusion-fission reactor fuel cycle costs for the THR reactor driver/fuel cycle combinations identified in this study are given in Table 6.5. Detailed fuel cycle cost estimates are given in Appendix B. Costs are reported as levelized fuel cycle costs per unit of electricity generated (see 9.0 for description). Parameters and unit cost assumptions used in calculations are given in Table 6.1. 
TABLE 6.5. Fuel Cycle Cost Summary $(\mathrm{Mi} 1 \mathrm{ls} / \mathrm{kWh})(\mathrm{a})(\mathrm{b})$

\begin{tabular}{lc} 
Fuel Cycle & Cost $(\mathrm{mills} / \mathrm{kW} \mathrm{hr}$ \\
\cline { 1 - 1 } Once-through & $5-4$ \\
Pu Recycle & $3-0$ \\
U-Pu Catalyst & $2-6$ \\
Refresh & $2-0$
\end{tabular}

(a) June 1978 price levels.

(b) Complete hybrid/LWR system costs.

\section{LEVELIZED ENERGY COSTS}

Levelized energy cost or unit electricity cost is the average cost per unit of generated electricity over the reactors operating lifetime (i.e., the average price that must be charged per unit of electricity generated to recover all costs of constructing and operating the reactor system). Capital investment costs, operating and maintenance costs and fuel cycle costs are expenses incurred in constructing and operating the reactor system, and are therefore, used as input for levelized energy cost calculations. Estimated fusion-fission reactor system levelized energy costs for each reactor driver/ fuel cycle combination identified in this study are given in Table 6.6. Detailed estimates of levelized energy costs are given in Appendix $B$.

TABLE 6.6. Levelized Energy Cost Summary (Mills $/ \mathrm{kWh})(\mathrm{a})(\mathrm{b})(\mathrm{c})$

\begin{tabular}{lc} 
Fuel Cycle & Cost $(\mathrm{mills} / \mathrm{kW} \mathrm{hr}$ \\
\hline Once-through & $46-81$ \\
Pu Recycle & $18-25$ \\
U-Pu Catalyst & $15-76$ \\
Refresh & $18-57$
\end{tabular}

\footnotetext{
(a) June 1978 price levels.

(b) Complete hybrid/LWR system costs.

(c) Levelized energy cost for a plutonium recycle LWR system is $15.2 \mathrm{mi} 11 \mathrm{~s} / \mathrm{kWh}$.
} 
Levelized energy costs were estimated using the general economic condition input parameters and utility description data input parameters listed in Table 6.1. Input parameters assume a real or deflated dollar analysis (i.e., input parameters reflect values that would be found if there were no inflation). A real cost of capital of $4 \% /$ year and no cost escalation were assumed.

Levelized energy cost estimates may vary considerably for similar systems due to differences in the input parameters and the estimating methodology used. This study used a discounted cash flow/levelized energy cost estimating methodology.

The relationship between the annual unit cost of generating electricity and the levelized energy cost is shown graphically in Figure 5:1. Annual capital investment costs are fixed by the initial financing and are constant over the system's operating lifetime. Because operating and maintenance costs and fuel cycle costs typically increase over time as affected by inflation and

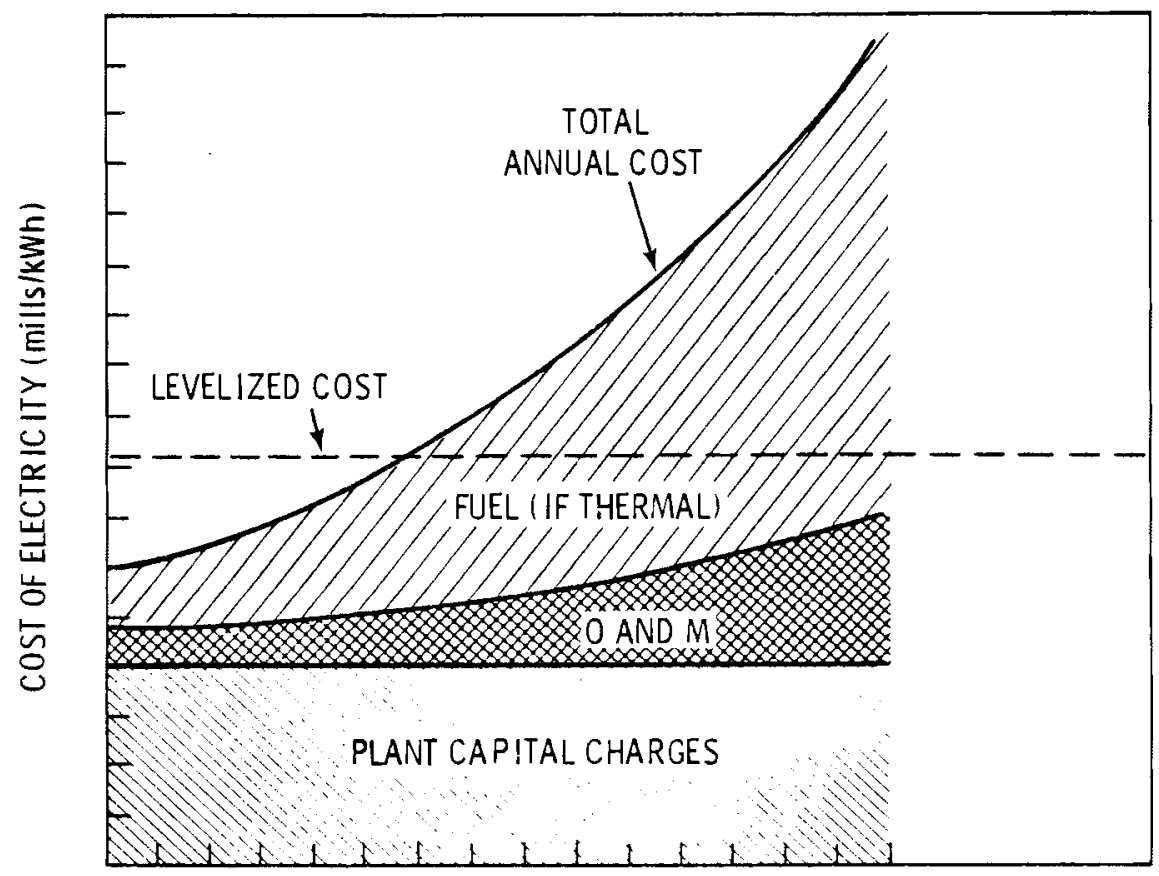

TIME (years)

FIGURE 6.1. Annual Cost of Electricity and Levelized Energy Cost 
real fuel price increases, the annual cost of generating electricity increases over time. The levelized cost or levelized energy cost is simply a present valued average measure of the increasing total annual costs.

\section{FISSILE FUEL VALUE}

A second criteria for judging the economic attractiveness of a particular fusion-fission reactor system is the value of the selling price of the fissile fuel produced. This fissile fuel value or breakeven value is defined as the price at which reactor breed fissile fuel could be sold, assuming the producing reactor is operating competitively. For reactor systems with relatively small construction and operating costs, revenues from fissile fuel sales need not be 1 arge to allow the reactor system to operate competitively. Under these conditions, the fissile fuel value would be low. For reactor systems with greater construction and operating costs, revenues from fissile fuel sales must be greater (to offset increased construction and operating costs), resulting in higher fissile fuel values. In this study, a fusion-fission reactor system (producing fissile fuel) is assumed to be operating competitively if its levelized energy cost is equivalent to the levelized energy cost of a conventional LWR plutonium recycle system. Fissile fuel breakeven values for both a fissile plutonium production/sell fuel cycle for the THR are given in Table 6.7.

TABLE 6.7. Fissile Fuel Breakeven Values(a)

$\begin{array}{lc}\frac{\text { Fuel }}{\text { Fissile plutonium }} & \text { Value (\$/gram) } \\ \text { Fissile uranium } & 130\end{array}$

(a) June 1978 price levels.

\section{MARKET PENETRATION}

Fusion-fission reactor systems will not commercially deploy until the present value benefits of a sustained commercial fusion-fission economy become positive. Projections of the extent to which the fusion-fission reactor 
systems identified in this study would deploy as commercial power generating systems and the resulting economic benefits accruing to society due to this deployment are described.

The benefits resulting from deployment are best measured as present value benefits or present value energy generation cost savings resulting from displacement of expensive alternative energy sources by cheaper fusion-fission reactor systems. For this reason, the benefits resulting from fusion-fission reactor system deployment are sensitive to the generating costs of alternative energy sources. Two different alternative energy source situations or scenarios are examined in this study. These scenarios are described in Table 6-8.

TABLE 6.8. Energy Supply Scenarios

$\begin{array}{lccc} & \text { Scenario 1 } & & \text { Scenario 2 } \\ \text { LMFBR Availability } & \text { None } & & 1993 \\ \text { CTR Availability } & 2010 & 2010 \\ \text { Fusion-Fission Availability } & 2000 & & 2000 \\ \text { Electricity Demand } & \text { Moderate/High } & \text { Moderate/High }\end{array}$

Examination of the estimated costs of the fusion-fission reactor systems identified in this study revealed that none of the systems would be economically competitive energy sources (i.e., all reactor systems were estimated to be more costly to construct and operate than alternative electricity generating sources). Therefore, this assessment of market penetration potential is aimed at identifying the reduction in estimated system costs that would have to occur before fusion-fission systems could be projected to be competitive energy generation sources.

"Capitalized costs" are used as the aggregate measure of system construction and operating cost. Capitalized costs are comprised of 1) the initial capital investment cost (i.e., plant cost), 2) the present value of all fuel cycle cost streams (except purchase costs and sales revenues of nuclear materials) over the systems operating lifetime, and 3) the present value of al1 interim capital replacement cost streams over the system's operating lifetime. This cost measure does not include plant operating and maintenance 
costs, costs or credits for electricity use or generation, nuclear fuel purchases or credits, taxes, and insurance costs. Capitalized costs and other measures of system performance are given in Table 6.9.

TABLE 6.9. Market Penetration Assessment(a) Economic and Performance Parameters

\begin{tabular}{lc}
\multicolumn{1}{c}{ Parameter } & Estimated Value \\
\hline Capital Costs (b) & 2696 \\
Fissile Fuel Production & 1950 \\
(kg/hr) & \\
$\begin{array}{l}\text { Reactor Thermal Power } \\
\text { (MWth) }\end{array}$ & 4144 \\
Net Electric Output & 1000 \\
(MWe) &
\end{tabular}

(a) Plutonium producing blanket assumed. (b) June 1978 price levels.

The extent to which the identified fusion-fission reactor systems can be expected to deploy are given in Table 6.10 for the Scenario 1 energy supply

TABLE 6.10. Market Penetration Assessment/Scenario 1

Assumptions: 1) Moderate-High Electricity Demand

2) No LMFBR Availability

3) Year 2000 Fusion-Fission Availability

4) Year 2010 Pure Fusion Availability

\begin{tabular}{|c|c|c|c|}
\hline Driver & $\begin{array}{l}\text { Capitalized Cost }(a)(c) \\
(\$ / k W \text { th })\end{array}$ & $\begin{array}{l}\text { Number of } 2500 \text { Mwth } \\
\text { Fusion-F ission Power } \\
\text { Reactors Operating } \\
\text { in Year } 2030 \\
\end{array}$ & $\begin{array}{l}\text { PV Benefits } \\
\text { to } \\
\text { Year } 2040 \\
\end{array}$ \\
\hline \multirow[t]{3}{*}{ Tok amak } & 650 (Estimated Cost) & -- & Negative \\
\hline & 540 & 0 & 0 \\
\hline & 430 & 600 & 10 Billion \\
\hline
\end{tabular}

(a) June 1978 price levels.

(b) $8.8 \% /$ yr discount rate.

(c) Plutonium Recycle Fuel Cycle. 
situation. Deployment projections assuming a Scenario 2 energy supply situation are given in Table 6.11. Fusion-fission system deployment is stated both in terms of the number of fusion-fission power reactor plants operating in the year 2030 and in terms of the present value benefits through year 2040 of deployment. Reductions in estimated capitalized costs required to make system projections look economically competitive and deployable are also given.

TABLE 6.11. Market Penetration Assessment/Scenario 2

Assumptions: 1) Moderate-High Electricity Demand

2) No LMFBR Availability

3) Year 2000 Fusion-Fission Availability

4) Year 2010 Pure Fusion Availability

\begin{tabular}{|c|c|c|c|}
\hline Driver & $\begin{array}{l}\text { Capitalized Cost }(a)(c) \\
(\$ / \text { kWth })\end{array}$ & $\begin{array}{l}\text { Number of } 2500 \text { MWth } \\
\text { Fusion-Fission Power } \\
\text { Reactors Operating } \\
\text { in Year } 2030 \\
\end{array}$ & $\begin{array}{c}\text { PV Benefits } \\
\text { to } \\
\text { Year } 2040 \\
\end{array}$ \\
\hline \multirow[t]{3}{*}{ Tokamak } & 650 (Estimated) & -- & Negative \\
\hline & 460 & 0 & 0 \\
\hline & 360 & 500 & 10 Billion \\
\hline
\end{tabular}

(a) June 1978 price levels.

(b) $8.8 \% / y r$ discount rate.

(c) Plutonium Recycle Fuel Cycle.

NONPROL IFERATION IMPACT

When the economics of proliferation resistant fusion-fission systems are assessed, one characteristic quickly becomes evident. The additional costs of utilizing nonproliferation mechanisms in fusion-fission systems, given that the systems are developed with adequate planning and integration, are not greatly relative to the total costs of constructing and operating the systems. Preliminary estimates have indicated that when properly implemented, proliferation resistant fusion-fission power generating systems would yield power costs only $8 \%$ greater than power costs of fusion-fission systems not specifically planned to be proliferation resistant. Five mechanisms have been 
identified as candidates for making fusion-fission systems more proliferation resistant. These mechanisms and their expected costs of implementation are discussed below.

\section{Nuclear Center}

The concept of an institutionalized nuclear center is very attractive. The primary advantage of such centers is a lessened opportunity for nuclear material diversion resulting from reduced nuclear material shipping distances. Increased system costs would be primarily due to increased transmission distances. Given that centers are properly situated, decreased costs could result from lessened licensing problems, lessened construction and operating worker impacts, and sharing of common facilities. In addition, cost decreases could result from shortened nuclear material shipping distances and use of an integrated security system for all facilities. The generating costs of a proliferation resistant fusion-fission system located within a nuclear center very likely would be less than the costs of a decentralized fusion-fission system with much greater potential for proliferation.

\section{"Throw Away" Fuel Cycle}

A second method for alleviating fissile material proliferation is to "throw away" or dispose of the fusion-fission reactor spent fuel blanket containing the fissile materials. However, such disposal would penalize the fusion-fission systems as their primary function lies as fissile fuel breeders. The specific economic penalty of utilizing a throw-away fuel cycle can be approximated from results obtained in this study. Once-through "throw away" fuel cycle systems are projected to operate at levelized energy costs of 40 mills/kWh greater than reprocessing fuel cycle systems. Given an average demand for nuclear center generated electricity between the years 2000 and 2030 of 1,000 GWe $(2.6 \times 1014 \mathrm{kWh}$ cumulative), the economic cost of utilizing the proliferation resistant "throw away" cycle between these years is in excess of 10 trillion dollars.

\section{Co-processing}

Coprocessing is a third mechanism for reducing fusion-fission system proliferation potential. Fusion-fission system cost reductions with coprocessing 
would result from lessened spent fuel reprocessing requirements. Coprocessing cost increases would result from increased volumes of radioactive fuel materials requiring remote handling, increased transportation costs (due to additional fuel material volumes), and increased reenrichment and refabrication costs. In this study, the costs of reprocessing, transportation, and fuel fabrication in a plutonium recycle system are estimated to make up only $8 \%$ of the system's power cost. Given that fusion-fission system fuel cycle operations are planned and integrated, the additional costs of including coprocessing in fuel cycles should increase power costs by less than this $8 \%$.

\section{Refresh B lanket}

The refresh fuel cycle/blanket concept is a fourth mechanism for retarding fusion-fission system proliferation potential. In this fuel cycle concept, the fuel blankets are laden with fission and activation products making them highly radioactive and providing themselves proliferation resistance. Results obtained in this study indicate that the additional costs of utilizing such a nonproliferation device are negligible.

Denaturing

Denaturing fissile $233 \mathrm{U}$ or ${ }^{235} \mathrm{U}$, using $238 \mathrm{U}$ as a dilutant provides a fifth mechanism for obtaining proliferation resistant fuel cycles. Like coprocessing, this mechanism affects only the reprocessing, transportation, enrichment, and refabrication stages of fuel cycles resulting in a maximum impact on system levelized energy costs or power costs of $8 \%$.

\section{SECTION 6.0 REFERENCES}

Guide for Economic Evaluation of Nuclear Reactor Plant Designs. 1969. NUS-531, United States Atomic Energy Commission, Division of Technical Information, Washington, D.C.

The Handy-Whitman Index of Public Utility Construction Costs. 1977. Whitman, Requardt and Associates, Baltimore, MD.

Schulte, S. C., T. L. Willke and J. R. Young. 1978. Fusion Reactor Design Studies - Standard Accounts for Cost Estimates, PNL-2548, Pacific Northwest Laboratory, Richland, WA. 



\subsection{CONCEPTUAL PLANT DESIGN}

This study has concentrated on coupling the tokamak driver and the blanket fuel cycle (Once-through, Pu-recycle, Pu-catalyst and refresh). Therefore, only minimal effort has gone into assessing and characterizing conceptual plant design. The following discussion deals with the plant layout, energy conversion system, and primary system vessel and piping for the Tokomak Hybrid Reactor (THR).

\section{PLANT LAYOUT}

The fusion driver being used is a scale-up of the University of Wisconsin TETR (Teofilo et al. 1977; Teofilo 1977; Badger et a1. 1977). The blanket module design was discussed in previous sections of this report. A schematic diagram of the reactor hall and its dimensions is given in Figure 7.1.

The power conversion system is shown in Figure 7.2. The thermal storage system provides two functions. First, it combines the energy collected from all sources (i.e., inner shield, divertors and blankets) into the main helium circuit. Secondly, it minimizes temperature fluctuations in the helium coolant due to the pulsed operation of the tokamak driver.

\section{POWER ANALYSIS}

A schematic diagram for the Tokamak Hybrid Reactor is shown in Figure 7.3. Accompanying plant parameters for each of the fusion blankets are listed in Table 7.1. The neutral beam injectors supply $200 \mathrm{MW}$ to the plasma during the three-second startup phase of the reactor cycle. An additional $405 \mathrm{MW}$ is required for the remainder of the reactor support systems. A breakdown of the THR recirculating power requirements is given in Table 2.3. The ignited plasma supplies $1160 \mathrm{MW}$ of fusion power to the blanket, shield, first wall and divertor. 


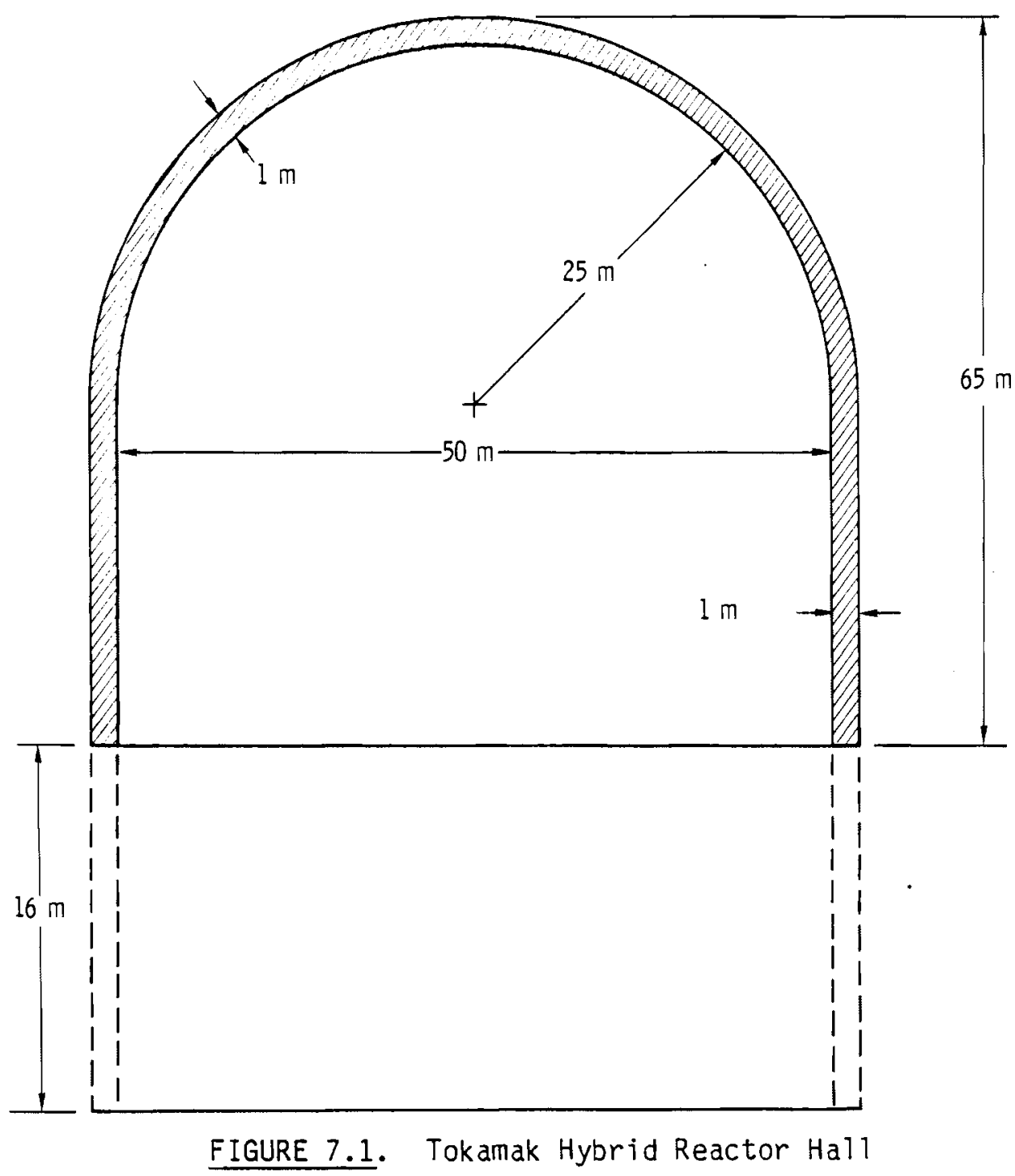

7.2 


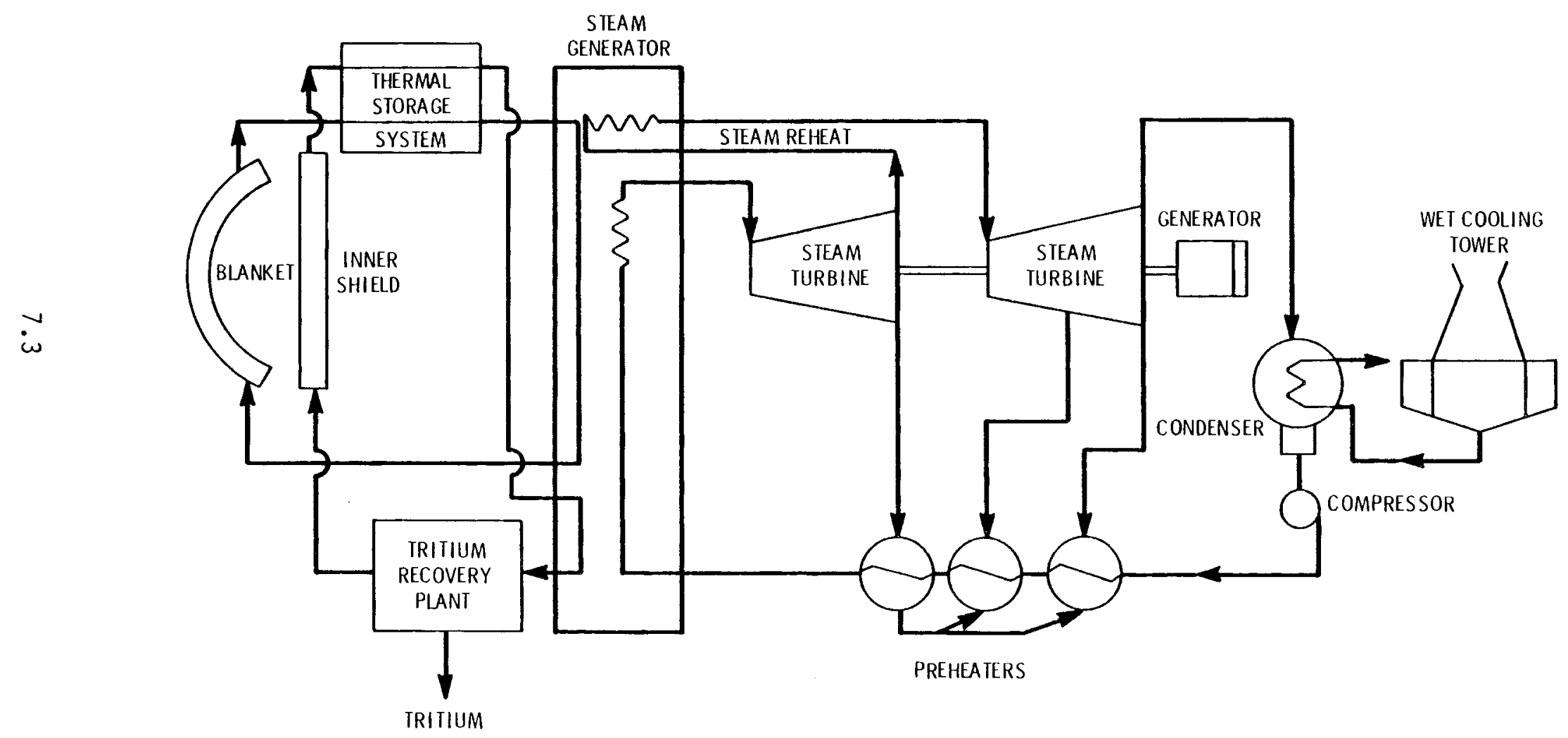

FIGURE 7.2. Power Conversion System for Tokamak Hybrid Reactor 


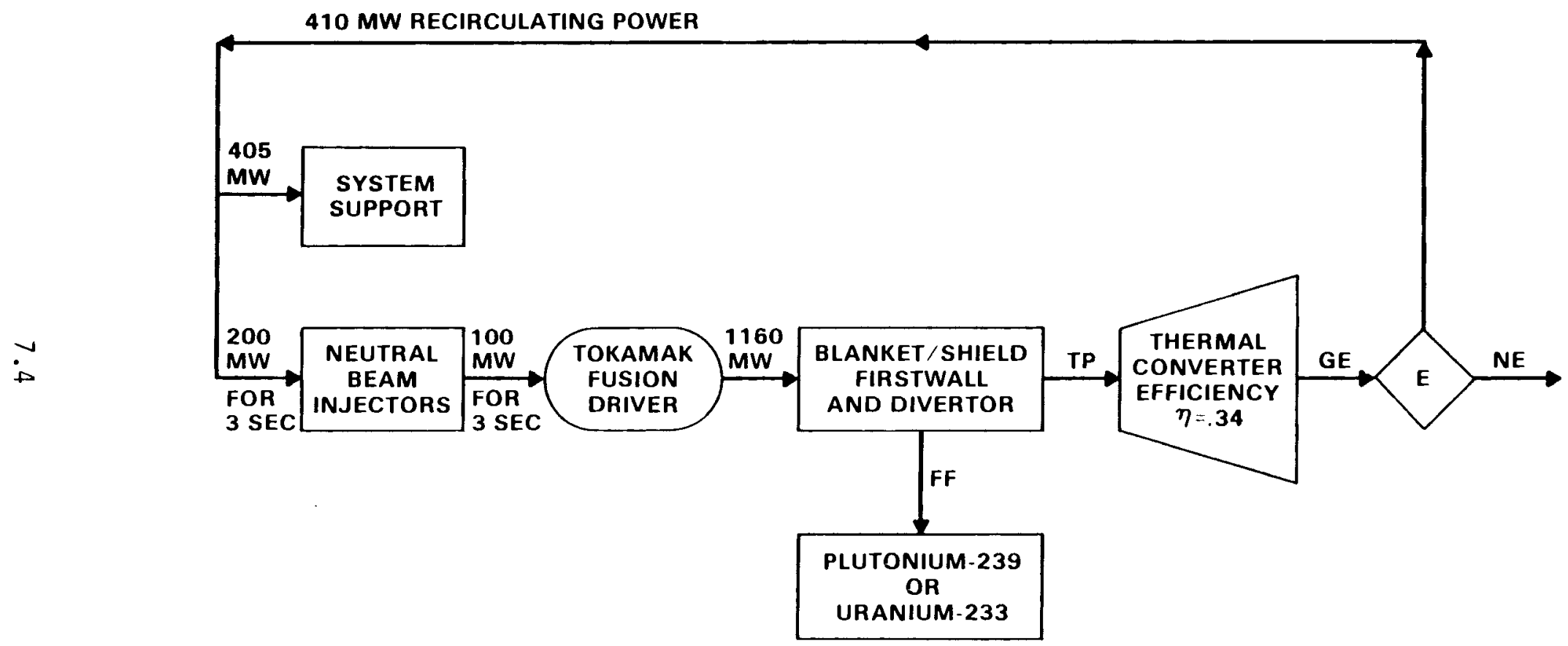

FIGURE 7.3. Tokamak Hybrid Plant Schematic 
TABLE 7.1. (a) Tokamak Hybrid Plant Parameters

\begin{tabular}{|c|c|c|c|c|c|c|}
\hline Blanket & $\begin{array}{l}\text { Thermal Power } \\
\text { Due to Fissions } \\
\text { FP (MW) }\end{array}$ & $\begin{array}{c}\text { Total Thermal } \\
\text { Power } \\
\text { TP (MWt) } \\
\end{array}$ & $\begin{array}{c}\text { Plant } \\
\text { Efficiency } \\
\text { E } \\
\end{array}$ & $\begin{array}{l}\text { Gross } \\
\text { Electric } \\
\text { GE (MWe) }\end{array}$ & $\begin{array}{l}\text { Net } \\
\text { Electric } \\
\text { NE (MWe) }\end{array}$ & $\begin{array}{l}\text { Fissile Fuel } \\
\text { Production Rate } \\
\text { FF (kg/yr) }\end{array}$ \\
\hline Pu-Recycle/Once Through & 2615 & 4150 & 0.71 & 1410 & 1000 & $1950 \mathrm{Pu}$ \\
\hline $\mathrm{UO}_{2}-$ Refresh & 2210 & 3715 & 0.675 & 1263 & 853 & $1390 \mathrm{Pu}$ \\
\hline
\end{tabular}

(a) See Figure 7.2. 
Badger, B. et al. 1977. TETR, A Tokamak Engineering Test Reactor to Qual ify Materials and Blanket Components for Early DT Fusion Power Reactors. UWFDM-191, University of Wisconsin, Madison, WI.

Teofi10, V. L. 1977. "Tokamak Demonstration Hybrid Reactor." In Proceedings of Second Fusion-Fission Energy Systems Review Meeting, p. 513. Washington, D.C.

Teofilo, V. L. et al. 1977. "A Tokomak Hybrid Blanket Design." Proceedings of the Seventh Symposium on Engineering Problems of Fusion Research. IEEE p. 62 No. 77CH1267-4-NPS, p. 1624. Knoxville, TN. 


\subsection{PROL IFERATION RESISTANCE CONSIDERATIONS}

A number of general issues must be considered in a discussion on prol iferation resistance. Many insights into the compact of a Tokamak Hybrid System can be made by considering the existing nuclear industry. Nuclear power programs are relevant to proliferation risk because they provide potential access to weapon-usable fissile material and may influence either the decision to seek nuclear weapons or the ability to implement such a decision. For future fusion-fission reactors or existing LWRs, the prevention of proliferation will not be assured by unilaterally developing alternative fuel cycles or delaying reprocessing in the United States. The potential for further world-wide proliferation is both immediate and diffuse, since over 200 commercial nuclear power reactors exist and at least as many research reactors around the world are producing plutonium today. Fusion-fission reactors containing uranium are simply another potential source of plutonium.

\section{GENERAL CONSIDERATIONS}

A distinction must be made between two types of proliferation that concern today's policy makers. The first type is a country-specific scenario of nations close to weapon capability now: the near-term proliferation problem, which must be dealt with on a case-by-case basis. The second type of proliferation, the longer-term problem, relates to the world-wide advancement in nuclear and other industrial technologies and is a more general and abstract problem, but nonetheless is real. The second proliferation type forms the basis for reevaluating alternative fuel cycles by attempting to control the role of plutonium in future nuclear power. Discrimination is the most difficult aspect of this approach; the problem becomes one of defining those "qualified" (for using plutonium) without antagonizing others (Nucl Power and Nucl Weapons Proliferation 1978).

The issue of terrorism and other forms of subnational diversion or theft of nuclear material is important, but is not defined as proliferation in this report. Terrorist threats to nuclear material are of a different nature and are susceptible to very different forms of protection than are the risks of governmental diversion and national proliferation. Furthermore, governments 
possess both resources and nearly unlimited authority and power to counter subnational threats, while the risks of national diversion must be dealt with through the relatively limited tools of diplomacy, international institutions, and sanctions.

\section{Reprocessing}

It should be noted that many alternative routes to nuclear weapons other than the acquisition of fissile fuel from a civilian nuclear power reactor exist (Starr and Zebroski 1977). At the present time, plutonium separation in a chemical reprocessing facility is regarded as a basic point of connection between nuclear power and nuclear weapons capabilities (Nucl Power and Nucl Weapons Proliferation 1978). If plutonium stockpiles were to accumulate in national hands, international safeguards to detect diversion and therefore to deter its use in weapons with advance warning become less meaningful.

Some countries view reprocessing, however, as essential to the prudent long-term management of nuclear waste, and are reluctant to proceed with large-scale exploitation of nuclear power until permanent waste management is available (Nucl Power and Nucl Weapons Proliferation 1978). In some cases government regulations require reprocessing and/or firm $\mathrm{plans}$ for waste management as a precondition for installing additional nuclear power plants. If recovered plutonium is not reprocessed and recycled, large accumulations of spent fuel in many locations could pose hazards to public health and an increased proliferation risk.

Because hybrid reactors could produce power as well as fuel to extend the fuel supply for fission reactors, they are capable of fueling multiple burnerconverters and can serve a useful function in the perceived market $p l a c e$ by the year 2000. However, previous studies conclude that to compete in the market $\mathrm{place}$ hybrid breeders must produce and sell power at least sufficiently to offset the power consumed by the devices (Deonigi and Engel 1977; Deonigi 1978; Augestein 1978). The sale of fissile material probably requires chemical processing of the blanket to recover the fuel, although recycle without reprocessing may be possible (Schultz et al. 1978). 


\section{Fusion-Fission Reactors Studied}

In fusion-fission systems the principal factor that influences nonproliferation considerations is the fuel cycle selected. The fuel cycle options discussed in Section 3.0 were:

- no chemical reprocessing, with the options of

- once-through throwaway/stowaway

- refreshing and mechanical reprocessing

- chemical reprocessing and recycling, with the options of

- Pu recycle

- Pu and $233 \mathrm{U}$ recycle.

\section{Fuel Cycle Operations for Non-Proliferation}

The fuel cycle operations of interest are those that give rise to the prospective availability for fissile materials diversion to illicit uses. They are: reprocessing, which produces highly enriched ${ }^{235} \mathrm{U}$, or ${ }^{239} \mathrm{U}$, or ${ }^{233} \mathrm{U}$; processing and storage of plutonium, ${ }^{233} \mathrm{U}$ and highly enriched ${ }^{235} \mathrm{U}$; and transportation and storage of spent fuel containing highly enriched $235 \mathrm{U}$ and/or plutonium, and/or ${ }^{233} \mathrm{U}$. These operations can in theory be performed at one site, but in practice are often performed at separate facilities.

The fuel cycle operations that are not considered relevant to this study are: uranium exploration, mining and milling; conversion and fabrication of low enrichment ${ }^{235} \mathrm{U}$ into fuel elements; and their transportation and storage as "fresh" fuel elements, even though low-enriched fuels may offer some improved prolification resistance due to their diminished fissile fuel streams in the conversion process.

\section{Standard of Comparison}

To place the hybrid concept in perspective the candidate hybrid fuel cycles should be related to the fuel cycle scenarios and technical fixes being considered for fission reactors. Such a perspective gives an indication as to whether or not these fuel cycles possess desirable nonproliferation qualities that may permit the appropriate criteria for proliferation resistance to be achieved (Deonigi and Engel 1977). 


\section{NO REPROCESSING}

The THR hybrid blanket concepts are discussed in Section 3.0 in which a comparison of the average $\mathrm{U}_{3} \mathrm{O}_{8}$ feed requirements and plutonium discharge per year is tabulated. Compared with the LWR once-through system, these hybrid blanket concepts offer greater proliferation resistance because of the absence of enrichment requirements, assuming that similar safeguards are provided for the spent fuel. The concepts also can have markedly improved resource utilization since they can utilize depleted uranium or thorium. However, they appear to be economically inferior since they involve plants with significantly greater capital costs (Augenstein 1978).

The second hybrid fuel cycle that operates in the no reprocessing mode is the "refresh cycle", which is discussed in Section 3.0. Their average $\mathrm{U}_{3} \mathrm{O}_{8}$ feed requirements and plutonium discharged per year for the different drivers are also tabulated in Section 3.0 .

In addition to the "refresh" cycle just discussed, any hybrid might be used to "refresh or reenrich" normal spent fuel where the fresh fuel is enriched to $\sim 1.0 \%{ }^{235} U$ in $U$ at the end of its life. In this concept fission reactor spent fuel would be shipped from the reactor discharge basin to a refabrication center. The spent fuel would be mechanically refabricated into fresh hybrid blanket module assemblies. This fuel would then be reenriched in the hybrid and, after an appropriate decay period, returned to the fission reactor.

With no reprocessing, the principal advantage of hybrids (i.e., their ability to produce copious amounts of fissile fuel) is lost.

\section{REPROCESSING AND RECYCLING}

The hybrid fuel cycles considered here are somewhat analogous to fission breeders because they extend natural resources by converting uranium and/or thorium to fissile material. The applications include hybrid blankets that produce only fissile material for sale to support fission reactors, as well as those that produce both fissile material and electricity (or synthetic fuel) as salable products. Variants on the blanket fuel cycle include use of uranium, thorium, or mixtures of both. 


\section{Plutonium Recover and Recycle}

Because LWRs do not convert. enough of plutonium to completely fuel themselves, an external plutonium source is needed to sustain the system and allow it to grow. Then, the hybrid could be the external source of proliferation resistant plutonium. The sources of uranium include mixed natural, depleted uranium from the enrichment plants and/or the uranium recovered in reprocessing spent $\mathrm{UO}_{2}$ LWR fuel. Material flows for these plutonium-recirculating cycles are tabulated in Section 3.0 .

For concepts involving recycling of plutonium to fission reactors, proliferation resistance may be adequate only if the hybrid, reprocessing and fuel refabrication facilities are located in a secure International Nuclear Center (INC) and

- the fissile and fertile materials are kept together at all times (e.g., coprocessed $\mathrm{U}-\mathrm{Pu}$ ) to dilute the fissile content to below weapons-grade, or

- the fuel is made highly radioactive (e.g., having highly radioactive materials in the fuel) to preclude handling, or

- the above two are combined in the CIVEX process (Starr 1977; Culler 1977, Zebroski 1977; Flowers et al. 1977).

Aliied-General Nuclear Services has proposed that denaturing plutonium by mixing it with a sufficient quantity of ${ }^{238} \mathrm{Pu}$ can make the plutonium unusable for weapons because of its high heat generation rate (The Energy Daity 1978). This could be accomplished by recovering uranium and ${ }^{237} \mathrm{~Np}$ from the spent fuel. The isotope ${ }^{236} \mathrm{U}$ builds up during irradiation of the fresh $\mathrm{UO}_{2}$ fue 1 in the LWR. Subsequent irradiation of the ${ }^{236} \mathrm{U}$ and ${ }^{237} \mathrm{~Np}$ produces ${ }^{238} \mathrm{Pu}$ in the plutonium.

Denatured 233 U Cycie

Thorium blanket concepts that involve the recycling of $233 \mathrm{U}$ denatured fuels to fission reactors are more proliferation resistant than plutonium recycling blankets, even though they may also require locating the hybrid reactor, reprocessing and refabrication activities in an INC. Here, the 
fission reactor fuel probably should be denatured by mixing with ${ }^{238} \mathrm{U}$. This concept has high resource utilization since it uses thorium and recycled $233 \mathrm{U}$, which can produce relatively high conversion ratios in the thermal fission reactors. Furthermore, the isotope ${ }^{232} \mathrm{U}$ builds up in these cycles to the point where the radiation levels are sufficient to require massive shielding during handling and processing. The requirements for shielding are perceived as adding proliferation resistance to the fuel cycle.

High-Gain Mixed Cycle

A potentially more attractive hybrid blanket is one that uses depleted uranium and recycled plutonium for neutron and energy multiplication that breeds ${ }^{233} U$ in a thorium region (Su, Woodruff and McCormick 1976). Such a design incorporates the superior performance of ${ }^{238} \mathrm{U}$ and ${ }^{239} \mathrm{Pu}$ in a highenergy spectrum while producing $233 \mathrm{U}$, a superior fuel for thermal reactors. In this cycle, depicted in Figure 3.9, the hybrid, reprocessing, and refabrication plants should all be within the INC. The plutonium is separated and sent to storage, while the ${ }^{233} U$ is used to feed the LWRs located outside the INC. The circulating uranium is denatured with ${ }^{238} \mathrm{U}$. The $\mathrm{U}_{3} \mathrm{O}_{8}$ requirements and the buildup of plutonium are also shown in Figure 3.9.

For Pu recovery and recycle fuel cycles, hybrids located in an INC with reprocessing facilities are believed to have a great advantage over conventional breeders due to their superior fissile fuel production.

\section{PROLIFERATION RESISTANCE ENGINEER ING}

No established "technical fix" exists that can be applied to the fusionfission reactor with a U-Pu fuel cycle to sever its potential link with proliferation. However, since plutonium must be continually stored, no technical fix exists even for the light water reactor program currently underway in the United States. The closest approximation to a technical fix is to avoid chemical reprocessing of spent fuel so that all countries, including the United States, are at least one step removed from a ready supply of plutonium. This arrangement would be a continuation of the "status quo" and could ultimately lead to a fissile fuel shortage and to severe economic penalties. The possibility of denaturing ${ }^{239} \mathrm{Pu}$ with ${ }^{238} \mathrm{Pu}$ and ${ }^{237} \mathrm{~Np}$ in LWR fuel has yet to be 
technically established. If this concept becomes technically viable, then hybrids would have a marked proliferation advantage since they are capable of producing copious quantities of ${ }^{238} \mathrm{Pu}$ and ${ }^{237} \mathrm{~Np}$ along with ${ }^{239} \mathrm{Pu}$.

In principle, any such measures or "fixes" that may be available to fission reactor fuel cycles can also be employed in the hybrid reactor system. Thus, the hybrid reactor designs will be reviewed in the context of the progress made toward making fission systems more proliferation resistant.

Two basic approaches exist for enhancing proliferation resistance: technical barriers to proliferation (e.g., the isotopic, radiation, or reprocessing access barriers) and institutional barriers (e.g., special siting constraints for sensitive fuel cycle facilities and storage of sensitive fissile materials). The proliferation resistance of hybrids should be accomplished with a combination of the two approaches:

- The hybrid reactor, any reprocessing and refabrication facilities, and all storage facilities should be located within an International Nuclear Center (Strauch 1978).

- Some form of radiation barrier, denaturing an/or coprocessing barrier, or both should be used for all fissile material recycled to the LWRs.

In addition no plutonium should be permitted outside the INC except in full reactor subassemblies that contain fission product activity to a level of $\geq 1000 \mathrm{rem} / \mathrm{h}$ at $1 \mathrm{~m}$ (Laney and Huebotter 1978). Furthermore, no such subassembly should leave the fuel cycle center unless the plutonium content plus any other fissile material present in the fuel is $\leq W \%$ by weight in the fuel, where $w=30$ for oxide fuel, 20 for metal fuel, and 35 for carbide and nitride fuel.

No $233 \mathrm{U}$ shall leave the INC except when contained in full reactor subassemblies. A radiation level of $\geq 1000 \mathrm{rem} / \mathrm{h}$ at $1 \mathrm{~m}$ is required when the $233 \mathrm{U}$ content in uranium exceeds $x \% \mathrm{~m}$ where $X=4$. The upper 1 imit of $233 \mathrm{U}$ plus other fissile material in the fuel is $w \%$, where $w$ is defined as above.

In the case of ${ }^{235} \mathrm{U}$, bulk material may leave the INC provided the ${ }^{235} \mathrm{U}$ content in uranium is $\leq 4 \%$. Higher levels require fabrication into full subassemblies within the center. Gamma activity $>1000 \mathrm{rem} / \mathrm{h}$ at $1 \mathrm{~m}$ is required when the 
$235 \mathrm{U}$ concentration in uranium exceeds $Y \%$, where $Y=12$. The upper limit of ${ }^{235} \mathrm{U}$ plus other fissile material in the fuel is $Z \%$, where $Z$ - 40 for oxide fuel, 30 for metal fuel, and 35 for carbide and nitride fuels.

All spent subassemblies containing chemically separable fissile material should be returned to a fuel cycle center before the activity level drops below $1000 \mathrm{rem} / \mathrm{h}$ at $1 \mathrm{~m}$.

The intent of these last four restrictions on the form and condition of fissile material outside of fuel cycle centers is not to introduce any temptations for diversions of material at either the front or back end of the oncethrough LWR cycle. Upper limits are set on the fissile content of fuel to prevent the direct conversion of a stolen subassembly to a weapon with only simple mechanical operations such as duct removal and fuel pin chopping.

Coprocessing with conventional solvent extraction systems can produce about $12 \% \mathrm{Pu}$ and subsequent conversion of the mixture to a form suitable for mixed-oxide fuel fabrication seems technically feasible but has not been demonstrated on a commercial scale (Field and Touper 1978). However, for nonproliferation, plutonium can be recovered from coprocessed material by simple chemical processes (ion exchange, solvent extraction), so some form of radiation barrier should also be added.

This addition of a radiation source to the uranium-plutonium mixture to discourage unauthorized use can be accomplished by several techniques, as is shown in Table 8.1. For proliferation purposes, no added advantage can be associated with spiking beyond that required to assure the need for shielded equipment to process the plutonium mixture.

\section{Proliferation Resistance Effectiveness Evaluation}

Proliferation resistance effectiveness evaluation (PREE) estimates how effective the above measures are at any given site or transportation link. As yet, predictive models are needed because no established historical record exists from which to evaluate proliferation resistance.

One approach to predictive proliferation resistance evaluation can involve determining the probabilities of proliferation prevention for specified proliferation scenarios. Such overall probabilities involve products of 
TABLE 8.1. Methods of Spiking Plutonium(a)

Spiking

Effect Fuel

Method

Fabrication

Means to Defeat

Radiation Level

With Fission Products

Incomplete Removal

Yes

Recycle

Depends on design

Selective Partition

Yes

Avoid add-back

High decay depends on

and Add-Back

No

Bypass

irradiation

isotople

Irradiate Fuel After

Fabrication

With Cobalt Sources

Mix with Pu Fuel

Yes

Separate

High decays with 5-yr half-life

Attach source to Fuel Assembly at

No Remove source

Pu Fabrication Plant

With $238 \mathrm{pu}$ or $236 \mathrm{Pu}$

No

I sotope

separation

Adjustable, will decay faster

$$
\text { half-life }
$$

Minor $(f e w R / h)$

(a) Source: Trans. Am. Nucl. Society, p. 320.

probabilities of 1) a nation having the resources to attempt a diversion of special nuclear material in order to fabricate a nuclear weapon, 2) a nation attempting such a diversion, and 3 ) another nation (and ultimately the United States) not detecting such a diversion with sufficient advanced warning that diplomatic negotiations would fail.

A number of scenario models have been developed for the domestic safeguarding of special nuclear materials and some useful results can be envisioned from such techniques for assessing proliferation as well (Krell et al. 1977; Kendrick et a1. 1976; Bennett et al. 1976). Unfortunately, these techniques lack sufficient detail at this time to make meaningful comparisons between fusion-fission systems and LWRs. Some progress should be possible, however, by generically examining the different fuel cycles. 


\section{SECTION 8.0 REFERENCES}

Augenstein, B. 1978. "Fusion-Fission Hybrid Breeders - Economic and Performance Issues - Role of Advanced Converters, Interdependence Between Fission and Fusion Programs." Proc. of the Second Fusion-Fission Energy Systems Review Meeting Vol. II, pp. 183. CONF-771155, Washington, D. C.

Bennett, H. A., D. D. Boozer, L. D. Chapman, S. C. Danie1, B. C. Hulme and G. B. Varnado. 1976. "Safeguard System Effectiveness Modeling." Nuclear Materials Management 5.

Culler, F. L., Jr. 1978. "Precedents for Diversion-Resistant Nuclear Fuel Cycles." In Proceedings of the Fifth Energy Technology Conference. p. 111. Government Institute, Inc., Washington, D.C.

Deonigi D. E., and R. L. Engel. 1977. Performance Targets for Fusion Fission Hybrid Reactors BNWL-2139, Pacific Northwest Laboratory, Richland, WA.

Deonigi, D.'E. 1978. "Economic Regimes." Proc. of the Second Fusion-Fission Energy Systems Review Meeting Vol. II, pp. 327.

The Energy Daily, $6(142): 1$, July 25, 1978.

Field, F. R. and F. E. Touper. 1978. "Reprocessing and Fuel Fabrication Systems," Trans. Am. Nucl. Soc. 28:67.

Flowers, R. H., K. D. B. Johnson, J. H. Miles and R. K. Webster. 1978. "Possible Long Term Options for the Fast Reactor Plutonium Fuel Cycle." In Proceedings of the Fifth Energy Technology Conference. p. 256. Government Institute, Inc., Washington, D.C.

Kendrick, H., E. Loftgren, D. E. Rundquist and R. R. Fullwood. 1976. "An Approach to the Evaluation of Safeguards System Effectiveness," Nuclear Materials Management 5.

Kull, L., L. Harris, Jr. and J. Clancy. 1977. "A Method for Evaluating the Effectiveness of a Facility Safeguards System," Nuclear Materials Management 6.

Laney, R. V. and P. R. Huebotter. 1978. "Nonproliferation Criteria for Nuclear Fuel Cycles." Trans. Am. Nucl. Soc. 28:320.

Nuclear Power and Nuclear Weapons Proliferation, Vol. I. 1978. The Atlantic Council of the United States, Westview Press, Boulder, Co.

Schultz, K. R., R. H. Brogli, G. R. Hopkins, G. W. Shirley and S. C. Burnett. 1978. "Preliminary Evaluation of a U-233 Fusion-Fission Power System Without Reprocessing." Proc. of the Second Fusion-Fission Energy Systems Review Meeting Vol. I. p. 183. CONF-771155, Washington, D.C. 
Starr, C. 1977. "Nuclear Power and Weapons Proliferation-The Thin Link." Nuclear News, 20(6):55, June 1977.

Starr, C. 1978. "Proliferation-Resistant Nuclear Technology." On Proceedings of the Fifth Energy Technology Conference. p. 103. Government Institute, Inc., Washington, D.C.

Starr, C. and E. Zebroski. 1977. "Nuclear Power and Weapons Proliferation," Proceedings of the American Power Conference, April 18-20, 1977, Chicago, Illinois.

Strauch, S. 1978. "Alternative Reactor Fuel Cycles under Consideration and Their Design Ramifications." Trans. Am. Nucl. Soc. 28:573.

Su, S. F., G. L. Woodruff and N. H. McCormick. 1976. "A High-Gain Fusion Fission Reactor for Producing Uranium-233." Nucl. Tech. 29:392.

Zebroski, E. 1978. "A Fast Breeder System concept." In Proceedings of the Fifth Energy Technology Conference. p. 256. Government Institute, Inc., Washington, D.C. 



\subsection{LICENSING AND SAFETY}

Before a detailed discussion of the specific licensing and safety issues associated with the tokamak hybrid is given, a generic discussion of the problems facing the hybrid concept in general is needed.

\section{GENERIC DISCUSSION OF THE HYBRID CONCEPT}

The fusion-fission hybrid reactor concept is based on the energy gain realized when neutrons produced by a thermonuclear deuterium-tritium plasma interact with a surrounding blanket containing fissile or fissionable material. A large array of concepts is possible among the magnetic and inertial confinement fusion driver concepts available, as well as the choice of fission fuel cycle, heat removal cycle, etc. Typically, the fusion reaction is confined to the interior of a large vacuum vessel (torus or cylinder, etc.), which then dictates the general blanket geometry.

The fission zone is usually quite thin ( $\sim 1 \mathrm{~m}$ or less); however, because of the size of the "shell" structure it is typically divided into quadrants, often with independent coolant loops, and further divided into modules or assemblies. The placement of energy systems required to initiate the fusion reaction (superconducting magnets, injector or beam lines, cryopanels, etc.) and the routing of the cooling system add further complexity to the structure, of ten resulting in complex shapes with access problems for fabrication, refue1ing and maintenance.

In addition, the blanket region must breed sufficient tritium for operation of the fusion driver. Lithium or lithium compounds must then be included, sometimes in the form of a liquid metal, which it can also operate as a reactor coolant.

Major design features include the lack of any reactivity controls. The fission blanket itself is designed to be subcritical over the fuel lifetime, and any large excursions in fusion neutron production are considered highly unlikely. Power densities are usually below those found in pure fission reactors, and the segmented blanket design tends to isolate coolant flow 
disturbances. A number of generic safety and licensing issues are likely for this type of technology, and are discussed below.

\section{Radiation Exposure}

Many of the safety and licensing aspects of hybrid plants will focus on the presence of radioactive materials, which will include tritium, activation products, fission products and actinides. These are found to varying degrees in modern fission reactors; however, for safety analysis and licensing the specific radionuclide inventories, as well as their chemical form and location in hybrid systems must be identified. In addition, it must be demonstrated that the hybrid blanket modules can operate safely in close conjunction with high energy fusion systems. Of concern are unique initiating events leading to loss of containment, as well as the identification of routine occupational exposure during plant operation, refueling and maintenance. The following various radioactive materials are present during plant operation.

\section{Tritium}

A hybrid system may be the first commercial applicaton of the D-T fuel cycle because the lower energy balance constraints placed on the fusion driver. To meet daily requirements, an extraction and separation process will probably require tritium to be present in kilogram quantities in the blanket.

Tritium $(\bar{T})$, a radioactive isotope of hydrogen, decays by emitting a soft beta particle $\left(\bar{E}=5.7 \mathrm{keV}, E_{\max }=18 \mathrm{keV}\right)$ and no gamma ray, and is therefore a significant radiological hazard only if ingested. Since $T_{2}$ is virtually insoluble in human tissue (about $98 \%$ of $T_{2}$ inhaled is immediately exhaled), it is relatively innocuous. Tritiated water ( $T_{2} \mathrm{O}$, HTO or DTO), however, is a much greater hazard. The maximum permissible concentration (MPC) value for tritiated water in air is $0.2 \mu \mathrm{Ci} / \mathrm{m}^{3}$ (uncontrolled area), 1/200 of the comparable value for $T_{2}$.

Research and developmient is therefore required for tritium monitors capable of discriminating between molecular tritium and tritiated water and capable of accurate real-time measurement of tritium concentrations on the order 
of $0.01 \mu \mathrm{Ci} / \mathrm{m}^{3}$. Without this development all tritium detected in the facility atmosphere must be assumed to be tritiated water. Such an assumption will decrease design and operational flexibility and increase costs.

In-plant tritium releases during normal operation would primarily result from leaks, particularly around valves, and would greatly exceed contributions from permeation. One cause of leaks is the damage to elastomeric seals resulting from tritium exposure. The identification of tritium-resistant materials should proceed. For maintenance purposes, every tritium handiing component should be designed so it can be purged. Components contaminated by tritium alone, however, do not require remote maintenance; a combination of glove boxes, plastic tents and bubble suits with independent air supply will be adequate for maintenance operations.

Design parameters for emergency cleanup systems will depend on the accident scenarios identified and the form of tritium released as discussed above. The conversion rate of $T_{2}$ to tritiated water (mostly HTO) will be a strong function of environment in the reactor hall (e.g., surface conditions, temperature, humidity, etc.). The identification of design basis accidents will be discussed under the section on accidents.

Although the safety and licensing aspects of large-scale tritium use are being investigated for the magnetic fusion program, the specific tasks and schedules for this research may have to be reevaluated for early application in hybrid systems.

\section{Blanket and Structure Activation}

D-T fusion drivers, as copious sources of neutrons, will activate structural, blanket and shielding materials with profound effects on overall machine design, operational planning, and costs. In particular, maintenance operations on components within or proximal to the fusion device will be affected. Most near-term concepts project the use of stainless steel, which will surely make a substantial remote maintenance capability necessary. Because the fusion structures typically require replacement after several years of operation, the vacuum vessel must be designed with remote cutting and disassembly in mind. 
The mass transport of activated structural materials in the coolant system (corrosion) and in the vacuum system (evaporation, sputtering, blistering, etc.) must also be considered. In fission reactors, unforeseen radioactive crud buildup in areas requiring maintenance is of ten the major source of occupational exposure. Test loops to identify problems in liquid lithium cooled systems are now underway. Mass transport in vacuum systems may require some operational experience to pinpoint problem areas.

\section{Fission Products and Actinides}

The presence of fission products and actinides in the hybrid blanket have three aspects that require unique investigation. First, the hard fusion neutron spectrum is likely to generate different radionuclide concentrations for the many fuel cycles and fuel types (carbides, oxides, metals, salts, etc.) under consideration for hybrids. Licensing considerations then require that the research include the following for all fuel combinations:

- establish nuclear data files for fusion spectrum

- determine radionuclide inventories at exposure

- determine decay heat curves.

The nuclear data are being formulated today; however, all hybrid neutronics to date have relied on fission reactor spectra and light water decay heat curves. Although this type of analysis is an acceptable approximation for today's design studies, it could not serve as the basis for component design of decay heat removal systems for actual systems subject to regulatory review.

The second area requiring work deals with the mechanical performance of the fuel in a hybrid application. Many fusion drivers operate in a cyclic or rapidly pulsed mode, resulting in thermal and radiation conditions far different from those found in fission reactors that operate in a relatively steadystate mode. Commercial applications will require that the fuel be fully qualified in the hybrid environment during startup, operation and shutdown of the reactor. As with fission reactors, the hybrid would then be licensed to operate within a specific performance envelope defined by the fusion driver characteristics and fuel response. Fuel failure rates are also required to identify circulating inventories in cooling systems for accident analysis. 
Finally, the shape of the fission blanket itself will introduce problems for refueling and maintenance. Many hybrid designs use large, irregularly shaped fuel modules that are welded into the reactor structure and cooling system. Refueling then requires remote cutting and welding and the transport of large assemblies. Safety analysis will be required to provide input into reactor design to minimize exposure during these operations.

\section{Accidents}

The formulation of regulatory codes and design standards and materials qualification will impact the licensing of hybrid systems more in the area of accident analysis than anywhere else. This is recognized as an iterative process, with initial scoping studies forming the basis for early design requirements. These studies will then eventually form the basis for the regulatory licensing functions, which must provide the following:

- design basis accidents

- analysis codes and assumptions

- design standards and criteria.

Regulatory review will interact between preliminary and final safety systems design and, of course; update standards on the basis of operational experience.

Much of the unique accident analysis and safety design work required for licensing hybrid systems will deal with the containment of the radioactive materials just discussed. Initiating events leading to loss of coolant in the fission blanket, possibly followed by fuel melting and loss of containment, or accidents affecting the sub-critical nature of the blanket are of particular concern. The fission blanket can operate safely in close conjunction with any high energy fusion systems.

\section{LOCA/LOFA Accidents}

At this stage of hybrid development in the various conceptual blanket designs, initiating events that could lead to local flow reduction or blockage events, or more serious accidents involving larger portions of the cooling system are difficult to identify. Analyzing the blanket response to a postulated event poses the same problem because of the complex structural geometry. The modular design of most hybrids with independent cooling loops serving a 
quadranted blanket are believed to have a tendency to isolate disturbances making that fuel melting propagation unlikely. However, this geometry distributes the fission blanket over a large region and makes difficult the placement of guard vessels around all structures for containment if meltthrough does occur. Because of this difficulty localized melting may still result in widespread contamination of other reactor systems. Also, because no one portion of the blanket can be isolated from the fusion driver during operation, a large instrumentation system will be required to spot isolated cooling problems that would require a power reduction in the entire blanket.

The response of a hybrid blanket to a loss of flow or coolant-type accident will depend directly on the type of coolant, the operating power density, the speed with which reactor shutdown can occur, and the decay heat levels that were discussed earlier. Initial hybrid designs had very low power densities (10 to $20 \mathrm{w} / \mathrm{cm}^{3}$ ), making decay heat cooling by natural convection with liquid metal systems possible if provided with a functioning heat sink. For more recent designs, average blanket power densities have increased significantly with most relying on helium coolant. Although the power densities are well within modern HTGR and GCFR technology, forced circulation must be maintained with the gas cooled hybrid design to prevent fuel melting from decay heat. Another problem with the gas cooled designs is the system's limited thermal inertia, making rapid shutdown of the fusion driver (and the initiation of auxiliary cooling if possible) imperative in a loss of flow accident. Rapid shutdown is easily achieved with inertial confinement and some pulsed magnetic fusion drivers; however, tokamaks or mirrors may require a significant cooldown period to quench the fusion reaction and avoid damage caused by a plasma dump. A safety system consisting of an emergency injection of impurities or an overfill of hydrogen may be required to improve the shutdown response for large plasma devices.

Criticality

One of the major safety objectives of the hybrid design is to insure that the fission blanket remains subcritical under all conditions. Although the blankets are designed to be subcritical over the entire fuel lifetime, various mechanisms are available for reactivity insertion. If criticality could be 
achieved, large power excursions and energetic disruptions leading to large scale release of radionuclides can be envisioned. This possibility must and can be eliminated.

Changes in blanket geometry caused by gross physical displacement (e.g., collapse of structures), or by fuel melting in LOFA/LOCA accidents, or by the introduction of steam or water in blanket voids are considered to be the most serious ways of changing blanket reactivity. The hybrid blanket differs from pure fission reactors because it is structured around the fusion driver vacuum vessel and is far from being in its most compact geometry. Also, most hybrid fuel cycles are designed to be breeders, with fissile fuel content increasing with exposure. The blanket response to various reactivity insertion accidents then becomes more serious with time.

The criticality calculations done for hybrids to date are highly conservative because they typically assume total collapse of the fission blanket. plotting the reactivity ( $K_{\text {eff }}$ ) resulting from this "accident" as a function of blanket exposure (fissile fuel content) then defines the useful blanket $l$ ifetime to keep $K_{\text {eff }}<1$. Criticality calculations used to date for fuel meltdown accidents follow the same pattern, where reconfiguration is assumed to be as a sphere, which is the most reactive geometry.

Steam ingress accidents for gas cooled designs have the potential for neutron thermalization in a blanket designed for a fast spectrum, possibly leading to criticality with a sufficient fissile buildup. However, this requires the accident to progress from steam leakage in the blanket to failure of the blanket with steam and water filling the vacuum vessel, followed by overpressurization and expansion of the blanket. With low burnup blankets the volume of water required to achieve criticality is estimated to greatiy exceed steam generator inventories.

Greatly increased neutron output from the fusion reaction is not seriously considered as a source for reactivity input. Due to the difficulty in initiating the reaction, below par performance of the fusion driver will more likely be the case.

Motion in the fuel assemblies caused by thermal bowing or flow induced vibrations will not be unique to hybrid designs. 
Conservative criticality calculations to date then indicate that hybrid designs that eliminate the chance of criticality are possible and that this can be considered an inherent safety feature. However, it again remains to establish more realistic design accidents and analyses to allow for the optimization of blanket performance $\left(K_{e f f}\right)$ while still retaining this feature.

\section{Vacuum Vessel Safety}

The presence of the large vacuum vessel in the center of the fission blanket has been mentioned several times. This structure is often used to provide support for the blanket as well as to contain the fusion reactions. As such its failure is capable of affecting the integrity of cooling systems and fuel geometry, as discussed earlier for LOFA/LOCA accidents and criticality. Missile generation upon failure could also affect the cooling system and possibly the magnet systems for magnetic fusion devices.

Licensing considerations would then be directed towards appropriate materials qualification. Engineering for the necessary structural support is not foreseen as a serious problem (although designing for access and maintenance may be); however, the lead time required to qualify new materials may be substantial. For example, it now takes approximately 8 years to qualify a new material or alloy for the ASME boiler codes.

\section{Hazardous Materials}

Finally, materials that present occupational hazards or accident potential are used in the fusion driver systems. A major concern is the explosive nature of hydrogen, which is used in all fusion drivers, and its potential for releasing tritium. Hydrogen contains a great deal of potential energy, 60,000 Btu/lb vs. 20,000 Btu/lb for gasoline and 17,000 Btu/lb for dynamite. There is a $90 \%$ chance that hydrogen leaks will ignite spontaneously under certain conditions. Hydrogen will auto-ignite at $585^{\circ} \mathrm{C}$.

The various design solutions suggested are:

- surge volumes and/or rupture discs

- double walled, inert atmosphere tritium transfer lines 
- explosion-proof electric motors and coated wires in tritium facility buildings

- $\mathrm{H}_{2}$ detectors, $1.5 \%$ turnoff source and sprinkler initiators

- limit combustibles

- Halon $\left(\mathrm{CBF}_{3}\right)$ explosion suppressors.

The advantages and disadvantages of inert atmosphere use will have to be resolved.

The other safety and licensing issues that impact accident analysis or occupational safety are associated with the fusion driver. However, these tend to be design dependent (liquid lithium, magnets, laser light, etc.). Such issues will be addressed in the following discussion of the Tokamak Hybrid Reactor, if applicable.

\section{TOKAMAK HYBRID}

The main fusion driver for the tokamak hybrid presented in this report is based on the Tokamak Engineering Test Reactor (TETR) designed by the University of Wisconsin. This pure fusion device has been modified by adding a heliumcooled first wall with a surrounding fission blanket. This particular design has been designated the Tokamak Hybrid Reactor (THR).

In the THR the thermonuclear deuterium-tritium plasma is confined magnetically in a toroidal vacuum chamber with a major radius of $5.4 \mathrm{~m}$ and a minor radius of $2.4 \mathrm{~m}$. A double-nu11 poloidal divertor directs impurities to particle collection plates. Final vacuum pumping is done by cryosorption panels located in the divertor region. Cryosorption panels are also used in the neutral beam injection ports, which introduce penetrations around the circumference of the torus. The entire vacuum vessel and divertor regions are encompassed by the toroidal field "D" magnets assumed to be superconducting niobium-tin in this design. The inner edge of all "D" magnets is then attached to a center support stanchion.

Due to the lack of access between the vacuum vessel and this inner stanchion, no fission assemblies are located here, just shielding to protect the 
magnets. In this particular design flowing natural liquid lithium has also been added to supplement the tritium breeding.

The fission blanket is then restricted to slightly less than $180^{\circ}$ of the outer poloidal angle of the vacuum vessel. It is divided into segments around the torus in "orange peel" fashion, with approximately three segments per toroidal field coil. Each segment is then further divided into the 11 modules. The final design number of "D" coils and blanket segments has not been established.

In the Pacific Northwest Laboratory (PNL) Hybrid modification of the TETR, the original steam-cooled stainless steel tubular first wall facing the plasma is replaced by a thin stainless steel water-cooled double wall with a carbon liner. Stainless steel cladding is specified for the fuel rods and $\mathrm{Li}_{2} \mathrm{O}$ contained in the modules. The blanket modules plug into the helium delivery and collection ducts directly behind the modules. Shielding is then placed outside of the blanket assemblies where more field shaping coils are located.

The power conversion system for the THR has not been specified yet, but is likely to consist of four independent primary cooling loops, each with two main steam-driven helium circulators. An auxiliary cooling system for each loop with electric-driven circulators and its own independent heat exchangers would provide backup or emergency decay heat removal. Both systems should be capable of providing adequate decay heat removal independently in a depressurization accident.

Safety and Licensing Issues for the THR

As mentioned in the generic discussion of safety and licensing issues for hybrids, one of the initial tasks in safety analysis of the THR will be to identify those unique operating characteristics or systems that may impact accident analysis.

The fusion driver for the THR operates in a cyclic mode with plasma heating lasting three seconds, followed by approximately 100 seconds of plasma burn and a 10 second cooldown and refueling cycle. With a driven tokamak, the temperatures required for the fusion reaction are maintained by beam injection 
and resistive heating; however, this design assumes an ignited plasma capable of maintaining the fusion reaction by utilizing the $3.5 \mathrm{MeV}$ alpha energy.

The impact of continued fusion energy production in loss of coolant type accidents must then be addressed, along with various methods of rapidly quenching the fusion plasma. The best approach will be the injection of impurities or cold hydrogen fuel to lower the plasma temperature. An emergency loss of confinement with a subsequent plasma dump to the first wall is another possibility, but has the potential for causing significant damage. For example, a highly localized dump has the potential for melting the first wall and dumping high pressure steam into the toroidal vacuum chamber. Temperatures for a bare stainless steel THR wall could exceed $1000^{\circ} \mathrm{C}$ in 0.2 seconds with a dump of $1500 \mathrm{~W} / \mathrm{cm}^{2}$. The carbon curtain gives added protection but can be vaporized in 10 seconds with a dump over $1000 \mathrm{~W} / \mathrm{cm}^{2}$. (Accidental disturbances in magnetic confinment and magnet failure have safety implications themselves, which will be addressed below.)

The operating power levels and decay heat curves for the various fuel cycles proposed for the THR will help determine an appropriate fusion driver response to disturbances in the cooling system. No decay heat curves have been calculated yet for the THR due to a lack of proper neutronics data. Even the more recent safety evalution of a gas cooled mirror hybrid design (Bender et al. 1978) relied on decay heat standards for thermal reactors (American Nuclear Society 1971). The calculations required for the various fuel cycles in THR are:

- time to fuel damage with reactor at full power following LOFA

- time to fuel damage following LOFA and shutdown from full power

- time to fuel damage following LOFA 48 hours after shutdown (refueling).

The qualification of fuel pin failure rates in the cyclic THR power cycle will also be required for licensing. As with all gas cooled reactors, the immediate hazard associated with reactor coolant leakage will be the radiological exposure due to coolant-borne tritium and fission products that leak 
out with the coolant. Fission products leaking out from defective fuel pins plate on the internal surface of the helium loop, have the potential for being lifted off and blown into the containment building during depressurization. The circulating tritium activity was expected to be comparable to the fission product activity, but because of the lower radiological toxicity of tritium it does not contribute significantly to the hazard potential in this type of accident. The actual circulating tritium inventory in the THR design will depend on the characteristics of the $\mathrm{Li}_{2} \mathrm{O}$ canisters used in the blanket modules.

In the THR design an evaluation of tritium containment and cleanup requirements must be extended to the liquid lithium breeding region in the central support region of the tokamak. Therefore, two different tritium process streams must be evaluated along with collection in the torus vacuum system and in the reactor coolant.

Again, as noted in the generic discussion of issues, when some hybrid concepts place high energy fusion systems in close proximity to the irregularly shaped blanket modules, identifying realistic accidents and predicting the system response becomes difficult. The placement of superconducting magnets near the liquid lithium region in the THR is an example of this problem.

\section{Liquid Lithium Spills}

Accidents affecting the integrity of the THR structure could cause the liquid lithium to be released. The lithium would then be very hot and chemically very reactive, and could cause damage to components that it contacts directly, such as shielding, structural supports or magnet components. At high temperatures it can ignite spontaneously in the air and would react vigorously with water and concrete. Lithium fires could then cause further damage directly, or lead to overpressurization and missile generation, which may damage other blanket components and containment.

Experimental programs for sodium-concrete and sodium-steel-concrete interactions, in support of LMFBR safety, are available to illustrate methods for treating lithium spills. The likelihood of serious lithium spills can be reduced by utilization of a number of safety features, such as maintaining an inert atmosphere outside the lithium loops and providing double-walled piping. 
A number of major research projects have been suggested for lithium safety in the magnetic fusion program. These include the following areas:

- lithium-concrete reactions

- lithium-material reactions

- lithium spill extinguishment

- lithium-aerosol behavior

- lithium air-cleaning concepts

- water/gas release from concrete

- hydrogen formation

- liner concepts

- use of sodium safety analysis codes.

Many of these areas are, in fact, $p l$ anned for investigation in the current program at the Hanford Engineering Development Laboratory in Richland, Washington.

The point to be made with the THR design is that the use of liquid lithium only to supplement tritium breeding will still require a major safety and materials qualification program for licensing. The exclusive use of $\mathrm{Li}_{2} \mathrm{O}$ pins would probably be more attractive for near-term reactor applications.

\section{Magnet Safey}

The superconducting toroidal field coils for the THR carry megajoule energies in close proximity to the fission blanket. The major safety concerns for magnet systems will then include:

- joule heating within a magnet or conductor sufficient to vaporize material

- sudden helium vaporization from heating resulting in destructive rupture of the helium coolant system

- thermal stress ruptures of magnets

- electric arcing with material vaporization and generation of hightemperature flying material

- generation of eddy currents and stray electric fields. 
For licensing purposes the above research would form the basis for identifying accident initiators whether they originate in the magnet or external to the magnet in other hybrid systems. The research would also produce the realistic assumptions and codes to be used in accident analysis, and the criteria for engineered safety features in magnet design. A large superconducting development program is underway for the magnetic fusion program, and on the basis of safety studies at Brookhaven National Laboratory (BNL) various engineered safety features can be envisioned for reactor applications as shown in Table 9.1.

TABLE 9.1. Engineered Safety Features for Fusion Magnets

\begin{tabular}{ll}
\multicolumn{1}{c}{ Safety Feature } & \multicolumn{1}{c}{ Function } \\
\hline Detection Systems & - detect local hot spots in coil. \\
& - detect lead overheating and failure. \\
& - detect arcs in coil. \\
& - detect loss of coolant or flow. \\
Temperature Equilibration & - drive all conductors normal early \\
Systems & - in a quench \\
Energy Removal Systems & - dump coil energy in external resistance. \\
Energy Dispersion Systems & - prevent excessive local deposition of \\
Containment Systems & coil energy.
\end{tabular}

Again, if the THR represents a near-term first application of fusion driver technology, the timetable for the above work woud have to be adjusted accordingly.

Criticality

The $K_{\text {eff }}$ of specific THR blankets has not been calculated, but the performance of a Pu catalyst fuel cycle can be extrapolated from previous 
designs. Reactivities as high as $k_{\text {eff }}=0.9582$ have been reported for designs after several years of operation (Su, Woodruff and McCormick 1976). This would be quite high for an initial hybrid application where design studies typically put $K_{\text {eff }} \simeq 0.5$. To operate the fission blanket at the Keff would imply that the THR be designed to some standard for reactivity insertion accidents beyond a simple "total collapse and melting to a sphere" type of calculation. This further implies that a significant amount of research into design basis accidents and the assumptions for accident analysis must precede the THR design to the point where the standards and criteria have been acepted as the basis for regulatory review and licensing. Blanket reactivity for THR in the $K_{\text {eff }}=0.5-0.6$ range would be more realistic for initial applications of hybrid technology.

\section{Magnetic Fields}

Magnet safety must also address the issue of occupational exposure to high-magnetic fields. The magnetic fields resulting from operation of a fusion driver may have strengths up to several hundred kilograms with pulse durations from several $\mathrm{msec}$ to hours and duty cycles of up to $80 \%$. Fusion plant employees could then be subject to high magnetic fields throughout their work period.

Numerous studies have been made to determine the biological effects of magnetic fields to humans. These studies include cardiac function, respiratory function, behavioral changes, food consumption and growth, fetal development, brain electrical activity, pathologic changes in spleen, liver, adrenal and bone marrow, metabolic rates, hematology (red blood cells and leukocytes), antibody production, wound healing, tumor growth, cell culture (growth and function), cell division, genetics, enzymes, neuromuscular function, and survival. However, the results from these studies are ambiguous; for example, several experiments on cell culture growth resulted equally among no effect, increased growth, and decreased growth. Such results could be due to the normal range in experimental resulis, failure to control or measure important variables, or some unknown reason. 
A series of closely controlled experiments has been recommended for the magnetic fusion program to determine the effects of exposure to magnetic fields. Typical biological effects that should be studied are:

- neurological and behavioral phenomena

- life span exposures

- developmental effects

- teratologic studies

- reproductive performance

- postnatal performance after prenatal exposure

- studies of combined insult

- radiation

- drugs or dietary alterations

- smoking

- chemical carcinogens

- epidemiologic

- avian

- mechanistic

In addition, there is a need for development of a personnel dosimeter.

The results of the above studies should be used to reevaluate the standards for exposure to magnetic fields. Although the U.S. and some foreign nations have established standards, the U.S. standards are considerably less stringent.

\section{Cryogenics}

Cryogenic systems have many applications in the THR fusion driver in addition to the superconducting coils just discussed. Specifically, cryogenic condensation or sorption panels are of ten specified for vacuum systems because of their high pumping speeds at low pressures. They al so find application in tritium containment and separation by distillation. These systems may then be subject to failure resulting in extreme temperature or pressure excursions capable of damaging other components or injuring personnel.

As with the superconducting magnets, the cryogenic systems will then require engineered safety features to detect both local heating or pressure 
increases, and will require containment systems to minimize the effect of cryogenic fluid loss. Again, studies will be required to determine potential accident initiators and resulting consequences.

Activation Products

The production of radioactive materials in the stainless steel first wall was calculated for the original TETR design. The activity peaks at 0.5 $\mathrm{Ci} /$ watt of fusion power generated after several years of operation. The use of helium is expected to minimize the problem of corrosion and activation product transport in the coolant system. The use of a carbon liner on the vacuum first wall is also expected to reduce the erosion and transport of stainless steel activation products in the vacuum system, the liner requires periodic replacement. At the high activation levels expected, remote maintenance will be required but special radiation exposure standards are not expected to be required. However, a great deal of analysis into the methods of remote fabrication and disassembly will obviously be required to demonstrate that compliance with radiation standards can be achieved.

\section{SECTION 9.0 REFERENCES}

Bender, D. J. et a1. 1978. Reference Design for the Standard Mirror Hybrid Reactor. UCRL-52478, General Atomics and Lawrence Livermore, Livermore, CA.

Proposed ANS Standard Decay Energy Release Rates Following Shutdown of Uranium-Fueled Thermal Reactors. 1971. ANS-5-1, American Nuclear Society, Chicago, IL.

Su, S. F., G. L. Woodruff and H. J. McCormick. 1976. "A High-Gain Fusion Fission Reactor for Producing 233U." Nucl. Tech. 24:392.

Tokamak Engineering Test Reactor. 1977. UWFDM-191, University of Wisconsin, Department of Nuclear Engineering, Madison, WI. 
. 


\subsection{ENVIRONMENTAL CONSIDERATIONS}

A fusion-fission hybrid reactor is expected to be a large-scale thermal energy facility. Therefore, many of the environmental impacts associated with the concept, such as site selection, site work, materials requirements, influx in population, etc., will be similar to those of modern fission reactors. In this section, a discussion of the tokamak hybrid concept will be oriented towards identifying any unique environmental impacts.

\section{FUSION FUEL CYCLE}

The fusion driver in this report is based on the deuterium-tritium fusion reaction.

Deuterium and Lithium

The fusion fuel cycle requires that the basic materials, deuterium and lithium, be delivered to the plant. A large lithium inventory (possibly in liquid metal form) surrounding the fusion reaction is the target material for creating tritium by neutron capture.

The procurement of deuterium is expected to be routine. Deuterium occurs in all natural waters at a concentation of about $150 \mathrm{ppm}$, and is readily extracted from water by use of a hydrogen sulfide extraction process (the Guerdler-Sulfide or G-S process) to obtain heavy water $\left(\mathrm{O}_{2} \mathrm{O}\right)$ and then electrolytic decomposition of the heavy water to obtain the deuterium. This process has been used commercially on a large scale for over 20 years and has an insignificant environmental impact consisting primarily of processing small quantities of water and releases of very small amounts of $\mathrm{H}_{2} \mathrm{~S}$ and $\mathrm{SO}_{2}$ The world inventory is estimated to be about $10^{13}$ metric tons and is available commercially at a relatively low cost $(\$ 600 / \mathrm{kg})$. Since at least a quarter of the current resources can be extracted without a significant increase in cost, an essentially unlimited supply is available at current costs.

Several hundred tons of lithium are typically used in the blanket of fusion reactors, and hybrids will require similar amounts. Only about $1 \%$ of the inventory will be consumed during a 30-year lifetime of the power plant in 
breeding tritium. Since this small consumption is less than the extra amount of lithium that would be kept in storage as an emergency supply, no additional shipments of lithium would likely be required beyond the initial startup.

The original procurement of lithium will require mining, milling and processing operations that will impact land and water use, and produce waste piles, waste ponds and chemical releases to the water and air. Modern waste control technology can be expected to prevent any serious adverse impacts. Tritium

As with safety and licensing, the primary environmental concerns will center on the potential for routine and accidental release of radioactive materials. Tritium, present in solid, liquid and gaseous effluents, will likely be the dominant radionuclide released. A preliminary evaluation of the performance of radwaste systems indicates that even though tritium will be present in kilogram quantities in reactor systems, the routine release to the environment can be kept to levels found in light water fission reactors $(<20$ Ci/day).

The consequences of an accidental release of a large tritium inventory must also be addressed. The worst credible accident is considered to be the failure of a liquid lithium blanket with a successive failure of the fire suppressant device. An analysis of a laser fusion reactor accident led to a maximum dose at the side boundary $(100 \mathrm{~m})$ of 0.7 rem for a cool ground level release, and $7 \times 10^{-4}$ rem for a hot fire release (Devaney et al. 1978). A $100 \mathrm{~m}$ stack would reduce the latter by a factor of 100 . The tritium inventory in a hybrid reactor would be less, resulting in a smaller release. If this worst possible accident were to occur, at the site boundary would receive a fatal chemical exposure to the lithium smoke long before one could receive a lethal tritium dose.

Tritium will also likely contaminate solid structures removed from the reactor for maintenance. Any solid waste disposal must then be examined for gradual tritium leakage to the environment.

Since tritium is expected to be the primary cause of radiation doses to the general public as a result of radioisotope releases, ample technology must 
be available to estimate the release rates, radiation doses and biological effects. To assure adequate ability to write environmental statements (Young 1976) the following information is needed (Young 1976):

- tritium permeation rates through fusion reactor structural materials

- tritium separations chemistry, including chemical and physical equilibrium relationships

- tritium separation processes for air and water streams

- optimum tritium storage methods

- tritium barrier technology

- application of current tritium control technology

- detailed designs for power plant subsystems containing tritium

- tritium concentrations and doses at long distances from release points

- tritium transport through the biosphere

- additional information on the relationship between dose and somatic and genetic effects, especially in relation to long-term exposure to tritium at very low concentrations.

\section{Activation Products}

The D-T fusion fuel cycle will produce an intense neutron source, leading to activation of structural materials and coolant impurities. Neutron streaming from ducts and beam ports can also lead to substantial generation of activation products. All of these must then be examined for source terms into the environment.

The replacement of structural materials because of radiation damage is expected to generate the bulk of the solid radwastes. Corrosion and erosion in the coolant system and vacuum system may also lead to waste streams that must be packaged and disposed of. The activated structural materials removed from the reactor are not thought to present any hazard in terms of an accidental dispersion into the environment, al though they will require shielding. 
The materials will be removed in such quantities that they will represent valuable resources, and it is likely that they will be stored for recycling after a period of radioactive decay.

While still in the reactor, only the most energetic accidents postulated would be capable of releasing radionuclides to reactor containment and then possibly to the environment. Although liquid metal fires or melting of fuel assemblies in the fission blanket are considered to be the only plausible methods of releasing the activation products in significant quantities, these accident scenarios would likely have more serious consequences than those associated with the release of activation products.

\section{FISSION FUEL CYCLE}

The environmental impacts associated with the four fuel cycles investigated in this report (once-through, $\mathrm{Pu}$ recycle, refresh, and $\mathrm{Pu}$ catalyst) will then come from acquisition of materials, initial fabrication, transportation, operation in the hybrid, transportation of spent fuel, reprocessing, and waste storage. Note that none of the fuel cycles being considered require enrichment of the original uranium feedstock, thereby eliminating impacts associated with gaseous or centrifuge enrichment plants.

The environmental impacts associated with acquisition of uranium and thorium and initial fabrication are identical to those now experienced with light water reactors. However, the resource utilization, or power generated per metric ton of ore mined, varies widely with the fuel cycles considered. The initial material requirements and mass flow diagrams in Section 3.0 indicate that the fuel breeders are capable of supporting several fission reactors with their fissile fuel production; however, a once-through hybrid is a very inefficient use of natural uranium. Due to the relatively low thermal power densities in the hybrid blanket, this throwaway fuel cycle requires a much higher uranium supply per kWe generated than light water reactors. In order of most efficient use of natural resources, the fuel cycles are Pu catalyst, Pu recycle, refresh, and finally, the once-through.

The fission products and actinides in the fission blanket will likely be relatively benign in routine operation of the hybrid reactor, as is the case 
in pure fission reactors. However, they have the potential for causing the most serious environmental damage if accidentally released at some point in the fuel cycle. Because of this potential, the hybrid reactor will require the same safeguards in reactor cooling, containment and aerosol blowdown systems.

Of interest here is the consideration that the fusion driver may produce a unique fission product inventory in the hybrid blanket. The neutron spectrum in a hybrid reactor is very different from that in a thermal or "fast" fission reactor due to the $14 \mathrm{MeV}$ fusion neutron source and the subcritical nature of the blanket. Very fast fission reactions will result in a different fission yield than normally experienced, with the probability of symmetric fission increasing by two orders of magnitude. The abundance of fission products with atomic mass number between 105 and 130 in the hybrid will reflect this fact. The actual distribution of fission products and actinide will further depend on the geometry of the blanket and the particular fuel cycle used. The research required for the identification of specific radionuclide inventories and the performance of fuel systems in the hybrid were discussed previously in the chapter on safety and licensing.

As with safety analysis, the verification of the fission fuel cladding in the hybrid nuclear environment will be one of the more important requirements for licensing from an environmental standpoint. Although the public tends to focus on the potential for 1 arge accidental releases from a nuclear facility (which certainly must be evaluated), in actual practice the routine release of small amounts of fission gases will determine the actual environmental impact. It must then be established that the hybrid fission blanket and associated cleanup systems can routinely perform up to the standards set for the fission industry in the nuclear environment of the fusion driver.

However, the accumulation of the actinides, including plutonium, will have the greatest impact on the potential environmental hazard presented by the hybrid fuel. The isotopes of americium, Am-241 and Am-243, are of particular biological concern. The once-through, Pu recycle and refresh fuel cycles have essentially no fissile fuel loading initially, but as seen in the performance tables in Section 3.0 , these fuel cycles all produce plutonium in metric 
ton quantities per full power reactor year of exposure. The buildup of other actinides such as americium is then dependent on the neutron flux spectrum in each specific blanket design. Although the hybrid has the potential for being an actinide burner, EPRI studies indicate that the inventory of actinides increases significantly before consumption by fission is effective (FusionDriven Actinide Burner Design Study 1977).

The remaining fuel cycle, the Pu catalyst, starts with an initial inventory of several metric tons of plutonium for all hybrids considered in this report. This $\mathrm{Pu}$ inventory then drives the thorium-uranium scheme:

$$
232 \mathrm{Th}+\mathrm{n} \rightarrow{ }^{233} \mathrm{Th} \stackrel{\beta}{\rightarrow}-233 \mathrm{UPa} \stackrel{\beta}{\rightarrow}-233 \mathrm{U}
$$

A previous examination of Th-U cycle suggested that higher actinides for the thorium-uranium fuel cycle would only appear if the U-233 were left for very long times in the blanket, thereby reducing the hazard potential for the fuel cycle (Bender et al. 1978). However, the use of the plutonium catalyst puts this in doubt. The buildup of U-232, which has a long decay chain of alpha emitters, may also present a problem. Again, the proper neutronics evaluation of actinide buildup for the four fuel cycles is not available.

The concentration of plutonium in the hybrid fuel and its isotopic composition must also be addressed. With the tokamak production rates in Section 7.0, $\mathrm{Pu}$ equilibrium concentrations in the discharged fuel range from 0.025 to 0.07 MT Pu/MT for the four fuel cycles. This compares to typical Pu discharge concentrations in PWRs of 20.01 MT Pu/MT (250 kg Pu in 1/4 core discharge, 33,000 MWd/MT burnup). The isotopic composition of plutonium in discharged PWR fuel is also typically spread over several isotopes $(1.7 \%$ Pu-238, 55.8\% Pu-239, 24.5\% Pu-240, 13.1\% Pu-241, 4.9\% Pu-242) where the plutonium in the hybrid fuel is expected to be $>90 \% \mathrm{Pu}-239$.

The presence of fission products in the hybrid blanket after exposure has been addressed; however no specific radionuclide inventories are available for inclusion in this report. A previous examination of this problem indicates that the change in the fission product yield curve for $14 \mathrm{MeV}$ fusion neutrons 
will result in a higher production rate (compared to LWRs) of hazardous radionuclides such as ruthenium-106 (Fusion-Driver Actinide Burner Design Study $1977)$. However, burnup reactions such as $(n, 2 n)$ may possibly reduce the difference in fission product inventories to insignificant levels. Fission product inventories in specific blanket volumes must, of course, be scaled to blanket power densitities (250-500 watts/ $\mathrm{cm}^{3}$ for LWRs) and exposure. The proper neutronics must be developed for the fusion neutron spectrum if these fuel cycles are to be investigated properly for licensing.

Per unit of power produced, the environmental impact of the fission products in the hybrid fuel cycles will likely be similar to those now experienced in light water reactors.

The environmental impact of the fission fuel cycle must also address the potential, if any, for release of these materials during transportation and reprocessing. The technology employed is expected to be identifical to that now developed for the fission industry. The analysis of transportation accidents must then address the higher concentrations of plutonium and other actinides in the spent hybrid fuel. The effluents released during reprocessing for all fuel cycles except the once-through are assumed to be those of their pure fission counterparts. Again, the neutronics are not available to estimate the release of the radioactive noble gases, krypton and xenon.

For high level waste storage, in addition to actinides and fission products, the once-through hybrid fuel cycle will require the disposal of metric ton quantities of plutonium each year. This will likely be unacceptable from a resource utilization and waste management point of view. The environmental impact analysis must address the relative hazards associated with long-term storage of spent fuel with these high fissile material concentrations as opposed to reprocessing.

\section{MAGNETIC FIELDS}

A fusion driver in this report is based on the magnetic confinement of the fusion reaction. The safety aspects associated with occupational exposure and the research required were outlined in the safety and licensing section. 
When the safety aspects of magnetic fields are concerned with occupational exposure to field strengths as high as several hundred gauss for short periods and several tens of gauss for long periods, the environmental impact will be determined by exposure to field strengths comparable to the earth's ( 0.5 gauss). For example, with the tokamak driver in this report, the toroidal field strength is over $60 \mathrm{kilogauss}$ in the plane of the torus, but it drops off rapidly and will be far below 0.5 gauss at the site exclusion boundary $(2800 \mathrm{~m})$. However, the poloidal field radiates both horizontally and vertically from the torus, and is expected to present a public exposure similar to that from the earth's natural field (Easterly, Shank and Shoup 1977).

The ability to demonstrate conclusively any biological effects associated with exposure to high magnetic field strengths is proving to be difficult. Because of this, any direct demonstration of effects from exposure to field strengths on the order of 1 gauss is unlikely. In all probability, the environmental impact assumed for licensing purposes will be based on some extrapolation of any effects observed at high exposure levels. This requires that a nonthreshold assumption be made similar to that used with low level ionizing radiation exposure.

\section{TOXIC LASER GASES}

In the laser fusion driver used in this study, the active laser gas, carbonyl selenide, is toxic. Accordingly, the laser building operates at a pressure of less than one atmosphere to contain routine releases. Provisions are also made to pump down and condense the carbonyl selenide in the event of an accidental release to the building. A release of the entire selenium inventory is estimated to bring concentrations to 200 times the allowable limits. Because of the above precautions the operation of the laser driver is not expected to have any measurable impact on the outside environment, even under the worst accident scenarios. However, the shipment of carbonyl selenide to the reactor site will have environmental impacts similar to the shipment of other toxic gases. 


\section{UNIQUE RESOURCE REQUIREMENT}

A large hybrid reactor economy can possibly result in a significant increase in demand for materials associated with the fusion driver, including the lithium discussed earlier. These materials include the possible use of beryllium as a neutron multiplier, or materials chosen for their resistance to radiation damage and reduced neutron activation in the intense fusion nuclear environment. The particular designs in this report use stainless steel as a structural and fuel cladding material.

The impact on domestic demand and materials supply is shown in Tables 10.1 and 10.2 and assumes a commercial fusion economy with 2810 GWe installed (Young 1976). The materials consumption in the hybrid should be lower per GWe installed due to the significant energy production in the fission blanket.

TABLE 10.1. Total Domestic Demand for Important Fusion Materials(a) (1975 to 2040)

\begin{tabular}{llccc} 
& \multicolumn{1}{c}{ Units } & & $\begin{array}{c}\text { Without } \\
\text { Fusion Reactors }\end{array}$ & $\begin{array}{c}\text { With } \\
\text { Fusion Reactors }\end{array}$ \\
\cline { 2 - 2 } Beryllium & $10^{3}$ metric tons & & 300 & 2,440 \\
Chromium & $10^{6}$ metric tons & 140 & 180 \\
Copper & $10^{6}$ metric tons & 410 & 440 \\
Iron Ore & $10^{9}$ metric tons & 25 & 25 \\
Helium & $10^{9}$ cu meters & 4 & 7 \\
Mercury & $10^{6}$ 35-kg flasks & 16 & 16 \\
Lithium & $10^{3}$ metric tons & 810 & 5,960 \\
Molybdenum & $10^{6}$ metric tons & 6 & 8 \\
Nickel & $10^{6}$ metric tons & 50 & 80 \\
Lead & $10^{6}$ metric tons & 690 & 760
\end{tabular}

(a) Source: Young 1976. 
TABLE 10.2. Depletion of 1974 U.S. Reserves of Important Fusion Power Plant Materials. (a)

\begin{tabular}{|c|c|c|}
\hline Material & $\begin{array}{l}\text { U. S. Reserve D } \\
\text { Without } \\
\text { Fusion Reactors }\end{array}$ & $\begin{array}{c}\text { tion Date (year) } \\
\text { With } \\
\text { Fusion Reactors }\end{array}$ \\
\hline Beryllium & Before 2010 & Before 2010 \\
\hline Chromium & \multicolumn{2}{|c|}{--Al1 chromium currentiy imported-- } \\
\hline Copper & Before 2010 & Before 2010 \\
\hline Iron & Before 2010 & Before 2010 \\
\hline Helium & After 2040 & 2030 \\
\hline Mercury & Before 2010 & Before 2010 \\
\hline Lithium & After 2040 & 2020 \\
\hline Molybdenum & 2030 & 2020 \\
\hline Nickel & Before 2010 & Before 2010 \\
\hline Lead & Before 2010 & Before 2010 \\
\hline
\end{tabular}

(a) Assumes no additions to reserves (Young 1976).

\section{SECTION 10.0 REFERENCES}

Bender, D. J. et al. 1978. Reference Design for the Standard Mirror Hybrid Reactor. UCRL-52478, GA-A14796. General Atomic Company and Lawrence Livermore Laboratory, Livermore, CA.

Devaney, J. J., L. A. Booth, J. H. Pendergrass and T. G. Frank. 1978. Environmental Effects and Potential Hazards of Laser Fusion Electric Generating Stations. LA-UR-77-2275. Presented at ICF Conference, San Diego, CA.

Easterly, C. E., K. E. Shank and R. L. Shoup. 1977. "Radiological and Environmental Aspects of Fusion Power." Nuclear Safety, 18:56.

Fusion-Driven Actinide Burner Design Study. 1977. EPRI-ER-451, Electric Power Research Institute, San Diego, CA.

Young, J. R. 1976. An Environmental analysis of Fusion Power To Determine Related R\&D Needs. BNWL-2010, Pacific Northwest Laboratory, Richland, WA. 


\subsection{TECHNOLOGY STATUS AND RESEARCH, DEVELOPMENT AND DEMONSTRATION REQUIREMENTS}

Tokamak fusion research in the U.S. is being conducted at a number of national laboratories and universities. The major ongoing experiments are located at Princeton Plasma Physics Laboratory (PPPL), Oak Ridge National Laboratory (ORNL), General Atomic Corporation (GA) and Massachusetts Institute of Technology (MIT). Research directions at these laboratories are summarized in Table 11.1. A list of current or planned U.S. tokamak experiments is tabulated in Table 11.2.

TABLE 11.1. U.S. Tokamak Research

\begin{tabular}{cl} 
Laboratory & \multicolumn{1}{c}{ Research Direction } \\
\cline { 2 - 3 } PPPL & $\begin{array}{l}\text { Demonstrate scientific feasibility of tokamak } \\
\text { fusion, evaluate divertor performance and sup- } \\
\text { plementary heating techniques }\end{array}$ \\
ORNL & $\begin{array}{l}\text { Examine efforts and means of reducing plasma } \\
\text { impurities developed from plasmal wall } \\
\text { interactions }\end{array}$ \\
GA & $\begin{array}{l}\text { Evaluate stability and performance of doublet } \\
\text { cross-section tokamaks }\end{array}$ \\
MIT & $\begin{array}{l}\text { Explore plasma confinement in high magnetic } \\
\text { fields }\end{array}$
\end{tabular}

The principal measures of progress in tokamak fusion physics are the ion temperature $T_{j}$, plasma density $n$ and energy confinement time $\tau$. The product of the last two $n \tau$ has been termed "the Lawson number." For tokamaks operating with ion temperatures near $10 \mathrm{keV}$, the Lawson number must exceed about $10^{14} \mathrm{~s} / \mathrm{cm}^{3}$ so that energy losses from the plasma are balanced by fusion energy. Figure 11.1 shows recent and expected progress in achieving high temperatures and $n \tau$ in both tokamak and mirror experiments.

Experimental results from the currently operating devices give encouraging signs for the success of the large, two-component tokamak Tokamak Fusion Test Reactor (TFTR) under construction at PPPL. Princeton Large Torus (PLT) has shown an $n \tau$ product of $10^{13} \mathrm{~s} / \mathrm{cm}^{3}$ with as high as $6 \mathrm{keV}$ temperatures, 
TABLE 11.2. U.S. Tokamak Experiments

\begin{tabular}{|c|c|c|c|c|}
\hline Exper iment & $\mathrm{R}(\mathrm{cm})$ & $a(c m)$ & $B_{\text {tor }}(T)$ & Laboratory \\
\hline PLT & 130 & 45 & 4.2 & PPPL \\
\hline ORMAK & 80 & 26 & 2.5 & ORNL \\
\hline ISX & 92 & 26 & 1.8 & ORNL \\
\hline Microtor & 30 & 10 & $6 / 25$ & UCLA \\
\hline Macrotor & 90 & 45 & $2 / 7$ & UCLA \\
\hline Doublet IIA & 66 & $30 / 100$ & 0.8 & GA \\
\hline Alcator A & 54 & 9.5 & 10 & MIT \\
\hline Alcator C & 64 & 17 & 14 & MIT \\
\hline PDX & 140 & 45 & 2.4 & PPPL \\
\hline Doub let II I & 140 & 45 & 2.6 & GA \\
\hline $\operatorname{TFTR}(a)$ & 265 & 110 & 5.6 & PPPL \\
\hline
\end{tabular}

(a) To begin operation in 1981

while Impurities Studies Experiments (ISX) at a lower magnetic field has demonstrated a plasma beta value (ratio of plasma pressure to confining magnetic presure) of $6 \%$. The MIT Alcator A experiment, at considerably higher density and magnetic field, has demonstrated $\mathrm{n} \tau$ in excess of $10^{13} \mathrm{~s} / \mathrm{cm}^{3}$ at a temperature of $1 \mathrm{keV}$. In this case the effective charge of the plasma is unity (no impurities), while in PLT it is a less desirable $Z_{\text {eff }}=2$. The Alcator $C$ and Doublet III experiments are expected to achieve $n \tau \geq 10^{14} \mathrm{~s} / \mathrm{cm}^{3}$, or near the Lawson condition for reactor ignition.

Tokamak theory has been developed to the point where many experimental results are well explained, particularly for macroscopic plasma performance. Mechanisms of energy loss from the plasma are not fully explained however, and observed electron heat conduction losses are larger than the neoclassical prediction by a factor of 10-500. The theoretical uncertainties in predicting energy loss at conditions near those required for fusion reactors have prompted physicists to establish empirical scaling laws that relate energy confinement times to plasma parameters such as density, temperature and size. 


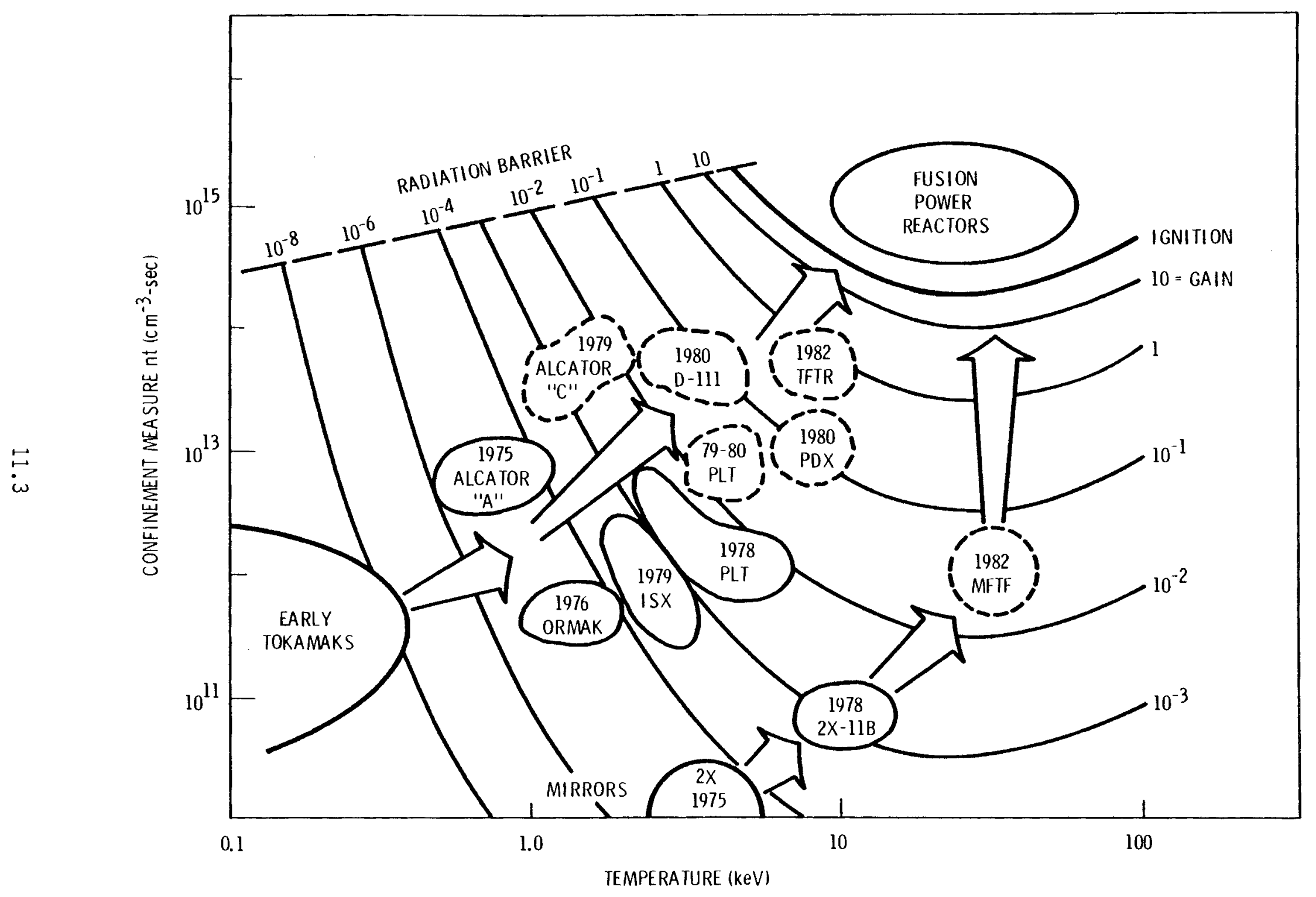

FIGURE 11.1. Technical Progress and Outlook in Magnetic Fusion Source: Magnetic Fusion Program Summary Document 
Fortunately, the data base to do this is strong and results from a variety of confirming diagnostic techniques. A recent assessment of the tokamak confinment data base notes it to be basically sound and credible (Aamodt et al. 1978). The data have been satisfactorily determined by an acceptable computerized compilation of many diagnostic techniques in numerous laboratories, with results showing an impressive consistency. The new and planned experiments of the Department of Energy-Office of Fusion Energy (DOE-OFE) tokamak confinement program is expected to reinforce or help establish the data base in areas of auxiliary heating, impurity control, $\beta$ limits and elongated plasma.

FUSION DRIVER RD\&D REQUIREMENTS

The technological development of the ignited tokamak fusion driver of the Tokamak Hybrid Reactor (THR) can fit into the OOE-OFE Confinement and Systems Development and Technology (D\&T) programmatic schedules, which $\mathrm{plan}$ to have operational a pure fusion device about the year 2015 (Figure 11.2). The progress of the major facilities is listed in Table 11.3. The major plasma physics input for an ignited Tokamak Engineering Test Facility (TETF), which could conceivably be an Hybrid Experiment Facility (HEF), would come from the U.S. devices through TFTR in addition to ORMAK-Upgrade, Alcator $C$, et al., as well as foreign experiments (Table 11.4).

The D\&T requirements (Figure 11.3 and Table 11.5) would come from the beam development for TFTR, the Large Coil Project (LCP) for the superconducting magnets, the High Intense Neutron Facility (HINF), the Multi-component Radiation Facility (MCRF), and Fusion Materials Irradiation Test (FMIT) for the materials qualifications, and the Tritium Systems Test Assembly (TSTA). The HEF features would allow its operation as early as c. 1989. The features that may represent some question include the matter of stabilizing a "D" shaped Magnetohydrodynamics (MHD) equilibrium plasma that has already been demonstrated on several tokamaks (e.g., Versator, Rector, TO-1) but would benefit from even further study. The technological development of divertor collection systems should perhaps be more clearly defined in the D\&T program. 


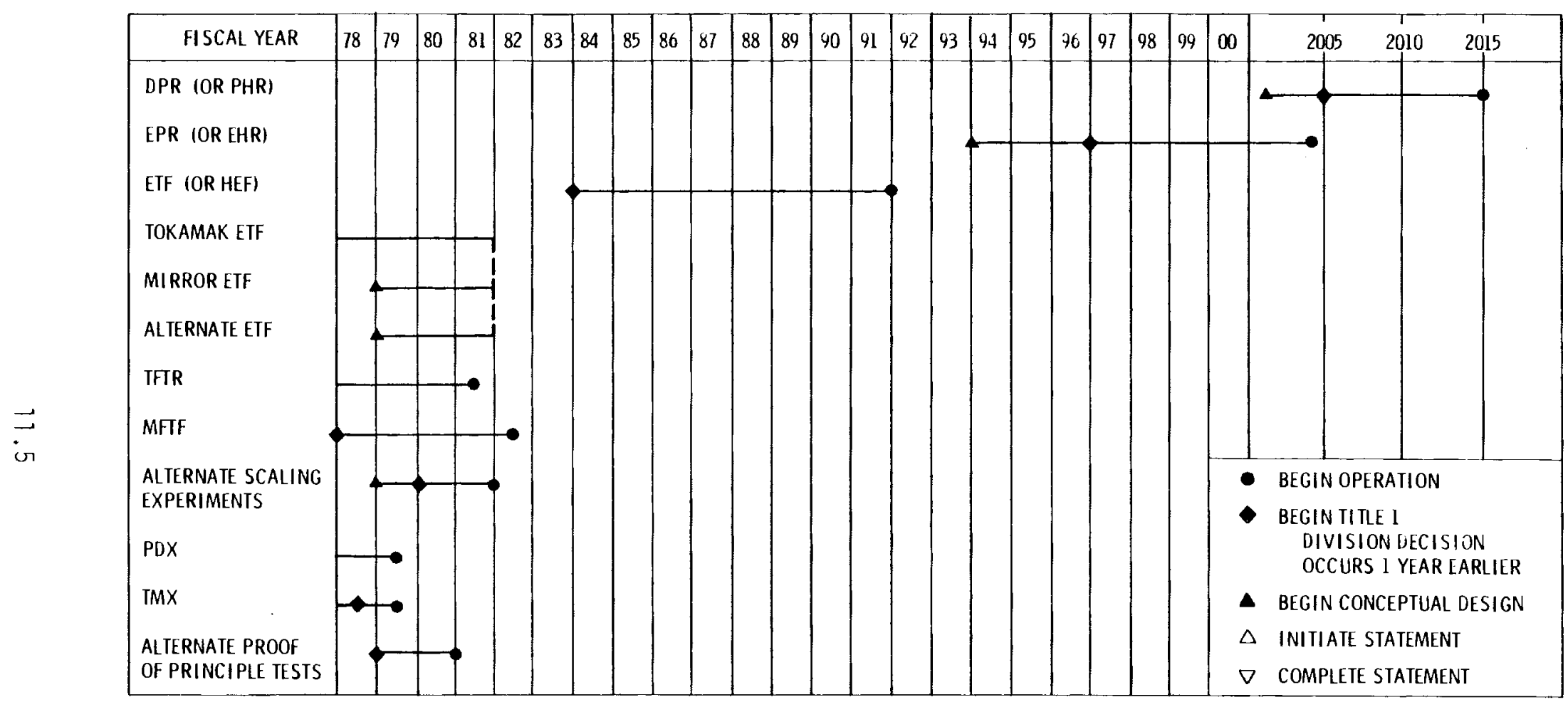

FIGURE 11.2. Major Facilities Schedule 
TABLE 11.3. Objectives of Major Fusion Reactor Facilities

\begin{tabular}{|c|c|c|c|}
\hline Reactor & Objective & $\begin{array}{r}\text { Immediate } \\
\text { Supporting } \\
\text { Devices }\end{array}$ & $\begin{array}{l}\text { Year of } \\
\text { Operation }\end{array}$ \\
\hline $\begin{array}{l}\text { TETR (Driven } \\
\text { Tokamak Eng ineer- } \\
\text { Test Reactor) }\end{array}$ & $\begin{array}{l}\text { Test Materials to } 10^{21} \\
\text { n/cm2 } \\
\text { Fueling }(E=14 \mathrm{MeV}) \\
\text { S/C Magnets Limited } \\
\text { T Breeding Neutronics Test } \\
\text { Remote Handling Blanket } \\
\text { Design Tests Performance } \\
\text { Test of Plasma } \\
\text { Operation Required for } \\
\text { Hybrid }\end{array}$ & $\begin{array}{l}\text { D-III, PDX, PLT, } \\
\text { TIA, RTNS, TFTR, } \\
\text { JET }\end{array}$ & $1990-92$ \\
\hline $\begin{array}{l}\text { EPR } \\
\text { (Experimental Power } \\
\text { Reactor) }\end{array}$ & $\begin{array}{l}\text { Limited Electrical } \\
\text { Generation } \\
\text { High Temperature Operation } \\
\text { Fabrication of CTR Vessel } \\
\text { Components in Field } \\
\text { Structural Material Test } \\
\text { (Fatigue) } \\
\text { Demonstrate Safe Handling } \\
\text { and Pumping of Liquid } \\
\text { Metals in CTR Environment } \\
\text { Reliability of S/C Magnets } \\
\text { Remote Assembly and Dis- } \\
\text { assembly } \\
\text { Breeding and Containing } \\
\text { Tritium }\end{array}$ & $\begin{array}{l}\text { TETR, TFTR, JET, } \\
\text { T-20-JT-60 }\end{array}$ & $2000-04$ \\
\hline DPR & $\begin{array}{l}\text { Demonstrate safe reliable } \\
\text { Power Generation in a } \\
\text { Reactor System that } \\
\text { Scales Readily to a } \\
\text { Commercial Reactor }\end{array}$ & TETR, EPR & $2010-15$ \\
\hline \multicolumn{4}{|c|}{$\begin{array}{l}\text { The successful operation of the HEF would impact the final design and } \\
\text { construction of the scheduled EPR, which could conceivably be an Hybrid Exper- } \\
\text { imental Reactor for operation c. } 1994 \text { with a hybrid blanket and appropriate } \\
\text { fuel and blanket remote handling capabilities. Such a facility would produce } \\
\text { power and demonstrate an integrated tritium handling and refueling capability. } \\
\text { Its operation in turn would impact the final design and construction of the } \\
\text { magnetic fusion Commercial Demonstration Power Plant (DEMO), which could be }\end{array}$} \\
\hline
\end{tabular}


TABLE 11.4. Features of the Tokamak Fusion Driver Related to Large Tokamak Experience

\begin{tabular}{|c|c|c|}
\hline Feature & Implication & $\begin{array}{c}\text { Relevant Preceding(a) } \\
\text { Experiments }\end{array}$ \\
\hline \multirow{2}{*}{$\begin{array}{l}\text { High Neutron Flux } \\
\text { and Small Size }\end{array}$} & TCT Operation & TFTR, JET \\
\hline & Nonc ircular Plasma & D-III, JET PDX-UG \\
\hline High $\tau_{p}$ and Low $Z_{\text {eff }}$ & Divertor, gas blanket & $\begin{array}{l}\text { DITE, JFT-2a/DIVA } \\
\text { PDX, ASDEX, ISX }\end{array}$ \\
\hline $\begin{array}{l}\text { Long Burn Time } \\
(\sim 30-60 \mathrm{~s})\end{array}$ & Pellet Fueling & ORMAK, ISX \\
\hline $\begin{array}{l}\text { Long Pulses at } \\
\text { Reasonable Power } \\
\text { Costs }\end{array}$ & $\begin{array}{l}\text { Superconducting Toroidal } \\
\text { Field Coils }\end{array}$ & $\begin{array}{l}\text { T-7, T-10M } \\
\text { Large Coil Project } \\
\text { MFTF }\end{array}$ \\
\hline $\begin{array}{l}\text { High Power Neutral } \\
\text { Beams }\end{array}$ & $\begin{array}{l}\text { Efficiency } \sim 50 \% \text { at } \\
150 \mathrm{keV}\end{array}$ & Beam Test Stands \\
\hline
\end{tabular}

(a) TFTR = Tokamak Fusion Test Reactor (PPPL)

JET = Joint European Torus (EEC)

D-III = Doublet-III (GA)

PDX-UG = Poloidal Divertor Experiment-Upgrade (PPPL)

$\mathrm{JFT} / 2 \mathrm{a}=$ Japanese Tokamak with Divertor (JAERI)

PDX = Poloidal Divertor Experiment (PPPL)

ASDEX = Axisymmetric Divertor Experiment (MPI-Garching)

ORMAK $=$ Oak Ridge Tok amak (ORNL)

T-7, T-10M = Tokamak-7, 10 Modified (Kurchatov)

MFTF = Mirror Fusion Test Facility (LLL)

a Prototype Hybrid Reactor (PHR) to operate c. 2000 that would precede the first Commercial Hybrid Reactor to be built and operated early in the next century.

PRESENT STATUS OF BLANKET ENGINEERING

Neutronics Design

Hybrid concepts have thus $f$ ar been subjected mainly to survey type neutronic analysis with specific requirements in the calculations, nuclear data, and experimental areas. Detailed calculations have not been made, in part 


\begin{tabular}{|c|c|c|c|c|c|c|c|c|c|c|c|c|c|c|}
\hline FISCAL YEAR & 78 & 79 & 80 & 81 & 82 & 83 & 84 & 85 & 86 & 87 & 88 & 89 & 90 & 91 \\
\hline BLANKET AND SHIELD & & & $\Delta$ & & & & & & & & & & & \\
\hline TSTA & & & & & & & & & & & & & & \\
\hline FMIT & & & & & & & & & & & & & & \\
\hline MCRF & 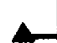 & & & & & & & & & & & & & \\
\hline & & & & & & \multirow{2}{*}{\multicolumn{9}{|c|}{$\begin{array}{l}- \text { BEGIN OPERATION } \\
\text { BEGIN TITLE I } \\
\text { DIVISION DECISION } \\
\text { OCCURS I YEAR EARLIER }\end{array}$}} \\
\hline LARGE COIL PROJECT & & & & & & & & & & & & & & \\
\hline HIGH FIELD TEST FACILITY & & & & & & \multicolumn{9}{|c|}{$\Delta$ BEGIN CONCEPTUAL DESIGN } \\
\hline
\end{tabular}

FIGURE 11.3. Engineering Facilities Schedule

because of the uncertainties associated with structural material choice and the requirements of definition from hydraulic and engineering analyses and the exact fluence limitation of a given design. Cost of conducting detailed analyses is another factor. Existing calculations of hybrid concepts, with few exceptions, have not been performed with the full sophistication available to fission reactor designers and with little attention to nuclear data problems. The experimental basis for the correlation of calculations is sparse and no experimental neutronics program on hybrid concepts presently exists.

\section{Nuclear Data}

The only nuclear data uncertainties that have been studied for hybrid concepts have been for the ${ }^{238} U$ nucleus. No nuclear data problems have been considered for ${ }^{232}$ Th or for the fissile isotopes and the minor isotopes that impact on fuel cycle problems. Complete evaluated nuclear data files have been prepared for essentially all of the actinide nuclei for the next version (V) of the U.S. DOE Evaluated Nuclear Data File (ENDF/B). These files have not yet been released for use and no assessment has been made of the ir uncertainties and adequacy for hybrid neutronics analysis. 
TABLE 11.5. Objectives of Major Fusion Engineering Facilities

Facility

Blanket and Shield Facility

Tritium Systems Test Assembly (TSTA)

Neutron Source Facilities

(FMIT, MCRF, HINF)

Large Coil Project

High Field Test Facility
Operation

1988

1982

$1979-83$

1982

1980
Objective

Test prototype blanket and first wall structures.

Test thermal/hydraulic performance and electromagnetic compatibility.

Test capability to accommodate accident conditions.

Demonstrate vacuum integrity and remote maintenance operations.

Test neutronic models and performance.

Demonstrate safe and economic handling of tritium.

Test small material samples in fusion neutron environments.

Test large superconducting magnet designs.

Test high-field superconducting magnet materials.

\section{Calculational Analysis}

Most existing hybrid neutronic calculations are very unsophisticated. Most have not included resonance self-shielding or temperature effects and only a few calculations exist with neutron thermalization and associated temperature dependence. With one exception, the minor isotopes ${ }^{232} \mathrm{U},{ }^{236} \mathrm{Pu}_{\mathrm{u}}$ and ${ }^{238} \mathrm{Pu}$ and their impacts on materials handling, operations, biological radiation dose, and safeguards have not been evaluated. Calculations of the fast-thermal ${ }^{233} \mathrm{U}$ refresh mode hybrid have been extremely cursory at this time. The ques tion of fission criticality safety has been subjected to little rigorous 
analysis and few studies have been made to determine optimum fuel management steps for improved blanket performance.

\section{Experiments}

No integral measurements experimental program exists for the hybrid concept. Some attempts have been made to define areas of microscopic neutron cross sections for hybrid applications that need improved experimental data, but no established experimental program exists to supply these needs. A single integral experiment performed some 20 years ago with a $14 \mathrm{MeV}$ neutron source in a natural uranium asembly has constituted the basic criterion for hybrid neutronics performance. All calculational comparisons except one, however, have to date incorrectly compared calculated and experimentally measured quantities.

\section{Thermal and Mechanical Design}

The thermal and mechanical design of the blanket is more dependent on the fusion driver than on the type of fission blanket selected. Configurations are laid out to fit the geometry of the fusion driver and to facilitate the removal of blanket material. This will be required of all designs, depending on the fission fuel cycle being considered and exposure capability of the fission fuel form and structural components utilized in the design. In conceptual design studies the required blanket configuration should be established early in the study. Preliminary thermal-hydraulic and structural analyses must be carried out in conjunction with neutronic survey calculations. The neutronic

performance is sensitive to the amount and type of structural material required in the blanket as noted previously, particularly for thermal and fast-thermal lattices. Knowing the blanket configuration is also important for estimating the integrated hybrid performance, since the overall performance is sensitive to the fraction of total fusion neutrons utilized by the bl anket.

\section{Fuel Form}

The selection of a fission fuel form for any given blanket has been based primarily on neutronic performance, but the candidate forms have been based on developed fission reactor technology. Fusion-fission hybrid designers 
utilizing near-term fusion drivers (i.e., those with high recirculating power and low plasma) have selected advanced fission fuel forms and cladding for their designs. Those utilizing fusion drivers having a high gain (e.g., ignition tokamaks), however, can obtain performance parameters of commercial interest with blankets utilizing near-term fission fuel forms and cladding such as UC clad in stainless steel.

Blanket Coolants

Selection of hybrid blanket coolants has been based on several factors:

- compatibility with neutronic requirements of the blanket

- status of power conversion system components

- availability of design analysis methods and supportive data bases

- compatibility with fuel form, cladding and structural materials

- compatibility with tritium processing requirements

- knowledge of magnetic field effects

- ability to pedict safety performance.

The selected coolant must be compatible with ultimate transfer of heat to a modern steam system to maintain reasonable power conversion efficiency within the temperature limitations of available blanket structural materials. In all the areas of technology previously mentioned, the most is known about water as a coolant. Extensive Research and Development (R\&D) in the LWR program has developed an adequate base and design methods to predict water-cooled blanket performance. However, water has not been considered as a blanket coolant to date because it is very difficult, if not impossible, to remove tritium from water. In LWRs tritium releases outside the plant are controlled simply by limiting the generation of tritium. Impurities ( $L i$ ) in the core are reduced to levels that limit the tritium production to amounts than can be released from the plant.

The HTGR and German Gas Cooled Reactor programs have developed and demonstrated helium-cooled power conversion system technology. Helium is compatible with all structural materials with the exception of refractory metals and alloys. The impurity levels attainable in real systems result in corrosion problems for the refractories. 
To get adequate heat transfer and transport properties, helium systems have to be operated at relatively high pressures (50 to 70 atms). In the complex geometries of hybrid blankets this results in a requirement for many structural material fractions that reduces neutronic performance (i.e., parasitic absorption of the neutrons). When cladding and structural materials are stainless steel, helium-cooled systems yield 30\% power conversion efficiency. If higher temperature alloys (TZM, Inconel, etc.) are used, efficiencies approaching $40 \%$ are possible. Because helium has good neutronic properties with no anticipated MHD or corrosion enhancement effects in magnetic fields, it has been a nearly unanimous choice of designers for use in Tokamak hybrid blankets.

The LMFBR program is developing data and system components for Na-cooled systems and an extensive safety related data base for $\mathrm{Na}$ coolant. These data will be directly applicable to assessing hybrid safety problems. The major uncertainties in $\mathrm{Na}$ cooled systems are the MHO effects in rapidly changing high magnetic fields and the effects of magnetic fields on corrosion and mass transport rates. Due to enhanced heat transfer, higher sodium temperatures can be achieved with stainless steel structural materials and thus power conversion efficiencies near $40 \%$ can be achieved without the use of high temperature alloys.

Most hybrid designers to date have proposed using $L i$ as a coolant. Although it is attractive neutronically for producing tritium, the technology base for $L i$ leaves uncertainties. $L i$ appears to be more corrosive than $\mathrm{Na}$ and so operating temperatures must be lower $\left(50^{\circ} \mathrm{C}\right)$ to be compatible with stainless steel, resulting in lower power conversion efficiency. The increased corrosion and mass transport rates make the applicability of current $\mathrm{Na}$ power conversion system components uncertain.

Because liquid metals can be used at low pressures, they result in low structural material requirement. When magnetic field effects are not important (laser applications), designers have proposed using both $\mathrm{Na}$ and $\mathrm{Li}$ as coolants to maximize the use of R\&D benefits from the LMFBR program. 
If candidate coolants were ranked by the available technology base, they would fall in the following order: water coolant, helium coolant, sodium coolant and lithium coolant.

\section{Design Analysis}

Methods currently being developed for the LWR safety program and LMFBR program should be adequate for analyzing the response of proposed fuel forms to start up transients or pulsed power operation. Ultimately experimental verification will be needed.

The calculational method for heat transfer and fluid flow, developed by the fission reactor programs, is adequate for conceptual hybrid reactor blanket designs. However, detailed design and safety analyses of start-up, pulsed operation and abnormal transients will require much closer coupling of thermal and mechanical analysis methods than now exists.

The structural analys is methods currently employed by designers (BOSOR 4, AXISOL, etc.) will require careful modeling bv experienced structural analysts to adequately predict the stresses that will be imposed on the complex modular and coolant header structures from the Tokamak hybrid conceptual design study. To date, none of the design teams have been adequately funded to take a design and set up all the structural calculations. This should be done to test the applicability of the current analytical methods as well as to give a preliminary assessment of the important design problems.

\section{BLANKET RD\&D REQUIREMENTS}

\section{Fission}

The specific fission research and development needs for fusion-fission hybrid blanket designs will depend to a large extent on the fuel form and cladding, coolant, structural complexity, and operational characteristics of the concept(s) to be developed. Conceptual design studies to date have not been performed to the depth to have identified a reasonable list of the necessary major R\&D requirements for development of any given concept. Therefore, the very general requirements that are resulting from the conceptual designers' preliminary choices are identified. 
Initial hybrid studies concentrated on fuels that have a good technological base from the fission reactor program. However, the more advanced studies have moved to advanced fuels and cladding that add uncertainty to the fabrication, irradiation behavior and reprocessing technologies involved. It is becoming increasingly apparent that hybrids with performance of commercial interest will require considerable development of the fission fuel form and associated technologies if near-term fusion drivers are utilized. Some alternative fuels considered are part of the current U.S. fission reactor R\&D program, while others are not. Nevertheless, the conditions imposed by $14 \mathrm{MeV}$ neutrons and pulsed operation will require considerable performance verification since current transient experiments on oxide fuel show very limited ability to withstand cyclic operation. Economically attractive blanket designs for all hybrid concepts tend to select fuel forms that maximize the heavy metal density in the blanket lattice. This means a carbide or metallic fuel form. On the assumption that the LMFBR Program will develop the basic irradiation performance data for these fuel concepts, the effect that $14 \mathrm{MeV}$ neutrons, pulsed operation, alternate high temperature cladding, and severe power gradients will have on the applicability of the basic data must be answered.

Methods for predicting fuel and clad transient response will have to be adapted from the LWR and LMFBR safety programs to the problems of predicting hybrid fuel response to rapid transients and pulsed operation. Experimental verification of these methods will have to be performed.

\section{Neutronics}

The neutronics RD\&D requirements fall into four general areas: nuclear data, analytical methods, conceptual design studies, and integral experiments.

The nuclear data area includes the development of evaluated nuclear data files, experimental measurements of microscopic nuclear cross-sectional data, and the function of nuclear data centers. The development, assessment, and improvement of the evaluated nuclear data files require a continuing effort throughout the hybrid development, preferably carried out in conjunction with an experimental measurements program and conceptual design studies. The 
experimental cross-section data program requires the partial support of one or more measurements facilities with continuous source energy capability to $14 \mathrm{MeV}$ neutrons.

The RD\&D effort in analytical methods consists of the development and maintenance of verified computer codes to handle radiation deep penetration problems with complicated geometries, voids, and anistotropies. It also requires the melding of fission reactor core physics and burnup codes along with the corresponding required nuclear data libraries.

The RD\&D efforts for conceptual design studies require the application of these codes and data in evaluations of conceptual hybrid designs. The studies required should emphasize performance optimization and full attention to the detail of all aspects of the nuclear fuel cycle.

The integral experiments require an improved high-density $14 \mathrm{MeV}$ neutron source facility with associated nuclear measurements capability. Integral measurements for verification of design studies and correlation with theoretical methods and nuclear data are required. The measurements program should proceed for simple homogeneous experiments through the complicated heterogenous blanket systems required for most hybrid concepts.

All of the above development could be implemented in the proposed blanket and shield experimental facility of Figure 11.3, which presumably has a source of $14 \mathrm{MeV}$ neutrons and capabilities for simulating the conditions of hybrid blanket neutronic exposures, as well as thermal, mechanical, and fuel testing. This facility could impact the Experimental Hybrid Reactrors (EHR) and Prototype Hybrid Reactor (PHR). However, in preparation for such a facility and to provide design data for the HEF, hybrid blanket and fuel development would have to be initiated earlier in more modest laboratory facilities to impact those designs.

\section{POSSIBLE HYBRID RD\&D PROGRAM}

The formulation of a definitive RD\&D program of the tokamak hybrid energy system concept would be too difficult to accomplish in this study. However, based on the current status and RD\&D requirements just reviewed, as well as 
hybrid blanket engineering and fission fuel, a hybrid RD\&D program can be proposed to serve as a framework for future RD\&D assessments and planning.

The advance technological requirements for commercializing hybrid reactors, some of which have been addressed in the preceding sections, are tabulated in Table 11.6. To implement this development, a series of integrated RD\&D facilities and projects may be $p l$ anned beyond alternate magnetic and inertial fusion driver development, selection and demonstration of scientific feasibility as indicated by the schedules of Figures 11.2 and 11.3. Assuming such driver development selection and demonstration will proceed through 1985, a proposed parallel schedule of hybrid development facilities with tokomak fusion drivers and hybrid blankets is shown in Figure 11.4.

In this program parallel HEF and EHR would be constructed with both magnetic and inertial fusion drivers that had survived their respective fusion development, selection and demonstration program. After operational experience of both magnetic and inertial EHRs, a fusion driver would be selected for the PHR of near or full comercial size. Preceding and in parallel with the dual HEF and EHR facilities, a program of facilities to conduct hybrid blanket and fuel development would be required.

\section{Prototype Hybrid Reactor}

The PHR will be a near or full commercial-sized hybrid system with all integrated components prototypical of those to be used in commercial systems. It would demonstrate electric power and fissile fuel production in a reliable, efficient, maintainable, integrated system that is licensed and operating on a utility grid. This will require high plant efficiency and availability of a plant in the $500-1000$ MWe range producing $1000-2000 \mathrm{~kg} / \mathrm{yr}$ of fissile fuel. The construction and operation costs should be able to be readily extrapolated to commercial hybrid plants.

Hybrid Blanket

The hybrid blanket facilities include parallel facilities to conduct blanket module coolant and fuel development and testing in thermally and mechanically simulated and fission reactor experimental environments. Such 
TABLE 11.6. Hybrid Reactor Technological Advance Requirements

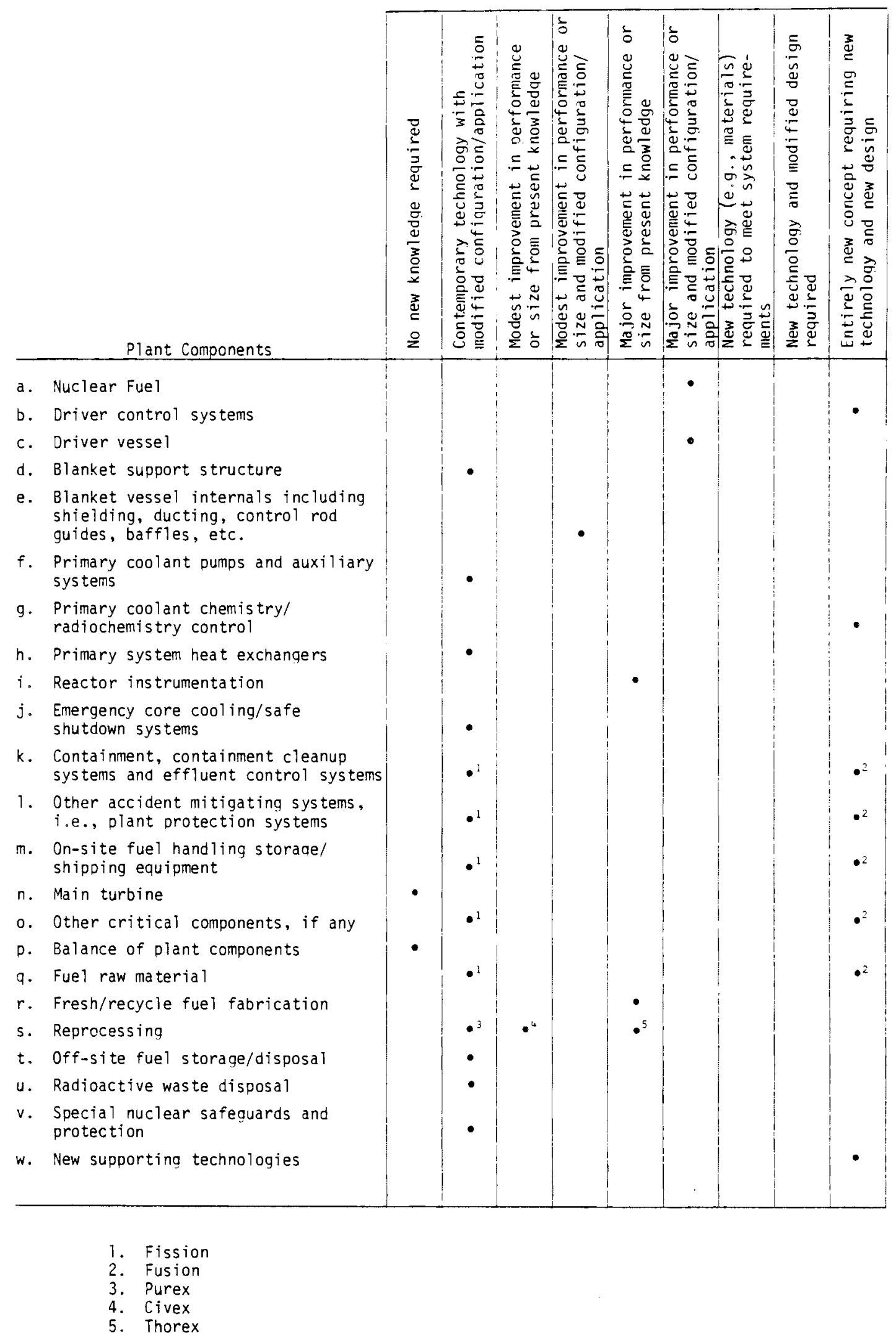




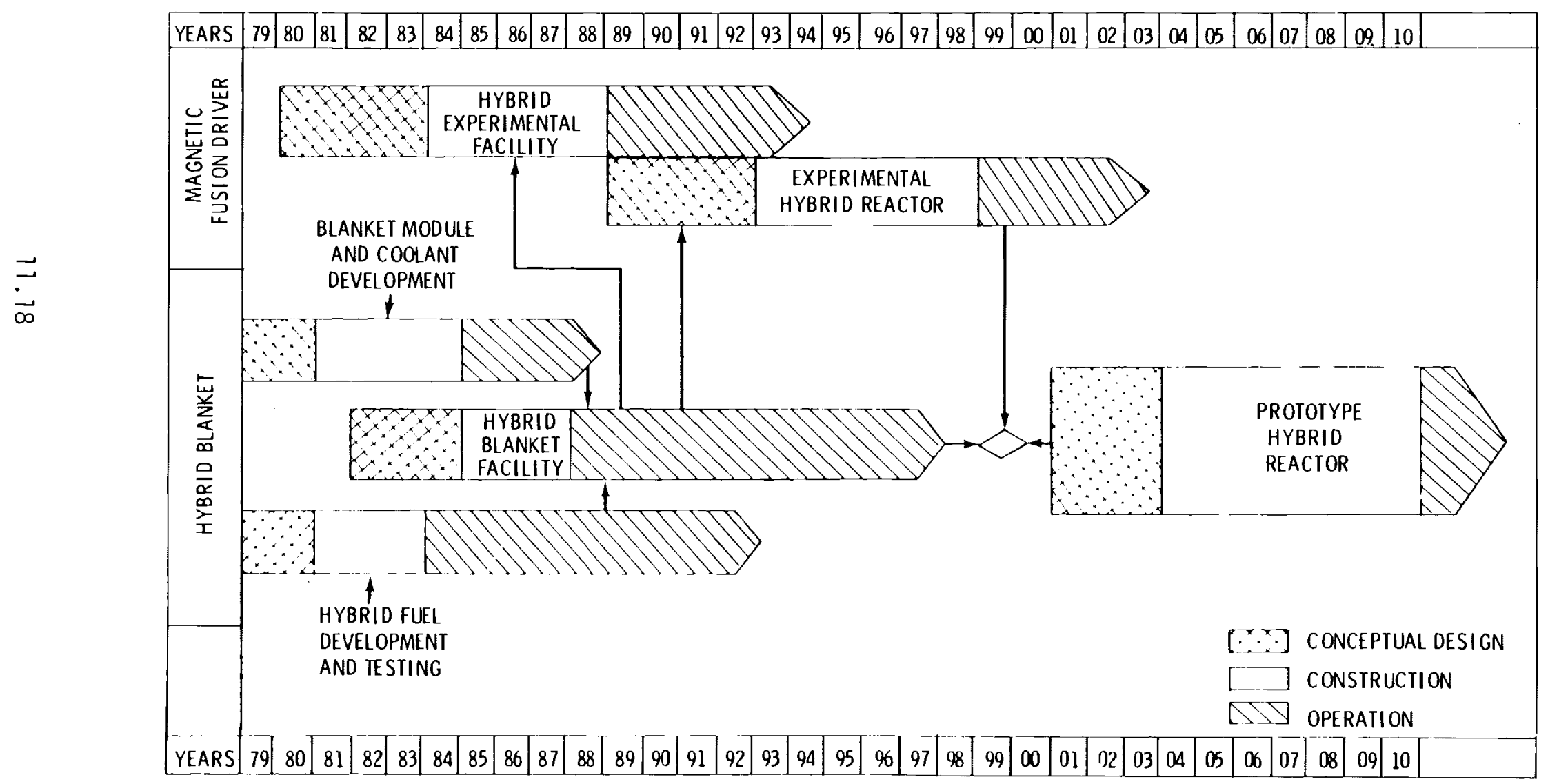

FIGURE 11.4. Hybrid Development Facilities Schedule 
development will support the Hybrid Blanket Facility (HBF), which will have a dedicated $14 \mathrm{MeV}$ neutron source of sufficient strength, fluence and target volume to perform single modular hybrid blanket experiments and testing. The HBF will be a long-term facility, which together with those support facilities, will qualify blanket module and fuel designs for testing in the HRE, EHR and eventually the PHR facilities.

Facilities

The HEF would be the hybrid equivalent of the magnetic fusion ETF and would require an appropriate minimum driver size to produce reactor grade plasmas and a sufficient duty cycle to perform engineering tests of the various driver subsystem components including first wall, blanket and shield, superconducting magnets, heating and fueling systems. Although it would not have to breed tritium, it must be capable of performing tritium breeding experiments in appropriate blanket modules. Its hybrid engineering capabilities must facilitate the in-situ experiments of various hybrid blanket module, fuel and coolant selections as initially developed in the hybrid blanket facilities.

The EHR would be the first power and fuel producing demonstration of the hybrid system and would have many scaled-down driver components prototypical of a commercialized sized hybrid. It would be capable of producing significant power (100 to $300 \mathrm{MWe}$ ) and fissile fuel (100 to $1000 \mathrm{~kg} / \mathrm{hr}$ ), while simultaneously breeding tritium in a self-consistent fusion fuel system. This capability would require a fully integrated reactor system having a reasonable duty cycle and plant factor.

Funding Requirements

Estimates of the total expenditures for development, design and construction of the hybrid program facilities have been made and are given in Table 11.8. These estimates are based upon the normalized cost estimating procedures, which have been developed by PNL for OFE and OLF and used in Section 6.0, as well as upon the cost estimates developed by PNL for the ICF facilities in the Engineering Development Program Plan. Note that the cost estimates do not include the operational and testing cost associated with the 
development program, which may require an additional $\$ 3$ to $\$ 5$ billion to commercialization. Also, the federally funded PHR facility is signicantly less expensive than the commercial hybrid systems costed in Section 6.0 because they are unoptimized advanced developed full-scale commercial systems funded with private capital. An optimization of the performance and cost of these systems is expected to implement cost reduction opportunities to achieve the same performance at a 15 to $20 \%$ cost reduction.

TABLE 11.8. Hybrid Facility Cost Estimates

\begin{tabular}{|c|c|c|}
\hline Facility & $\begin{array}{l}\text { Operational } \\
\text { Date (FY) } \\
\end{array}$ & $\begin{array}{l}\text { Development, } \\
\text { Design and } \\
\text { Construction } \\
\text { Costs (\$M 1978) }\end{array}$ \\
\hline \multicolumn{3}{|l|}{ Magnetic Fusion } \\
\hline HER & 1989 & 800 \\
\hline EHR & 1998 & 1200 \\
\hline \multicolumn{3}{|l|}{ Inertial Fusion } \\
\hline SIF & 1988 & 100 \\
\hline SPTF & 1989 & 500 \\
\hline HFF & 1993 & 600 \\
\hline EHR & 2000 & 1000 \\
\hline \multicolumn{3}{|l|}{ Bl anket } \\
\hline $\begin{array}{l}\text { Blanket Module and } \\
\text { Coolant Development }\end{array}$ & 1984 & 200 \\
\hline $\begin{array}{l}\text { Hybrid Fuel } \\
\text { Development and Testing }\end{array}$ & 1983 & 200 \\
\hline Hybrid Blanket Facility & 1988 & 400 \\
\hline Prototype Hybrid Reactor & 2010 & 2000 \\
\hline Total & & $\$ 7000 M$ \\
\hline
\end{tabular}




\section{SECTION 11.0 REFERENCES}

Aamodt, R. E. et a1. 1978. Assessment of the Tokamak Confinement Data Base. EPRI ER-714. Electric Power Research Institute, Palo Alto, CA.

Magentic Fusion Program Summary Document - FY-1980. 1979. HCP/73168001, TRW, Inc., Redondo Beach, CA. 

APPENDIX A

CAPITAL INVESTMENT COST ESTIMATES 
Ignited Tokamak Hybrid Reactor Capital Costs $\left(\$ 10^{6}\right)^{a}$

\begin{tabular}{ll} 
& Account Nu \\
\hline 20 & \\
21 & \\
& \\
& 21.01 \\
& 21.02 \\
& 21.03 \\
& 21.06 \\
& 21.98 \\
& 21.99
\end{tabular}

22

22.01

22.01 .01

22.01 .02

22.01 .03

22.01 .04

22.01 .05

22.01 .06

22.01 .09

22.02

22.02 .01

22.02 .02

22.03

22.04

22.05

22.06

22.07

22.98
22.99

23

23.01

23.02

23.03

23.06

23.98

24

24.98

24.99

25

25.01
25.02
25.07
25.98
25.99

91

92

93

25.01
25.02
25.98
25.99

92

LAND AND LAND RIGHTS

STRUCTURES AND SITE FACILITIES

Site Improvements and $\mathrm{Facilities}$

Reactor Building

Turbine Building

Miscellaneous Buildings

Spare Parts All awance $(0.5 \%)$

Contingency Allowance (20\%)

REACTOR PLANT EQUIPMENT

Reactor Equipment

Blanket and First wall

Shield

Magnets

Supplemental Heating

Primary Support and Structure

Reactor Vacuum Systems

Impurity Control

Direct Energy Converter

Main Heat Transfer and Transport Systems

Primary Coolant System

intermediate Coolant System

Auxiliary Cooling Systems

Radioactive Waste Treatment and Disposal

Fue 1 Handling and Storage Systems

Other Reactor Plant Equipment

instrumentation and Control

Spare Parts Allowance (1x)

Contingency Allowance (30\%)

Pu Recycle/

Once Through

2.5

6.12

72.81

30.62

91.44

1.00
40.20

$\underline{242.20}$

38.11

30.38

136.80

26.00

1.03

10.11

89.90

44.56

31.33

10.33

72.59

48.31

7.41

9.60

288.08

1257.92

TURBINE PLANT EQUIPMENT

Turbine-Generators

132.54

Main Steam (or other Fluid) System 150.53

Heat Rejection System

Other Turbine Plant Equipment

Spare Part Allowance (1x)

Contingency Allowance (20x)

150.53
55.73

42.11

3.81

$\begin{array}{r}76.18 \\ 460.90 \\ \hline\end{array}$

ELECTRIC PLANT EQUIPMENT

78.37

0.39

15.77

$\underline{95.04}$

MISCELLANEOUS PLANT EQUIPMENT

Transportation and Lifting Equipment

Air and Water Service

Other Plant Equipment

Spare Parts Allowance (1\%)
Contingency Allowance (20x)

Total Direct Cost

2058.48

CONSTRUCTION FACILITIES, EQUIP-

MENT AND SERVICES (15\%)

ENGINEER ING AND CONSTRUCTION

MANAGEMENT SERVICES (15\%)

OTHER COSTS (5x)

Total Indirect Cost

723.97

TOTAL CAPITAL COST $\begin{array}{r}1.71 \\ 1.41 \\ 5.07 \\ 0.08 \\ 1.64 \\ 9.92 \\ \hline\end{array}$

310.27

310.27

103.42

(a) June 1978 dollars 


\section{Ignited Tokamak Hybrid Reactor Capital Costs $\left(\$ 10^{6}\right)^{\text {a }}$ \\ LAND AND LAND RIGHTS \\ Refresh \\ Cycle}

\begin{tabular}{lr} 
& Account \\
\hline 20 & \\
21 & \\
& \\
& 21.01 \\
& 21.02 \\
& 21.03 \\
& 21.06 \\
& 21.98 \\
& 21.99
\end{tabular}

22

22.01

$$
\begin{aligned}
& 22.01 .01 \\
& 22.01 .02 \\
& 22.01 .03 \\
& 22.01 .04 \\
& 22.01 .05 \\
& 22.01 .06 \\
& 22.01 .08 \\
& 22.01 .09 \\
& 22.02 .01
\end{aligned}
$$

22.02

22.03
22.04

22.04

22.06

2.07

22.98

23

23.01

3.02

23.03

23.06

23.98

23.99

24

24.98

25

25.01
25.02
25.07
25.98
25.99

91

92

93
STRUCTURES AND SITE FACILITIES

$\begin{array}{lr}\text { Site Improvements and Facilities } & 6.12 \\ \text { Reactor Building } & 72.81 \\ \text { Turbine Building } & 30.62 \\ \text { Miscellaneous Buildings } & 91.44 \\ \text { Spare Parts Allowance (0.5\%) } & 1.00 \\ \text { Contingency Allowance (20) } & 40.20 \\ & \underline{242.20}\end{array}$

REACTOR PLANT EQUIPMENT

Reactor Equipment

Blanket and First Wall 38.11

Shield $\quad 30.38$

136.80

Supplemental Heating 26.00

Primary Support and Structure $\quad 1.03$

Reactor Vacuum Systems

Impurity Control

Direct Energy Converter

Main Heat Transfer and Transport Systems

Primary Coolant System

Intemediate Coolant System

44.56

Auxlliary Cooling Systems 31.33

Radioactive Waste Treatment and

Fue 1 Handling and Storage Systems 72.69

$\begin{array}{lr}\text { Other Reactor Plant Equipment } & 48.31 \\ \text { Instrumentation and Control } & 7.41\end{array}$

Spare Parts Allowance (18)

Contingency Allowance (30\%) 288.08

\section{TURBINE PLANT EQUIPMENT}

Turbine-Generators

Main Stean (or other Fluid) Systerm 135.07

Heat Rejection System

Other Turbine Plant Equipment 35.91

Spare Part Allowance ( $1 \%$ ) 3.41

\begin{tabular}{rr} 
Contingency Allowance (20x) & 68.17 \\
412.42 \\
\hline
\end{tabular}

ELECTRIC PLANT EQUIPMENT $\quad 67.20$

Spare Part Allowance (0.5\%) $\quad 0.34$

\begin{tabular}{ll} 
Contingency Allowance (20\%) & 13.44 \\
\hline
\end{tabular}

MISCELLANEOUS PLANT EQUIPMENT

Transportation and Lifting Equipment

Air and Water Service

Other Plant Equipment

Spare Parts Allowance (1x)

Contingency Allowance (20\%)

Total Direct Cost

CONSTRUCTION FACILITIES, EQUIP-

ENGINEERING AND CONSTRUCTION

MANAGEMENT SERVICES (15\%) 300.89

OTHER COSTS (5\%)

100.30

702.08

Total Indirect Cost

2708.02 
Ignited Tokamak Hybrid Reactor Capital Costs $\left(\$ 10^{6}\right)^{\text {a }}$

\begin{tabular}{ll} 
& Account \\
\hline 20 & \\
21 & \\
& \\
& 21.01 \\
& 21.02 \\
& 21.03 \\
& 21.06 \\
& 21.98 \\
& 21.99
\end{tabular}

22

22.01

$$
\begin{aligned}
& 22.01 .01 \\
& 22.01 .02 \\
& 22.01 .03 \\
& 22.01 .04 \\
& 22.01 .05 \\
& 22.01 .06 \\
& 22.01 .08
\end{aligned}
$$

22.02 22.01 .09

22.02 .01

22.02 .02

22.03

22.04

22.05

22.06

22.07

22.98
22.99

23.01

23.02

23.03

23.06

23.98

23.99

24

24.98

25

25.01

25.02

25.07

25.98
25.99

91

92

93

LAND AND LAND RIGHTS

Th-Pu

Catalyst

2.5

STRUCTURES AND SITE FACILITIES

Site improvements and Facilities

Reactor Building

Turbine Building

Miscellaneous Buildings

Spare Parts Allowance $(0.5 \%$

Contingency Allowance (20\%)

6.12

72.81

30.62

91.44

1.00

$\begin{array}{r}40.20 \\ 242.20 \\ \hline\end{array}$

REACTOR PLANT EQUIPMENT

Reactor Equipment

81 anket and First Wall 38.11

Shield $\quad 30.38$

Magnets $\quad 136.80$

Supplemental Heating $\quad 26.00$

Primary Support and Structure $\quad 1.03$

$\begin{array}{lr}\text { Reactor Vacuum Systems } & 10.11 \\ \text { Impurity Control } & 7.17\end{array}$

Direct Energy Converter

Main Heat Transfer and Transport Systems

Primary Coolant System

$\begin{array}{ll}\text { intermediate Coolant System } & 89.90\end{array}$

Auxiliary Cooling Systems 31.33

10.33

Fuel Handling and Storage Systems 72.69

Other Reactor Plant Equipment 48.31

$\begin{array}{ll}\text { Instrumentation and Control } & 7.41 \\ \text { Spare Parts Allowance (1\%) } & 9.60\end{array}$

Contingency All owance $(30 \%) \quad 288.08$

$\underline{1257.92}$

\section{TURBINE PLANT EQUIPMENT}

Turbine-Generators

Heat Rejection System

Other Turbine Plant Equipment $\quad 77.27$

Spare Part Allowance ( $1 \%$ ) 5.91

\begin{tabular}{ll} 
Contingency Al lowance $(20 \%)$ & 119.41 \\
\hline 122.41 \\
\hline
\end{tabular}

ELECTRIC PLANT EQUIPMENT 191.38

Spare Part Allowance $(0.5 \%) \quad 0.96$

\begin{tabular}{rr} 
Contingency Allowance (20\%) & 38.28 \\
\hline
\end{tabular}

MISCELLANEOUS PLANT EQUIPMENT

Transportation and Lifting Equipment

Air and Water Service

Other Plant Equipment

Spare Parts Allowance (18)

Total Direct Cost

2465.56

CONSTRUCTION FACILITIES, EQUIP-

MENT ANO SERVICES (15\%)

ENGINEER ING AND CONSTRUCTION

MANAGEMENT SERVICES (15\%)

369.83

OTHER COSTS (5\%)

123.28

Total Indirect Cost

862.95

TOTAL CAPITAL COST

3328.51

(a) June 1978 dollars 


\section{APPENDIX B}

LEVELIZED ENERGY COST ESTIMATES 
Ignited Tokamak Once Through Fuel Cycle Costs NASAP/Hybrid Levelized Busbar Energy Cost Mills/kWh (1978 Dollars

CAPITAL INVESTMENT COST

35.15

Hybrid Capital Investment Cost

35.15

LWR Capital Investment Cost

0.00

OPERATING AND MAINTENANCE COST

6.24

Hybrid Operating and Maintenance Cost

6.24

LWR Operating and Maintenance Cost

0.00

FUEL CYCLE ACTIVITY COSTS

5.42

Pur Int l Blkt Uc

0.31

Pur Yrly Blkt Uc

1.31

Pur Intl Blkt Fab

0.20

Pur Yrly Blkt Fab

0.84

Pur Int 1 B1kt 316SS

0.23

Pur Yrly Blkt 316SS

0.97

Pur Int 1 Tritium

0.05

Pur Yrly Deuterium

0.00

Pur Int l Lithium

0.21

Shpg Hybd Spnt Fuel Yrly

0.27

Disp Hybd Spnt Fuel Yrly

1.04

TOTAL COST

46.81 



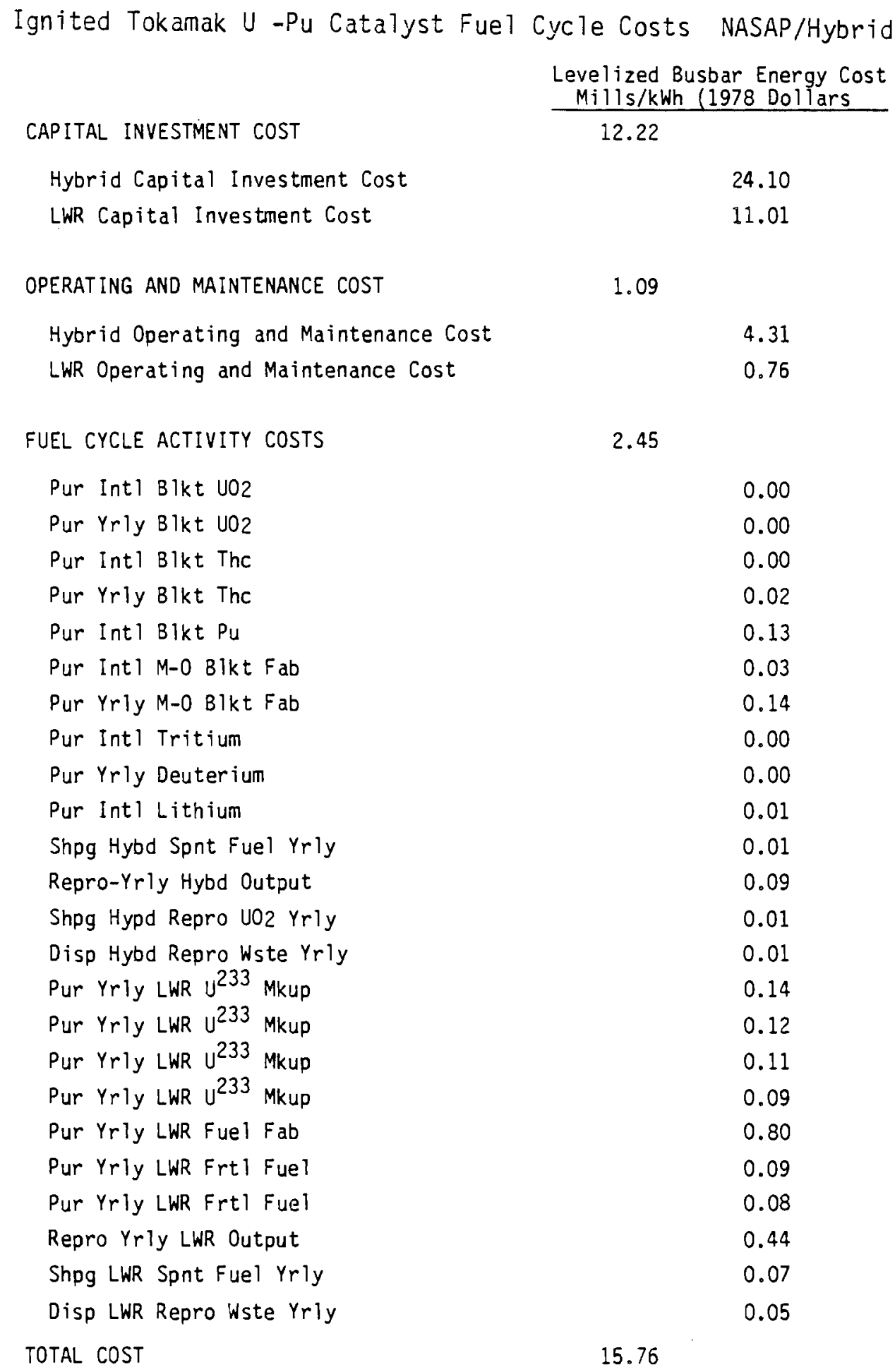


Ignited Tokamak Refresh Fuel Cycle Costs NASAP/Hybrid

Levelized Busbar Energy Cost

Mills/kWh (1978 Dollars

CAP ITAL INVESTMENT COST

14.91

Hybrid Capital Investment Cost

39.53

LWR Capital Investment Cost

11.01

OPERATING AND MAINTENANCE COST

1.63

Hybrid Operating and Maintenance Cost

7.14

LWR Operating and Maintenance Cost

0.76

FUEL CYCLE ACTIVITY COSTS

2.03

Pur Intl Blkt U02

0.03

Pur Yrly Blkt U02

0.12

Pur Intl Blkt Fab

0.03

Pur Yrly Blkt Fab

0.14

Pur Intl Blkt 316SS

0.04

Pur Yrly Blkt 316SS

0.16

Pur Intl Tritium

0.01

Pur Yrly Deuterium

0.00

Pur Intl Lithium

0.03

Shpg Fuel Yrly Hybd To LWR

0.03

Pur Int l LWR Pu Mkup

0.06

Pur Yrly LWR Pu Mkup

0.04

Pur Yrly LWR Frtl Fuel

0.20

Pur Yrly LWR Pu Mkup

0.02

Pur Yrly LwR Fuel Fab

0.82

Shpg Fuel Yrly LWR to Hybd

0.07

Disp LWR Wste

0.25

TOTAL COST

18.57 
PNL -2720

$U C-20 d$

\section{DISTR IBUTION}

No of

Copies

\section{OFFSITE}

$$
\begin{aligned}
& \text { A. A. Churm } \\
& \text { DOE Patent Division } \\
& 9800 \text { S. Cass Avenue } \\
& \text { Argonne, IL } 60439
\end{aligned}
$$

27 DOE Technical Information Center

E. J. Hanrahan

U.S. Department of Energy Germantown, MD 20767

S. Strauch

U.S. Department of Energy

Germantown, MD 20767

H. Rohm

U.S. Department of Energy

Germantown, MD 20767

E. Del aney

U.S. Department of Energy

Germantown, MD 20767

J. Baublitz

Office of Fusion Energy

U.S. Department of Energy

Germantown, MD 20767

E. Rossi

Office of Intertial Fusion

U.S. Department of Energy

Germantown, MD 20767

R. J. Braitsch

U.S. Department of Energy

20 Massachusetts Ave., N.W. Washington, DC 20545
No. of

Copies

P. Af ansenko

U.S. Department of Energy 20 Massachusetts Ave., N.W. Washington, DC 20545

T. Abernathy

U.S. Department of Energy

Technical Information Center P.0. Box 62

Oak Ridge, TN 37830

G. Feldman

U.S. Department of Energy

Germantown, MD 20767

W. C. Lipinski

Argonne National Laboratory

9700 S. Cass Avenue

Argonne, IL 60439

I. Spiewak

Oak Ridge National Laboratory

P.0. Box Y

Oak Ridge, TN 37830

T. H. Row

Oak Ridge National Laboratory

P.0. Box X

Oak Ridge, TN 37830

B. A. Pasternak

Booz-Allen and Hamilton

4330 East-West Highway

Bethesda, MD 20014 
No. of

Copies

J. Pirro

Burns and Roe Industrial

Services Corp.

P.0. Box 663

Route 17 South

Paramus, NJ 07652

W. R. Harris

Rand Corporation

1700 Main St.

Santa Monica, CA 90406

E. Straker

Science Applications, Inc.

8400 Westpark Drive

McLean, VA 22101

M. Higgins

Science Applications, Inc. 8400 Westpark Drive

McLean, VA 22101

A. Weitzberg

Science Applications, Inc.

8400 Westpark Drive

McLean, VA 22101

S. M. Stoller

S. M. Stoller Corp.

1250 Broadway

New York, NY 10001

2 NASAP Control Office

U.S. Department of Energy

Rm F-409 (Mait Stop B-107)

Germantown, MD 20767

5 Prof. F. L. Ribe

University of Washington

Benson Hall BF-10

Seatt Te, WA 98195
No. of

Copies

ONSITE

DOE - Richl and Operations

H. E. Ransom

Hanford Engineering

Development Laboratory

R. P. Omberg

15 Pacific Northwest Laboratory

W. E. Bickford

D. A. Dingee

B. R. Leonard

R. C. Liikala

D. A. Rockwood

A. M. Sutey

L. D. Williams

C. E. Willingham

Technical Information Files (5)

Publishing Coordination (2)

SF 